\author{
Universidade de São Paulo \\ Instituto de Física
}

\title{
Determinismo e estocasticidade em modelos de neurônios biológicos
}

\author{
Bóris Marin
}

Orientador: Prof. Dr. Reynaldo Daniel Pinto

Tese de doutorado apresentada ao Instituto de Física para a obtenção do título de Doutor em Ciências

Banca examinadora:

Prof. Dr. Reynaldo Daniel Pinto (IFSC - USP)

Prof. Dr. Alberto Saa (IMECC - UNICAMP)

Prof. Dr. Iberê Luiz Caldas (IF - USP)

Prof. Dr. Marcelo Bussotti Reyes (CMCC - UFABC)

Prof. Dr. Pablo Varona Martínez (EPS - Universidad Autónoma de Madrid) 


\section{FICHA CATALOGRÁFICA}

\section{Preparada pelo Serviço de Biblioteca e Informação}

do Instituto de Física da Universidade de São Paulo

Marin, Bóris

Determinismo e estocasticidade em modelos de neurônios biológicos. - São Paulo, 2013.

Tese (Doutorado) - Universidade de São Paulo. Instituto de Física. Departamento de Física Geral.

Orientador: Prof. Dr. Reynaldo Daniel Pinto

Área de Concentração: Física

Unitermos: 1. Caos (Sistemas Dinâmicos); 2. Neurofisiologia; 3. Biofísica 


\section{Resumo}

Investigou-se a gênese de atividade irregular em neurônios de centros geradores de padrões através de modelos eletrofisiologicamente realistas. Para tanto, foram adotadas abordagens paralelas.

Primeiramente, desenvolveram-se técnicas para determinar quais os mecanismos biofísicos subjacentes aos processos de codificação de informação nestas células.

Também foi proposta uma nova metodologia híbrida (baseada em continuação numérica e em varreduras força bruta) para análise de bancos de dados de modelos neuronais, permitindo estendê-los e revelar instâncias de multiestabilidade entre regimes oscilatórios e quiescentes.

Além disto, a fim de determinar a origem de comportamento complexo em modelos neuronais simplificados, empregaram-se métodos geométricos da teoria de sistemas dinâmicos. A partir da análise de mapas unidimensionais perturbados por ruído, foram discutidos possíveis cenários para o surgimento de caos em sistemas dinâmicos aleatórios.

Finalmente mostrou-se que, levando em conta o ruído, uma classe de modelos de condutâncias reproduz padrões de disparo observados in vivo. Estas pertubações revelam a riqueza da dinâmica transiente, levando o sistema a visitar um arcabouço determinista complexo preexistente - sem recorrer a ajustes finos de parâmetros ou a construções ad hoc para induzir comportamento caótico. 


\begin{abstract}
We investigated the origin of irregularities in the dynamics of central pattern generator neurons, through analyzing electrophysiologically realistic models. A number of parallel approaches were adopted for that purpose.

Initially, we studied information coding processes in these cells and proposed a technique to determine the underlying biophysical mechanisms.

We also developed a novel hybrid method (based on numerical continuation and brute force sweeps) to analyze neuronal model databases, extending them and unveiling instances of multistability between oscillatory and resting regimes.

Furthermore, in order to determine the origin of irregular dynamics in simplified neuronal models, we employed geometrical methods from the theory of dynamical systems. The analysis of stochastically perturbed maps allowed us to discuss possible scenaria for the generation of chaotic behaviour in random dynamical systems.

Finally we showed that, by taking noise into account, a class of conductance based models gives rise to firing patterns akin to the ones observed in vivo. These perturbations unveil the richness of the transient dynamics, inducing the system to populate a preexistent complex deterministic scaffolding - without resorting to parameter fine-tuning or ad hoc constructions to induce chaotic activity.
\end{abstract}




\section{Agradecimentos}

Agradeço a todos os envolvidos direta e indiretamente neste projeto. Em especial, sou grato aos professores Reynaldo Daniel Pinto e José Carlos Sartorelli pela escola de vida que foi fazer o doutorado na tradição LFNL-ana. Trabalhar para dominar todas as etapas do processo, por menos importantes ou nobres que pareçam, muda nossa relação com o mundo. Muito obrigado também ao professor Eduardo Colli por toda a ajuda, discussões e sugestões - em suma, por ter desempenhado o papel de um segundo orientador. Agradeço também à FAPESP, CNPq e CAPES $\mathrm{o}$ apoio financeiro. 


\section{Sumário}

1 Introdução 1

1.1 Contextualização do problema .......... I 1

1.2 Estrutura da tese . . . . . . . . . . . 4

2 Fenomenologia: Centros Geradores de Padrões 5

2.1 Eletrofisiologia . . . . . . . . . . . 6

2.2 Modelos detalhados . . . . . . . . . . . . . 13

2.3 Exploração numérica . . . . . . . . . . . . 15

3 Condutâncias individuais e codificação de informação 21

3.1 Realizações experimentais ... . . . . . . . . 24

4 Varredura por força-bruta 29

4.1 Ajuste de parâmetros em modelos complexos . . 29

4.2 Dissecção de espaços de parâmetros ... . . . . 31

5 Dinâmica em modelos neuronais 43

5.1 Excitabilidade e bifurcações . . . . . . . . . . . 44

5.2 Bursting: sistemas multiescala temporal . . . . . 46

5.3 Redução a mapas ... . . . . . . . . . . 55

6 Ruído em modelos simplificados 57

6.1 Assinaturas neuronais . . . . . . . . . . . 57

6.2 Modelo estocástico . . . . . . . . . . . . . . . . 59

6.3 Dissecção da dinâmica . . . . . . . . . . . . . . 60

6.4 Esqueletos das asas de pato .......... 64

7 Análise das aproximações unidimensionais $\quad 67$

7.1 Estrutura geral das reduções . . . . . . . . . . . 67

7.2 Bifurcações de acreção de spikes ........ . . 71

$7 \cdot 3$ Transição bursting-tônico . . . . . . . . 73 
7.4 Repulsores e atratores caóticos, caos induzido por ruído ................. 73

$7 \cdot 5$ Expoentes de Lyapunov e ruído . . . . . . . . . 76

7.6 Robustez do mecanismo . . . . . . . . 79

8 Discussão $\quad 85$

8.1 Estocasticidade . . . . . . . . . . . . 87

8.2 Caos e ruído . . . . . . . . . . . . . . . 88

8.3 Assinaturas . . . . . . . . . . . . . . 93

8.4 Abordagens via força bruta e bancos de dados . . 97

8.5 Ajustes de parâmetros e homeostase . . . . . . . 101

9 Conclusão 103

$\begin{array}{ll}\text { Apêndices } & 107\end{array}$

$\begin{array}{ll}\text { A Sistemas dinâmicos } & 109\end{array}$

A.1 Modelos deterministas . . . . . . . . . . . . . 109

A.2 Modelos de condutância . . . . . . . . . . . . 119

A.3 O modelo de Hodgkin e Huxley . . . . . . . . 121

A.4 Ruído na dinâmica neuronal . . . . . . . . . . . 124

$\begin{array}{ll}\text { B Métodos numéricos } & 127\end{array}$

B.1 Integração numérica . . . . . . . . . . . . 127

B.2 Continuação numérica . . . . . . . . . 130

$\begin{array}{ll}\text { Referências Bibliográficas } & \mathbf{1 3 3}\end{array}$ 



\section{Capítulo 1}

\section{Introdução}

Desde o trabalho pioneiro que introduziu as técnicas de voltage clamp e a modelagem matemática da atividade elétrica do axônio gigante da lula (Hodgkin e Huxley, 1952), modelos determinísticos para as condutâncias iônicas estabeleceram-se como paradigma na descrição da dinâmica macroscópica da membrana neuronal. A principal razão do sucesso destes modelos é sua capacidade de condensar, sob um formalismo matemático conciso, a maior parte do comportamento elétrico dos neurônios, incluindo a geração de potenciais de ação. Dentre os experimentais, esta classe de modelos mostrou-se atraente devido ao fato de muitos dos parâmetros do modelo poderem ser inferidos diretamente de experimentos tipo voltage clamp, nos quais a contribuição de cada população iônica para a corrente total pode ser separada e estudada em detalhe (Johnston e Wu, 1995; Dayan e Abbott, 2001).

\subsection{Contextualização do problema}

Entendem-se por determinísticos os modelos baseados em equações diferenciais que descrevem correntes transmembrânicas específicas - podendo também incluir outros processos biofísicos tais como o balanço de Cálcio intracelular. Nestes sistemas, uma vez escolhido dado conjunto de condições iniciais, determinase através de integração uma solução única representando a evolução temporal do potencial de membrana e das demais variáveis dinâmicas, usualmente associadas a processos de ativação/inativação descrevendo a permissividade de cada con- 
dutância iônica.

Entretanto, sabe-se que o comportamento dinâmico do potencial de membrana da maioria dos neurônios biológicos desvia-se daquele gerado por um processo puramente determinístico. Experimentos com neurônios isolados do córtex de mamíferos, aos quais foi repetidamente apresentado um padrão de entrada artificialmente gerado (Mainen e Sejnowski, 1995) mostraram, em desacordo com as previsões deterministas, que a precisão temporal nos potenciais de ação induzidos depende de propriedades estatísticas do sinal de entrada.

O bem estudado centro gerador de padrões (CPG) pilórico do gânglio estomatogástrico de crustáceos (STG, ver Mulloney e Selverston 1974; Selverston et al. 1976; Bal et al. 1988), especializado em produzir padrões motores periódicos, é um exemplo de sistema no qual a maioria dos neurônios da rede dispara trens irregulares de potenciais de ação (ou bursts) quando sinapticamente isolados (Rabinovich et al., 1997; Elson et al., 1999; Selverston et al., 2000).

Desenvolver modelos do tipo Hodgkin-Huxley ( $\mathrm{HH})$ para neurônios do STG, de forma a reproduzir a variabilidade do número de spikes por burst, sua duração e outras flutuações constitui-se num grande desafio (Nowotny et al., 2008; Falcke et al., 2000). Em Prinz et al. (2003a) é apresentado um banco de dados, construído a partir da simulação de 1.7 milhões de casos de um modelo, com valores de condutâncias amostrados em um espaço de parâmetros com 8 dimensões. Dentre todos os casos gerados, observou-se uma grande prevalência de comportamento regular em relação ao irregular, em desacordo com as observações experimentais de neurônios isolados (Elson et al., 1998; Rabinovich e Abarbanel, 1998).

Contudo, modelos estocásticos baseados em descrições microscópicas do chaveamento dos canais iônicos parecem capturar estas irregularidades. Em Carelli et al. (2005), apresentase um tradução para estocástico de um caso do modelo determinístico, que originalmente apresentava apenas atividade periódica. Este modelo estocástico foi capaz de reproduzir as irregularidades encontradas em neurônios biológicos - resultado à primeira vista evidente, dada a consideração de uma fonte de ruído. Não se esperava, porém, que estas séries temporais irregulares, quando analisadas usando técnicas da teoria de sistemas dinâmicos não-lineares (Abarbanel, 1996; Hegger et al., 
1999), apresentassem atratores de baixa dimensão e expoentes de Lyapunov positivos - conforme relatado para séries de dados experimentais (Falcke et al., 2000).

A abordagem qualitativa da teoria dos sistemas dinâmicos (Guckenheimer e Holmes, 1983; Kuznetsov, 1995; Izhikevich, 2000) consiste em determinar a estrutura geométrica da dinâmica, em particular sua dependência com variações dos parâmetros do modelo via análise de bifurcações. Conjuntos invariantes (como pontos de equilíbrio, ciclos limite, atratores caóticos) têm papel proeminente nesta estrutura. Com base nestas técnicas, é possível tomar um modelo eletrofisiologicamente realista multidimensional e identificar o cenário de bifurcações subjacente, reduzindo-o a uma dinâmica simplificada que retém as principais características do modelo original. Em particular, devido ao caráter dos modelos de neurônios bursting analisados, foi possível ir além desta simplificação, reduzindo-os a uma dinâmica discreta unidimensional. Estes mapas mostraram-se de grande valia na proposição de mecanismos através dos quais componentes aleatórias geram comportamento complexo.

Em primeira análise, a presença de ruído é tida como prejudicial à operação do sistema nervoso, já que aparentemente contribui para a descorrelação de sinais e perda de robustez e confiabilidade - em especial supondo cenários de código temporal. Entretanto, vêm acumulando-se evidências experimentais e teóricas de que a estocasticidade pode ter papel contrário, sendo fundamental em processos que aumentam sincronia, confiabilidade e coerência em neurônios (Moss et al., 2004; Hänggi, 2002; Wiesenfeld e Moss, 1995).

Existe uma extensa literatura (Arnold e Avez, 1968; Guckenheimer e Holmes, 1983; Berger, 2001) sobre o caráter estocástico de sistemas dinâmicos determinísticos que apresentam sensibilidade às condições iniciais, associado às propriedades de ergodicidade e mixing de atratores hiperbólicos. Por ergodicidade, entende-se que trajetórias típicas visitam quaisquer vizinhanças de quaisquer outros pontos do atrator ao longo de sua evolução, fazendo com que médias no espaço de estados correspondam a médias temporais. Desta forma, têm-se uma abordagem estatística para caracterizar regimes estacionários da dinâmica. A propriedade de mixing, por sua vez, implica que os estados em um elemento de volume do espaço de fases estarão, para tempos suficientemente longos, distribuídos ao largo de todo 
o atrator. Esta propriedade permite descrever estatisticamente a convergência deste ensemble a uma distribuição invariante, estando também associada à perda de correlações com a evolução temporal - característica para processos caóticos (Abarbanel, 1996; Hegger et al., 1999).

Neste contexto, decidiu-se utilizar diversas abordagens parelelas para estudar o efeito de ruído na dinâmica neuronal.

\subsection{Estrutura da tese}

Inicialmente (cap. 2), descrevem-se as propriedades dos neurônios do sTG que motivaram o trabalho. Em seguida, apresentamse um modelo determinista popular para tais neurônios, simulações deste modelo considerando o efeito de perturbações controladas e o comportamento obtido quando é considerado o ruído de chaveamento dos canais iônicos. No capítulo 3, mostrase como dissecar os processos biofísicos mais importantes para a codificação de informação em modelos bursting, além de verificações experimentais. Para tanto, foi proposto um novo protocolo, que consistiu em aplicar perturbações aleatórias sobre duas versões do sistema: um caso controle e outro onde determinadas dinâmicas foram congeladas.

A variabilidade dos parâmetros a que estão sujeitos neurônios biológicos motivou trabalhar com bancos de dados de modelos (Prinz et al., 2003a; Doloc-Mihu e Calabrese, 2011). Aliando métodos da teoria de bifurcações às varreduras força bruta, desenvolveu-se uma abordagem híbrida que permitiu estender bancos de dados (Marin et al., 2013) e determinar a presença de multiestabilidade (cap. 4). Esta análise motivou a busca de modelos simplificados que apresentassem as bifurcações associadas à classe de bursting observada nos experimentos (cap. 5). No capítulo 6, descrevem-se os efeitos de ruído em modelos simplificados, mostrando como as estruturas complexas presentes no caso determinista são reveladas por tais perturbações. Comparam-se então os resultados obtidos com séries experimentais irregulares de neurônios isolados. São analisados também os efeitos de ruído em bifurcações, nos expoentes de Lyapunov e no comportamento bursting, utilizando reduções unidimensionais (cap. 7). Finalmente, no capítulo 8 discutem-se os resultados obtidos. 


\section{Capítulo 2}

\section{Fenomenologia: Centros Geradores de Padrões}

Há mais de 40 anos, os Centros Geradores de Padrões (CPG) pilórico e gástrico do gânglio estomatogástrico (STG) de crustáceos têm sido considerados paradigmas de circuitos nervosos para o controle motor de atividades repetitivas. Fundamentalmente, as características celulares e sinápticas presentes neste gânglio - bem como soluções evolutivas para geração e modulação de padrões rítmicos - são as mesmas encontradas na maior parte dos sistemas nervosos, incluindo o cérebro de mamíferos (Nusbaum e Beenhakker, 2002; Marder e Bucher, 2001; HarrisWarrick, 1992). Entretanto, como o circuito é constituído por um número pequeno de células, seu conectoma (Sporns et al., 2005) completo pôde ser determinado.

O interesse experimental pelo sistema nervoso de crustáceos vem de uma conjunção de fatos. Esse animais não efetuam mastigação oral: para escapar de predadores, engolem o alimento inteiro rapidamente e buscam abrigo, aonde seu estômago adaptado executa a trituração do material via três ossículos no moinho gástrico. Os músculos pilóricos são responsáveis pelo bombeamento e filtragem do alimentos para o intestino. $\mathrm{O}$ STG contém aproximadamente 30 neurônios, cuja função é gerar padrões de atividade rítmica que controlam os músculos do estômago e dos dentes gástricos. Espantosamente, quando o gânglio é isolado experimentalmente do corpo do animal, são produzidos praticamente os mesmos padrões observados nos animais intactos, desde que se mantenha a conexão com os gânglios superiores que fornecem sinais moduladores. Sendo 
assim, este sistema constitui um excelente modelo experimental para o estudo da geração e modulação de padrões rítmicos, já que cada um dos neurônios pode ser identificado devido a sua atuação motora, até mesmo em animais distintos. Além disso, o fato do circuito manter seu funcionamento in vitro da mesma forma como in vivo possibilita a utilização de diversas técnicas experimentais impraticáveis em animais intactos.

Sendo bem conhecidos e estabelecidos os protocolos de eletrofisiologia, permitindo caracterizar em detalhe cada um dos tipos de célula do circuito, a quantidade de dados coletada é suficiente para construir modelos matemáticos razoáveis do comportamento elétrico desses neurônios. A partir destes modelos esperam-se obter simulações computacionais completas dos padrões produzidos nos CPG do STG, algo ainda não realizado satisfatoriamente, devido ao circuito como um todo se comportar como um sistema complexo muito suscetível às limitações dos modelos.

\subsection{Eletrofisiologia}

\section{Neurônios isolados}

Os experimentos com neurônios isolados consistem na remoção do sistema nervoso estomatogástrico de siris Callinectes sapidus e lagostas Panulirus interruptus, e sua fixação em placas de Petri contendo solução fisiológica (Elson et al., 1999). O gânglio estomatogástico, que contém o circuito pilórico, permenece conectado a gânglios anteriores cuja modulação descendente mantém a atividade bursting celular. Consideram-se de interesse dois neurônios motores, nomeados segundo os músculos que enervam: LP de Lateral Pilórico; e PD de Dilatador pilórico. Este par de células é costumariamente estudado devido ao papel dos neurônios PD como parte de um núcleo marca-passo para o circuito pilórico, e dos LP (únicas células do circuito que estabelecem sinapses químicas com os PD) por consolidarem um número elevado de sinapses com diversas outras células do STG.

Os neurônios LP ou PD são desconectados de entradas sinápticas via fotoinativação ou hiperpolarização profunda das células pré-sinápticas, bem como através de bloqueio farmacológico (Miller e Selverston, 1982; Bal et al., 1988; Elson et al., 1999). 
Após a isolação sináptica, os neurônios são empalados com dois microeletrôdos, para injeção de corrente e leitura do potencial de membrana.

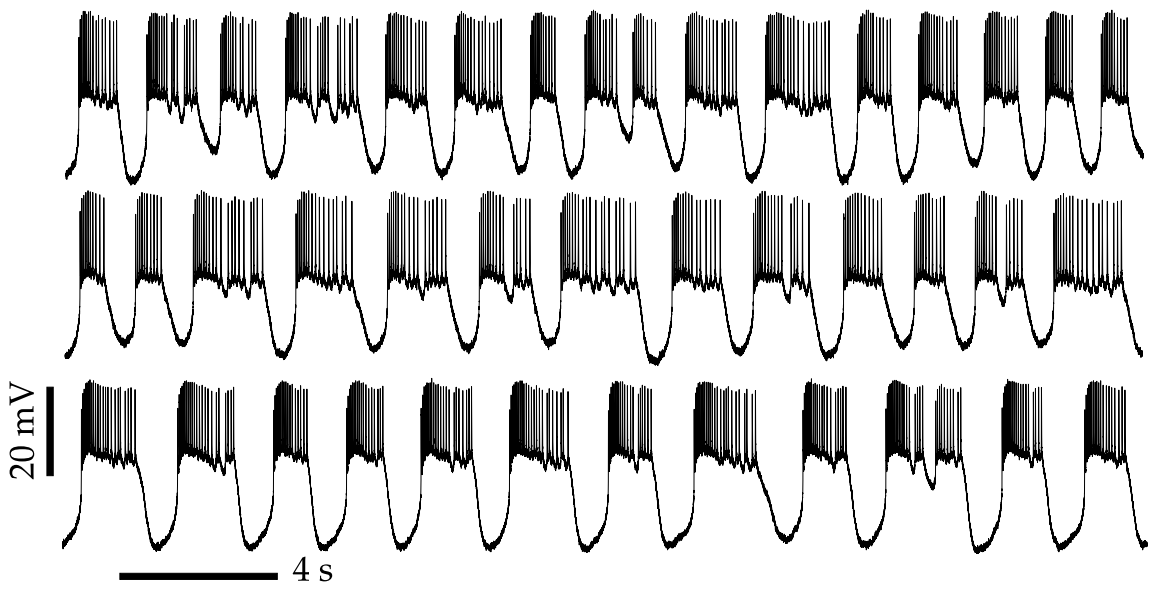

Séries temporais típicas para neurônios PD estão representadas na figura 2.1. Estes neurônios disparam bursts com número irregular de spikes, assim como os LP (Elson et al., 1999; Falcke et al., 2000; Carelli et al., 2005). Entretanto, alinhando-se um número suficiente de bursts utilizando o primeiro spike como referência (fig. 2.2), nota-se que há uma certa regularidade nos intervalos inter spike (ISI) ao início de cada burst, que vai sendo perdida conforme mais spikes são disparados.
PD

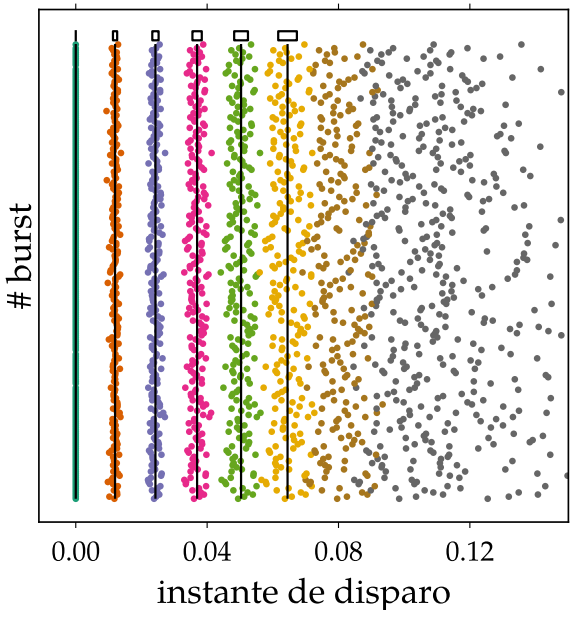

LP

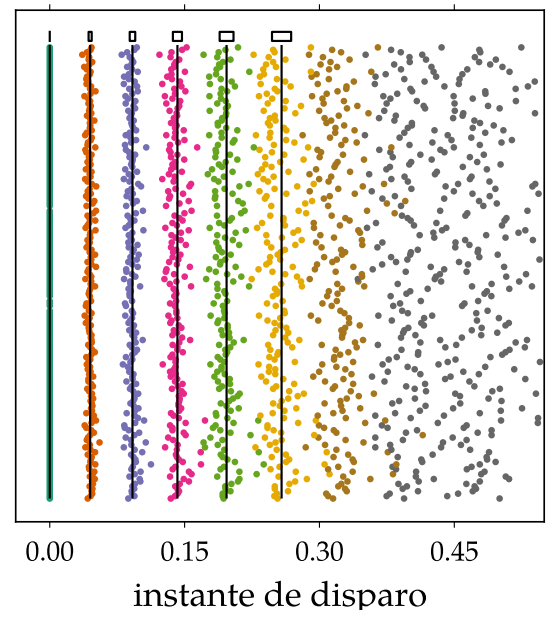

Figura 2.2: Bursts de neurônios LP e PD alinhados pelo primeiro spike. Cada cor representa um dos spikes ao longo do burst. Linhas pretas indicam valores médios, e caixas acima das linhas o desvio padrão correspondente. Apenas os 8 primeiros spikes estão representados.

Na figura 2.3(ESQ), é possível ver que há uma tendência de crescimento exponencial dos ISI finais de um burst. Outra 
observação importante é a presença de burstlets (fig. 2.3 DIR), blocos de spikes concatenados após a "sequência principal" (que inclui os ISI reprodutíveis) de bursts, precedidos por uma hiperpolarização maior do que a intra-spike típica. A gênese deste tipo de comportamento em modelos simplificados, com e sem ruído, é um dos pontos principais explorados nesta tese.

Figura 2.3: (ESQ):Crescimento monotônico dos ISI finais em bursts de neurônios LP. (DIR):Séries temporais do potencial de membrana de neurônios LP e PD farmacologicamente isolados.

No último burst do traço superior, bem como no penúltimo do inferior, nota-se a presença de burstlets (assinalados com setas).

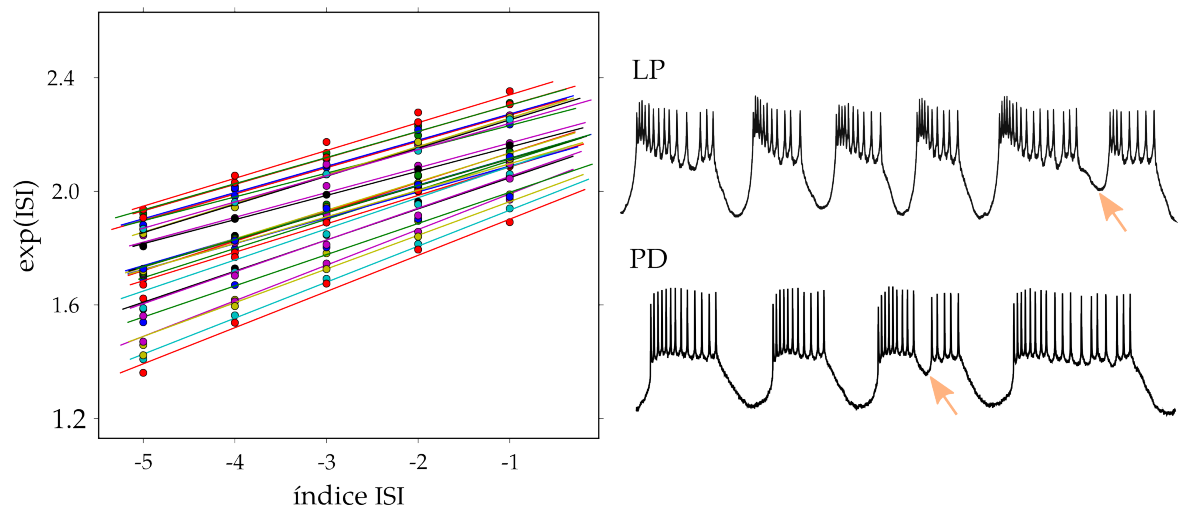

\section{Codificação de informação em bursts}

O comportamento dinâmico dos neurônios dos CPG consiste em bursts de spikes: as séries de intervalos entre spikes (ISI) apresentam sequências de intervalos curtos de tempo (correspondentes aos ISI de um mesmo burst) separadas por intervalos longos (correspondentes às hiperpolarizações da célula). Como músculos atuam como integradores da atividade neuronal, possuindo uma constante de tempo de relaxação de aproximadamente 100ms (quase uma ordem de grandeza acima do valor médio dos IsI dentro de um mesmo burst), tradicionalmente voltaram-se atenções apenas aos bursts como relevantes para o funcionamento do sistema (Lisman, 1997; Izhikevich et al., 2003), relegando-se a posição específicas de spikes em neurônios motores a um segundo plano. Desta maneira, as variações apresentadas no padrão de IsI intrabursts nunca foram motivo de investigação detalhada.

Apenas recentemente, graças à capacidade computacional em tempo real ter atingido um patamar mínimo necessário de velocidade, foram realizados experimentos mostrando que o padrão de ISI dentro de um burst (fig. 2.4) pode conter alguma informação sobre a conectividade do circuito, ou sobre 


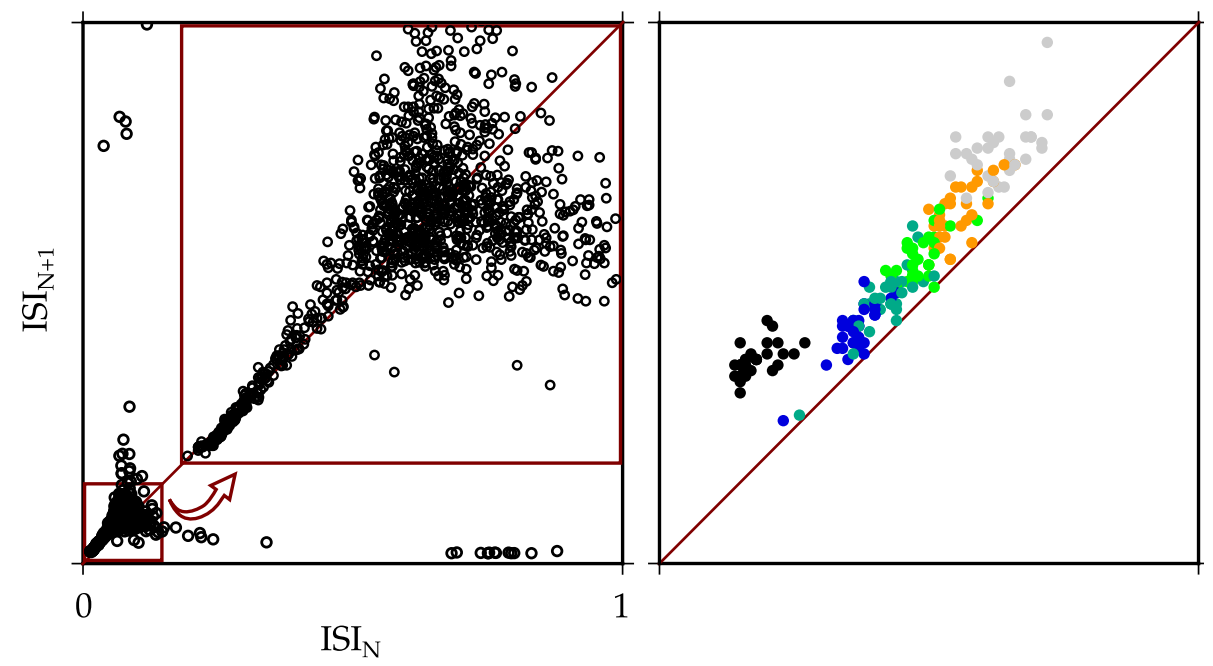

o funcionamento dos outros neurônios da rede (Szücs et al., 2003). Desde então, o Laboratório de Fenômenos não-Lineares do IFUSP (e posteriormente o Laboratório de Neurodinâmica do IFSC) tem dedicado ativamente uma de suas linhas de pesquisa ao estudo da codificação/transmissão de informação usando os padrões de ISI nos bursts de neurônios motores. Foram desenvolvidas ferramentas para estimular neurônios biológicos artificialmente, substituindo um deles por um gerador aleatório de padrões de spikes - implementado em um programa de dynamic clamp que produz as sinapses artificiais para interagir modelos computacionais com neurônios vivos (Pinto et al., 2001; Nowotny et al., 2006) - conforme mostrado na figura 2.5.
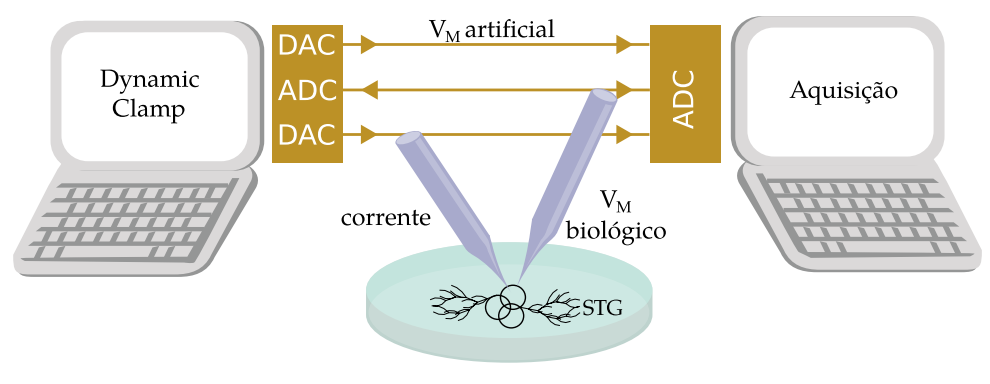

Recentemente (Brochini et al., 2011), foram analisados resultados de diferentes experimentos deste tipo à luz da Teoria da Informação. Segue-se uma discussão dos conceitos relevantes
Figura 2.4: Assinatura neuronal de um neurônio PD isolado. Os padrões observados em mapas de retorno dos ISI são semelhantes para a mesma célula em animais distintos, mesmo entre espécies, sendo sensíveis a conectividade da rede.

Figura 2.5: Esquema do aparato experimental que permite substituir um neurônio biológico por um neurônio artificial in silico, simulado em tempo real por um computador que, através de um protocolo dynamic clamp, produz sinapses artificiais entre o tecido vivo e o modelo virtual. Adaptado de Carelli (2008). 
de forma intuitiva, já que uma exposição detalhada está fora do escopo deste trabalho, podendo ser encontrada nas referências Borst e Theunissen (1999); Szücs et al. (2003); Nowotny et al. (2006); Brochini et al. (2011); Shannon (1948).

A grosso modo, a informação mútua média (IMM) é uma medida da dependência entre grandezas (supostas, mas não necessariamente, aleatórias). Desta forma, a IMM entre duas séries independentes é nula; no outro extremo, se houver uma relação funcional entre duas variáveis, dado que o conhecimento de uma única implica na completa determinação da outra, a IMM é o "conteúdo informacional" de uma delas isoladamente (este conteúdo deve ser igual em ambas) - que pode ser quantificado pela entropia informacional, ou de Shannon (Shannon, 1948). Esta definição está de acordo com a noção intuitiva de que fatos menos prováveis carregam mais informação do que os mais prováveis, bem como a de que a informação total obtida em um processo composto é a soma do conteúdo informacional de cada um dos subprocessos.

Figura 2.6: Substituindo neurônios LP biológicos por um gerador de spikes artificial. $\mathrm{O}$ LP biológico é hiperpolarizado, enquanto um padrão de pulsos inibidores é injetado no PD via uma sinapse química artificial. O momento da hiperpolarização do PD é automaticamente detectado e, após um atraso arbitrário, é gerado um padrão de ISI previamente estabelecido.

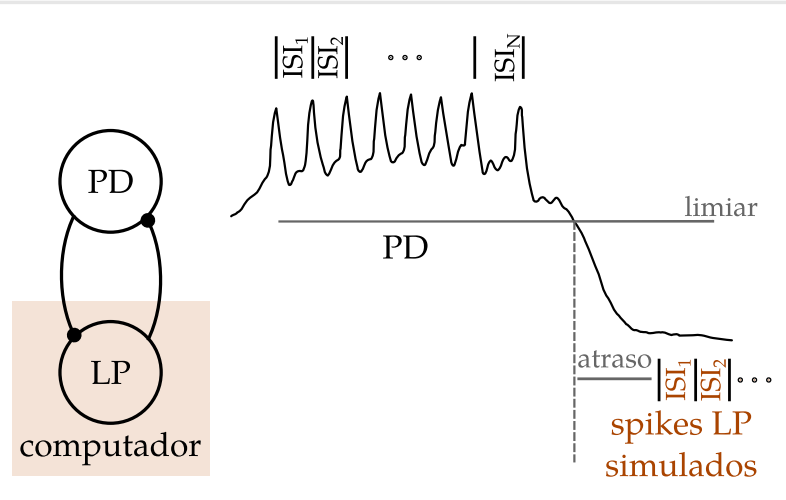

Uma das características importantes da maioria dos pares de neurônios do CPG pilórico é o acoplamento em mútua inibição, fazendo com que estes disparem bursts de spikes em antifase. Assim, um neurônio PD dispara um burst de spikes após ter sido inibido por pulsos de corrente sináptica produzidos pelo LP que, por sua vez, dispara apenas durante a fase hiperpolarizado dos bursts do PD. Com base nesta ideia, foram desenvolvidos protocolos de dynamica clamp que detectam a hiperpolarização do PD e produzem pulsos de inibição análogos aos do neurônio LP, conforme mostrado na figura 2.6 . 
Para ilustrar o mecanismo de transmissão de informação atuante nos neurônios biológicos do STG, toma-se como exemplo um experimento em que foi conectado um neurônio artificial CN a um neurônio PD biológico, injetando uma corrente negativa de amplitude suficiente para que o LP biológico ficasse hiperpolarizado, não disparando assim potenciais de ação (efetivamente desativando a sinapse biológica LP $\mapsto$ PD).

Um programa implementando o protocolo de dynamic clamp foi preparado para monitorar o comportamento dos neurônios PD, produzindo em um determinado momento de sua hiperpolarização (fase fixa escolhida a priori) bursts com características (número médio de potenciais de ação, duração) similares às do LP biológico antes da hiperpolarização - porém com a posição dos potenciais de ação dentro do burst escolhida aleatoriamente. O sinal do computador foi introduzido no PD biológico usando um modelo bastante simples de sinapse artificial, que apresenta pulsos de corrente de amplitude constante e independente do comportamento pós-sináptico. Com a sinapse artificial ativa ou inativa, nenhuma variação relevante na frequência ou duração (duty-cycle) de bursts do PD é observada, ou seja, os músculos comandados por esta célula estariam executando a mesma atividade em ambos os casos. As séries temporais dos disparos do neurônio artificial CN e do PD foram então codificadas conforme mostrado na figura 2.7 .

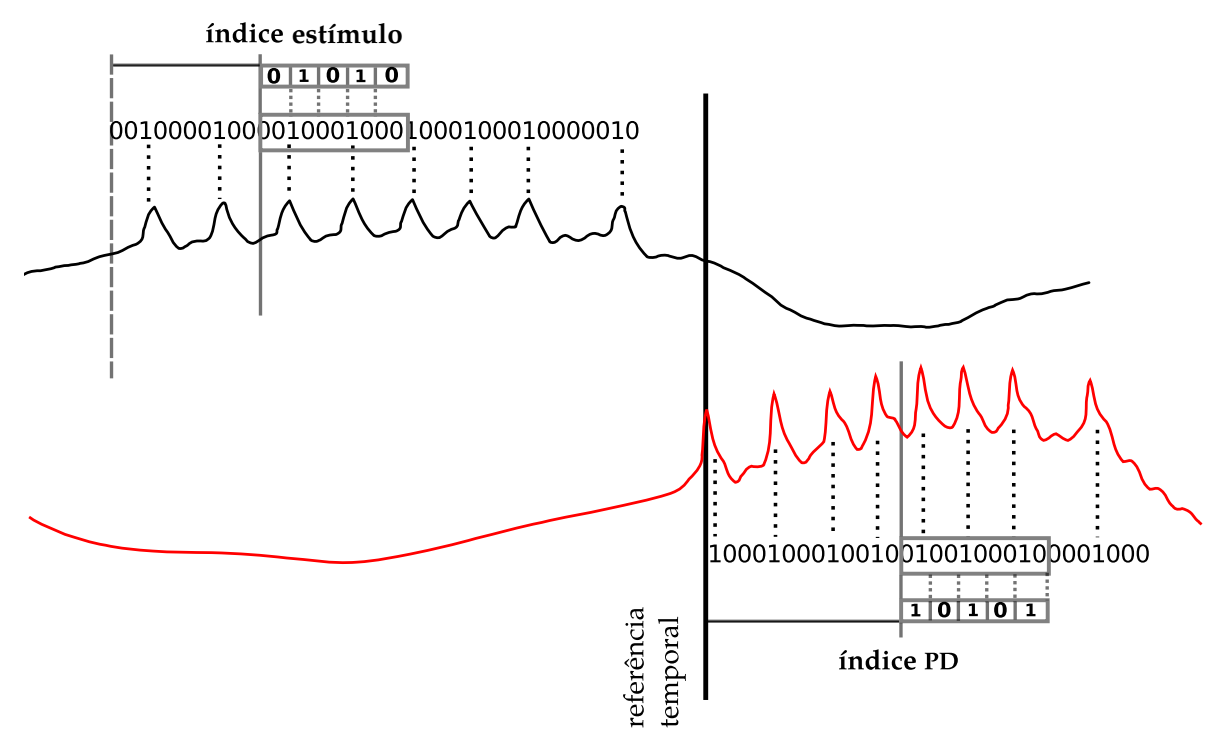

Figura 2.7: Definição dos índices utilizados na análise informacional. Discretizam-se os bursts, codificando-os em bits. Os índices estímulo e PD são utilizados para determinar de qual posição dentro do burst são extraídos os 8 bits usados no cálculo da informação, tanto para o estímulo quanto na resposta. Dessa forma, ao invés de somente um valor da IMM entre o modelo computacional e o neurônio biológico, será obtida uma matriz de valores de Iмм relacionando cada trecho do estímulo com cada trecho da resposta. 
Os resultados obtidos com o cálculo da IMM - tanto no caso em que o circuito é mantido intacto, como quando o neurônio LP é substituído por um neurônio modelo - são mostrados na figura 2.8. Observa-se que o neurônio biológico dedica grande parte de sua capacidade de codificar informação (aprox. 30\%) para expressar os padrões de disparos observados no início do burst do neurônio estímulo.

Figura 2.8: Informação mútua média pela entropia, neurônio PD. (ESQ):circuito intacto. (DIR):neurônio LP (estímulo) substituído por um neurônio modelo com dinâmica estocástica. Observam-se picos de IMM no início e final do burst PD, indicando que estes neurônios dedicam maior parte de sua capacidade de codificar informação para descrever padrões apresentados no início do burst estímulo. Cortesia de Pedro Carelli.
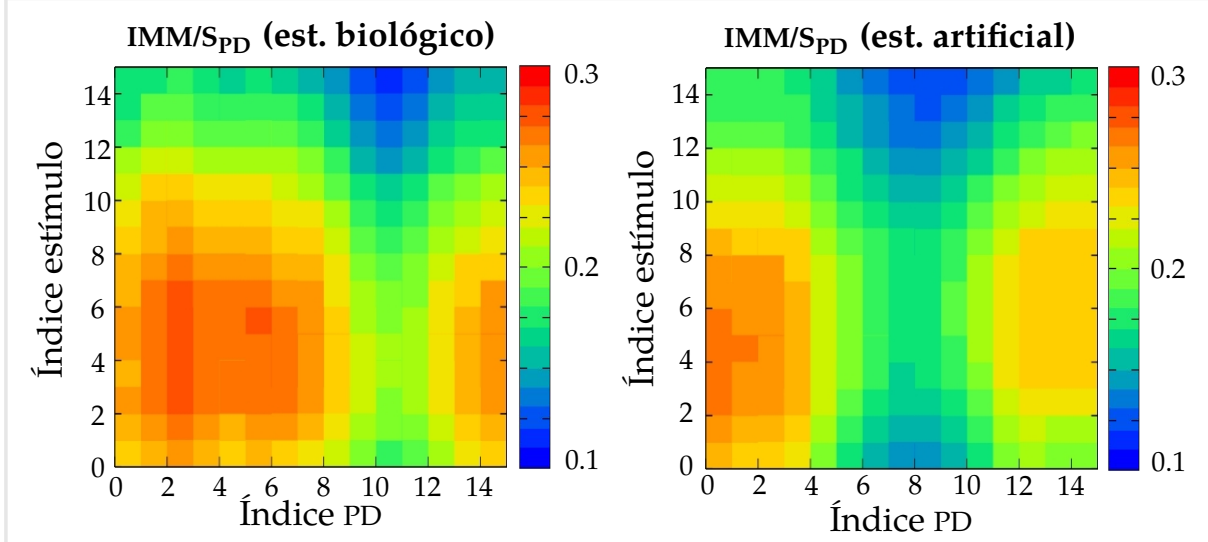

Uma vez determinada a possibilidade de codificação de informação em neurônios motores do CPG pilórico, levantou-se uma questão: há realmente uma apropriação fisiológica deste mecanismo pelo STG, ou é apenas um mecanismo possível, mas sem função biológica? Resultados experimentais recentes do Grupo de Neurodinâmica/Laboratório de Fenômenos NãoLineares apontam na direção de que essa informação é de fato usada pelo animal: trata-se de uma nova via de dados sobre o funcionamento do circuito, podendo ser aproveitada pelo cérebro em comparação com sinais sensoriais da resposta mecânica dos músculos. A via que a informação percorre de células do STG ao cérebro continua entretanto completamente desconhecida: ainda não se sabe quantos nem quais tipos de neurônios transmitem esse sinal.

Outro resultado interessante, com o mesmo arranjo experimental - apenas substituindo a fonte de estímulos de um modelo estocástico do neurônio LP para um determinístico (Carelli, 2008) - mostra que há menor codificação de informação de estímulos regulares (determinísticos) do que de sinais (mais biologicamente plausíveis?) gerados pelo modelo estocástico, 
novamente em acordo com a ideia intuitiva de que fatos menos prováveis carregam mais informação do que os mais prováveis. Isto indica que neurônios possuem, individualmente, uma capacidade de processamento informacional maior do que se acredita classicamente.

Diversos trabalhos estão sendo elaborados para relatar estes resultados do ponto de vista fenomenológico (Carelli et al., 2005; Brochini et al., 2011). Entretanto, fazem-se necessárias explicações fisiológicas para os mecanismos empíricos descobertos. Segue-se o desenvolvimento de procedimentos de análise e ferramentas que permitem determinar, através do estudo de modelos matemáticos simples, quais - e como - dinâmicas microscópicas são relevantes nestes processos.

\subsection{Modelos detalhados}

Modelos eletrofisiológicos para neurônios do STG não são raros (Buchholtz et al., 1992; Guckenheimer et al., 1993; Prinz et al., 2003b; Carelli et al., 2005; Nowotny et al., 2008). Para análises preliminares, escolheu-se um modelo do tipo Hodgkin e Huxley (ver apêndice A.2), que leva em conta sete condutâncias iônicas, observadas em experimentos com neurônios cultivados do gânglio estomatogástrico de crustáceos (mais detalhes em Turrigiano et al., 1995). A escolha deu-se devido à popularidade deste modelo nos mais diversos estudos relacionados ao STG (Prinz et al., 2003a; Carelli et al., 2005; Taylor et al., 2006, 2009; Marder e Taylor, 2011), tanto em simulações quanto em interações com experimentos via dynamic clamp; bem como resultados obtidos com a transcrição deste modelo para estocástico (Carelli et al., 2005), recuperando comportamento irregular (aparentemente raro no modelo original) similar àquele observado em experimentos.

As condutâncias deste modelo podem ser divididas grosseiramente em dois grupos: as geradoras de spikes - sódio $\mathrm{Na}$ e potássio retificador $\mathrm{K}_{\mathrm{d}}-\mathrm{e}$ as associadas a bursts e adaptação - Cálcio transiente $\mathrm{Ca}_{\mathrm{T}}$, Cálcio lento Cas e Potássio dependente de cálcio $\mathrm{K}_{[\mathrm{Ca}]}$. A corrente $\mathrm{Ca}_{\mathrm{T}}$ é ativada durante o início da despolarização, e logo em seguida desativada; ela é responsável pelo início do plateau a partir de onde ocorrem spikes. A corrente $\mathrm{Ca}_{S}$ é mais lenta, não possuindo inativação; é responsável por manter o plateau depolarizado durante o burst. 
A corrente $\mathrm{K}_{[\mathrm{Ca}]}$ finaliza um burst, ao ser ativada devido ao o influxo de $\mathrm{Ca}^{++}$proveniente das correntes $\mathrm{Ca}_{\mathrm{T}}$ e $\mathrm{Ca}$ ao longo do burst.

Segundo HH, o potencial de membrana é dado por

$$
C_{m} \frac{\mathrm{d}}{\mathrm{d} t} V_{\mathrm{M}}=I_{\mathrm{inj}}-\sum_{i} g_{i}\left(V-V_{i}\right)
$$

onde $g_{i}$ é o valor instantâneo da condutância de tipo $i$, calculado a partir de

$$
g_{i}(V, t)=\overline{g_{i}} m_{i}^{\zeta_{i}} h_{i}^{\xi_{i}}
$$

sendo $\overline{g_{i}}$ a condutância máxima para a i-ésima população de canais iônicos, $m_{i}$ e $h_{i}$ os fatores de ativação e inativação de $\mathrm{HH}$ (assumindo valores no intervalo $[0: 1]$ ), e $\zeta_{i}, \xi_{i}$ inteiros escolhidos para ajustar os dados experimentais.

A dinâmica de $m_{i}$ e $h_{i}$ para todas as condutâncias com exceção da $\mathrm{K}_{[\mathrm{Ca}]}$ é determinada por

$$
\begin{aligned}
& \tau_{i}^{m}(V) \frac{\mathrm{d}}{\mathrm{d} t} m_{i}=m_{i}^{\infty}(V)-m_{i} \\
& \tau_{i}^{h}(V) \frac{\mathrm{d}}{\mathrm{d} t} h_{i}=h_{i}^{\infty}(V)-h_{i}
\end{aligned}
$$

onde $m_{i}^{\infty}, \tau_{i}^{m}, h_{i}^{\infty}, \tau_{i}^{h}$ são as funções descritas na tabela 2.1, inferidas de dados experimentais.

\begin{tabular}{ccccc} 
canal & $\zeta$ & $\xi$ & $m^{\infty}$ & $\tau^{m}$ \\
\hline $\mathrm{Na}$ & 3 & 1 & $\Sigma(25.5,-5.29)$ & $2.64-2.52 \Sigma(120,-25)$ \\
$\mathrm{Ca}$ & 3 & 1 & $\Sigma(27.1,-7.2)$ & $43.4-42.6 \Sigma(68.1,-20.5)$ \\
$\mathrm{Ca}$ & 3 & 1 & $\Sigma(33.0,-8.1)$ & $2.8+14[\Xi(27.0,10.0)+\Xi(70.0,-13.0)]^{-1}$ \\
$\mathrm{~A}$ & 3 & $\mathrm{I}$ & $\Sigma(27.2,-8.7)$ & $23.2-20.8 \Sigma(32.9,-15.2)$ \\
$\mathrm{K}_{[\mathrm{Ca}]}$ & 4 & $\mathrm{o}$ & $\frac{[\mathrm{Ca}]}{[\mathrm{Ca}]+3} \Sigma(28.3,-12.6)$ & $180.6-150.2 \Sigma(46.0,-22.7)$ \\
$\mathrm{K}_{\mathrm{d}}$ & 4 & $\mathrm{o}$ & $\Sigma(12.3,-11.8)$ & $14.4-12.8 \Sigma(28.3,-19.2)$ \\
$\mathrm{H}$ & $\mathrm{1}$ & $\mathrm{o}$ & $\Sigma(75.0,5.5)$ & $2.0[\Xi(169.7,-11.6)+\Xi(-26.7,14.3)]^{-1}$ \\
canal & & $\boldsymbol{h}^{\infty}$ & $\boldsymbol{\tau}^{h}$ \\
\hline $\mathrm{Na}$ & & $\Sigma(48.0,5.18)$ & $1.34 \Sigma(62,-10)\left[1.5+\Xi^{-1}(34.9,3.6)\right]$ \\
$\mathrm{Ca}$ & & $\Sigma(32.1,5.5)$ & $210-179.6 \Sigma(55.0,-16.9)$ \\
$\mathrm{Ca}$ & & $\Sigma(60.0,6.2)$ & $120+300[\Xi(55.0,9.0)+\Xi(65.0,-16.0)]^{-1}$ \\
$\mathrm{~A}$ & & $\Sigma(56.9,4.9)$ & $77.2-58.4 \Sigma(38.9,-26.5)$
\end{tabular}

Tabela 2.1: Fatores de ativação/inativação. Definem-se $\Sigma(x, y) \equiv$ $\left[1+\exp \left(\frac{V+x}{y}\right)\right]^{-1}, \quad \Xi(x, y) \equiv \exp \left(\frac{V+x}{y}\right)$ 
Há também um buffer de cálcio, modelado com base na competição entre mecanismos de extrusão do $\mathrm{Ca}^{++}$e os influxos provenientes das correntes $\mathrm{Ca}_{\mathrm{S}}$ e $\mathrm{Ca}_{\mathrm{T}}$ :

$$
\tau_{\mathrm{Ca}} \frac{\mathrm{d}}{\mathrm{d} t}\left[\mathrm{Ca}^{++}\right]=-\mathrm{f}\left(I_{\mathrm{Ca}_{T}}+I_{\mathrm{Ca}_{S}}\right)+\left[\mathrm{Ca}^{++}\right]-\left[\mathrm{Ca}^{++}\right]_{0}
$$

com $\mathrm{f},\left[\mathrm{Ca}^{++}\right]_{0}$ e $\tau_{\mathrm{Ca}}$ constantes. Ver Prinz et al. (2003b) para detalhes.

\subsection{Exploração numérica}

Como abordagem exploratória inicial, utilizou-se integração numérica direta do modelo determinístico, a fim de determinar respostas a diferentes classes de estímulos. Em particular, deuse ênfase à perturbações de estado em pontos sobre o atrator correspondente à atividade bursting, já que tinha-se como hipótese a coexistência desta órbita periódica com estruturas comportando dinâmica expansiva (para a terminologia de sistemas dinâmicos, consultar o apêndice $\mathrm{A}$ ), bem como com atratores correspondentes a distintas classes de disparo. Em sistemas multiestáveis, estímulos deste tipo podem provocar mudanças drásticas na atividade, caso ocorra um salto entre bacias de atração. Esta exploração via força bruta, apesar de não ter sido frutífera no propósito inicial de revelar coexistências entre atratores periódicos e caóticos, colocou em ênfase propriedades fundamentais do sistema, levantando uma base empírica para a análise subsequente em termos de modelos simplificados. Adicionalmente, foi instrumental na proposição de um mecanismo para o comportamento de codificação de informação descrito anteriormente, revelando o papel fundamental da segregação de escalas temporais na modulação da atividade do potencial de membrana.

$\mathrm{Na}$ figura 2.9, tem-se a superposição de bursts para três séries temporais, a da esquerda correspondente ao modelo determista, a do meio ao modelo estocástico de Carelli et al. (2005) e a da direita a um neurônio LP biológico (ter em conta também a figura 2.2). Nota-se que o modelo estocástico dispara ISI similares ao longo do começo de um burst, mas com perda de precisão temporal ao final - ao contrário do 
Figura 2.9: Confiabilidade no começo, instabilidade no final. Superposição de bursts do (E) modelo determinista (periódico); (M) modelo estocástico; (D) neurônio LP. Gentilmente cedida por Pedro Carelli.

Figura 2.10: Projeção de duas trajetórias num espaço onde a estrutura de um burst torna-se evidente (utilizando o potencial de membrana e as funções de estado corrente de Cálcio transiente e de Potássio dependente de Cálcio). Ambas trajetórias (verde e vermelha) partem de condições iniciais próximas, na fase hiperpolarizada de um burst. Entretanto, essa diferença é amplificada ao final do burst subsequente: o número total de potenciais de ação é distinto nos dois casos. Alças marcadas com números indicam o disparo de potenciais de ação. determinista, totalmente periódico. Esta perda de precisão é também observada nas séries biológicas, de modo que o modelo estocástico parece ser mais fidedigno em primeira análise. A

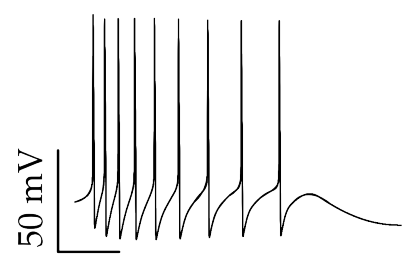

$100 \mathrm{~ms}$

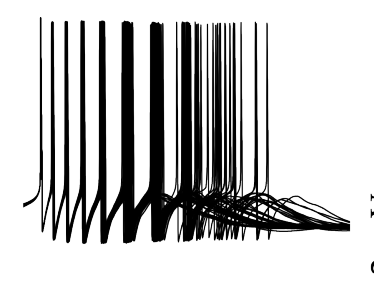

$100 \mathrm{~ms}$

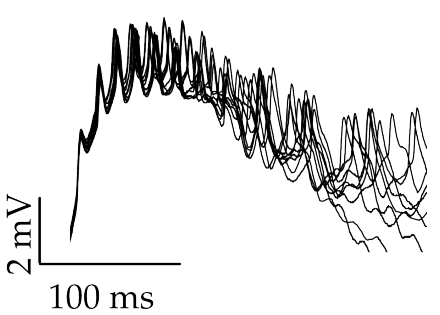

partir de perturbações de estado instantâneas, determinou-se que esta é uma propriedade inerente à dinâmica determinista, o que pode ser visto claramente nas simulações apresentadas nas figuras 2.10 e 2.11 .

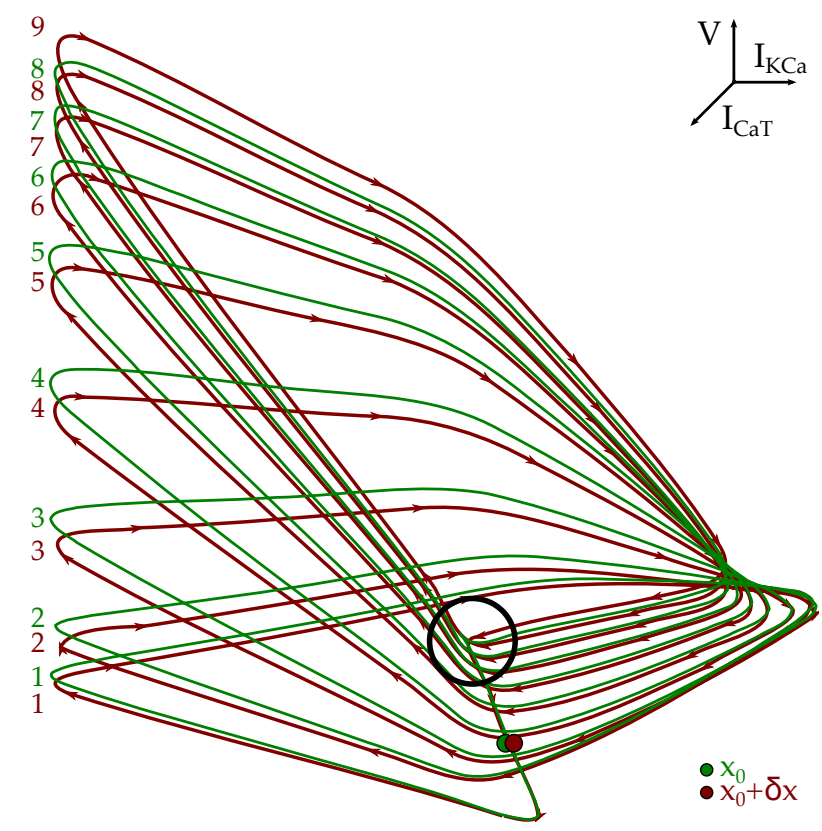

No caso, perturbações feitas na fase hiperpolarizada de um burst são aparentemente "absorvidas" (supondo que, como em geral é caso para situações experimentais, o único observável seja o potencial de membrana), mas acarretam em uma mudança drástica de comportamento ao final do burst: ocorre a acreção de um spike, após vários disparos com Isı similares ao caso não perturbado. 

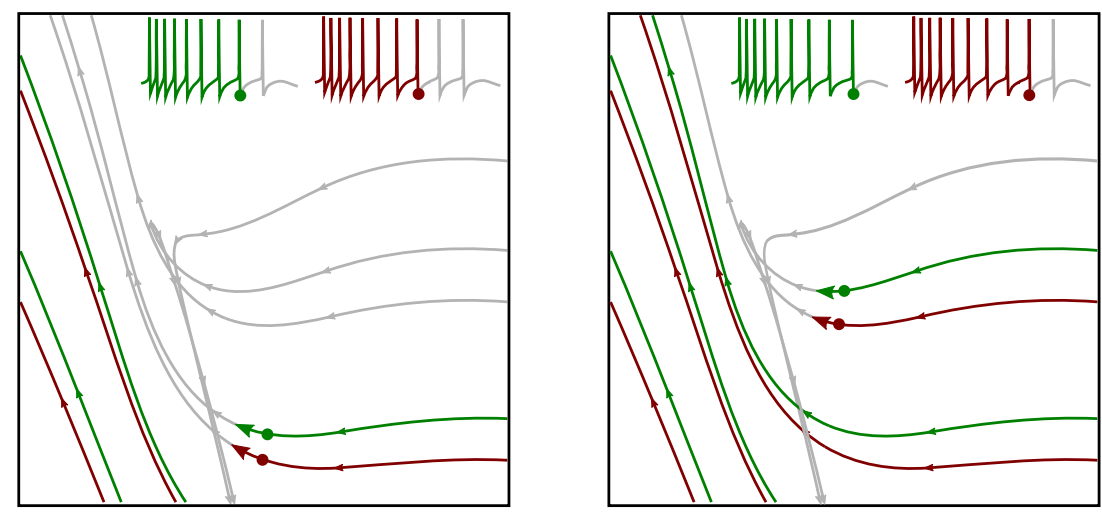

\section{Perturbações e modulação de bursts}

Inicialmente, a fim de investigar o efeito de ruído sobre o modelo detalhado, adotou-se um procedimento "experimental" (no sentido de experimento numérico), que consistiu em estudar o efeito de perturbações instantâneas nas variáveis dinâmicas sobre grandezas associadas aos bursts. Os resultados experimentas em codificação de informação em bursts determinam que a informação é codificada em um código temporal, ou seja, na sequência de IsI. Desta maneira, tomou-se um conjunto de grandezas descritivo para um cenário de código temporal (esquematizado na fig. 2.12), consistindo nos ISI intraburst e na fase (intervalo entre o primeiro spike de bursts antes da perturbação e o primeiro spike do burst pós perturbação).

Nas simulações, tais perturbações de estado manifestam-se de maneira estereotipada no perfil do potencial de membrana da célula estimulada, analogamente ao efeito de estímulos externos em uma célula conectada em rede.

Perturbar diretamente as variáveis dinâmicas (conforme a figura 2.10) é conveniente para análises geométricas da dinâmica do sistema de EDO estudado. Entretanto, biologicamente, entradas sinápticas provocam a injeção de corrente transmembrânica, e não variações instantâneas em variáveis isoladas - o que consiste numa perturbação de $I_{\text {inj }}$ na equação 2.1. Neste caso, modela-se a injeção de corrente devido à entrada sináptica como uma alpha function (Johnston e Wu, 1995; De Schutter, 2009) de forma

$$
I_{\text {inj }}=I_{0}\left(t-t^{*}\right) \exp \left[1-\frac{\left(t-t^{*}\right)}{\tau}\right]
$$

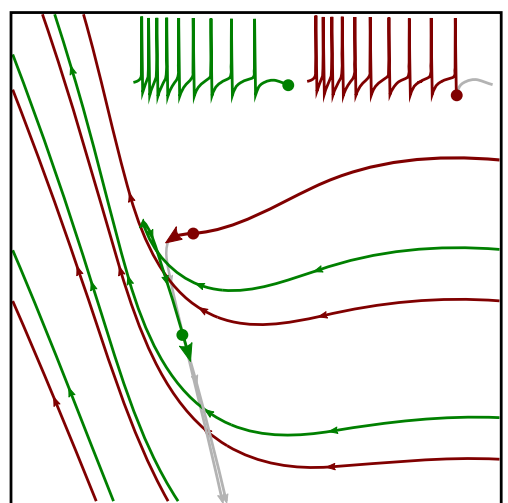

Figura 2.11: Evolução temporal de condições iniciais próximas à pseudoseparatriz (ampliação do círculo na figura 2.10). As trajetórias perturbada (verde) e não perturbada (vermelha), após descreverem a alça correspondente ao oitavo spike, evoluem de maneira substancialmente distinta: o burst perturbado termina com 8 spikes, enquanto o não perturbado contém um spike adicional antes da hiperpolarização. 


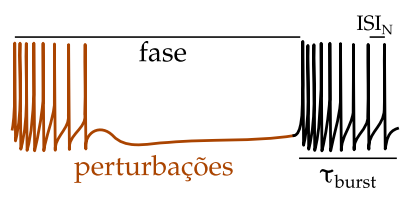

Figura 2.12: Perturbações de corrente sobre o modelo. São feitas varreduras para injeções de corrente em instantes e amplitude variáveis, calculando o efeito sobre grandezas como os ISI no próximo burst e o início do próximo burst (fase).
Figura 2.13: Espaços de perturbações para variações no (ESQ)tempo total e (DIR) fase do burst subsequente à perturbação. Injeções de corrente positiva durante a hiperpolarização intraburst podem ocasionar a supressão de spikes ao final do próximo onde $\tau$ é um tempo característico, no caso sempre igual a $1 \mathrm{~ms}$.

Na figura 2.8, nota-se que neurônios PD dispendem a maior parte de sua capacidade de codificar informação nos padrões iniciais do burst estímulo, ao invés de nos padrões finais (temporalmente mais recentes), o que é contraintuitivo. Para verificar a relação entre este resultado e a previsão do modelo, foram realizadas varreduras do espaço de parâmetros para a amplitude e instante de perturbação.

Apesar da fase de bursting alterar-se muito pouco (2.13), uma mudança drástica de comportamento é observada nos gráficos de $\tau_{\text {burst }}$ e no número de spikes no próximo burst. Ou seja, o neurônio modelo é muito sensível ao que acontece durante a sua hiperpolarização, podendo alterar o número de spikes e a duração de seu próximo burst apenas devido a introdução de um único pulso perturbativo, o que demonstra que um simples spike pode produzir um efeito bastante perceptível desde que ocorra em um momento adequado. Este é exatamente o mecanismo que se observa-se na figura 2.8: o neurônio biológico altera seu padrão de spikes em um burst de acordo com o padrão de pulsos inibitórios que recebe durante a sua hiperpolarização, e este efeito é mais pronunciado em determinados instantes da hiperpolarização do que em outros.

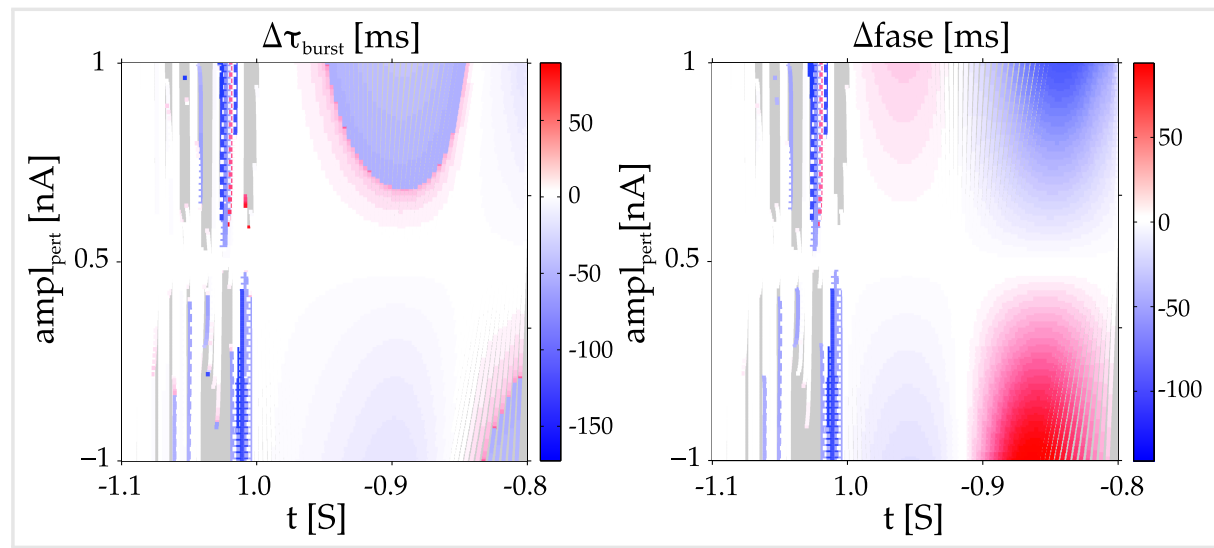

Desta maneira, é possível associar os comportamentos empíricos de processamento/codificação de informação observados nos experimentos com neurônios biológicos, com as perturbações que são introduzidas nas variáveis dinâmicas de um modelo simples para este neurônio. Seguindo esta abordagem, é possível identificar em qual população de canais iônicos 
determinada perturbação é "armazenada", para em seguida dar origem a um comportamento macroscópico distinto.

Prosseguindo o estudo de perturbações no modelo eletrofisiologicamente detalhado, foram refeitas simulações semelhantes às apresentadas na seção de análise numérica do modelo mudando entretanto a referência temporal para o primeiro spike do burst "resposta" (após estímulo). Esse procedimento, apesar de contraintuitivo neste tipo de simulação, justificase por ter análogo experimental direto (experimentos com o gânglio estomatogástrico de siris realizados no LFNL), além da análise informacional empregada considerar como referência o burst de resposta.

$\mathrm{Na}$ figura 2.14, pode-se ver que as perturbações alteram os instantes de ocorrência dos spikes no burst resposta. $\mathrm{O}$ maior efeito é observado no último spike, podendendo inclusive suprimí-lo. No próximo capítulo, apresenta-se um refinamento deste protocolo de perturbações, para determinar quais mecanismos eletrofisiológicos podem estar envolvidos nestes efeitos. 


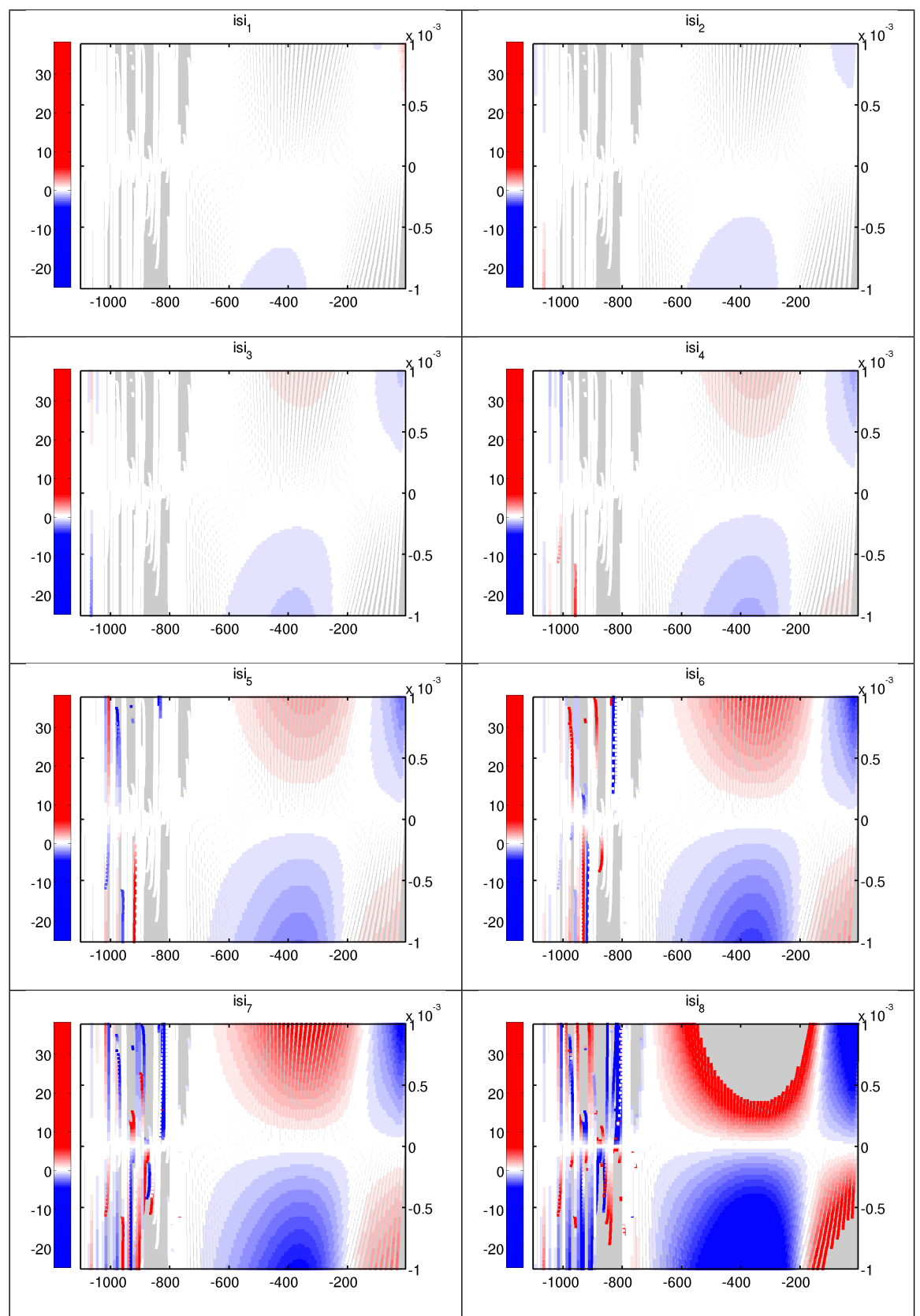

Figura 2.14: Efeito de perturbações de corrente sobre os 8 intervalos entre spikes (ISI $N$ ) no burst após a perturbação. No eixo horizontal, tem-se o tempo em ms com relação ao primeiro spike do burst resposta, enquanto no vertical, a amplitude de modulação da alpha-function que define a perturbação de corrente. A escala de cores dá a diferença (em ms) introduzida pela perturbação, em relação a cada IsI no modelo não perturbado. A cor cinza corresponde a pontos inexistentes. Note a clara diferença de efeito em cada um dos ISI, mais pronunciada no final do burst - de acordo com a análise informacional de dados experimentais. 


\section{Capítulo 3}

\section{Condutâncias individuais e codificação de informação}

Até mesmo as mais primitivas redes neurais exibem repertórios dinâmicos sofisticados, advindos da interação de diversos mecanismos iônicos operando em múltiplas escalas temporais. Com base nos resultados exploratórios apresentados anteriormente, foi concebido um método para determinar o papel de condutâncias individuais nas capacidades de processamento de informação de neurônios bursters. Devido às escala temporais reportadas nos resultados experimentais, $\Delta_{\text {ISI }} \approx \mathrm{ms}$, é plausível supor que o processamento de informação esteja associado a dinâmicas das condutâncias iônicas e não a outros processos biofísicos, de maneira que a reprodução destas propriedades em um modelo tipo $\mathbf{H H}$ - onde somente são considerados os processos de chaveamento de condutâncias transmembrânica corroboraria esta hipótese.

Anteriormente, mostrou-se que perturbações análogas à injeção de corrente sináptica podem modular os ISI no burst posterior ao instante de perturbação врг (2.14), mesmo quando estas se dão na fase hiperpolarizada. Verificou-se também que perturbações instantâneas em variáveis dinâmicas têm efeitos semelhantes, podendo inclusive suprimir/adicionar spikes ao final do BPP, mantendo os ISI anteriores praticamente inalterados. É natural então tentar determinar como perturbaçõe sinápticas são transduzidas à dinâmica transiente das condutâncias iônicas, e o papel de cada uma destas em processos de codificação e transmissão de informação. Para tanto, foi desenvolvido um protocolo de simulação que consistiu em emular os expe- 
Figura 3.1: Transmissão de informação entre neurônios biológicos acoplados em mútua inibição. A informação mútua média relativa ao longo dos bursts mostra o quanto a variabilidade da resposta está associada àquela do estímulo.
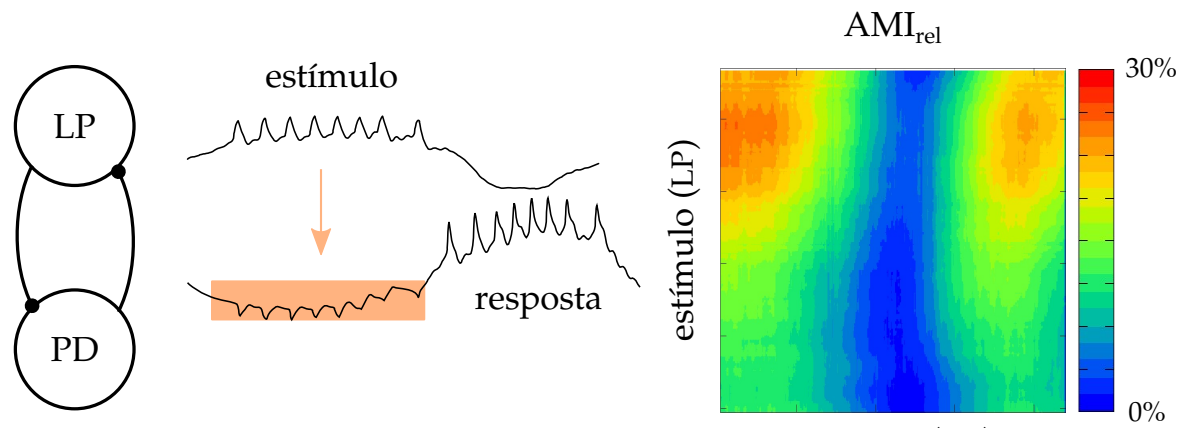

resposta $(\mathrm{PD})$

rimentos in vivo descritos em Brochini et al. (2011) (conforme a fig. 3.1). Dez dentre dezesseis preparações experimentais distintas apresentaram resultados qualitativamente semelhantes aos vistos na figura 3.1. Nestes casos, observaram-se dois picos na informação mútua média relativa, correspondendo ao final de bursts LP (estímulo) com o começo de bursts PD (resposta), bem como ao final de ambos os bursts. Estes picos são uma indicação de um fluxo de informação de bursts do LP aos bursts seguintes do PD. O primeiro dos picos não deixa de ser esperado classicamente, já que quaisquer modelos capturando comportamento tipo integra/dispara devem apresentá-lo (início do burst resposta sensível a final do burst estímulo).

Foram criados dois protocolos de simulação, seguindo o paradigma de pares de séries bursting estímulo/resposta, substituindo entretanto os neurônios biológicos pelo modelo detalhado (ver seção 2.2) perturbado por injeções de corrente sináptica, escolhidas aleatoriamente. $\mathrm{O}$ modelo foi ajustado para, quando isolado, produzir bursts com duração e número de spikes próximos aos dos neurônios $\mathrm{PD}$, enquanto que o gerador de spikes/corrente sináptica seguia distribuições de ISI de neurônios LP.

O primeiro protocolo (controle) consistiu em simplesmente determinar se o modelo detalhado apresentava as mesmas propriedades de processamento de informação observadas em experimentos. Repetindo a análise informacional obteve-se que, de fato, modelos de condutância reproduzem esta capacidade: na figura 3.2, observam-se picos na informação mútua média em posições semelhantes (começo e final do estímulo com início da resposta).

Uma vez determinado que os processos biofísicos descritos 


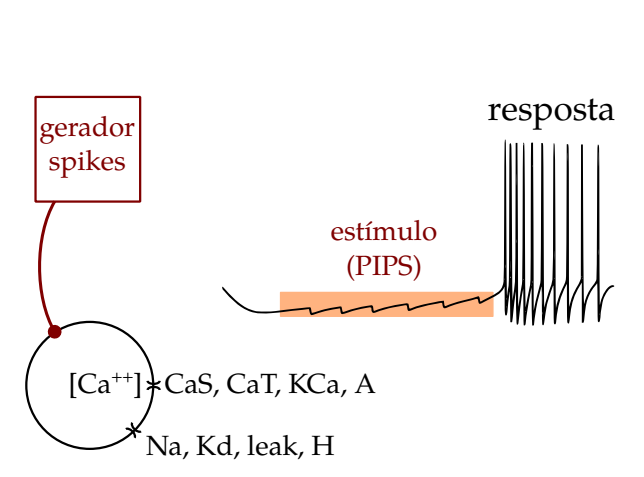

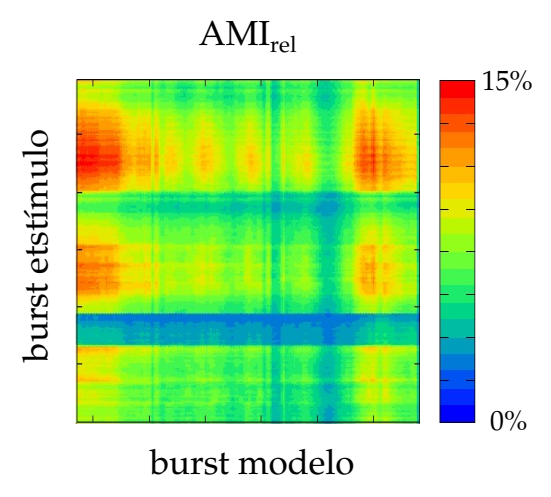

pelo formalismo de HH são suficientes para simular o fenômeno, foi proposto um segundo protocolo, a fim de dissecar o papel de cada dinâmica na codificação de informação. Tal protocolo, esquematizado na figura 3.3, consistiu em repetir as simulações
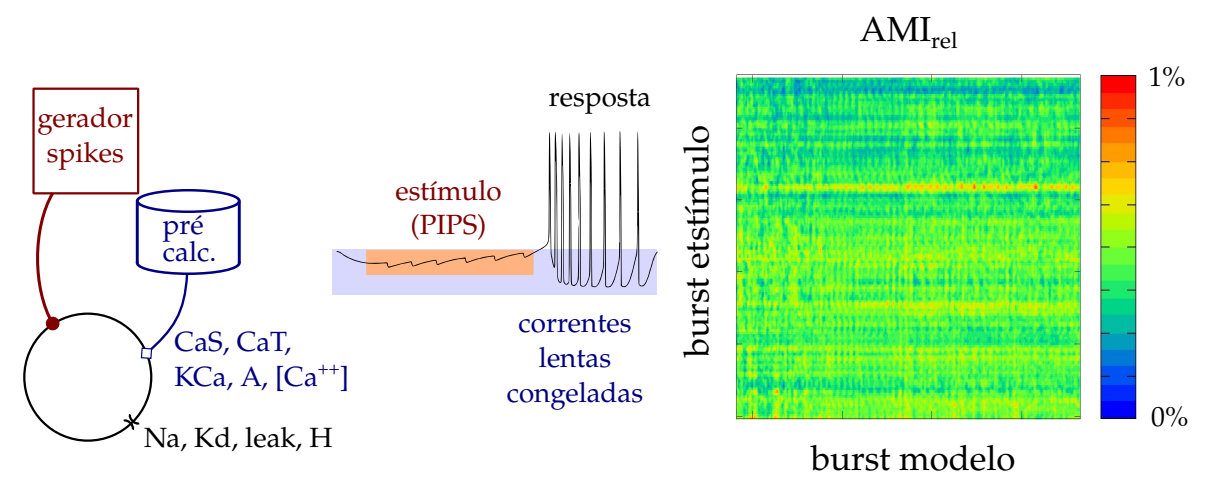

anteriores, substituindo entretanto o modelo por uma variante possuindo apenas as condutâncias mais rápidas e independentes de Cálcio $\left(\mathrm{I}_{\mathrm{Na}}, \mathrm{I}_{\mathrm{K}}, \mathrm{I}_{\text {leak }}, \mathrm{I}_{\mathrm{H}}\right)$. As correntes restantes $\left(\mathrm{I}_{\mathrm{CaT}}, \mathrm{I}_{\mathrm{CaS}}\right.$, $\mathrm{I}_{\mathrm{A}}, \mathrm{I}_{\mathrm{KCa}}$ ), bem como a dinâmica da concentração intracelular de Cálcio, também entraram na dinâmica do potencial de membrana. Entretanto, ao invés de calcular seu valor a cada instante integrando o modelo, foram utilizadas séries temporais pré-calculadas para um ciclo completo de bursting - o que foi denominado método das condutâncias congeladas. Desta maneira, o modelo segue disparando bursts, mas as dinâmicas lentas não mais são sensíveis à história de estímulação. Repetiramse então as simulações com inibição via um gerador de spikes e subsequente análise informacional. Desta vez, entretanto, não foram obsevados picos de IMM (fig. 3.3).

Desta maneira determinou-se que, em analogia ao caso
Figura 3.2: Transmissão de informação de um gerador de spikes aleatórios para um neurônio modelo tipo HH do sTG. Compare com os resultados experimentais, fig. 3.1.

Figura 3·3: Supressão da transmissão de informação em um modelo com dinâmicas lentas congeladas, ou seja, pré-calculadas. Compare com as figs. 3.1, 3.2. 
biológico, modelos de condutância para neurônios motores podem codificar informação contida na estrutura fina dos ISI do estímulo. Além disso, tais propriedades estão intimamente associadas às dinâmicas lentas, em particular ao subistema dependente de Cálcio, no modelo. Aplicando o protocolo de congelamento a condutâncias individuais, é possível ainda determinar com maior especificidade o papel de cada uma das dinâmicas na regulação do processamento de informação. À luz dos resultados preliminares com perturbações sobre variáveis dinâmicas, conjectura-se que a possibilidade de multicódigos em um mesmo burst, informação codificada nos ISI e na duração total ou fase, por exemplo - estão ligados às propriedades dinâmicas de condutâncias iônicas distintas, em particular às respectivas escalas temporais de operação.

\subsection{Realizações experimentais}

Através de protocolos de dynamic clamp, é possível introduzir condutâncias arbitrárias em neurônios biológicos (Pinto et al., 2001; Nowotny et al., 2006). Uma possibilidade interessante seria induzir o mecanismo de codificação de informação em neurônios diversos, conectando-os a condutâncias simuladas por computador. Tomando um neurônio hipotético, excitável mas incapaz de disparar bursts - devido à inexistência de canais de Cálcio, por exemplo - é possível transformá-lo em um burster, através de uma corrente lenta artificial.

Evidentemente, um sinal oscilante que cruze o limiar de disparo em determinadas fases pode induzir bursts. Entretanto, é possível fazê-lo com um subsistema tipo $\mathrm{HH}$, até mesmo unidimensional: basta gerar uma corrente lenta, com potencial de reversão abaixo do potencial de repouso, ativada para valores de $V_{\mathrm{M}}$ próximos ao valor médio dos disparos tônicos do neurônio: desta forma, enquanto o neurônio está disparando, essa corrente vai sendo gradativamente ativada, até atingir um valor alto o suficiente para interromper os spikes. Com a queda para o potencial de repouso, a corrente lenta é desativada, e com a perda de corrente hiperpolarizante o membrana volta gradativamente a disparar spikes. Esta dinâmica pode ou não ser congelada.

Com base nestas idéias, suscitou-se um desdobramento desta 

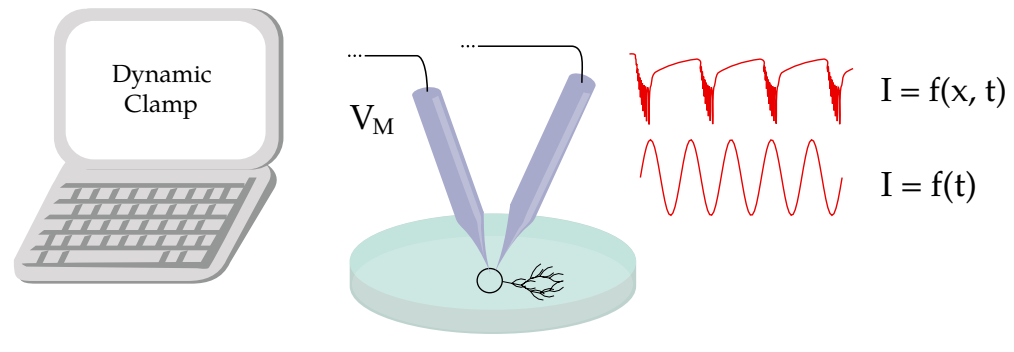

Figura 3.4: Experimento para dissecção do papel de condutâncias individuais na codificação de informação. Neurônios biológicos, tônicos ou quiescentes, são induzidos a exibir comportamento em bursts mediante um estímulo externo, ora um forçamento periódico, ora uma corrente lenta que pode ser dinâmica (sensível) ou congelada (insensível ao estado do neurônio biológico). tese no trabalho de mestrado de Rafael G. Viegas (2011). Neste trabalho utilizaram-se neurônios pertencentes ao CPG gástrico do STG de crustáceos. A maioria dos neurônios gástricos não apresenta condutâncias lentas operando em escalas temporais típicas da dinâmica bursting no circuito pilórico (frequência de disparo de bursts em torno de $1 \mathrm{~Hz}$ ) e, quando in vitro, apresentam atividade quiescente ou disparo tônico. Seguindo as ideias acima descritas, buscou-se induzir comportamento bursting nestas células, mediante a introdução de correntes lentas artificiais via dynamic clamp (fig. 3.4). Determinouse então a resposta destes neurônios a bursts de estímulos artificiais aleatórios, gerados por computador, a fim de verificar o papel das correntes lentas na codificação de informação.

A simples comparação entre experimentos envolvendo bursting induzido por um forçamento autônomo (excitação periódica externa, insensível ao estado do neurônio ou às perturbações) e uma corrente dinâmica (modelada segundo $\mathrm{HH}$ e introduzida via dynamic clamp, por exemplo) seria evidência suficiente dos pontos levantados. Entretanto, devido a mecanismos celulares de homeostase - os neurônios gástricos tendem a se adaptar às injeções de correntes artificiais, voltando ao seu comportamento original quiescente ou tônico - uma única corrente não foi suficiente para induzir o comportamento em bursts, tornando necessária a introdução de uma corrente externa "estática", além da condutância lenta artificial.

Foram então realizados dois experimentos (I e II), ambos com injeção de uma corrente senoidal estática, bem como 
Figura 3.5: Resultados de experimento de transmissão de informação para neurônios gástricos. A,B: realização I. C,D realização II. A,C: condutância lenta artificial dinâmica. B,D: condutância lenta artificial congelada. Observa-se que picos de IMM (marcados com oval) desaparecem quando se congela a corrente lenta artificial. C,D: um pico de IMM de menor amplitude (retângulo) persistiu nos dois casos, podendo ser devido à conectividade do circuito ou a alguma corrente intrínseca presente no neurônio utilizado. Figura adaptada de Viegas (2011).
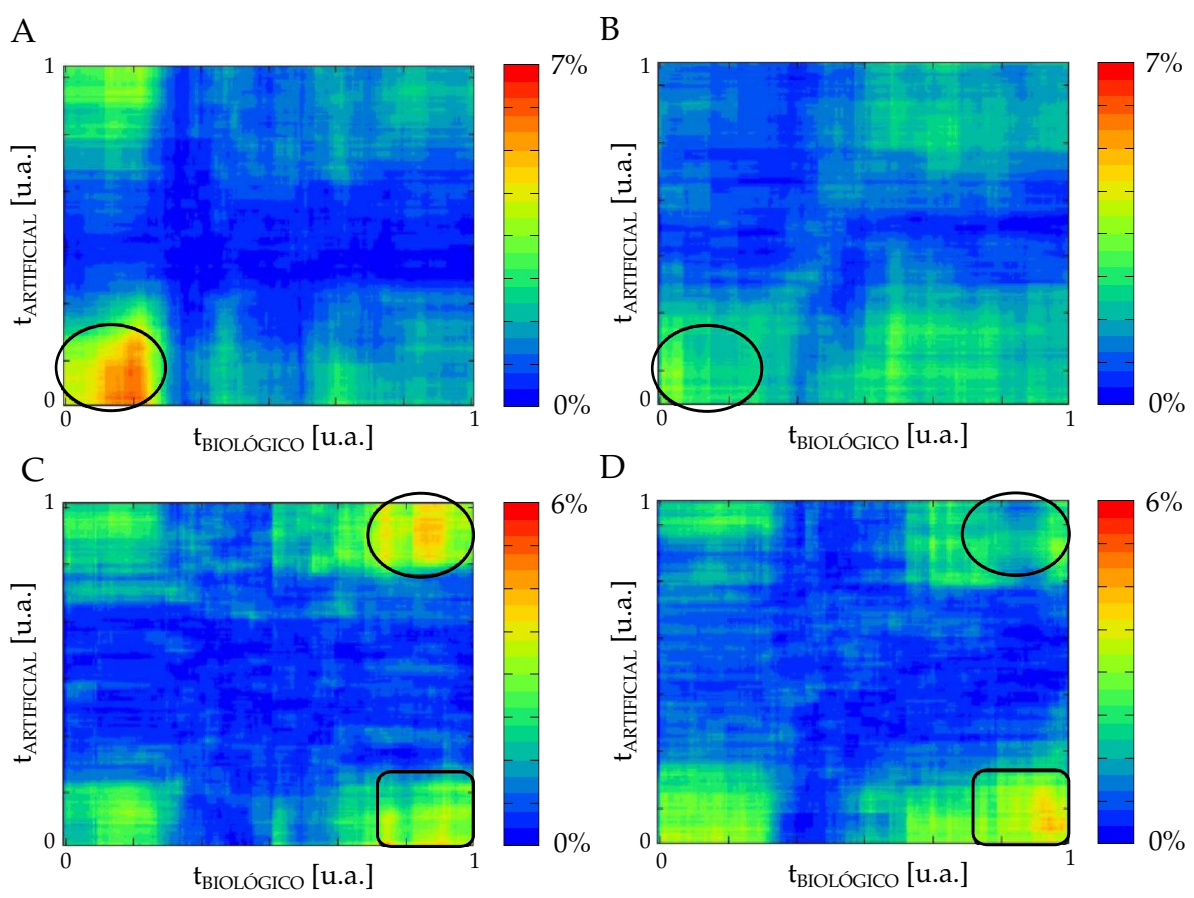

dois protocolos para a corrente lenta artificial produzida por dynamic clamp: uma versão dinâmica, sensível ao potencial de membrana dos neurônios gástricos em tempo real; e uma versão congelada, pré-gravada na ausência de estímulos. Os experimentos envolveram células gástricas distintas, além de valores díspares de parâmetros para as correntes artificiais.

$\mathrm{Na}$ figura 3.5, apresenta-se o resultado destes experimentos. Observa-se que protocolos com a versão dinâmica da corrente reproduzem qualitativamente o resultado de picos na IMM entre resposta e estímulo, observado tanto em células pilóricas (fig. 3.1, Brochini et al., 2011) quanto nas simulações com o modelo detalhado (fig. 3.2), enquanto o mesmo não ocorre nos experimentos com a versão congelada da corrente (fig 3.3).

Evidencia-se que os neurônios utilizadas nestes experimentos são totalmente distintos daqueles para os quais foram obtidos resultados de transmissão de informação (Brochini et al., 2011), tanto em suas propriedades intrínsecas quanto por fazerem parte de outro circuito. Além disso, as correntes lentas utilizadas em ambas realizações do experimento (completamente artificiais e com valores de parâmetros muito distantes nos casos I e II, ajustados apenas para que cada um dos neurônios gástricos continuasse a apresentar bursts), não 
se aproximam de quaisquer correntes conhecidas nos neurônios pilóricos do STG (Viegas, 2011). Entretanto, considerando o protocolo de corrente lenta dinâmica, os resultados qualitativos para a IMM são análogos em células gástricas (modificadas) e pilóricas: ocorre a codificação de parte do padrão aleatório nos intervalos de ISI do neurônio resposta.

Associando estes resultados aos trabalhos onde se mostrou que neurônios de animais diferentes - mas pertencentes a um mesmo tipo funcionalmente equivalente - apresentam conjuntos de condutâncias individuais bastante diversos entre si (Taylor et al., 2009; Marder et al., 2007; Prinz et al., 2004), levantase uma questão importante: até que ponto é válido ajustar finamente um dado modelo para reproduzir determinado resultado experimental? Ou mesmo, quais atributos biofísicos determinam a "identidade funcional" de um neurônio em um circuito? Estas indagações reforçaram o interesse pelo desenvolvimento de análises detalhadas de bancos de dados de modelos, apresentadas a seguir. 



\section{Capítulo 4}

\section{Análise crítica da busca de parâmetros por força bruta}

\subsection{Ajuste de parâmetros em modelos complexos}

Modelos eletrofisiologicamente realistas são usualmente descritos em termos de variáveis dinâmicas e parâmetros com correlato empírico direto. Esta aparente facilidade - em comparação com modelos abstratos, nos quais arbitrariedades na escolha de parâmetros e na interpretação de variáveis são aceitáveis em prol de se manter a elegância formal - é muitas vezes compensada pela alta dimensionalidade dos espaços de estados e de parâmetros. Afora as dificuldades na análise da dinâmica - a ser explorada em capítulos subsequentes - a simples determinação de conjuntos de parâmetros satisfatórios para reproduzir determinado comportamento experimental se mostra problemática, fazendo-se necessário o emprego de métodos sistemáticos de busca.

Em centros geradores de padrão usualmente são empregados modelos tipo $\mathrm{HH}$, de modo que é possível estimar parte dos parâmetros via medidas intracelulares (voltage clamping) de células isoladas. Contudo, as simulações são usualmente confrontadas com resultados de experimentos com redes intactas, através de medidas extracelulares, em condições muito diversas às de células isoladas em cultura. Adicionalmente, há evidências crescentes (Marder e Goaillard, 2006; Schulz et al., 2006) de que parâmetros celulares (como condutâncias máximas 
de espécies iônicas) variam por ordens de grandeza - tanto para um mesmo tipo celular em espécimes distintos, quanto em células individuais. Desta maneira, mesmo aplicando todos os vínculos derivados de medidas e considerações fisiológicas, restam sempre ajustes finos a serem feitos a fim de que o modelo se comporte de maneira satisfatória no confronto com resultados experimentais.

Na figura 4.1, são apresentados esquematicamente procedimentos de ajuste de parâmetros a modelos complexos, conforme grande parcela de trabalhos (Prinz et al., 2003a; Doloc-Mihu e Calabrese, 2011; Bhalla e Bower, 1993; Günay et al., 2009) em neurociência computacional.

Figura 4.1: Esquema representando o procedimento usual de ajuste de parâmetros a modelos complexos. As regiões coloridas indicam valores de parâmetros para os quais $o$ modelo apresenta atividade funcional, e são determinadas através de varreduras unidimensionais a partir de um conjunto de parâmetros dito canônico (estrela). в: varredura do espaço por força bruta, através da integração direta do modelo em uma grade. Figura adaptada de De Schutter (2009).
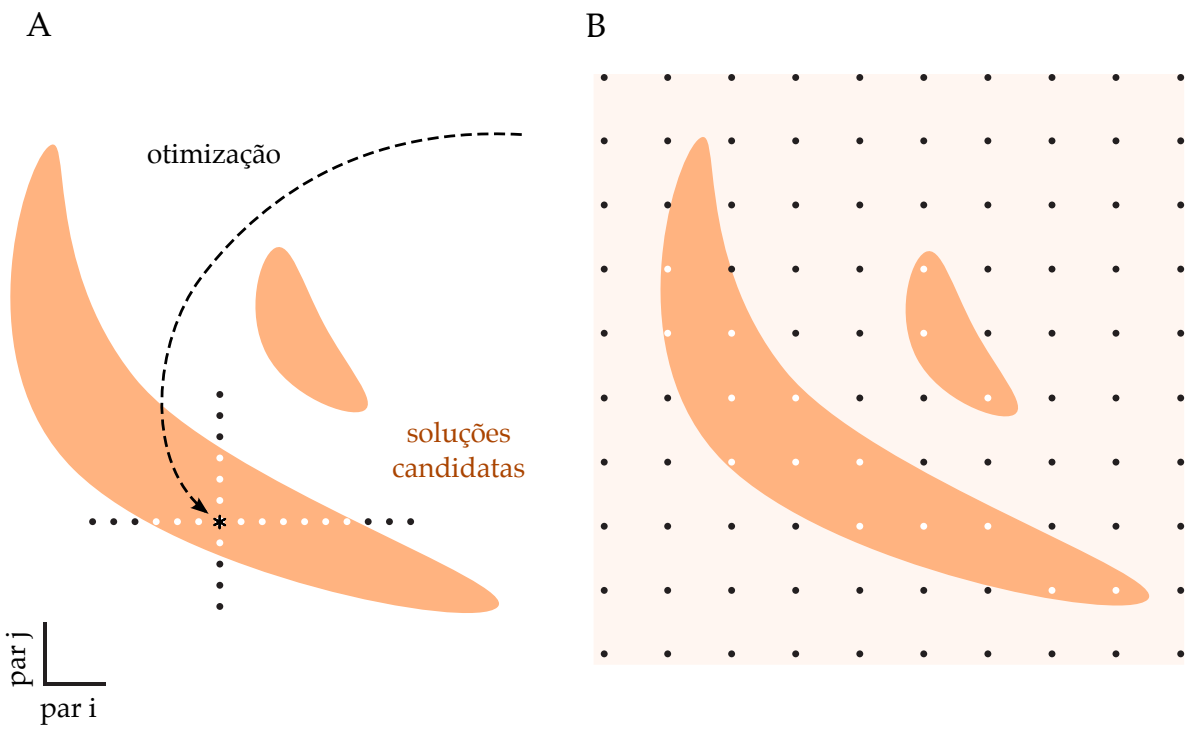

Hipoteticamente, pode-se particionar o espaço de parâmetros em regiões que dão origem a um comportamento funcional (definido em termos do sistema que está sendo modelado: espera-se que um CPG gere ritmos oscilatórios ao invés de disparar tonicamente) quando integrada a dinâmica. Desta maneira, o procedimento de otimização de parâmetros constituise em determinar e classificar estas regiões.

Após uma delimitação grossa inicial baseada em considerações fisiológicas, aplicam-se algoritmos de otimização sobre funções de estado relevantes ao problema estudado - como taxas de disparo, duty-cycle de bursts ou potenciais de repouso no caso de modelos neuronais - para encontrar um conjunto 
de parâmetros dito "canônico" (estrela no painel A da fig. 4.1). Varre-se então o espaço ao longo de cada um dos parâmetros, a fim de determinar e classificar as possíveis soluções funcionais.

Uma das idiossincrasias desta abordagem evidencia-se na figura 4.1: as soluções candidatas podem constituir regiões não contíguas, exigindo maior cuidado ao aplicar algoritmos de otimização, e limitando a aplicabilidade da varredura unidimensional a partir de um modelo canônico. Por outro lado, o fato de que conjuntos muito diversos de parâmetros venham a gerar comportamento funcional é atraente do ponto de vista biológico: em um sistema sujeito a grande variabilidade, tanto intrínseca quanto extrínseca (ambiente), há mais possibilidades de corregulação a serem exploradas a fim de atingir a homeostase.

Uma maneira de contornar essa dificuldade é a varredura por força bruta, discretizando o espaço de parâmetros em uma grade e integrando a dinâmica para cada um dos pontos (fig. 4.1B), armazenando os resultados em um banco de dados. Esta técnica tem se tornado cada vez mais popular (Prinz et al., 2003a; Günay et al., 2009; Doloc-Mihu e Calabrese, 2011), especialmente sob o enfoque de que conjuntos de modelos satisfazendo a determinados vínculos fisiológicos são mais plausíveis do que um único modelo "ótimo", obtido via ajuste fino de parâmetros em algoritmos de minimização. A este fato somam-se considerações técnicas associadas à escalabilidade no poder de processamento e armazenamento proporcionada por clusters de PCs de baixo custo.

\subsection{Nova metodologia para dissecção de espaços de parâmetros de modelos neuronais}

Modelos neuronais tipo $\mathrm{HH}$ apresentam um repertório rico de atividades, dependente do regime de parâmetros escolhido. Abordagens do tipo força bruta classificam estas dependências, inferindo o papel de correntes transmembrânicas e sinápticas no sistema de interesse em situações normais e patológicas (Prinz et al., 2003a; Doloc-Mihu e Calabrese, 2011; Günay et al., 2009). Bancos de dados de simulações de modelos computacionais são ferramentas versáteis, usadas para deter-

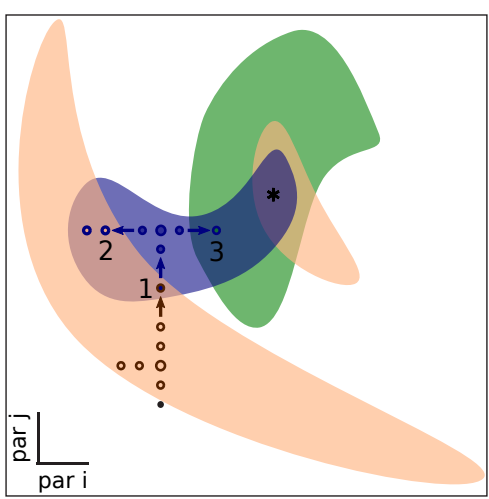

Figura 4.2: Dificuldades inerentes à varredura por força-bruta em sistemas multiestáveis, devido à histerese. Cores representam atratores distintos, de modo que há regiões de coexistência. Cordões de círculos representam integração das EDO mediante variação de um parâmetro, usando as condições finais da última integração como condições iniciais para a próxima. A cor interna dos círculos indica o atrator obtido; biestabilidade é indicada por uma cor de contorno distinta da interna. Desta maneira, não é possível determinar as fronteiras de multiestabilidade diretamente (note pontos de transição entre regiões indicados com numerais). $\mathrm{O}$ ponto indicado com uma estrela corresponde a triestabilidade: há três regimes de atividade atrativos, dependendo da condição inicial escolhida. 
minar como diferentes componentes da dinâmica neuronal interagem na geração de atividade funcional. Estes métodos mostraram-se efetivos em localizar conjuntos de parâmetros que ajustam a atividade observada experimentalmente, como uma alternativa aos procedimentos não automatizados de fine-tuning de modelos. Surpreendentemente, mostrou-se (Prinz et al., 2004; Marder et al., 2007; Marder e Taylor, 2011) que, em redes de neurônios simples, conjuntos de parâmetros muito distintos podem dar origem a comportamentos similares.

Tendo em conta a hipótese inicial de que regimes de atividade caótica coexistiam com atratores periódicos, voltaramse atenções a bancos de dados preexistentes. Apesar da possibilidade de coexistência de atratores ter sido mencionada em alguns trabalhos (Prinz et al., 2003a; Doloc-Mihu e Calabrese, 2011), nenhum procedimento sistemático para determinar a presença de multiestabilidade foi proposto. Esta constatação levanta imediatamente uma fragilidade no procedimento de varredura de espaços de parâmetros via integração direta (força bruta): há uma arbitrariedade inerente à escolha de condições iniciais que pode levar a classificações incompletas, caso não sejam amostradas todas as possíveis bacias de atração.

Dessa forma, determinar se modelos neuronais apresentam multiestabilidade através de integração direta e subsequente classificação da atividade resultante é computacionalmente custoso, já que envolveria integrar o mesmo sistema a partir de um número grande de condições iniciais, analisando as séries temporais subsequentes. Evidentemente, há um limite técnico na utilização de força bruta (no espaço de parâmetros) sobre força bruta (no espaço de estados), atingido rapidamente em modelos eletrofisiologicamente realistas dada a dimensionalidade de ambos espaços.

Foi desenvolvida então uma técnica híbrida (Marin et al., 2013), combinando métodos da teoria de bifurcações (em particular continuação numérica, ver apêndice B.2) com varreduras via força-bruta, para estender os banco de dados de modelos agregando informação sobre todos os estados de equilíbrio, estáveis e instáveis, independentemente da escolha de condições iniciais. Desta maneira, novos regimes de atividade do sistema puderam ser acessados facilmente - incluindo a presença de multiestabilidade - de maneira eficiente. 


\section{Descrição do método e exemplo de aplicação}

O método descrito foi utilizado para estender o banco de dados descrito em Doloc-Mihu e Calabrese (2011), construído para estudar a atividade de CPG que controlam o ritmo cardíaco de sanguessugas em diversas situações experimentais. O sistema consiste em dois neurônios conectados em mútua inibição, formando um half-center oscillator (HCO). Cada uma das células possui oito condutâncias iônicas (Hill et al., 2001), modeladas segundo o formalismo de $\mathrm{HH}$. O banco de dados foi construído variando 8 parâmetros chave (potencial de reversão da corrente de leak, condutâncias máximas sinápticas e de seis das correntes iônicas); cada um dos pontos neste espaço de parâmetros de oito dimensões - correspondendo a um particular modelo de HCO foi integrado e a atividade de cada uma das células armazenada no banco de dados. No total, em Doloc-Mihu e Calabrese (2011) foram analisadas mais de dez milhões de simulações.

Inicialmente, foi selecionado um subconjunto de modelos do banco de dados, correspondente aos 38713 casos que dão origem a HCO funcionais. Os modelos correspondentes foram integrados utilizando o método RADAU5 (Hairer et al., 2002), adequado para sistemas stiff, e reclassificados (ver apêndice B). A reclassificação fez-se necessária pois em Doloc-Mihu e Calabrese (2011) os autores utilizaram o integrador do simulador genesis (baseado no método de Euler exponencial), e diferentes escolhas de algoritmos de integração levam a resultados distintos. Cada um dos estados estacionários foi classificado como quiescente, tônico ou bursting, a partir da detecção de spikes como cruzamentos de um limiar de $-10 \mathrm{mV}$ e de bursts como séries com spikes que apresentassem IsI maiores que 1 s.

A análise foi restringida aos 2671 casos que apresentaram bursts para ao menos uma das condições inicias. Para cada uma destas séries, foram calculadas estatísticas descritivas da atividade bursting. Casos que apresentaram coeficientes de variação maiores que $10 \%$ para o período dos bursts foram consideradas irregulares e excluídos da análise, bem como séries que apresentaram bursts tipo "platô" (spikes de pequena amplitude sobre modulação lenta). Desta forma, foi definido o conjunto final de modelos analisados, chamado de bursters robustos. 
Para cada um dos modelos no conjunto de bursters robustos, foi aplicada a técnica de continuação numérica de equilíbrios, utilizando o pacote PyDSTool (Clewley et al., 2010). O parâmetro de controle utilizado foi a condutância máxima da corrente leak, iniciando a continuação a partir do equilíbrio estável obtido por integração do sistema com um valor alto de $g_{\text {leak }}(20 \mathrm{nS})$. Com a análise de bifurcações do ramo de equilíbrios, foram determinados os valores das variáveis dinâmicas em cada um dos equilíbrios, bem como a estabilidade destes estados para cada valor do parâmetro de controle. Os intervalos para os quais os modelos apresentavam disparo em bursts foram determinado por integração direta. A condutância $g_{\text {leak }}$ foi alterada em passos de \pm 1 nS, e o sistema reintegrado, até que uma transição de bursts em disparo tônico, silêncio ou bursts irregulares fosse detectada. O processo foi repetido iterativamente, a partir do último ponto que levara a atividade bursting, mas com um passo dez vezes menor, até um passo de $10^{-4} \mathrm{nS}$.

A fim de determinar o efeito de células multiestáveis em um HCO, foi construído um modelo composto por duas células conectadas através de duas sinapses (uma mediada por spikes e outra graduada, conforme Cymbalyuk et al., 2002; Hill et al., 2001). O protocolo de simulação consistiu em ajustar as condutâncias máximas sinápticas $g_{\text {syns }}$ e $g_{\text {synG }}$ a $150 \mathrm{nS}$ e 30nS respectivamente, e integrar o sistema por 100s. As sinapses foram então "desligadas" por 5s, ajustando as respectivas condutâncias a $0 \mathrm{nS}$, enquanto uma das células teve seu estado levado à proximidade de um equilíbrio estável. Após este período, as condutâncias sinápticas foram restauradas, e o sistema integrado por 100s adicionais. A atividade do sistema foi analisada separadamente para os intervalos inicial e final.

\section{Equilíbrios e multiestabilidade}

A partir das curvas de equilíbrios calculadas para cada um dos bursters robustos, obtém-se diretamente informação acerca do comportamento assintótico do sistema, dificilmente obtida através da integração direta de condições inciais aleatórias. 
A

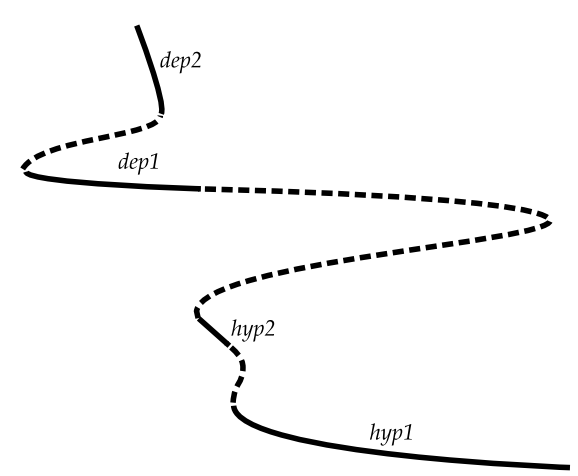

C

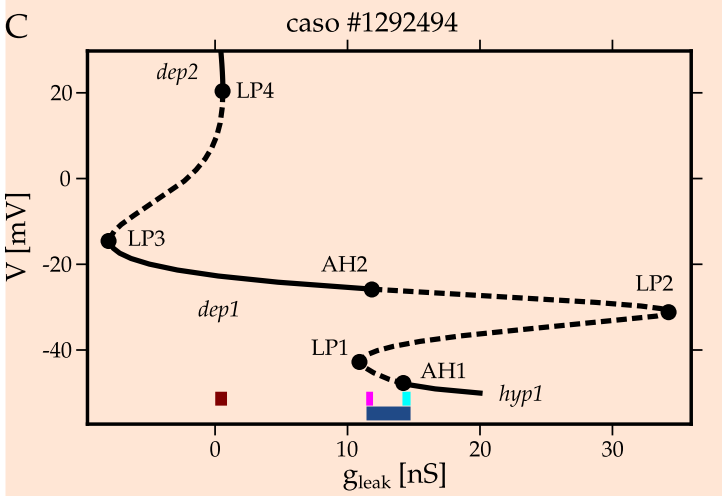

E

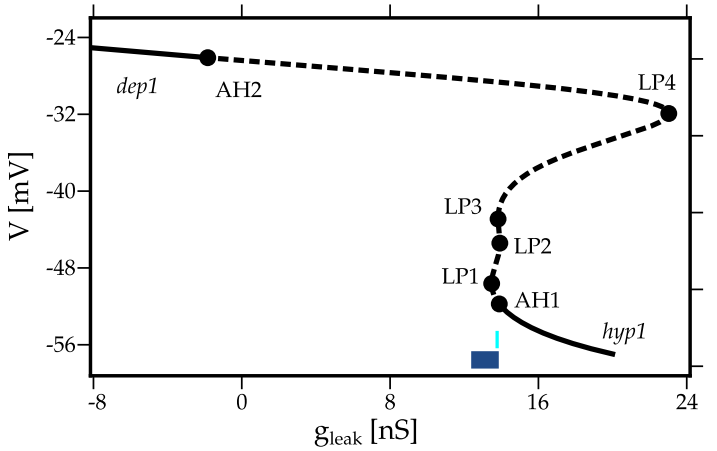

B

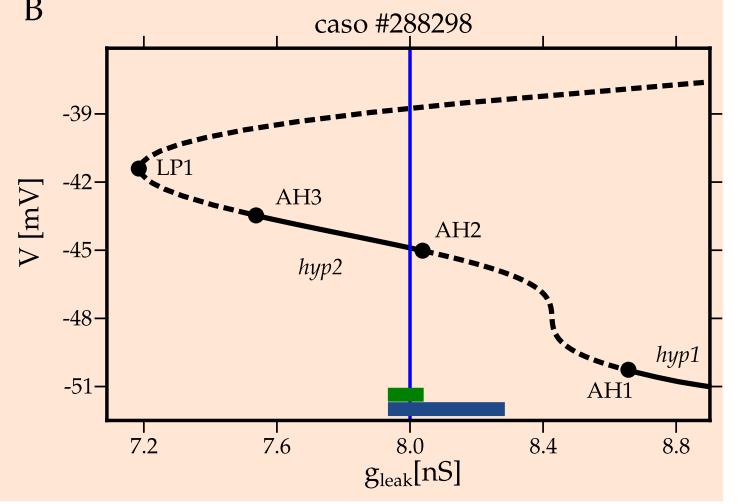

$\mathrm{D}$
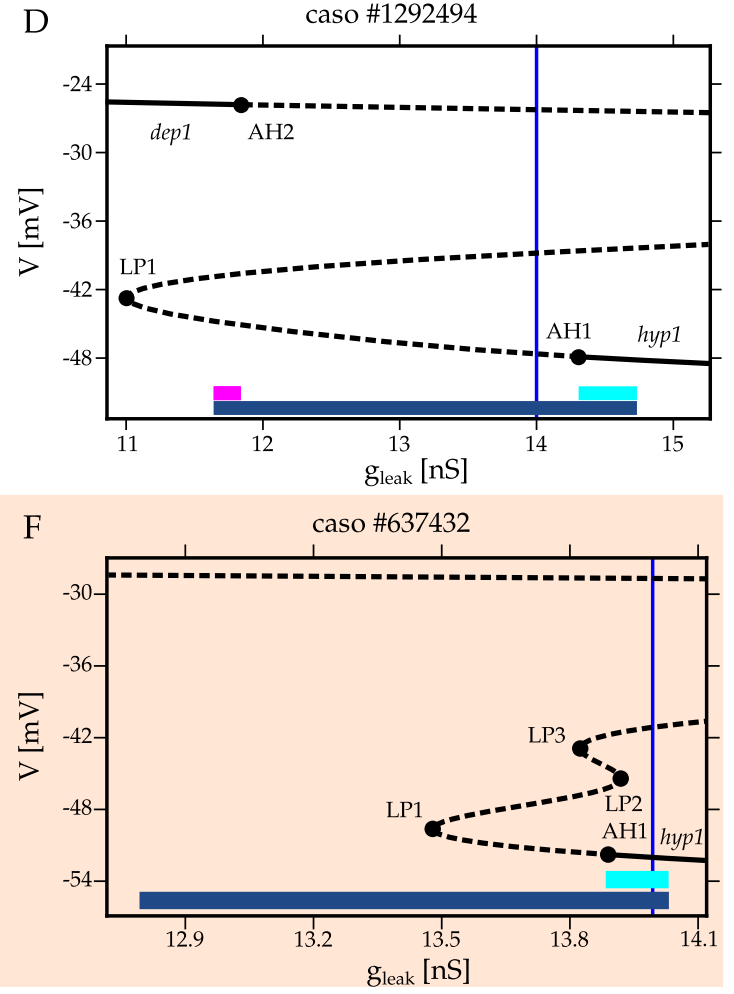

Figura 4.3: Diagramas de bifurcação para equilíbrios dos modelos no banco de dados, com a condutância da corrente ohmica $g_{\text {leak }}$ como parâmetro. A: Diagrama de bifurcação estilizado, ilustrando as convenções adotadas ao nomear trechos estáveis do ramo de equilíbrios. B: Ampliação do diagrama de bifurcação para o caso \#288298, que apresenta um intervalo de estabilidade hyp2 no ramo central, delimitado por duas bifurcações de Hopf. As barras verdes denotam um intervalo que comporta a coexistência de bursting e de equilíbrios estáveis hyp2. C,D: Para o caso \#1292494, há três intervalos comportando equilíbrios estáveis; c: a barra vermelha indica um intervalo que comporta a coexistência dos estados dep1 e dep2. O intervalo depı é delimitado pelas bifurcações de Andronov-Hopf AH1 e sela-nó LP3, enquanto LP4 delimita a borda direita do intervalo dep2. C,D: a barra magenta marca a coexistência de dep 1 e bursting, delimitada à esquerda pelo intervalo que comporta bursting e à direita pela bifurcação AH2. A barra ciano indica biestabilidade de bursting e hyp entre AH1 e a borda onde desaparecem os bursts. E,F: caso onde o valor de $g_{\text {leak }}$ (linha azul) do banco de dados pertence a um intervalo que comporta biestabilidade. A classificação do comportamento por integração direta mostra-se então ambígua, já que depende da escolha de condições iniciais. 
Um exemplo de informação não usual obtida é a existência de dois equilíbrios estáveis hiperpolarizados, bem como dois equilíbrios depolarizados. O diagrama de bifurcações na figura 4.3C mostra que o caso \#1292494 apresenta dois equilíbrios estáveis depolarizados, para potenciais de membrana próximos de $-23 \mathrm{mV}$ e $+19 \mathrm{mV}$. Uma transição entre estes estados pode ser induzida por pulsos de corrente, conforme ilustrado na figura 4.4.

Figura 4.4: Chaveamento entre os estados dep2 e depi por um pulso hiperpolarizante. $\mathrm{O}$ valor de $g_{\text {leak }}$ utilizado pertence ao intervalo de coexistência dos ramos depi e dep2. O modelo foi integrado a partir de uma condição inicial próxima ao estado dep2 (segmento azul da curva), sendo perturbado após 10s (verde). O pulso induz uma transição para o estado dep1, conforme infere-se pela parte vermelha da curva. caso \#1292494

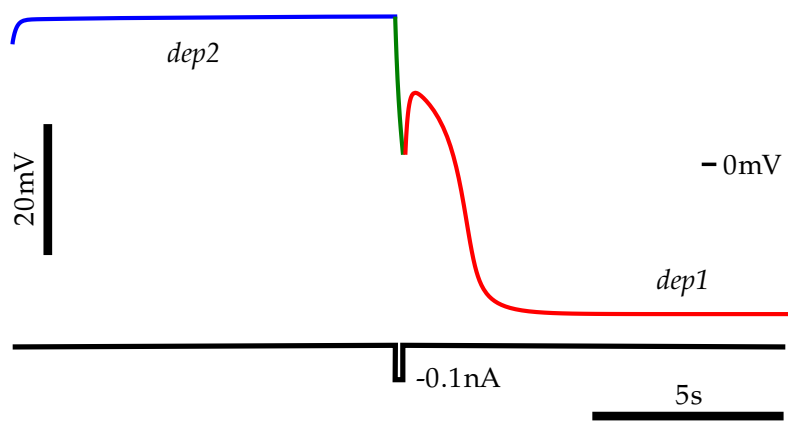

É possível também analisar sistematicamente a presença de multiestabilidade nos modelos, quando os intervalos de $g_{\text {leak }}$ comportando equilíbrios estáveis e disparo em bursts se sobrepõem. Na figura 4.5, observa-se que para o caso \#861497 há três intervalos de $g_{\text {leak }}$ comportando multiestabilidade: a zona amarela denota coexistência de três regimes: bursts e equilíbrios estáveis hypı e dep (triestabilidade); a zona laranja, coexistência de equilíbrios hyp 1 e dep 1 (biestabilidade); enquanto que a zona magenta indica coexistência de bursting e quiescência dep1.

$\mathrm{Na}$ figura 4.7, ilustra-se a presença de triestabilidade integrando o caso \#861497 a partir de três condições iniciais distintas. A primeira condição inicial (traço do topo) dá origem a disparo em bursts. A segunda (traço do meio) a oscilações tipo spike amortecidas até atingir o estado dep1. A terceira (traço inferior), a oscilações sublimiar amortecidas indo assintoticamente a hyp. 
A

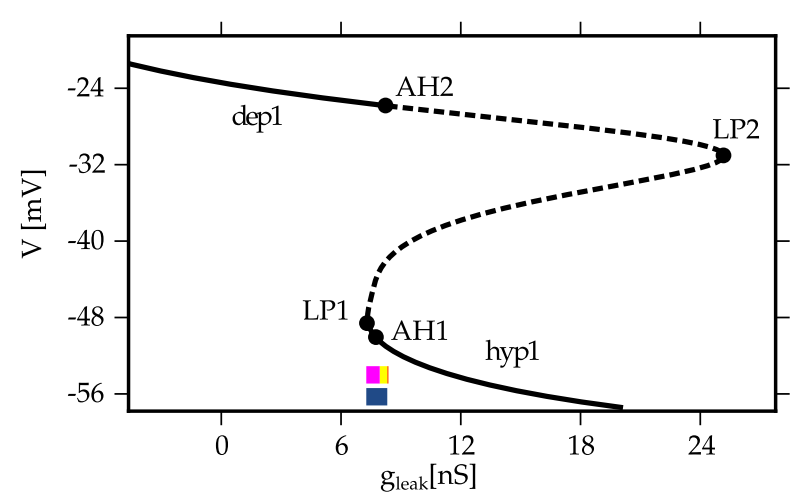

B

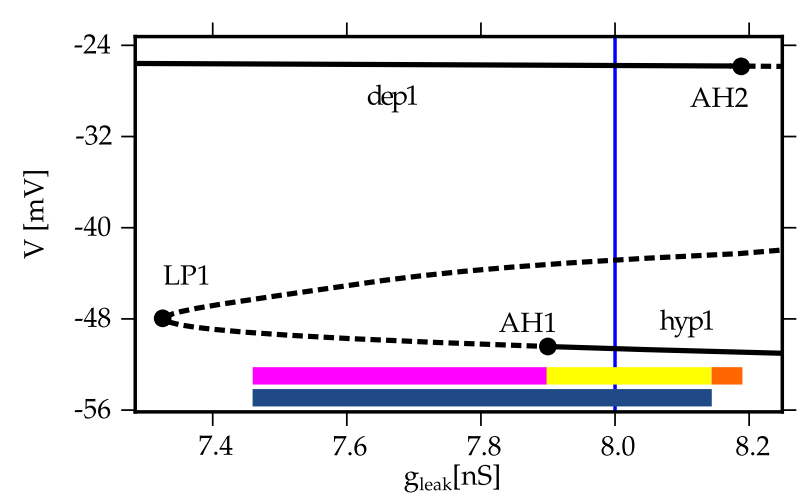

Figura 4.5: Diagrama de bifurcação descrevendo triestabilidade no caso \#861497.

O intervalo de $g_{\text {leak }}$ para o qual o regime bursting é um atrator é indicado pela barra azul escura. A barra magenta denota o intervalo de coexistência entre bursting e o estado depi. O intervalo de $g_{\text {leak }}$ que comporta triestabilidade - onde coexistem bursting, hypi e dep1-é indicado pela barra amarela. $\mathrm{O}$ intervalo que comporta a coexistência de hyp 1 e dep1- mas não bursting - é indicado pela barra laranja. É importante frisar que o valor de $g_{\text {leak }}$ original $(8 \mathrm{nS})$ do banco de dados pertence ao intervalo de triestabilidade. 4.3D). Adicionalmente, treze casos apresentaram um intervalo com coexistência de bursting e hyp1, e outro com coexistência de dep1 e dep2 (fig. 4.3C). Sete casos apresentaram um intervalo de coexistência de hypı e depı, e outro de bursting e dep 1 (fig. 4.3E).

Três intervalos com exatamente dois regimes atrativos Foram encontrados dois casos com três intervalos biestáveis, envolvendo coexistências de dep1 e dep2, bursting e dep1, bursting e hyp (fig. 4.3C,D, 4.5F).

Três intervalos de coexistências, envolvendo triestabilidade Todos os modelos com intervalos de $g_{\text {leak }}$ comportando tri- 


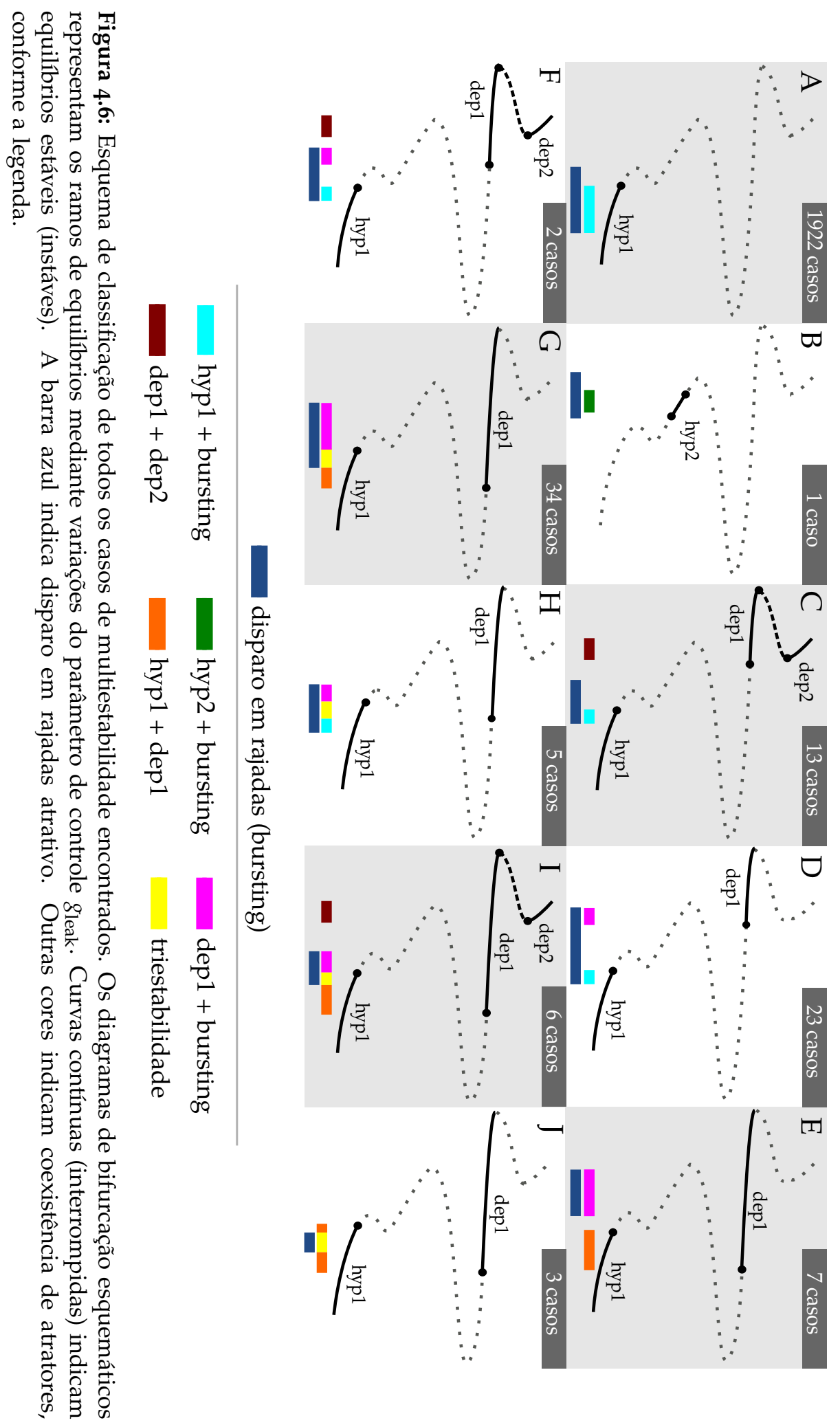


caso \#861497

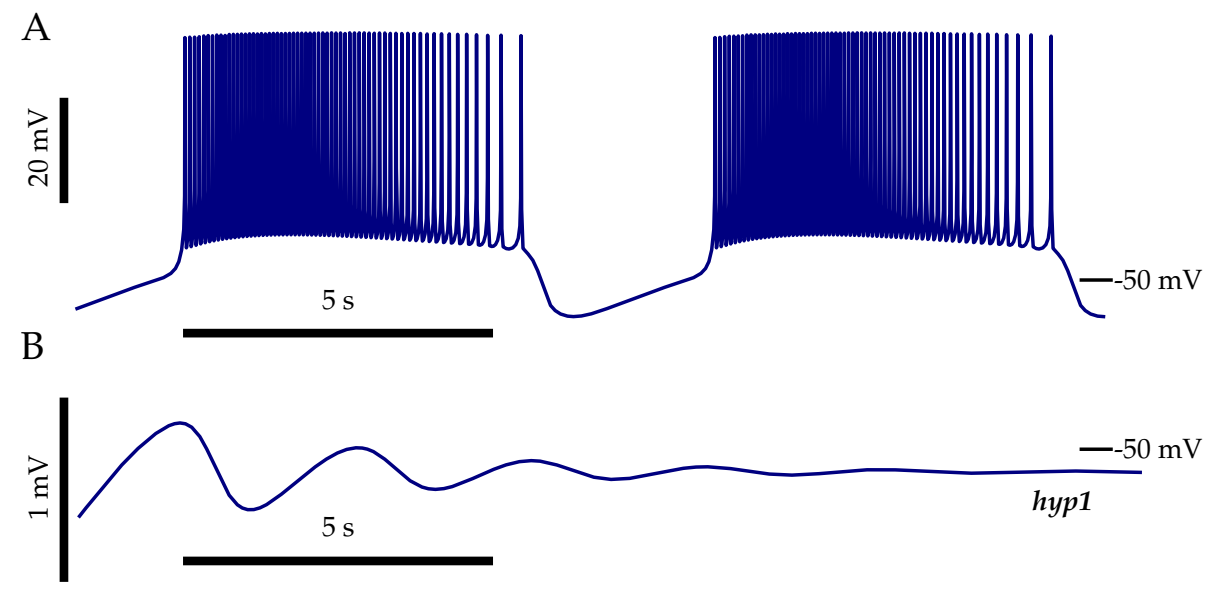

C

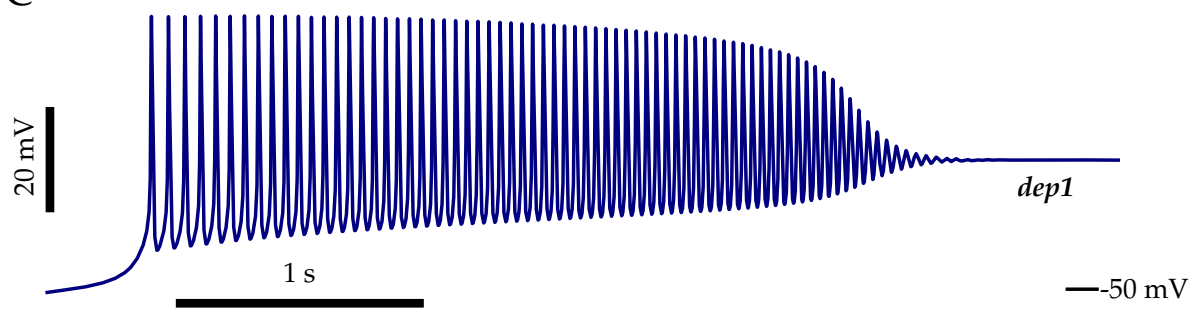

Figura 4.7: Três regimes de atividade distintos são atratores em um modelo triestável. No diagrama de bifurcações do caso \#861497, há um intervalo de valores de $g_{\text {leak }}$ que comporta triestabilidade entre bursting, hyp 1 e dep 1 (fig. 4.5B, barra amarela). O modelo foi integrado usando o valor de $g_{\text {leak }}$ original do banco de dados, $8 \mathrm{nS}$, a partir de três condições iniciais distintas, previstas pela metodologia. A: O neurônio exibe disparo em rajadas; в: oscilações lentas amortecidas, decaindo ao estado hyp1; c: disparos transientes, amortecidos tendendo ao equilíbrio depi.

estabilidade apresentaram também intervalos adicionais de biestabilidade. Em 34 casos, há dois intervalos de biestabilidade, um deles envolvendo a coexistência dos equilíbrios estáveis hypi e dep1, e o outro de bursting e depı (fig. 4.6G). Três casos apresentam dois intervalos distintos de biestabilidade entre hypı e depı (fig. 4.6J). Juntamente com o intervalo comportando triestabilidade, cinco casos exibem um intervalo com biestabilidade entre hур1 e dep1, outro entre bursting e dep1, bem como um terceiro de coexistência de dep1 e dep2 (fig. 4.6J).

Quatro intervalos de multiestabilidade Juntamente com um intervalo comportando triestabilidade, seis casos exibiram um intervalo com biestabilidade entre hyp 1 e dep 1 , um intervalo de coexistência de depı e bursting, bem como um de biestabilidade entre depı e dep2 (fig. 4.6I).

No total, foi encontrada triestabilidade em 48 dos 2223 bursters robustos (2\%). Quanto à coexistência de atratores 
mediante variações nos valores de $g_{\text {leak, }}$ obtiveram-se 2016 (91\% dos casos) modelos propensos à multiestabilidade.

Dentre os 2223 modelos bursting robustos, 421 (18\%) exibem multiestabilidade para o valor original de $g_{\text {leak }}$ do banco de dados de Doloc-Mihu e Calabrese (2011). Desses 421 modelos, 361 exibem biestabilidade entre bursting e hyp ; 47 biestabilidade entre bursting e dep1; um único biestabilidade entre bursting e hyp2. Adicionalmente, 12 casos apresentam triestabilidade envolvendo a coexistência de bursting, hypı e dep1 (fig. 4.5B).

Figura 4.8: Prevalência de muliestabilidade - definida como a razão do tamanho do intervalo em $g_{\text {leak }}$ comportando coexistência de atratores e o intervalo compatível com atividade bursting. Todos os modelos multiestáveis foram considerados.

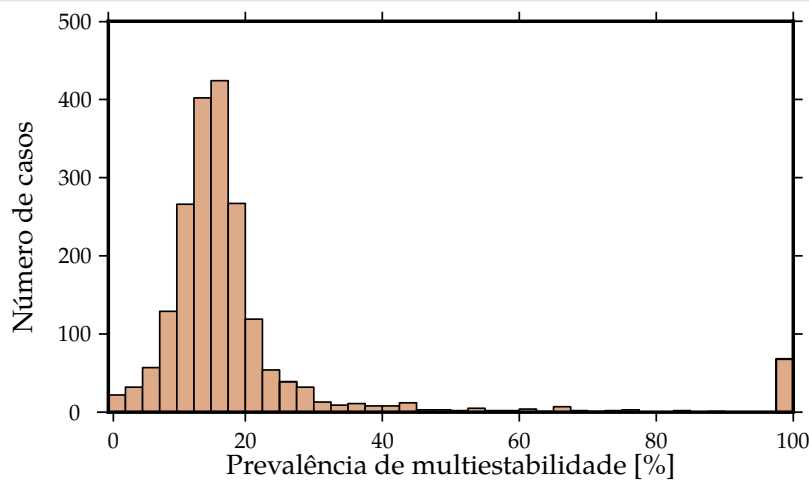

Considerando que, in vivo, flutuações nas propriedades neuronais extrínsicas e intrínsicas implicam um conjunto de casos do modelo, e não um único representante "ótimo", a questão da prevalência de comportamento multiestável para variações nos parâmetros é tão importante quanto a simples determinação de possíveis coexistências de atratores. Para tanto, foi calculada a razão entre o tamanho dos intervalos de $g_{\text {leak }}$ que comportavam bursting e multiestabilidade, de quaisquer dos tipos observados (4.6). Na figura 4.8, há um histograma para estes dados. Nota-se um pico elevado ao redor de $15 \%$ indicando que, na maioria dos casos, esta fração do intervalo de $g_{\text {leak }}$ compatível com atividade bursting comporta também outro atrator. O pico secundário em 100\% está associado aos casos de triestabilidade (ver figs. 4.5, 4.6).

\section{Geradores de padrões com unidades multiestáveis}

Os neurônios analisados no banco de dados são subunidades de um HCO que controla os batimentos cardíacos de sanguessugas. A possibilidade de uma das células ir a um equilíbrio estável 
representa uma situação de risco de vida para o animal. Como grande parte $(89 \%)$ dos modelos analisados apresenta ao menos um intervalo de multiestabilidade envolvendo um equilíbrio, foi desenvolvido um protocolo para determinar a confiabilidade de HCO construídos a partir de células multiestáveis. Na figura 4.9, apresentam-se dois exemplos: um para uma célula biestável (painel A) e outro para uma célula triestável (painel в).

Para o primeiro caso, quando as sinapses são bloqueadas e o estado da célula de baixo é levado às proximidades do equilíbrio estável hypı, a célula de cima continua a disparar segundo sua dinâmica intrínseca, já que não está sendo inibida. Quando o acoplamento sináptico é restaurado (parte verde das séries temporais), a célula de cima está na fase hiperpolarizada do regime bursting, perto de iniciar um novo burst. A corrente sináptica não é suficiente para retornar a célula de baixo ao regime bursting, de modo que esta última segue próxima ao estado hyp1. Quando a célula de cima dispara (já que não está sendo inibida fortemente pela célula de baixo), a corrente sináptica perturba a célula de baixo para fora da bacia de atração do equilíbrio, recuperando a atividade bursting e a funcionalidade do sistema como um half-center oscillator.

Para o segundo caso (fig. 4.9B), onde duas células triestáveis estão acopladas, quando a corrente sináptica é restaurada a célula de baixo já está disparando um burst devido à sua dinâmica intrínseca, de modo que a célula de baixo é imediatamente deslocada do estado estável depı para bursting, e o HCO recupera seu comportamento basal de disparos em antifase. Obtém-se um comportamento similar perturbando a célula para o estado hyp 1 ao invés de dep1, analogamente ao caso biestável (fig. 4.6A).

Para o último caso (fig. 4.9C), apresenta-se uma situação onde um HCO constituído por duas células triestáveis (caso \#820216) perde funcionalidade devido à coexistência de bursting com os equilíbrios estáveis hypı e depı. Não é necessário que ambos os equilíbrios estejam presentes (triestabilidade): a perda do padrão rítmico pode ocorrer para casos biestáveis, ficando as duas células "presas" no mesmo equilíbrio (hypi/hyp ou $\operatorname{dep} 1 / \operatorname{dep} 1)$.

Aplicando este protocolo aos 421 modelos originalmente triestáveis no banco de dados, nota-se que 353 deles (85\%) davam origem a HCO funcionais, independentemente de quaisquer perturbações. Dentre os casos funcionais, $96 \%$ recuperaram o 
comportamento rítmico regular após a perturbação, mostrando que o acoplamento em mútua inibição dá origem a HCO robustos mesmo com células multiestáveis.

Figura 4.9: Simulações de HCO construídos com unidades multiestáveis. Em cada um dos exemplos, o traço superior(inferior) corresponde ao potencial de membrana da primeira(segunda) célula do par. (A:) caso que apresenta biestabilidade entre bursting e o estado hyp1. (B,С:) casos triestáveis (coexistência de bursting e estados hyp1, dep1). A parte azul de cada um dos traços representa a atividade durante 50s iniciais, com o acoplamento sináptico presente. Ambas as células disparam bursts em antifase, característicos de HCO funcionais. Os segmentos vermelhos denotam um período de $5 \mathrm{~s}$, quando o acoplamento sináptico é eliminado, e a célula de baixo tem seu estado levado à vizinhança de um equilíbrio estável. Os traços verdes correspondem aos 50s seguintes, quando o acoplamento sináptico é restaurado.
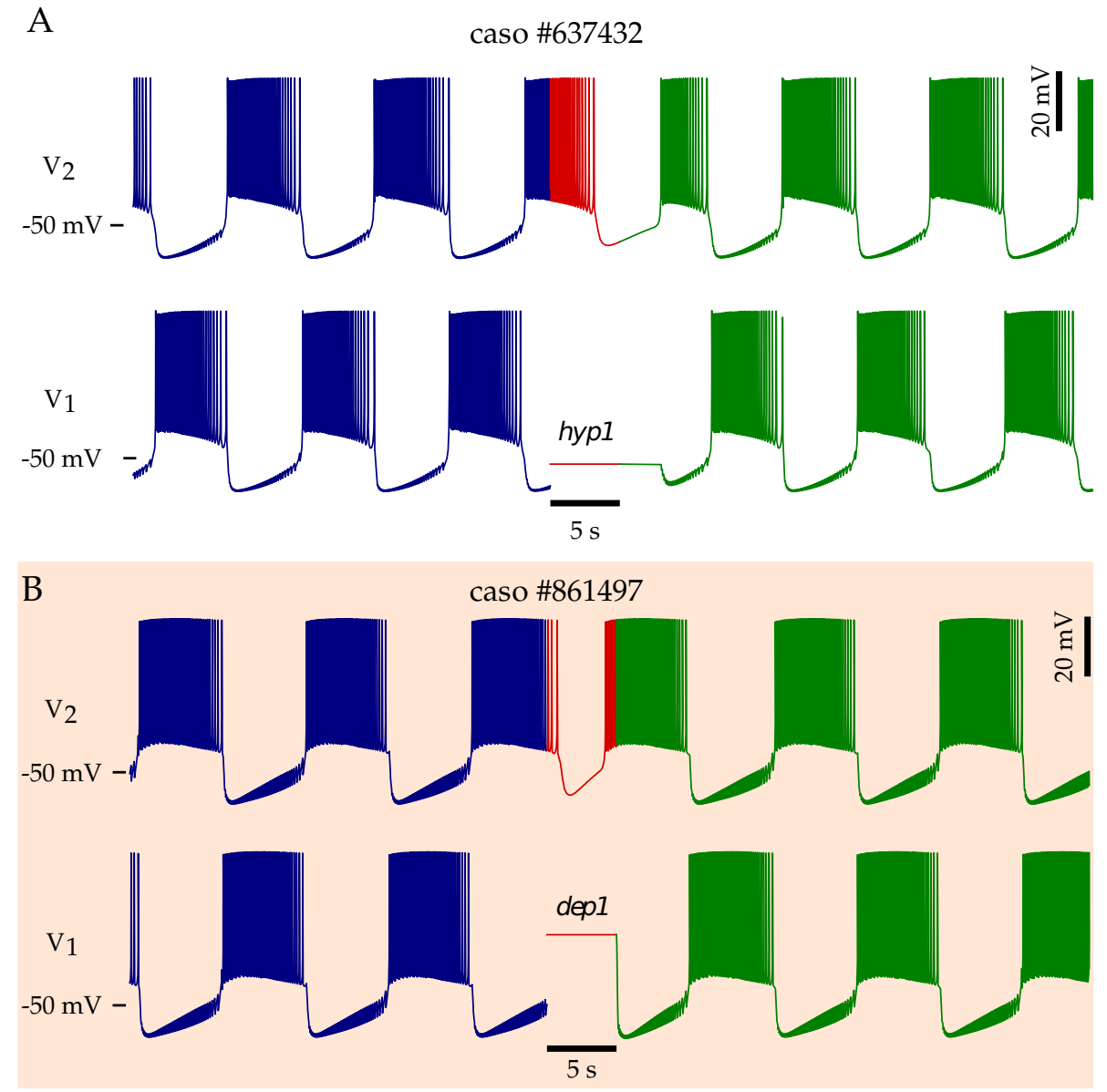

C

caso \#820216

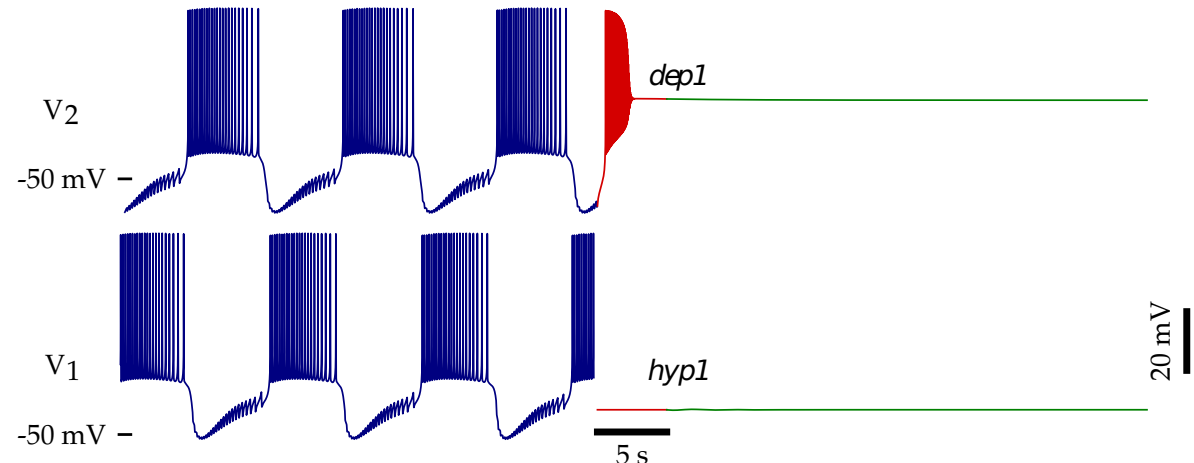




\section{Capítulo 5}

\section{Dinâmica em modelos neuronais}

O tipo de investigação numérica apresentado nos capítulos precedentes permite estudar o comportamento do modelo completo desde um ponto de vista de "experimento computacional" onde determinam-se as respostas do sistema como um todo a estímulos controlados, de uma maneira similar ao trabalho em uma bancada de laboratório. Um procedimento de análise complementar consiste em desenvolver modelos simplificados, que apresentem dinâmica equivalente ao modelo eletrofisiologicamente detalhado. Desta maneira, buscam-se os mecanismos dinâmicos responsáveis pelos comportamentos observados nos experimentos (tanto numéricos quanto com tecido vivo).

Os resultados de simulações com condutâncias congeladas determinaram que modelos baseados em condutâncias possuem capacidade de codificação informacional, similares às observadas em neurônios do STG, via a modulação dos ISI em um burst. Por outro lado, simulações do modelo completo indicaram que é possível fazer ajustes finos na posição de spikes em um burst, mediante perturbações controladas nas variáveis dinâmicas. Em modelos simplificados, é possível determinar geometricamente o efeito de tais perturbações, de maneira a caracterizar com detalhes os mecanismos através dos quais dinâmicas em escalas temporais distintas interagem, gerando padrões complexos de atividade elétrica. 


\subsection{Excitabilidade e bifurcações}

O primeiro passo na análise geométrica qualitativa consiste em propor modelos com dinâmica simples, que capturem algumas propriedades importantes do neurônio em questão. Diversos modelos "caricaturais" - assim chamados por não necessariamente descreverem mecanismos eletrofisiológicos, gerando entretanto comportamento elétrico plausível - tornaramse famosos, como os descritos em Fitzhugh (1961); Morris e Lecar (1981). O tipo de análise apresentada a seguir se deve aos trabalhos de Rinzel (1998), estendidos e sistematizado por Izhikevich (2000, 2006).

Figura 5.1: Definição de sistema excitável: as trajetórias fazem uma excursão longa

(alça marcada com PA no diagrama da esquerda) pelo espaço de estados mediante uma pequena perturbação, antes de voltar ao repouso. Este tipo de comportamento indica que o sistema está próximo a uma bifurcação, sendo possível fazer com que o sistema passe de excitável a periódico distorcendo levemente o campo vetorial (trazendo o ponto de equilíbrio à região de início da trajetória correspondente a um disparo, marcada com um quadrado). Adaptado de Izhikevich (2006).

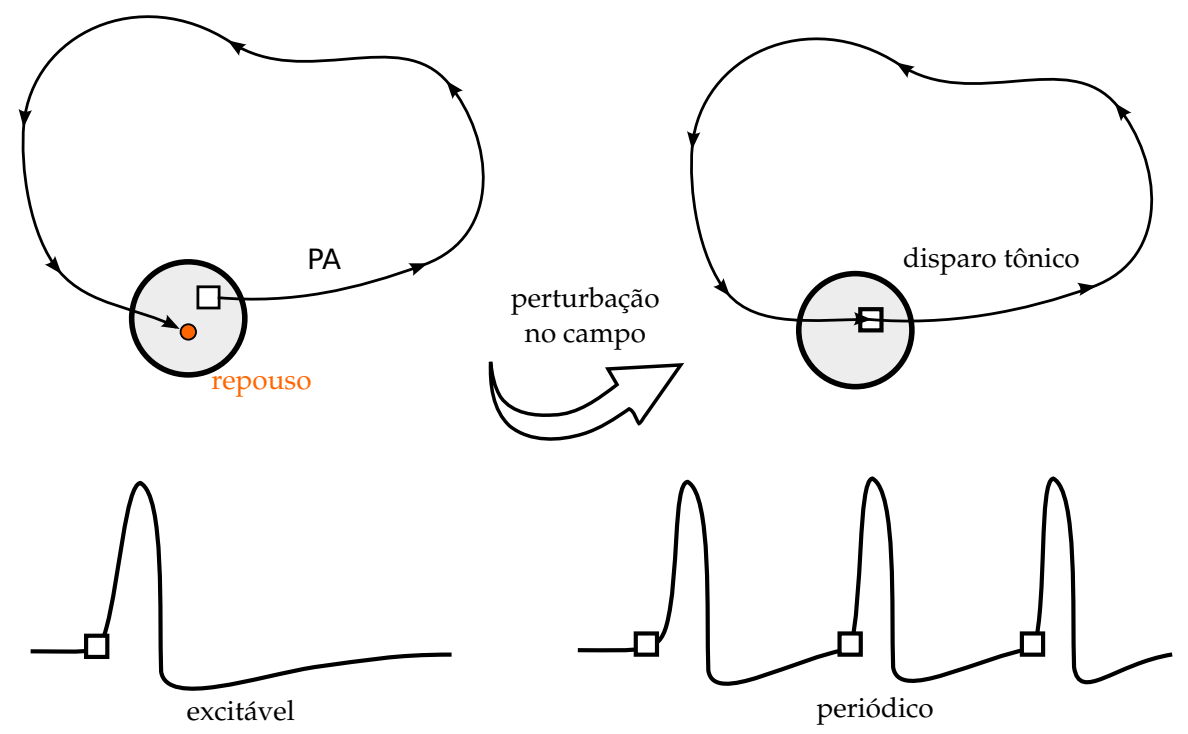

A metodologia adotada é esquematizada na figura 5.1. Neurônios podem ser descritos como sistemas excitáveis, apresentando um estado de equilíbrio (repouso), que pode ser perturbado de modo a produzir trajetórias transientes de grande amplitude. Nesta situação é possível, através de pequenas alterações sobre o campo vetorial que define a dinâmica, tornar as trajetórias transientes num ciclo limite estável - caracterizando uma bifurcação. Em suma, um sistema excitável está próximo a uma bifurcação que substitui um equilíbrio estável por uma órbita periódica estável. A análise geométrica da dinâmica 


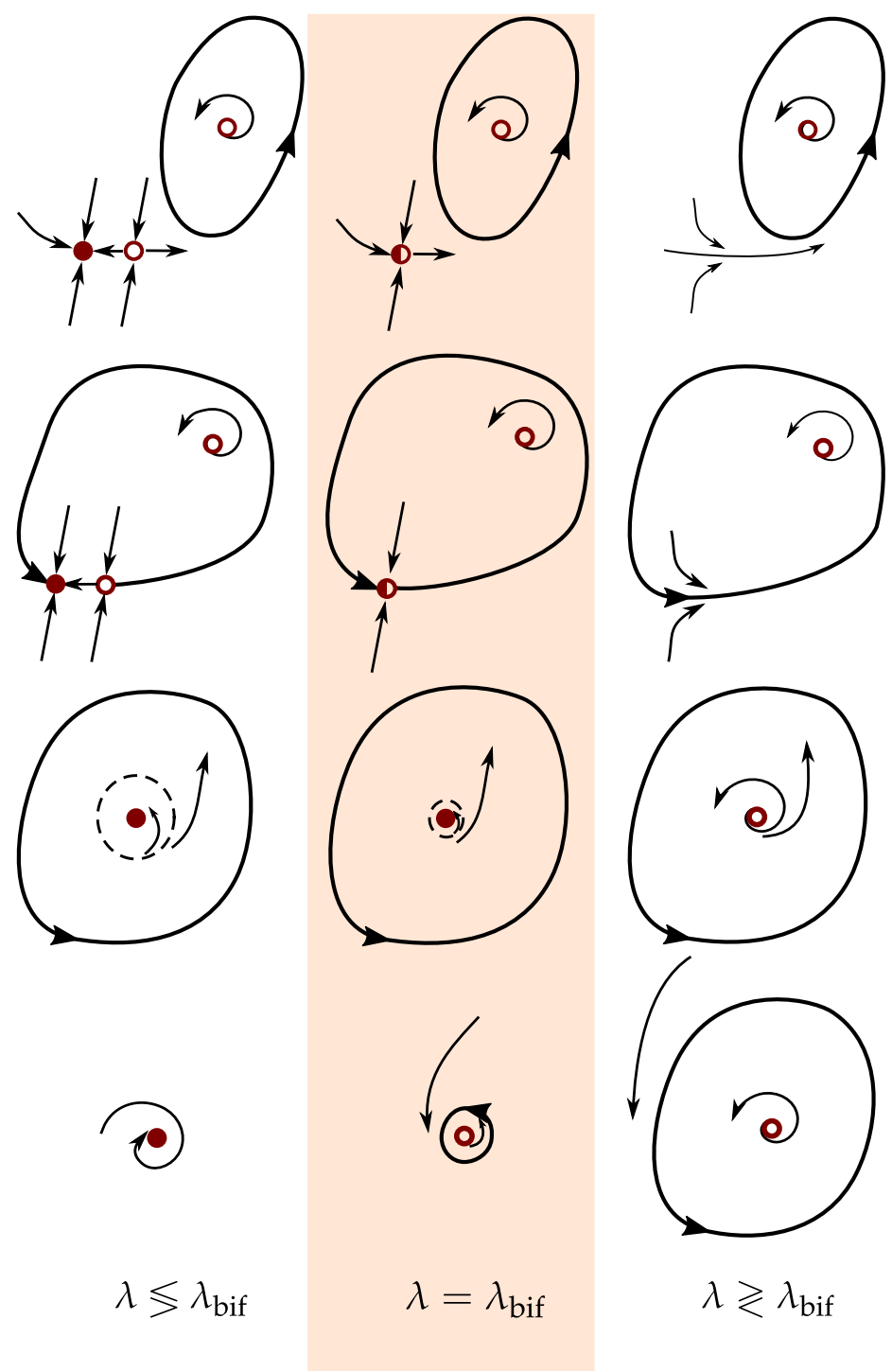

neuronal consiste em determinar quais tipos de bifurcações sofre o modelo, a fim de caracterizar seu comportamento.

No caso de modelos bidimensionais, só há quatro possibilidades de bifurcações (ver a figura 5.2, bem como o apêndice A) de um estado de equilíbrio que levam o sistema do repouso a disparos periódicos:

- sela-nó (figura 5.2 primeira linha): coalescência e mútua aniquilação de equilíbrios nó e sela. O fluxo é então atraído então para um ciclo estável preexistente.
Figura 5.2: Possíveis bifurcações envolvendo equilíbrio e ciclo limite no plano. No eixo vertical, tem-se o potencial de membrana, enquanto no horizontal uma variável de recuperação (como por exemplo ativação de uma corrente de Potássio). Na coluna da esquerda, é representado o retrato de fases antes(após) a ocorrência da bifurcação; na central, a situação (estruturalmente instável) no ponto exato de bifurcação; na da direita, como fica o sistema após(antes) a bifurcação. Caso A: bifurcação sela-nó; в: bifurcação sela-nó em ciclo limite (SNIC); c: bifurcação de Hopf subcrítica; D: bifurcação de Hopf supercrítica. Adaptado de Izhikevich (2006). 
- sela-nó em ciclo invariante (snic) (figura 5.2 segunda linha): análoga à anterior, mas os equilíbrios encontramse sobre um ciclo invariante, que torna-se órbita periódica com o desaparecimento da sela e do nó.

- Hopf subcrítica (figura 5.2 terceira linha): Um foco estável desaparece juntamente com um ciclo limite instável, que vinha diminuindo de amplitude com a variação do parâmetro de controle. Resta então o ciclo limite estável preexistente.

- Hopf supercrítica (figura 5.2 quarta linha): Um foco estável dá origem a um foco instável e um ciclo limite estável, inicialmente de pequena amplitude.

Cada um dos cenários de bifurcação acima descritos dá origem a comportamentos característicos, permitindo identificar sua ocorrência em modelos complexos, bem como em séries temporais experimentais. Por exemplo, sistemas nas proximidades de bifurcações de Hopf apresentam oscilações amortecidas do potencial de membrana (subthreshold oscillations), ao relaxarem para o equilíbrio - devido ao fato deste ser um foco; no caso de bifurcações sela-nó e Hopf subcrítica, como há coexistência de equilíbrios e ciclos-limite, é possível alternar o sistema entre estado de repouso e comportamento tônico com perturbações adequadas, devido à biestabilidade.

\subsection{Bursting: sistemas multiescala temporal}

Em muitos casos, um modelo que apresenta comportamento de disparos em bursts pode ser reduzido a um subsistema responsável pelos spikes (dito rápido), que é quiescente para um determinado valor de corrente injetada, e dispara potenciais de ação periodicamente (comportamento tônico) para outros. Esse subsistema é modulado por uma dinâmica mais lenta, que hora atinge valores acima do necessário para disparo do subsistema rápido, hora abaixo. Com isso, tem-se o comportamento em bursts. O subsistema rápido sofre então bifurcações envolvendo a perda de estabilidade de um equilíbrio, de 
modo que a trajetória é atraída por um ciclo limite (transição quiescente $\rightarrow$ spiking), e a subsequente perda de estabilidade deste regime, com a qual o sistema retorna ao equilíbrio (transição spiking $\rightarrow$ quiescente). Para um caso tridimensional (subsistema rápido/lento bi/unidimensional), pode-se ter apenas os tipos de transição equilíbrio $\rightarrow$ ciclo limite descritos na figura 5.2, enquanto que para a transição ciclo limite $\rightarrow$ equilíbrio são possíveis os seguintes cenários de bifurcação (detalhes no apêndice $\mathrm{A})$ :

- sela-nó em ciclo invariante: análogo à figura 5.2, segunda linha.

- órbita homoclínica de sela: o ciclo limite torna-se uma órbita homoclínica de um ponto de sela, com período indo a infinito. Após a bifurcação, o ciclo desaparece.

- Andronov-Hopf supercrítica: análoga à figura 5.2, quarta linha.

- sela-nó para ciclos: análoga a uma bifurcação sela-nó de equilíbrios, entretanto deve-se à colisão e subsequente aniquilação de um ciclo sela (instável) com um ciclo atrator.

Assim como para os casos de bifurcações do estado de repouso, cada bifurcação do estado tônico leva a diferentes propriedades dinâmicas - outra informação muito útil na compreensão (geralmente começando por uma simplificação) das propriedades de excitabilidade de um dado sistema.

Formalmente, sendo $\mathbf{x}$ um vetor correspondente às variáveis dinâmicas rápidas, e $\mathbf{u}$ às lentas, obtém-se um sistema

$$
\left\{\begin{array}{l}
\frac{\mathrm{d}}{\mathrm{d} t} \mathbf{x}=\mathbf{f}(\mathbf{x}, \mathbf{u}) \\
\frac{\mathrm{d}}{\mathrm{d} t} \mathbf{u}=\epsilon \mathbf{g}(\mathbf{x}, \mathbf{u})
\end{array}\right.
$$

Fazendo $\epsilon \rightarrow 0$, desacoplam-se as duas dinâmicas, e é possível tratar u como parâmetro no subsistema rápido. Este procedimento é conhecido como "dissecção" da dinâmica de bursts, ou aproximação fast-slow, e está embasado na teoria de perturbações singulares, em especial nos resultados de Fenichel (1979). Procede-se então determinando as bifurcações em uma família de subsistemas rápidos, parametrizada pela variável 
lenta, obtendo em particular as bifurcações correspondentes a transições quiescente $\rightarrow$ tônico e tônico $\rightarrow$ quiescente.

No caso dos neurônios do STG, busca-se um modelo mínimo compatível com a fenomenologia apresentada no capítulo 2. Tenta-se desta maneira propor um sistema com menos variáveis dinâmicas, mas que reproduza - ao menos qualitativamente - as propriedades julgadas fundamentais dos neurônio modelados. Trabalhando em poucas dimensões, é possível explorar argumentos geométricos mais a fundo, dando interpretações diretas para propriedades contraintuitivas apresentadas pelo sistema.

Para a redução do modelo detalhado, há evidências que excluem a priori determinados tipo de dinâmica: o modelo não apresenta oscilações de pequena amplitude em torno do equilíbrio, tampouco gradação na amplitude dos potenciais de ação ao longo de um burst - o que afasta a possibilidade de bifurcações de Hopf tanto do equilíbrio quanto da órbita periódica. $\mathrm{O}$ fato dos ISI irem crescendo ao longo de um burst (fig. 2.3) indica a possibilidade de que o regime ativo desapareça em bifurcações tipo sela-nó em ciclo invariante ou de órbita homoclínica de selas, já que ambas dão origem a ciclos com período indo a infinito no ponto de bifurcação. $\mathrm{O}$ fato de que bursts podem ser truncados durante a fase ativa com perturbações apropriadas, bem como a presença de burstlets (fig. 2.3) são evidências de biestabilidade entre equilíbrio e ciclo limite no subsistema rápido, conforme explorado em detalhes adiante. Desta maneira, há evidências suficientes para adotar um modelo simplificado onde a transição disparos-quiescência se dê via uma bifurcação tipo órbita homoclínica de sela (s-H). Quanto à bifurcação quiescência-disparos, estando excluídos casos envolvendo focos (Hopf), restam apenas bifurcações selanó(sN) e sela-nó em ciclo invariante (SNIC). O segundo caso envolve um decrescimento dos ISI ao longo do início do burst, o que não é observado (figs. 2.3, 2.4). Em suma, o cenário de bifurcações sela-nó/homoclínica (que engloba neurônios classicamente classificados como square bursters) parece ser adequado em primeira aproximação.

\section{Origem de bursts em um modelo reduzido}

O procedimento de dissecção dos bursts discutido anteriormente pode ser aplicado a modelos tipo HH, no caso de dinâmi- 
cas operando em escalas temporais muito distintas (satisfazendo as condições da aproximação fast-slow). Técnicas de continuação numérica permitem então estudar o comportamento do sistema rápido tratando a dinâmica mais lenta como um parâmetro, via análise numérica de bifurcações.

Segue-se a análise de um modelo de condutâncias, semelhante ao conhecido modelo de Morris-Lecar (Morris e Lecar, 1981), com um subsistema rápido bidimensional e uma modulação lenta unidimensional, responsável pelo bursting. Este modelo foi proposto inicialmente por Izhikevich (Izhikevich, 2006) como mínimo para descrever bursters do tipo selanó/homoclínica.

Considera-se uma membrana contendo canais de Sódio persistentes (por não possuírem dinâmica de inativação), bem como canais de Potássio de dois tipos, com dinâmica de ativação rápida(lenta) descrita pela variável dinâmica $\mathrm{m}_{\mathrm{K}}\left(\mathrm{m}_{\mathrm{K}_{\mathrm{M}}}\right)$; bem como uma corrente passiva de leakage. Adicionalmente, a dinâmica de ativação dos canais de Sódio é tratada como instantânea - sendo esta muito mais rápida que as outras dinâmicas envolvidas - de modo que a variável de ativação $m_{\mathrm{Na}}$ assume $\mathrm{o}$ valor $m_{\mathrm{Na}}^{\infty}(V)$. Os valores para os parâmetros relevantes estão descritos na tabela 5.1. Este modelo é denominado $\mathrm{Na}_{\mathrm{p}} \mathrm{KK}_{\mathrm{M}}$.

$$
\begin{aligned}
& \left\{\begin{aligned}
C \frac{\mathrm{d}}{\mathrm{d} t} V= & I_{\text {ext }}-g_{\text {leak }}\left(V-E_{\text {leak }}\right)-\overline{g_{\mathrm{Na}}} m_{\mathrm{Na}}^{\infty}\left(V-E_{\mathrm{Na}}\right)+ \\
& -\overline{g_{\mathrm{K}}} m_{\mathrm{K}}\left(V-E_{\mathrm{K}}\right)-\overline{g_{\mathrm{K}}} m_{\mathrm{K}_{\mathrm{M}}}\left(V-E_{\mathrm{K}}\right) \\
\tau_{i} \frac{\mathrm{d}}{\mathrm{d} t} m_{i}= & m_{i}^{\infty}(V)-m_{i} \quad i=\mathrm{K}, \mathrm{K}_{\mathrm{M}}
\end{aligned}\right. \\
& \text { sendo } m_{i}^{\infty}(V)=\frac{1}{1+\exp \left(\left(V_{i}^{1 / 2}-V\right) / k_{i}\right)} \quad i=\mathrm{Na}_{\mathrm{p}}, \mathrm{K}, \mathrm{K} \mathrm{M}
\end{aligned}
$$

\begin{tabular}{cccccc} 
condutância & $V^{1 / 2}$ & $k$ & $\tau$ & $\bar{g}$ & $E^{\mathrm{rev}}$ \\
\hline $\mathrm{Na}_{\mathrm{p}}$ & -20 & 15 & - & 20 & 60 \\
$\mathrm{~K}$ & -25 & 5 & 0.152 & 9 & -90 \\
$\mathrm{~K}_{\mathrm{M}}$ & -20 & 5 & 20 & 5 & -90 \\
leak & - & - & - & 8 & -80
\end{tabular}

Tabela 5.1: Modelo $\mathrm{Na}_{\mathrm{p}} \mathrm{KK}_{\mathrm{M}}$ 
Figura 5.3: Retrato de fase para o modelo $\mathrm{Na}_{\mathrm{p}} \mathrm{KK}_{\mathrm{M}}$ (equação 5.3 e tabela 5.1), exibindo disparo de bursts periódicos. Este regime consiste em uma trecho quiescente, que é injetado na helicoide correspondente ao disparo de potenciais de ação.

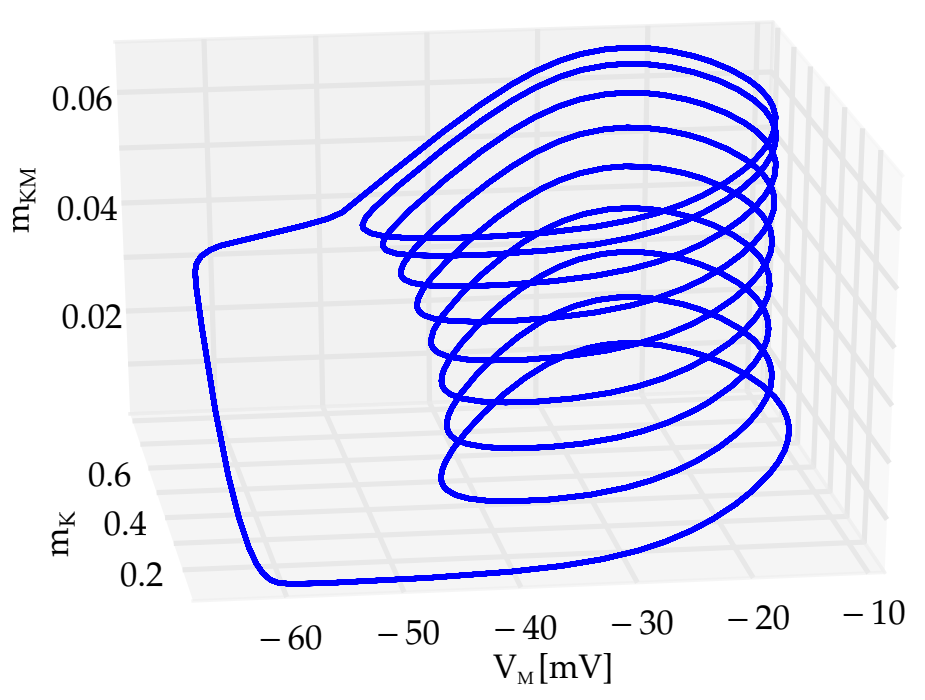

Não é difícil, intuitivamente, perceber que este modelo possui comportamento de disparo em bursts - as correntes rápidas $\mathrm{Na}_{\mathrm{p}}-\mathrm{K}$ são similares às clássicas geradoras de potenciais de ação no axônio gigante de HH (sem a dinâmica de inativação dos canais Sódio, contudo). A corrente de Potássio lenta não está ativa com a célula em repouso (note que o valor de $V_{\mathrm{K}_{\mathrm{M}}}^{1 / 2}=-20 \mathrm{mV}$, associado ao potencial de membrana para a meia-ativação da condutância, está bem acima do potencial de repouso $V_{\text {rep }} \approx-60 \mathrm{mV}$ ). Esta ativação vai aumentando gradativamente devido aos potenciais de ação: a dinâmica de $\mathrm{m}_{\mathrm{K}_{\mathrm{M}}}$ por evoluir numa escala temporal mais de uma ordem de grandeza menor do que a do subsistema spiking, é suscetível ao valor médio $\langle V\rangle$, que cresce conforme se dão disparos. Para um valor suficientemente grande de corrente de Potássio lenta o trem de spikes é interrompido, e as trajetórias tendem ao potencial de repouso. Contudo, com a subsequente queda de $\langle V\rangle, \mathrm{m}_{\mathrm{K}_{\mathrm{M}}}$ volta a decrescer, até que não haja mais corrente hiperpolarizante suficiente para manter a quiescência, e o ciclo se fecha. $\mathrm{O}$ retrato de fase correspondente é visto na figura 5.3.

Na figura 5.4, é apresentado o diagrama de bifurcações do subsistema rápido $\mathrm{Na}_{\mathrm{p}}-\mathrm{K}$, em função de $\mathrm{m}_{\mathrm{K}_{\mathrm{M}}}$ como um parâmetro. Esta construção, essencialmente devida à aproximação fast-slow (desacoplando as dinâmicas lenta e rápidas), põe em evidência a estrutura geométrica do modelo completo (figura 5.3), permitindo analisar em profundidade seu comportamento intrínseco, bem como determinar a resposta a perturbações. 


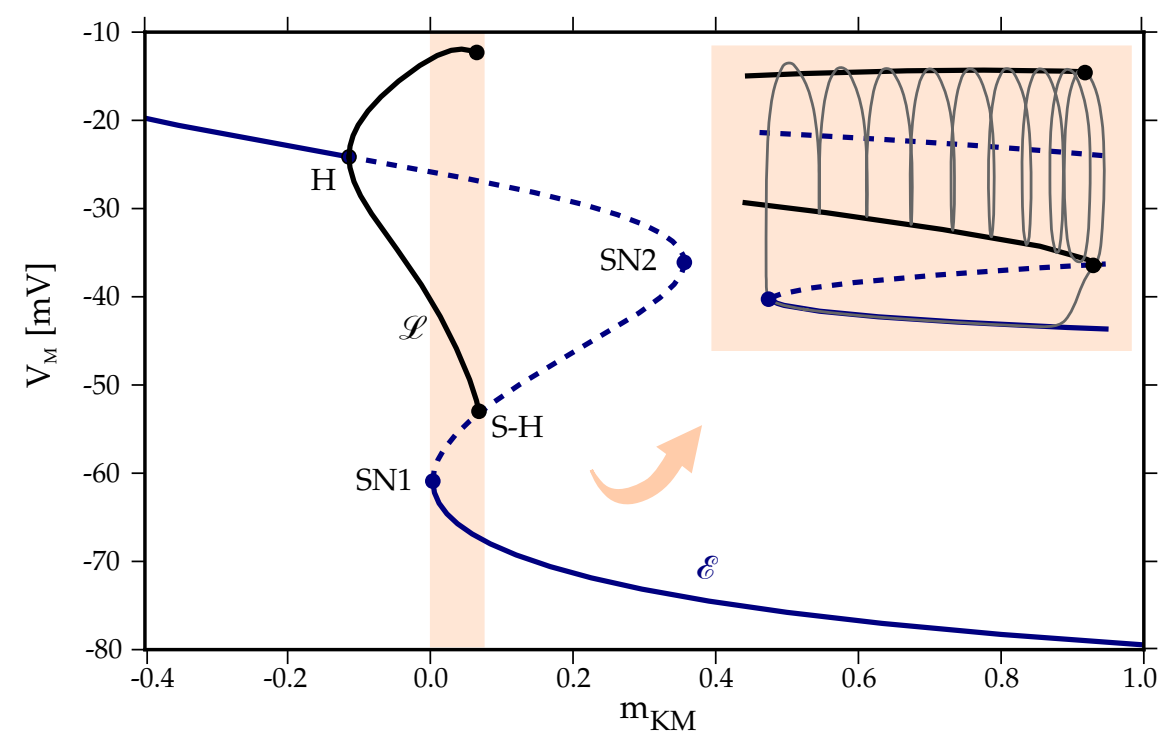

No diagrama 5.4, há um equilíbrio estável para $\mathrm{m}_{\mathrm{K}_{\mathrm{M}}}<$ -0.1139 . Em $\mathrm{m}_{\mathrm{K}_{\mathrm{M}}} \approx-0.1139$ (ponto marcado como $\mathrm{H}$ na figura 5.4) o equilíbrio sofre uma bifurcação de Hopf supercrítica, perdendo estabilidade e dando origem um ciclo limite estável. Em $\mathrm{m}_{\mathrm{K}_{\mathrm{M}}} \approx 0.003501$ (ponto $\mathrm{SN1}$ ) ocorre uma bifurcação selanó, com o aparecimento de um novo equilíbrio e uma sela, cuja variedade estável serve como separatriz entre a bacia de atração do ciclo limite e do equilíbrio estável. $\mathrm{O}$ ciclo vai aumentando de amplitude conforme varia o parâmetro e, com $\mathrm{m}_{\mathrm{K}_{\mathrm{M}}} \approx 0.06748$ (encontro do ciclo limite com as variedades da sela) ocorre a bifurcação tipo órbita homoclínica de sela (s-H) com seu subsequente desaparecimento.

Em síntese, a dinâmica lenta de $\mathrm{m}_{\mathrm{K}_{\mathrm{M}}}$ conduz o subsistema rápido de uma região do espaço de parâmetros onde há equilíbrio a outra onde há ciclos-limite, em um loop de histerese, de maneira oscilatória. É importante destacar que, na faixa de transição entre comportamento de disparos e quiescente (próximo ao ponto $\mathrm{S}-\mathrm{H}$ ), coexistem ambos equilíbrio e ciclo limite. Situações de multiestabilidade como esta desempenham um papel fundamental na origem de comportamento complexo nesta classe de sistemas, um ponto a ser explorado nos capítulos subsequentes.
Figura 5.4: Continuação numérica dos equilíbrios e ciclos-limite do subsistema rápido do modelo $\mathrm{Na}_{\mathrm{p}} \mathrm{KK}_{\mathrm{M}}$. A ativação da corrente de Potássio lenta $\mathrm{m}_{\mathrm{K}_{\mathrm{M}}}$ é tratada como um parâmetro. A curva azul $\mathcal{E}$ representa o ramo equilíbrios estáveis/instáveis, e os pontos SN bifurcações sela-nó. As curvas em preto correspondem aos máximos/mínimos de uma variedade "tubular" $\mathcal{L}$ folheada por ciclos limite que surgem com a bifurcação de Hopf no ponto $\mathrm{H}$, terminando em uma bifurcação homoclínica em s-H.

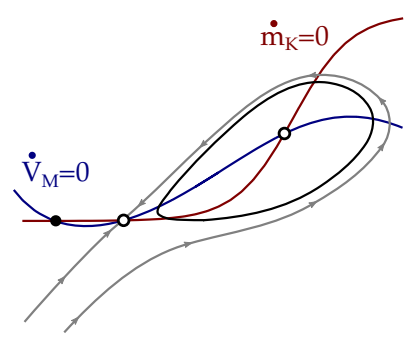

Figura 5.5: Retrato de fase para um valor de $m_{K_{M}}$ que comporta biestabilidade no subsistema rápido. As separatrizes estáveis são indicadas em cinza, e as isóclinas nulas das variáveis rápidas $V$ e $\mathrm{m}_{\mathrm{K}}$ em azul e vermelho. $\mathrm{O}$ ciclo limite em preto é uma secção da variedade de disparos $\mathcal{L}$. 
Figura 5.6: Retratos de fase para valores decrescentes de $\mathrm{m}_{\mathrm{K}_{\mathrm{M}}}$. A curva azul(vermelha) é a isóclina nula para $V\left(\mathrm{~m}_{\mathrm{K}}\right)$. Os pontos marcados com $\times$ são condições iniciais. Inicialmente

(1), há um equilíbrio estável.

Ocorre então a bifurcação homoclínica, dando origem a um ciclo limite estável coexistente com o equilíbrio (2).

Após uma bifurcação sela nó, os equilíbrios estável / instável mais à esquerda se aniquilam (3). Finalmente, o ciclo limite perde estabilidade em uma bifurcação de Hopf (4).

Bursting ocorre quando o subsistema rápido é conduzido ciclicamente entre 1-2-3.
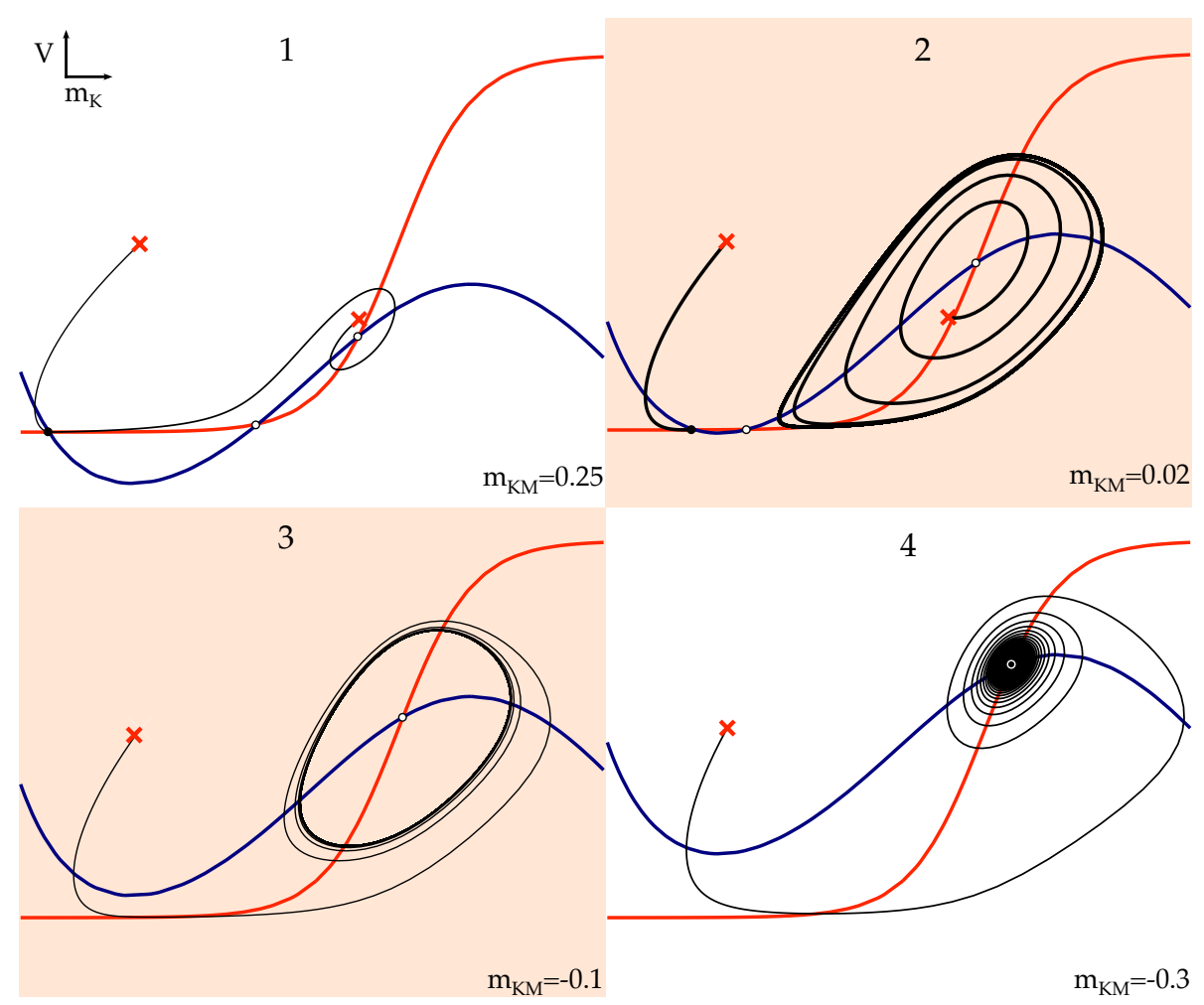

\section{A escolha de um modelo reduzido}

Em neurônios do STG, a dinâmica rápida (associada aos potenciais de ação) é essencialmente devida aos canais de Sódio e Potássio, como no modelo de HH. A grosso modo, a modulação lenta responsável por gerar os bursts advém do subsistema de correntes e remoção de Cálcio, bem como a corrente de Potássio dependente de Cálcio. Desta forma, a fase ativa de um burst promove o acúmulo gradativo de $\mathrm{Ca}^{++}$intracelular, que acaba por ativar a corrente $\mathrm{I}_{\mathrm{KCa}}$, hiperpolarizando a membrana e interrompendo o burst. $\mathrm{Na}$ fase quiescente não há influxo de Cálcio ( $\mathrm{I}_{\mathrm{Ca}}$ inativa) e, desta maneira, a dinâmica lenta de remoção destes íons traz a $\left[\mathrm{Ca}^{++}\right]$novamente a valores para os quais $\mathrm{I}_{\mathrm{KCa}}$ é inativa. Sem o efluxo de Potássio, a membrana volta a depolarizar, até serem ativados os canais de Sódio: está completo um ciclo, perfazendo um burst.

É natural então, de um ponto de vista eletrofisiológico, buscar um modelo mínimo que leve em conta ao menos as correntes $\mathrm{I}_{\mathrm{Na}}, \mathrm{I}_{\mathrm{K}}, \mathrm{I}_{\mathrm{Ca}}, \mathrm{I}_{\mathrm{KCa}}$ e algum mecanismo de decaimento na concentração intracelular de Cálcio $\left[\mathrm{Ca}^{++}\right]$. Um modelo 
plausível, denominado $\mathrm{Na}_{\mathrm{p}} \mathrm{KK}_{[\mathrm{Ca}]} \mathrm{Ca}$, implementa esses ingredientes da seguinte maneira: o mesmo subsistema rápido do modelo $\mathrm{Na}_{\mathrm{p}} \mathrm{KK}_{\mathrm{M}}$ discutido anteriormente, com as correntes de Sódio persistente $\mathrm{I}_{\mathrm{Nap}}$ e Potássio $\mathrm{I}_{\mathrm{K}}$; um subsistema lento composto por uma corrente instantânea de Cálcio $\mathrm{I}_{\mathrm{Ca}}$; uma corrente instantânea de Potássio dependente de Cálcio $\mathrm{I}_{\mathrm{KCa}}$, conforme uma função de Hill (Johnston e Wu, 1995)

$$
g_{\mathrm{K}[\mathrm{Ca}]}=\frac{\left[\mathrm{Ca}^{++}\right]}{\left[\mathrm{Ca}^{++}\right]+3} ;
$$

e um mecanismo de remoção de íons de Cálcio segundo um decaimento simples. Deste modo, a dinâmica da $\left[\mathrm{Ca}^{++}\right]$é dada por

$$
\tau_{\mathrm{Ca}} \frac{\mathrm{d}}{\mathrm{d} t}\left[\mathrm{Ca}^{++}\right]=\left(-0.9 \mathrm{I}_{\mathrm{Ca}}-\left[\mathrm{Ca}^{++}\right]\right)
$$

onde o prefator que multiplica $\mathrm{I}_{\mathrm{Ca}}$ é dado pela razão entre a área da célula e o volume aonde $\left[\mathrm{Ca}^{++}\right]$é medida. Como $\left[\mathrm{Ca}^{++}\right]$é variável dinâmica, o potencial de Nernst para estes íons deve ser calculado a cada instante, segundo (ver o apêndice A.2)

$$
V_{\mathrm{Ca}}=\frac{R T}{2 F} \log \frac{\left[\mathrm{Ca}^{++}\right]_{\text {ext }}}{\left[\mathrm{Ca}^{++}\right]}
$$

Os parâmetros relevantes encontram-se na tabela 5.2.

\begin{tabular}{cccccc} 
condutância & $V^{1 / 2}$ & $k$ & $\tau(V)$ & $\bar{g}$ & $E_{\text {rev }}$ \\
\hline $\mathrm{Na}_{\mathrm{p}}$ & -20 & 15 & - & 20 & 60 \\
$\mathrm{~K}$ & -25 & 5 & 0.152 & 9 & -90 \\
leak & - & - & - & 8 & -80 \\
$\mathrm{Ca}$ & -20 & 5 & - & 0.25 & [eq. 5.6] \\
$\mathrm{K}_{[\mathrm{Ca}]}$ & \multicolumn{2}{c}{ [eq. 5.4] } & 1. & -90
\end{tabular}

Tabela 5.2: Modelo $\mathrm{Na}_{\mathrm{p}} \mathrm{KK}_{[\mathrm{Ca}]} \mathrm{Ca}$. Parâmetros adicionais: $\mathrm{I}_{\mathrm{ext}}=7 \mathrm{nA} \mathrm{cm}{ }^{-2}$, $C=1 \mu \mathrm{F} \mathrm{cm}^{-2}, T=300 \mathrm{~K},\left[\mathrm{Ca}^{++}\right]_{\mathrm{ext}}=3000 \mathrm{~nm}$.

$\mathrm{O}$ diagrama de bifurcações para o modelo $\mathrm{Na}_{\mathrm{p}} \mathrm{KK}_{[\mathrm{Ca}]} \mathrm{Ca}$ pode ser visto na figura $5 \cdot 7$, com a projeção de uma trajetória superposta em cinza. Nota-se que a dinâmica é análoga à do modelo $\mathrm{Na}_{\mathrm{p}} \mathrm{KK}_{\mathrm{M}}$, com uma acumulação de spikes ao final do "tubo" (superfície folheada pelos ciclos-limite do subsistema rápido) devido à bifurcação homoclínica. 
Figura 5.7: Cenário sela-nó/homoclinica de geração de bursts em um modelo com um subsistema rápido constituído pelas corrente de Sódio persistente $\mathrm{I}_{\text {Nap }}$ e Potássio $\mathrm{I}_{\mathrm{K}}$, e um subsistema lento bidimensional composto por uma corrente de

Cálcio $\mathrm{I}_{\mathrm{Ca}}$, uma de Potássio dependente de Cálcio $\mathrm{I}_{\mathrm{KCa}} \mathrm{e}$ um mecanismo de remoção de $\left[\mathrm{Ca}^{++}\right]$intracelular.

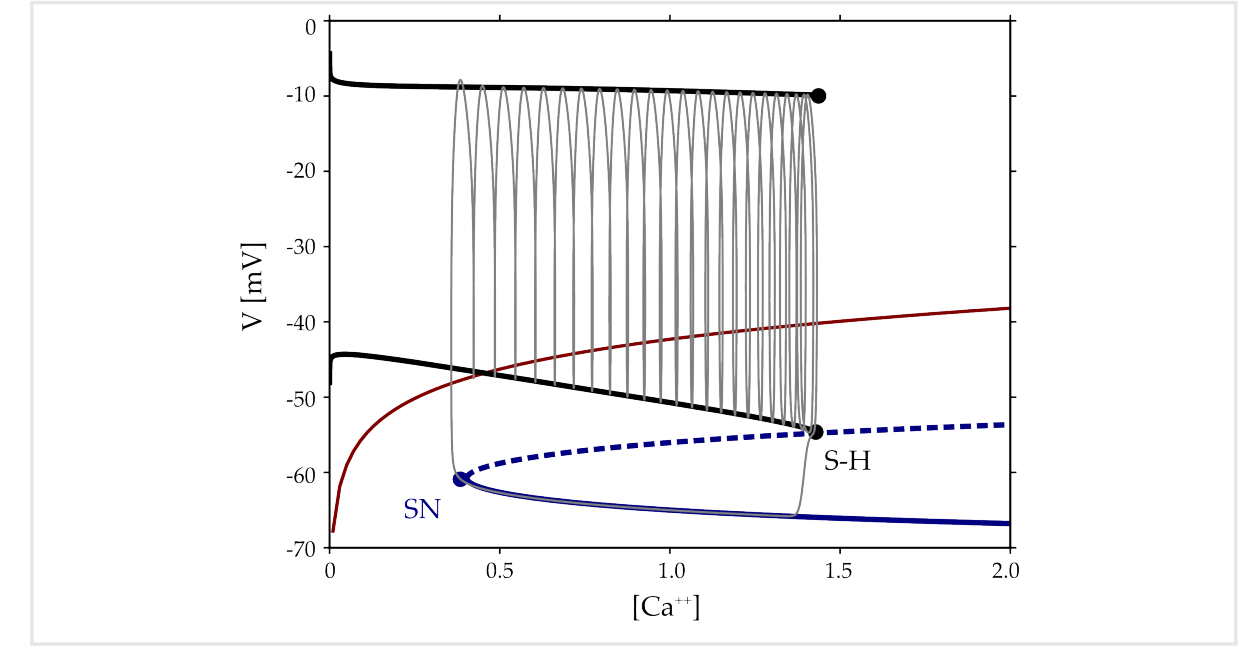

Desta maneira, tem-se que é possível obter a mesma classe de dinâmica apresentada pelo modelo eletrofisiologicamente distinto $\mathrm{Na}_{\mathrm{p}} \mathrm{KK}_{\mathrm{M}}$, porém utilizando condutâncias e mecanismos biofísicos mais condizentes com os dos neurônios do STG. Como os resultados a serem derivados posteriormente fazem jus a estas propriedades dinâmicas, será utilizado o modelo $\mathrm{Na}_{\mathrm{p}} \mathrm{KK}_{\mathrm{M}}$ como representante da classe dos square bursters, subentendendo que este comportamento também é subjacente a modelos eletrofisiologicamente mais fiéis às células do STG.

\section{Além da codimensão um}

Através de continuação numérica, é possível ir ainda além da dissecção da dinâmica de bursts, obtendo informação adicional acerca dos efeitos de variações de outros parâmetros no sistema. Como exemplo de aplicação destas técnicas, determina-se a robustez do cenário sela-nó/homoclínica, mediante variações na corrente externa $\mathrm{I}_{\text {ext }}$. Na figura 5.8, mostra-se que este cenário é observável para intervalos extensos de corrente, sendo determinado pela persistência do "canal" entre as curvas de bifurcação homoclínica (verde) e sela-nó (azul). Casos do modelo com corrente alta, como o apresentado no painel da direita, apresentam comportamento caótico robusto, fato a ser explorado em capítulos subsequentes. Bifurcações de codimensão dois - como a de Bogdanov-Takens neste exemplo desempenham desta forma papéis importantes na estruturação 

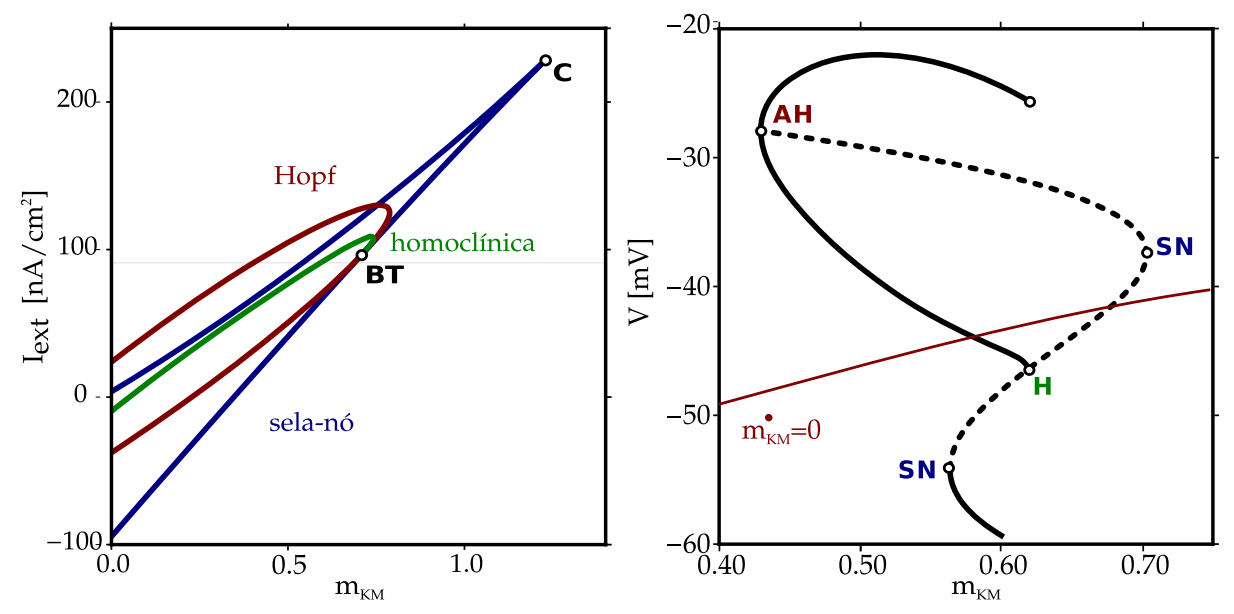

de espaços de parâmetros de modelos neuronais.

\subsection{Redução a mapas}

Em modelos descritos por equações do tipo da 5.3, onde há dinâmicas operando em escalas temporais muito distintas, derivadas altas para estados fora das variedades lentas (atratores do subsistema rápido) fazem que descrições em termos de mapas unidimensionais sejam surpreendentemente precisas. A maneira usual de reduzir um fluxo a um mapa se dá através de seções de Poincaré, com a escolha de uma (hiper)superfície apropriada. No caso de modelos neuronais, é natural considerar alguma superfície associada à dinâmica de spikes, costumeiramente adotando-se o mapa de retorno dos máximos do potencial de membrana (superfície definida por $\dot{V}=0$ ), conforme a figura 5.9.

Há entretanto dificuldades na construção de mapas de Poincaré via integração direta, já que para situações envolvendo órbitas periódicas, após transientes são obtidas apenas intersecções destas com $\Sigma$. Para revelar a dinâmica transiente, é necessário então adicionar ruído ao sistema, integrando por intervalos suficientemente longos. Existem também abordagens alternativas que não envolvem integração estocástica, muito convenientes no caso particular de sistemas bursting. Uma delas consiste em se fazer valer da decomposição fast-slow, adotando
Figura 5.8: ESQ: Diagrama de bifurcações em dois parâmetros para o modelo $\mathrm{Na}_{\mathrm{p}} \mathrm{KK}_{\mathrm{M}}$. As curvas coloridas indicam conjuntos de ocorrência de bifurcações (verde: homoclínica, azul: sela-nó, vermelho: Andronov-Hopf). Os pontos indicados com letras, bifurcações de codimensão dois (вт: Bogdanov-Takens; C: cúspide). DIR: Diagrama de bifurcação em $\mathrm{m}_{\mathrm{K}_{\mathrm{M}}}$ para $\mathrm{o}$ modelo $\mathrm{Na}_{\mathrm{p}} \mathrm{KK}_{\mathrm{M}}$, com $\mathrm{I}_{\text {ext }}=95 \mathrm{nA} \mathrm{cm}^{-2}$ (linha cinza no diagrama da direita) 
Figura 5.9: Seção de Poincaré. A superfície $\Sigma$ é folheada pelas isóclinas nulas $\dot{V}=0$ do subsistema rápido, conforme a variável lenta é varrida como parâmetro na aproximação fast-slow. Somente cortes em uma direção definida são anotados (no caso, os máximos). A curva azul representa o ramo de equilíbrios do subsitema rápido, enquanto a preta uma trajetória com condições iniciais sobre a variedade instável de uma sela neste ramo.

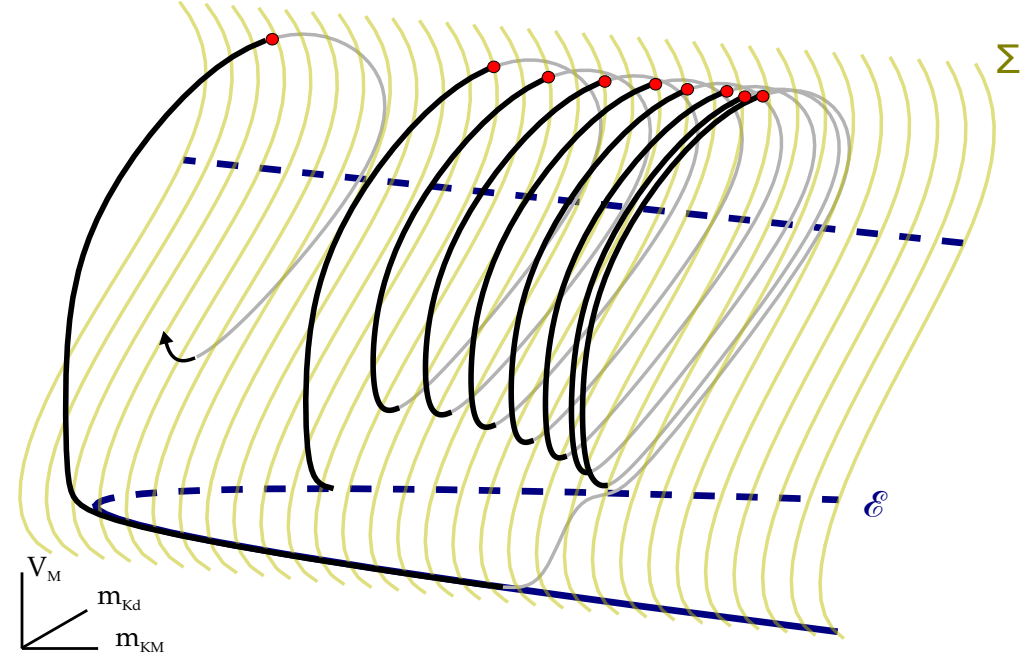

a dinâmica discreta da variável lenta como descrição unidimensional da dinâmica do modelo completo. Iniciando com um valor fixo da variável lenta, integra-se o subsistema rápido (no plano) até que seja atingido um dos ciclos-limite que compõem o "tubo". Tomam-se então as coordenadas correspondentes ao máximo de $V_{\mathrm{M}}$ neste ciclo, acrescidas do valor atual da variável lenta, como condição inicial para integração do sistema completo, até novo corte em $\Sigma$. Fazendo uma varredura para vários valores da variável lenta $(z)$, é possível então determinar pares $(z, \mathbf{f}(z))$ que compõem a dinâmica discreta buscada. 


\section{Capítulo 6}

\section{Ruído em modelos simplificados}

Utilizou-se o modelo mínimo para o cenário de bursting selanó / homoclínica descrito anteriormente (modelo $\mathrm{Na}_{\mathrm{p}} \mathrm{KK}_{\mathrm{M}}$ ), acrescido de ruído de chaveamento dos canais iônicos, para reproduzir propriedades tanto do modelo detalhado (seção 2.2), quanto de experimentos com neurônios do sTG. O emprego de um modelo mínimo tridimensional permite analisar a dinâmica geometricamente, facilitando a elaboração de mecanismos para a gênese atividade bursting complexa. Surpreendentemente, além de resultados qualitativamente similares aos observados in vivo - sem utilizar procedimentos de ajuste fino de parâmetros foram também obtidas correspondências na estrutura detalhada dos ISI em cada burst, evidenciadas através da construção das assinaturas neuronais.

A partir de considerações geométricas, argumenta-se que o mecanismo de geração de assinaturas complexas se deve à riqueza da dinâmica transiente de modelos tipo square burster. A adição de ruído faz com que a dinâmica popule este arcabouço determinístico complexo - denominado esqueleto - mesmo para modelos que exibem apenas atividade estacionária periódica no limite de ruído nulo, seja ela bursting ou tônica.

\subsection{Assinaturas neuronais}

Assinaturas neuronais são estruturas estereotipadas observadas em mapas de primeiro retorno para intervalos interspike. 
Figura 6.1: Mapas de primeiro retorno para ISIS de um neurônio LP do STG. As estruturas observadas neste tipo de diagrama são muito similares em neurônios de uma mesma classe, o que motivou chamá-las de "assinaturas". As cores correspondem à ordem do ISI ao longo burst. O gráfico à direita é uma ampliação do da esquerda, enfatizando a estrutura fina ao longo da diagonal, para os ISI iniciais.
Observou-se (Szücs et al., 2003; Tristan et al., 2004; Garcia et al., 2005; Zeck e Masland, 2007) - em particular nas células do gânglio estomatogástrico de crustáceos - que as séries temporais aparentemente irregulares de $V_{M}$ apresentavam uma estrutura subjacente, conforme visto na figura 6.1. A reprodutibilidade

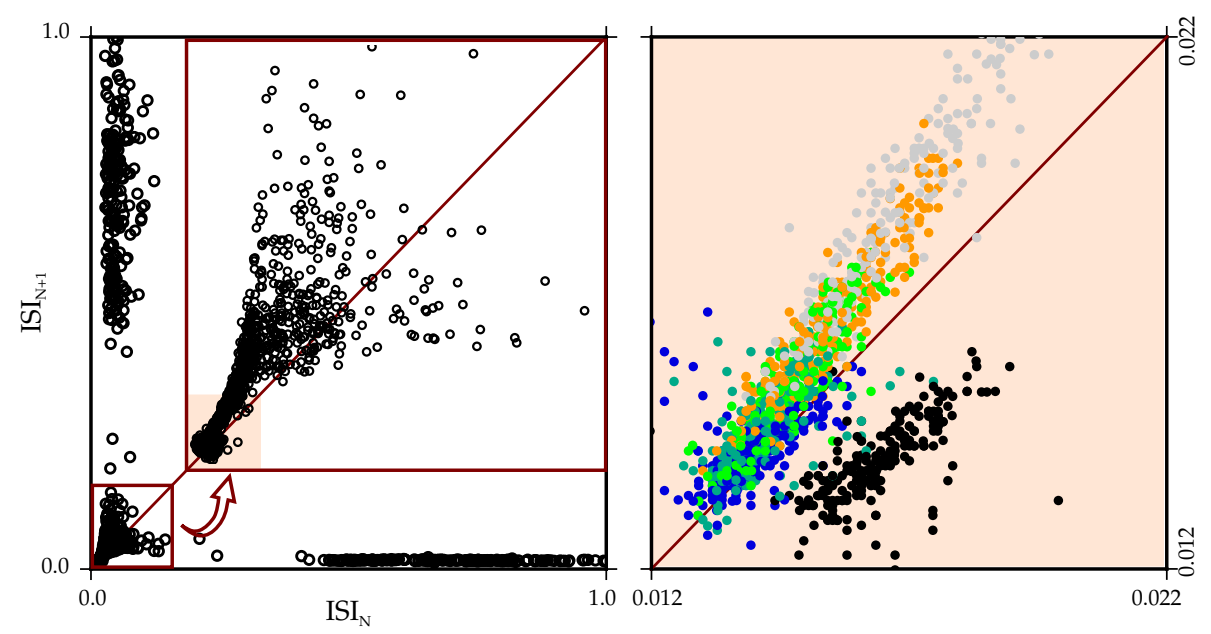

destas estruturas permite identificar tipos neuronais mesmo em circuitos apresentando distintas frequências, duty-cycles, número de spikes por burst e até mesmo entre espécies animais distintas (Brochini et al., 2011). Além disso, há evidências de que as assinaturas reflitam a conectividade do circuito (Szücs et al., 2003, 2005), expressem informação recebida de neurônios présinápticos (Brochini et al., 2011), e sejam responsáveis por modular funções motoras (Zhurov e Brezina, 2006). Em de Borja Rodríguez et al. (2002); Latorre et al. (2006); Tristan et al. (2004), foram exploradas propriedades de processamento informacional de CPG, utilizando modelos e simulação numérica. Os autores propuseram uma rede que, além de produzir um padrão rítmico trifásico (associado ao comando motor), era capaz de reconhecer e responder a assinaturas geradas por neurônios de uma subrede distinta.

Desta forma, foi dada muita atenção a aspectos fenomenológicos e funcionais das assinaturas em redes pequenas. Entretanto, nunca foram divulgadas análises sistemáticas dos mecanismos através dos quais padrões de ISI tão ricos podem ser produzidos. Células do STG apresentam tais assinaturas, apesar dos padrões de disparo mudarem significativmente para neurônios isolados do circuito (fig. 6.1). As células isoladas 
foram caracterizadas como caóticas (Selverston et al., 2000), possuindo assinaturas estereotipadas que refletem regularidades nos primeiros ISI, perdendo entretanto precisão temporal ao longo da evolução de cada burst (conforme figuras 2.2, 2.1). Apesar disso, modelos de condutância detalhados para estes neurônios - analisados em detalhe via a construção de um banco de dados, conforme o capítulo 4 e Prinz et al. (2003b) - geram comportamento periódico para janelas grandes de parâmetros biologicamente plausíveis, com assinaturas incompatíveis com as observadas em experimentos. Em Carelli et al. (2005), é apresentada uma transcrição do modelo detalhado para estocástico, aparentemente recuperando o comportamento irregular nas assinaturas. Pretende-se, complementando o modelo mínimo para square bursting com um componente simplificado de ruído, obter e determinar os mecanismos geradores de assinaturas complexas.

\subsection{Modelo estocástico}

O modelo de ruído utilizado é baseado numa aproximação de um esquema microscópico de transições para os canais iônicos. A dinâmica de abertura de canais individuais pode ser descrita através de uma equação mestra (Johnston e $\mathrm{Wu}$, 1995), que por sua vez pode ser aproximada por uma equação de Langevin (Fox, 1997), conforme a discussão apresentada no apêndice A.4. Esta equação pode ser resolvida mediante a utilização de um método de integração estocástico (Kloeden e Platen, 1992), vide apêndice B.I; no caso, foi utilizado o método de EulerMaruyama:

$$
\begin{aligned}
x_{n+1} & =f\left(x_{n}\right) \Delta t+g\left(x_{n}\right) W_{n} \\
W_{n} & \approx \sqrt{\Delta t} \mathcal{N}(0,1)
\end{aligned}
$$

onde os $W_{n}$ constituem um processo de Wiener, realizado sorteando números de uma distribuição normal $\mathcal{N}(0,1)$ de média nula e variância unitária.

A parte determinística do modelo está descrita no capítulo anterior. O disparo de bursts se dá através de um loop de histerese da variável lenta $\mathrm{m}_{\mathrm{K}_{\mathrm{M}}}$, que leva a dinâmica de um ramo de equilíbrios $\mathcal{E}$ (hiperpolarização intra-burst) a uma 
variedade de ciclos limite $\mathcal{L}$ (spikes no burst) do subsistema rápido, conforme o diagrama de bifurcações na figura 6.2. Em relação ao modelo discutido no capítulo anterior, foi feito um ajuste (via observação do comportamento qualitativo, não sistemático) de parâmetros, a fim de obter bursts com maior número de spikes e duty cycle qualitativamente mais próximos aos dos neurônios isolados do sTG. Estes ajustes refletem-se principalmente na posição da isóclina nula de $m_{K_{M}}$ em relação ao ramo de equilíbrios $\mathcal{E}$ (fig. 6.2). Os valores distintos utilizados foram: $V_{\mathrm{Na}_{\mathrm{p}}}^{1 / 2}=-19.9 \mathrm{mV}, V_{\mathrm{K}_{\mathrm{M}}}^{1 / 2}=21.2 \mathrm{mV}$.

Figura 6.2: Retrato de fase do modelo. A curva cinza representa uma trajetória do sistema sem ruído. As curvas azuis representam o ramo de equilíbrios do subsistema rápido $\mathcal{E}$; trechos contínuos/tracejados denotam estados estáveis/instáveis. $\mathrm{O}$ "tubo" preto corresponde aos máximos e mínimos dos ciclos-limite que folheam a variedade spiking $\mathcal{L}$. Em vermelho, a isóclina nula da variável lenta $\mathrm{m}_{\mathrm{K}_{\mathrm{M}}}$.

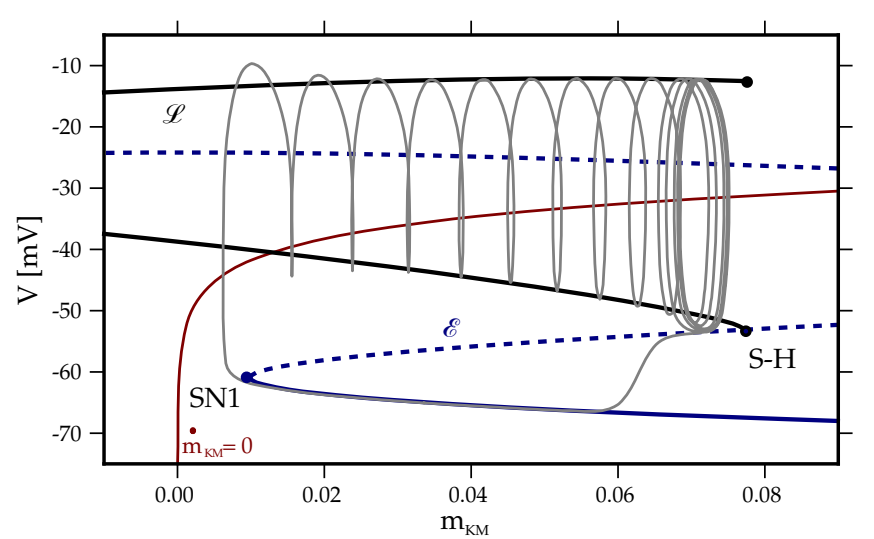

\subsection{Dissecção da dinâmica}

A integração do modelo definido pela equação 6.1 dá origem a séries temporais irregulares, similares às observadas experimentelmente em neurônios isolados do STG- reproduzindo inclusive detalhes finos da assinatura (compare as figuras 6.1 e 6.3). A fim de separar os efeitos do ruído da parte determínstica da dinâmica, procedeu-se buscando definir um "esqueleto" determinista, que seria populado pelo ruido dando origem às irregularidades.

Inicialmente, trabalhou-se com uma redução do modelo sem ruído a uma dinâmica na reta, através de uma seção de Poincaré (fig. 5.9) segundo a prescrição descrita no capítulo anterior. Foi obtida a dinâmica $\mathbf{f}\left(\mathrm{m}_{\mathrm{K}_{\mathrm{M}}}\right)$ representada na figura 6.4(ESQ). A este mapa se associa um observável $\mathcal{T}\left\{\mathrm{m}_{\mathrm{K}_{\mathrm{M}}}\right\}$ 


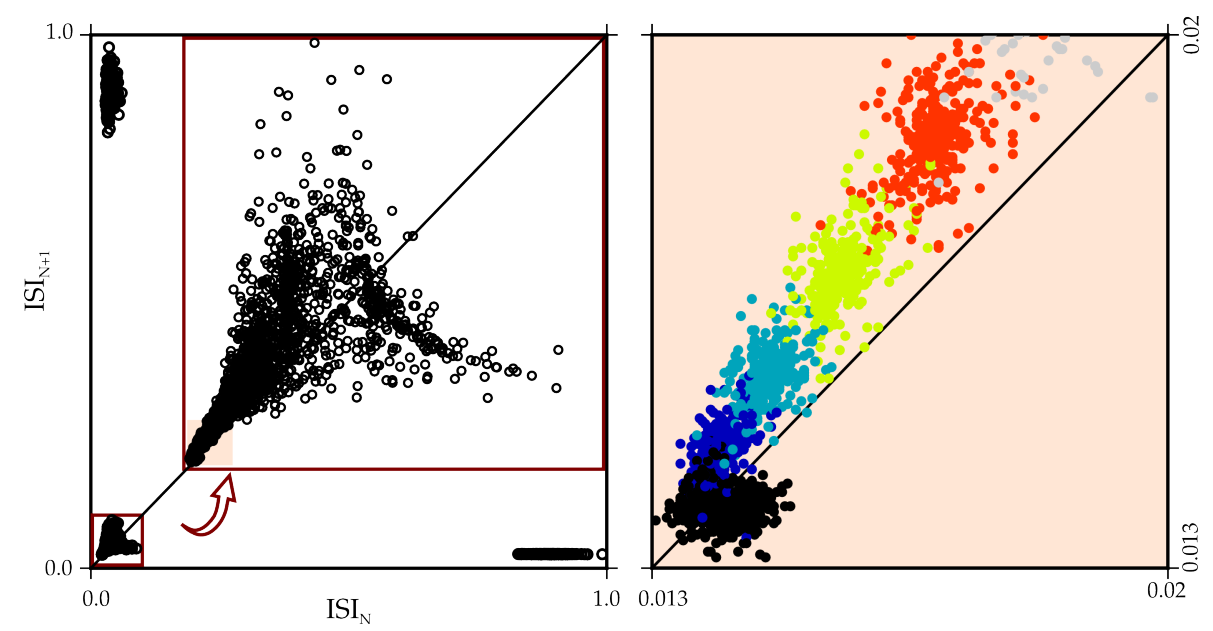

(fig. 6.4(centro)), correspondendo ao tempo dispendido até o próximo cruzamento de $\Sigma$. As assinaturas podem então ser descritas como os pares $\left(\mathcal{T}\left\{\mathrm{m}_{\mathrm{K}_{\mathrm{M}}}\right\}, \mathcal{T}\left\{\mathbf{f}\left(\mathrm{m}_{\mathrm{K}_{\mathrm{M}}}\right)\right\}\right)$, conforme a figura 6.4(DIR).
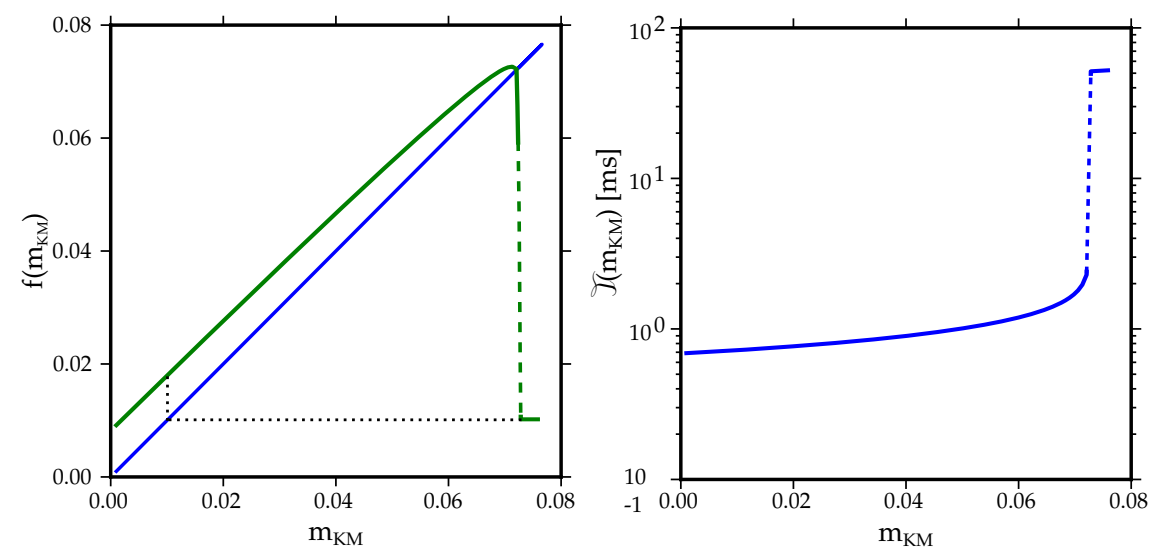

Esta redução unidimensional não é exata, já que as variedades lentas $(\mathcal{E}, \mathcal{L})$ existem apenas no limite singular (dinâmicas rápida e lenta desacopladas). Desta forma, para determinar detalhes finos convém analisar a dinâmica sobre a seção, considerando o tempo de mapeamento $\mathcal{T}$ como uma função de $\Sigma$ sobre os reais.

A figura 6.5 representa a dinâmica numa projeção do plano de seção sobre o plano $V_{\mathrm{M}} \mathrm{m}_{\mathrm{K}_{\mathrm{M}}}$, acrescido das isócronas para mapeamento. Pode-se determinar a origem de "bicos" para ISI pequenos nas assinaturas (figuras 6.1 e 6.3), observando que o
Figura 6.3: Assinatura gerada pelo modelo 6.1, com ruído multiplicativo sobre as variáveis de ativação das condutâncias de Potássio $m_{K}$ e $\mathrm{m}_{\mathrm{K}_{\mathrm{M}}}$. Note a semelhança com a figura 6.1, apesar de não ter sido feito nenhum ajuste fino de parâmetros utilizando dados experimentais

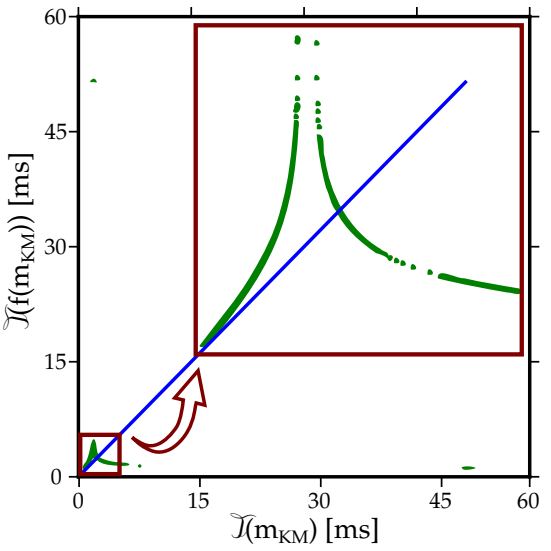

Figura 6.4: Redução unidimensional do modelo $\mathrm{Na}_{\mathrm{p}} \mathrm{KK}_{\mathrm{M}}$. (ESQ): dinâmica da variável lenta $\mathbf{f}\left(\mathrm{m}_{K_{\mathrm{M}}}\right)$. A região de derivada alta (pontilhado) é fundamental para os mecanismos de disparo complexo; (CENTRO): observável $\mathcal{T}\left\{\mathrm{m}_{\mathrm{K}_{\mathrm{M}}}\right\}$ correspondendo ao tempo para o próximo corte na seção; (DIR): Assinatura neuronal, definida em termos do mapa $\mathcal{T}\left\{\mathrm{m}_{\mathrm{K}_{\mathrm{M}}}\right\}, \mathcal{T}\left\{\mathbf{f}\left(\mathrm{m}_{\mathrm{K}_{\mathrm{M}}}\right)\right\}$ 
Figura 6.5: Isócronas de retorno à seção. Tempos longos foram descartados (regiões brancas) para facilitar a visualização. A curva preta indica a variedade de ciclos-limite $\mathcal{L}$. Pontos vermelhos correspondem aos cortes em $\Sigma$ de uma trajetória ruidosa. $\mathrm{O}$ ruído tende a espalhar as entradas verticalmente, fazendo com que spikes de ordens diferentes gerem IsI semelhantes, originando "bicos" na assinatura. ruído dispersa os cortes em $\Sigma$ associados aos primeiros spikes em um burst, de modo que cortes correspondentes a spikes distintos podem estar sobre a mesma isócrona, constituindo uma "dobra" na assinatura.

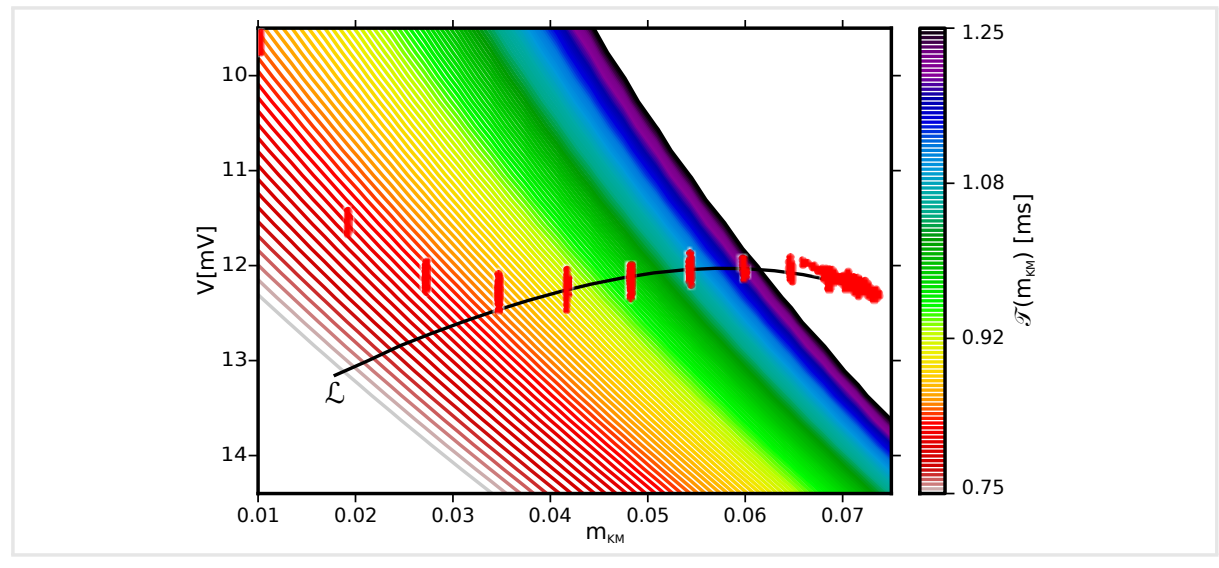

A irregularidade no disparo de spikes ao final do burst (expressa pelo borrão vermelho próximo ao final do tubo na figura 6.5) tem uma origem geométrica evidente. Observando a figura 6.4(ESQ), nota-se que, próximo ao final do burst (bifurcação homoclínica no subsistema rápido), o mapa varia de maneira aparentemente descontínua. Enfatiza-se que a dinâmica não pode ser caótica: dado o segmento praticamente horizontal (à direita, para $\mathrm{m}_{\mathrm{K}_{\mathrm{M}}}>0.07$ ), trajetórias são sempre reinjetadas para o começo do tubo no mesmo ponto. Entretanto, é possível que - devido ao ruído - trajetórias atinjam a região (praticamente vertical) de aparente descontinuidade de $\mathbf{f}()$ e sejam mapeadas para a esquerda, recomeçando a escalada sobre o tubo. A derivada alta de $\mathbf{f}()$ indica ainda que reinjeções deste tipo podem dar origem a sensibilidade a condições inicias apesar do sistema ser regular devido ao platô dissipativo. Desta forma, a expansividade da dinâmica neste ramo amplifica o ruído microscópico, dando origem a padrões irregulares nos ISI e durações total dos bursts, mesmo quando o sistema sem ruído comporta apenas comportamente de disparo periódico.

Voltando ao espaço de estados do modelo completo, é possível determinar a origem da variação brusca, entretanto contínua, na dinâmica unidimensional próxima ao ponto fixo: há um conjunto de estados ao final da variedade de disparos 


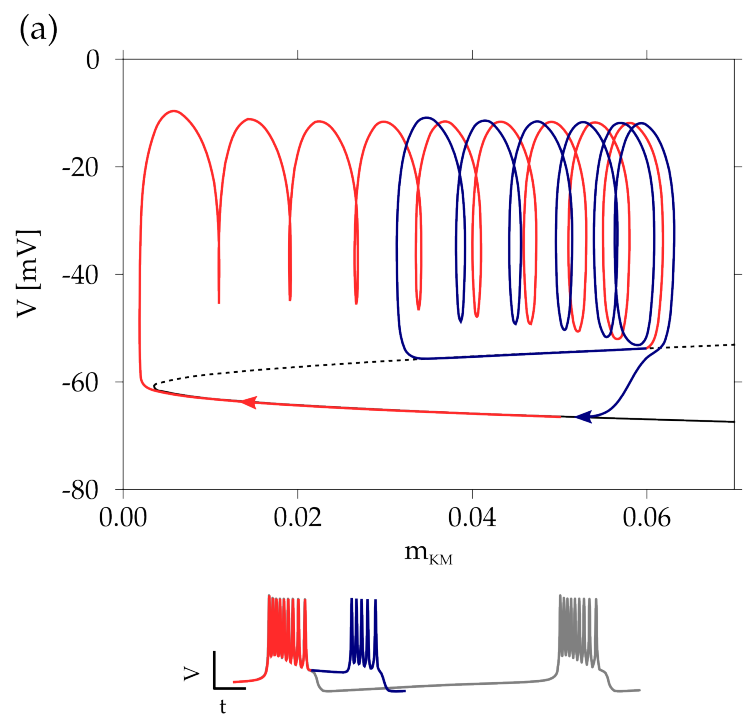

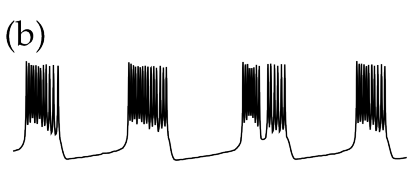

(c)

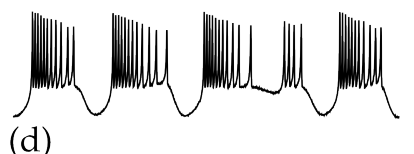

(d)
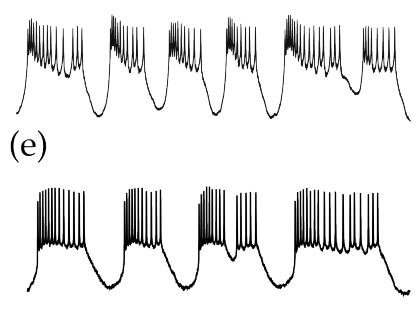

$\mathcal{L}$ (curva preta na fig. 6.2) que, ao evoluirem em direção à hiperpolarização, ficam "presos" sobre o ramo de pontos de sela da variedade de equilíbrios $\mathcal{E}$ (trecho pontilhado em azul). Desta forma, a dinâmica os leva de volta a $\mathcal{L}\left(\mathrm{m}_{\mathrm{K}_{\mathrm{M}}}<0\right.$, já que o ramo de selas encontra-se abaixo da isóclina nula de $\mathrm{m}_{\mathrm{K}_{\mathrm{M}^{\prime}}} \mathrm{em}$ vermelho). Estas trajetórias correspondem a pronlongamentos no burst, ou burstlets, onde spikes adicionais são concatenados à "sequência principal" de um burst. Exemplos de burstlets em séries temporais de modelos e neurônios biológicos podem ser vistos nos painéis $\mathrm{B}, \mathrm{C}, \mathrm{D}, \mathrm{E}$ da figura 6.6.

Trajetórias que evoluem sobre estruturas instáveis, tais como o ramo de selas em $\mathcal{E}$, são chamadas de canards. É fundamental notar que, a priori, a reinjeção em $\mathcal{L}$ pode acontecer em qualquer ponto desta, até a bifurcação sela-nó (ver fig. 6.2), dependendo de por quanto tempo a órbita acompanha o ramo de selas. É precisamente este conjunto de órbitas canard que dá origem ao "esqueleto dinâmico" das assinaturas, o substrato determinístico que é preenchido quando se acresce de ruído o sistema. 


\subsection{Esqueletos das asas de pato}

Para "desenterrar" o esqueleto, tomam-se condições iniciais sobre as variedades instáveis (aproximadas através dos autovetores correspondentes a autovalores positivos da dinâmica linearizada) de um conjunto de selas do ramo $\mathcal{E}$, integrandose então o sistema completo até o primeiro corte em $\Sigma$. Estes cruzamentos formam a reta cinza na figura 6.7. Iterando esta reta (cada cor na figura corresponde a um iterado), é formada uma estrutura em forma de "asa" na seção. Define-se finalmente o "esqueleto" da assinatura como o conjunto pares $\left(\mathcal{T}\left\{\mathrm{m}_{\mathrm{K}_{\mathrm{M}}}\right\}, \mathcal{T}\left\{\mathbf{f}\left(\mathrm{m}_{\mathrm{K}_{\mathrm{M}}}\right)\right\}\right)$ destas trajetórias, conforme a figura 6.8 .

Figura 6.7: Projeção $V_{\mathrm{M}}, \mathrm{m}_{\mathrm{K}_{\mathrm{M}}}$ da seção de Poincaré. A reta cinza corresponde a cortes na seção, para órbitas com condições iniciais sobre variedades instáveis de pontos no ramo de selas. Conforme esperado, esta liga os extremos da órbita periódica (burst de 9 spikes). As outras curvas coloridas são iterados sucessivos da curva cinza.

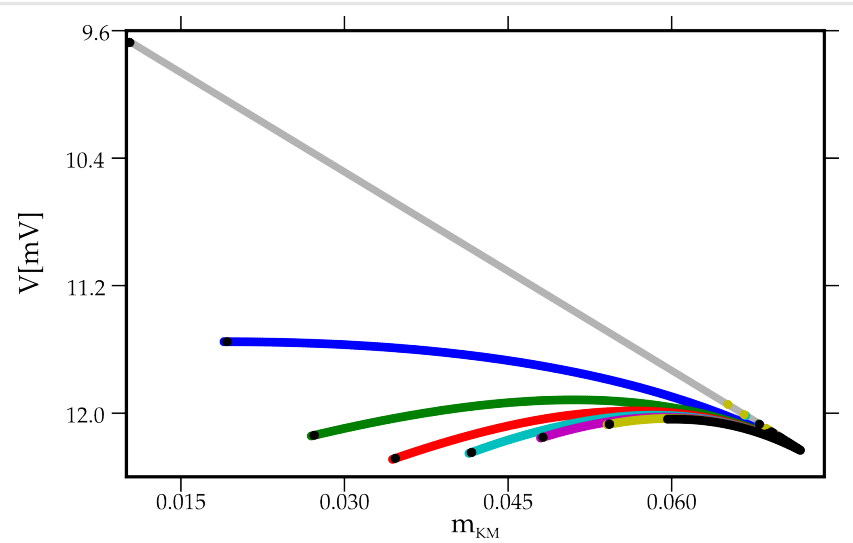

A integração do modelo completo (ruidoso) resulta na assinatura (pontos cinzas) sobreposta ao esqueleto na figura 6.8. Desta forma, reproduz-se qualitativamente a assinatura de neurônios isolados do STG (fig. 6.1), incluindo detalhes finos como o "bico" na sequência de ISI correspondentes ao início de um burst, bem como a variabilidade em ambos número de spikes e intervalos interburst, refletidas na difusividade ao final da sequência principal e extensão dos "braços" isolados de ISI altos.

Todas estas idiossincrasias se devem em última instância à infraestrutura determinista transiente - expressa pelo esqueleto - revelada mediante a consideração de ruído no modelo.

Ainda mais uma evidência de que o mecanismo proposto se aplica em neurônios do STG pode ser vista na figura 6.9. Nesta figura, enumeram-se os ISI ao longo de um burst do modelo reduzido e de uma série temporal de um neurônio PD. 


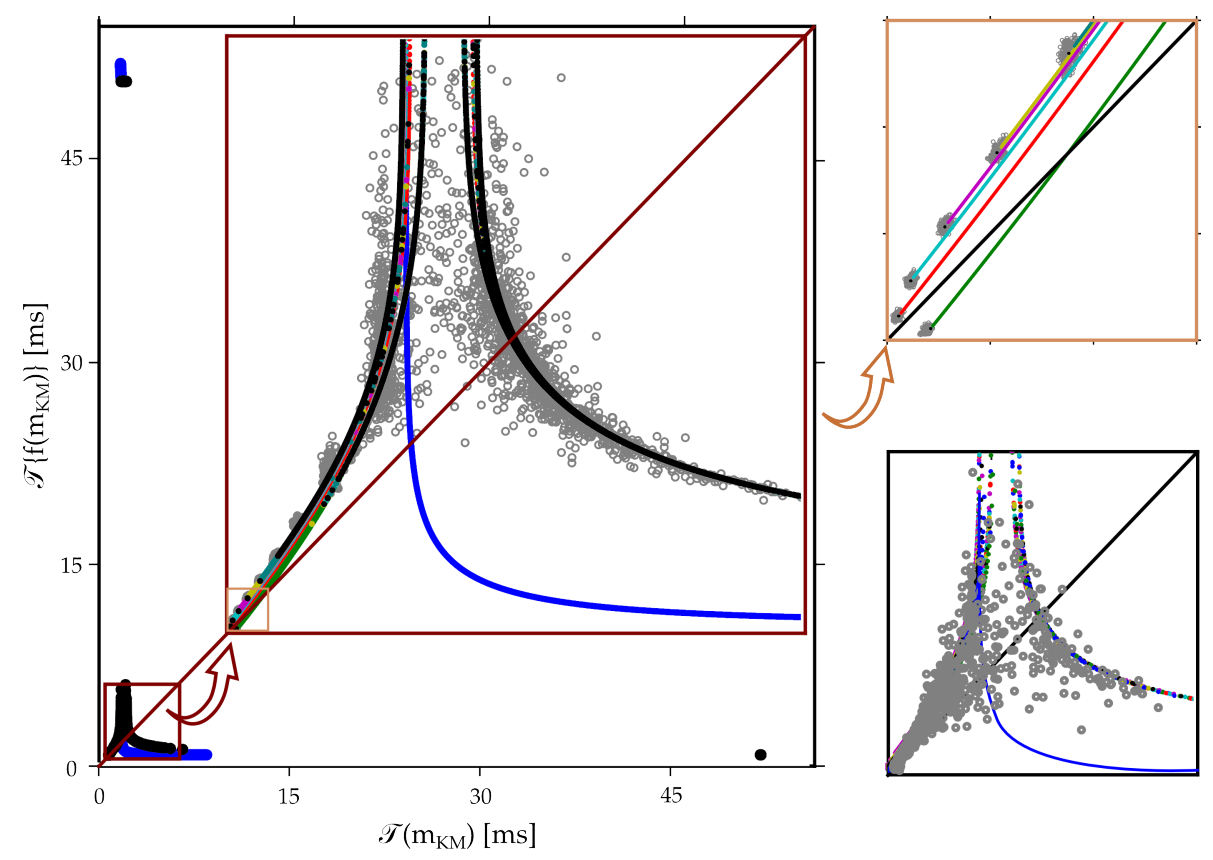

A estrutura geral da assinatura é compatível em ambos os casos: há o "bico" para o primeiro ISI, logo a escalada da "sequência principal" paralela à diagonal (verde), até um par de IsI muito similares (sobre a diagonal, em azul), que correspondem à proximidade ao ponto fixo estável da redução unidimensional. Segue-se então uma sequência alternada (vermelho/amarelo), devido à evolução na região de derivada negativa, "espalhando" Os ISI e dando origem aos "braços" na assinatura.

A existência do ramo de derivada negativa, associado às órbitas canard, está intimamente ligada à posição do corte da isóclina nula de $\mathrm{m}_{\mathrm{K}_{\mathrm{M}}} \operatorname{com} \mathcal{E}$ em relação ao ponto de bifurcação homoclínica, bem como à relação entre as escalas temporais dos subsistemas lento/rápido. No sistema sem ruído, para que uma trajetória seja "capturada" pelo canal estreito levando aos canards, o fluxo deve estar passando próximo ao ramo de selas quando da bifurcação homoclínica.

Desta maneira, há uma interação entre a dinâmica de geração de spikes e a de finalização de um burst, já que graças à órbita homoclínica o subsistema rápido evolui em uma escala temporal comparável à do lento. Devido a estes fatores, no processo de adição de spikes ao burst - bem como próximo à transição bursting/tônico - são visitadas as trajetória canard, e
Figura 6.8: Mapa

$\left(\mathcal{T}\left\{\mathrm{m}_{\mathrm{K}_{\mathrm{M}}}\right\}, \mathcal{T}\left\{\mathbf{f}\left(\mathrm{m}_{\mathrm{K}_{\mathrm{M}}}\right)\right\}\right)$ para a linha cinza e iterados,

mostrados na figura 6.7. A estrutura formada é somente acessível pelo sistema quando acrescido de ruído, dada a forte atração para a órbita periódica. Os pontos em cinza são resultado da integração do modelo completo, com ruído (superpostos ao esqueleto no detalhe a direita inferior). 


\section{é observado comportamento caótico.}

Figura 6.9: Enumeração dos spikes na assinatura de um único burst de um neurônio PD e do modelo. $\mathrm{O}$ "ramo principal", em verde, está associado à escalada via $\mathrm{o}$ trecho quase paralelo à diagonal na aproximação unidimensional. Após dois ISI similares (azul), associados à presença de uma órbita periódica instável, são disparados spikes "alternadamente" (vermelho/amarelo), devido à derivada negativa do ponto fixo instável.

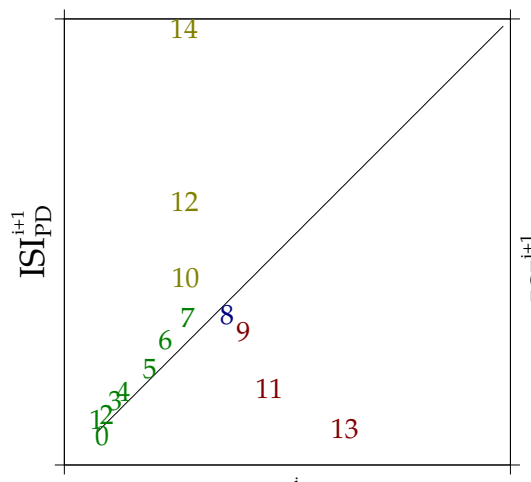

$\operatorname{ISI}_{\mathrm{PD}}^{\mathrm{i}}$

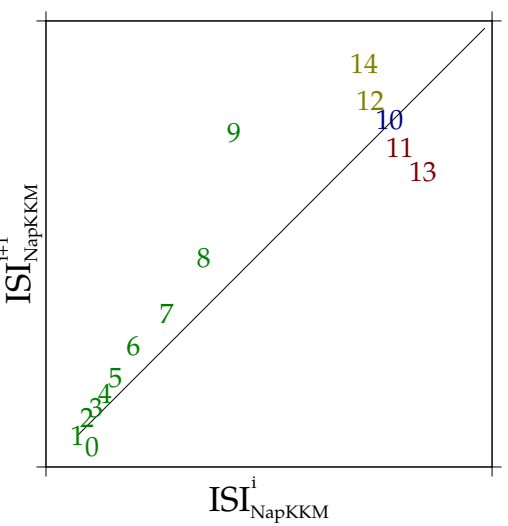

A fim de determinar a fundo estes cenários, propõe-se analisar a classe de mapas obtidos mediante a redução unidimensional do modelo, para diversos valores de parâmetros. Em particular, pretende-se estudar os efeitos de ruído, determinando se este pode ou não induzir o aparecimento comportamento caótico. 


\section{Capítulo 7}

\section{Análise das aproximações unidimensionais}

Aplicando o esquema de aproximação e redução de modelos descritos por EDO apresentado anteriormente, obtém-se uma descrição sintética da dinâmica subjacente ao disparo em bursts. Mediante a exploração dos diversos mapas unidimensionais assim construídos, é possível dissecar muitas das propriedades não triviais observadas no fluxo, tais como a acreção ou supressão de spikes em um burst, a transição bursting-tônico, a robustez do comportamento caótico e transientes caóticos. Apesar do esquema de redução ser aplicável a diversas classes de bursters, é dada ênfase à análise dos mapas obtidos para o modelo $\mathrm{Na}_{\mathrm{p}} \mathrm{KK}_{\mathrm{M}}$, no regime de square bursting - já que diversos aspectos fenomenológicos dos neurônios isolados do STG parecem ser capturados por esta classe dinâmica. Para uma revisão do uso mapas na descrição da dinâmica neuronal, sugere-se o trabalho de Ibarz et al. (2011).

\subsection{Estrutura geral das reduções}

Para a classe de modelos em questão (bursters tipo selanó/homoclínica), as reduções unidimensionais têm a estrutura qualitativa vista nas figuras 7.1. Por conveniência, chama-se o mapa para a variável lenta de $\mathbf{f}(z)$. Na parte inicial do burst (ramo principal), a variável lenta cresce monotonicamente, ao longo de um trecho com derivada próxima - mas menor - que 1. Dessa maneira, não há divergência nem dissipação 
Figura 7.1: Mapas decorrentes da redução unidimensional do modelo $\mathrm{Na}_{\mathrm{p}} \mathrm{KK}_{\mathrm{M}}$ (ver também fig. 6.4), ilustrando (ESQ) disparo tônico e (ESQ) bursts irregulares para variações nos parâmetros $\mathrm{I}_{\mathrm{ext}}, V_{\mathrm{K}_{\mathrm{M}}}^{1 / 2}$. Os traços inferiores indicam as séries de $V_{\mathrm{M}}$ geradas pelo modelo completo correspondente. No segundo caso, após um transiente longo obtém-se bursting periódico com 26 spikes.
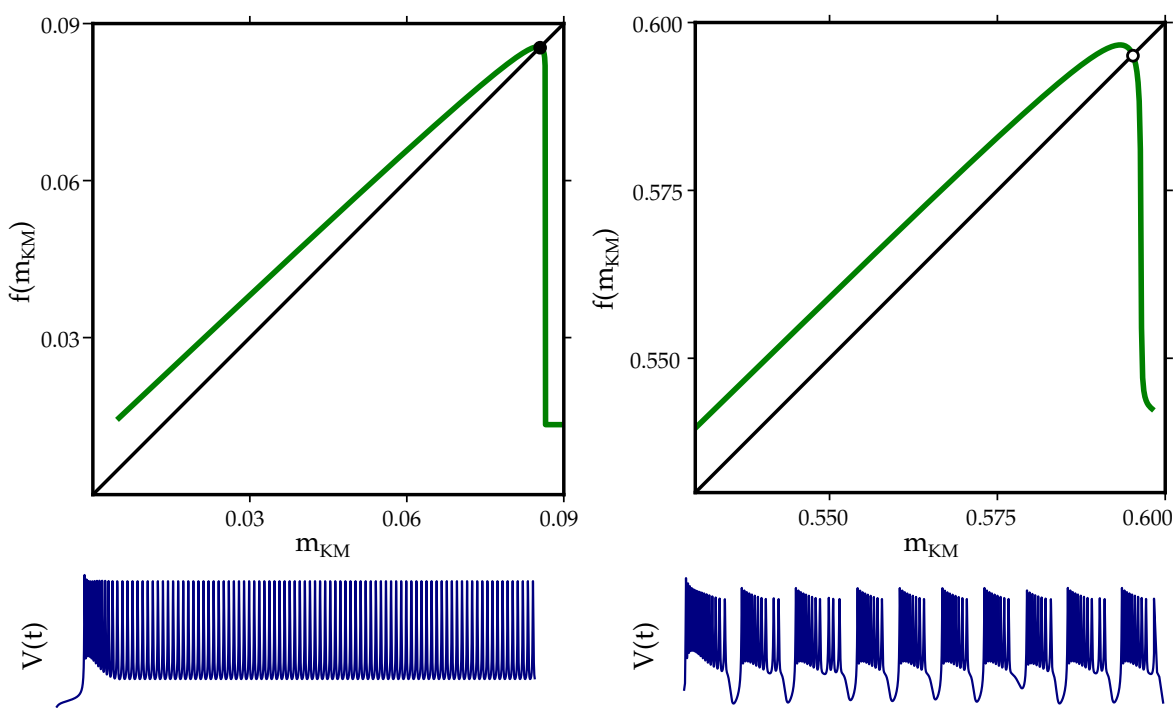

alta, e trajetórias próximas correspondem a disparos de pares de spikes com IsI semelhantes. As órbitas voltam ao ramo principal via um mecanismo de reinjeção (no sistema completo, correspondente à evolução ao longo do ramo de equilíbrios estáveis, após o desaparecimento da variedade de ciclos-limite $\mathcal{L}$, fig. 6.2), representado pelo platô (ramo Dissipativo) para valores altos de $z$.

O formato deste platô é determinante para a presença de caos no sistema, já que uma grande dissipação (platô aproximadamente horizontal) elimina eventuais expansões. Dado que o mapa provém de uma seção de Poincaré de um fluxo gerado por uma EDO, o ramo principal e o platô de reinjeção devem estar conectados continuamente. O ramo expansivo $\left(f^{\prime}(z) \ll-1\right)$ que une $\mathrm{P}$ a $\mathrm{D}$, é de fundamental importância na gênese de comportamento complexo no modelo - conforme discutido no contexto de órbitas canard no fluxo (capítulo anterior).

Mediante a variação de parâmetros, tipicamente a corrente externa injetada, caracterizam-se os distintos regimes de atividade exibidos pelo modelo (fig. 7.2). Na figura 7.1, ilustram-se casos com comportamento de disparo tônico - devido à estabilidade do ponto fixo - e de bursts transientes irregulares (caindo eventualmente em uma órbita periódica de período grande correspondente a bursts com um número elevado de spikes). 


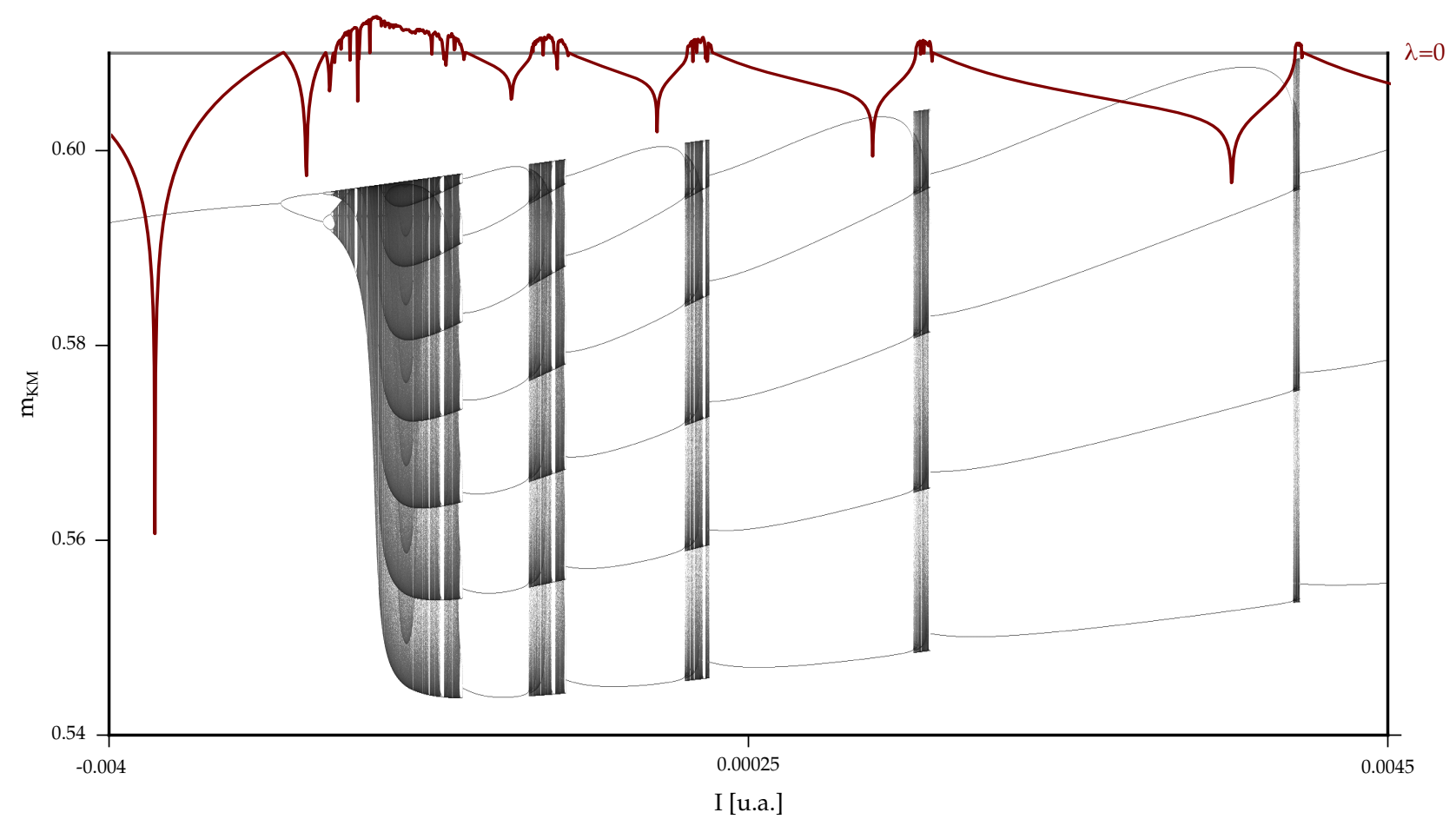

Conforme discutido no capítulo anterior, a redução unidimensional do modelo com valores canônicos de parâmetros possui um platô dissipativo praticamente horizontal. Para um cenário puramente determinista, este fato implica a presença de uma órbita periódica fortemente atrativa, correspondente aos iterados do valor de $m_{K_{M}}$ no platô. A fim de expor em mais detalhe a gênese de comportamento caótico no modelo, utiliza-se um conjunto de parâmetros para os quais o cenário sela-nó/homoclínica é preservado, mas reduzindo o efeito da dissipatividade. Operacionalmente, trabalhar no regime de correntes altas (ver figura 5.8), com um correspondente ajuste na meia ativação da corrente lenta, é suficiente. Isso se deve à maior separação, no subsistema rápido, entre o ponto de sela envolvido na bifurcação homoclínica e o equilíbrio estável coexistente (ver fig. 5.5): desta forma, após a destruição de $\mathcal{L}$ o fluxo é menos suscetível à atratividade de $\mathcal{E}$. Essa escolha efetivamente amplia os intervalos de parâmetros no modelo sem ruído para os quais é observado comportamento caótico, sendo conveniente tanto do ponto de vista gráfico quanto numérico. A maior parte dos exemplos numéricos subsequentes refere-se ao modelo neste regime.

Figura 7.2: Diagrama de bifurcações e expoentes de Lyapunov (vermelho) para a redução unidimensional, considerando variações na corrente injetada. Note que esta foi reescalada e invertida (valores negativos são depolarizantes). 
Apresenta-se a seguir a construção de mapas que condensam toda a informação de interesse da dinâmica. Tais mapas representam o primeiro retorno a um domínio fundamental - nada mais do que um intervalo por onde passam necessariamente todos os iterados - indicando o número de iterações necessárias (spikes) para que se dê o retorno.

Figura 7.3: Construção do mapa de primeiro retorno $\mathbf{f}()$ ao domínio fundamental (intervalo entre o ponto fixo instável e sua pré-imagem)
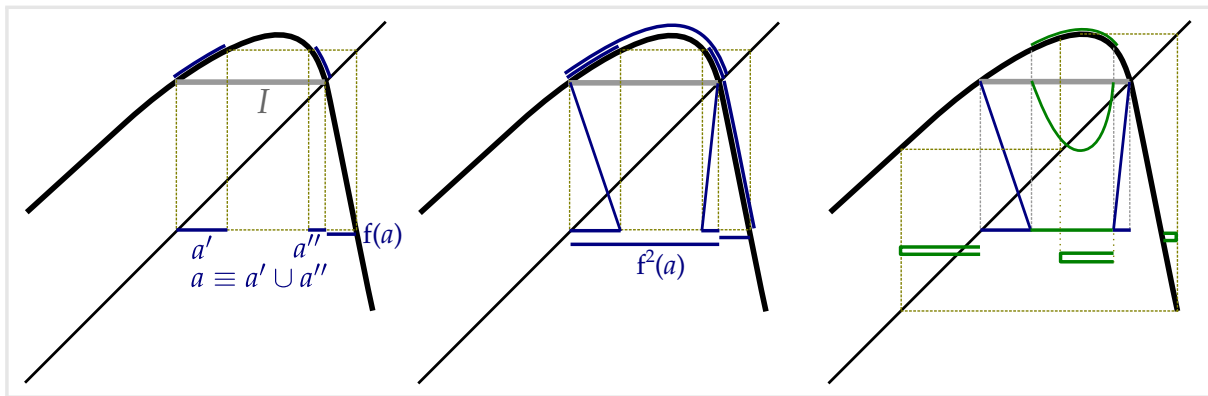

Na figura 7.3, apresenta-se um caso esquemático possuindo uma órbita de perído 3, hipoteticamente correspondente a "bursts" de 3 "spikes" (mediante a adoção de um observável $\mathcal{T}\{z\}$ conveniente, conforme o capítulo anterior). O domínio fundamental $I$, no caso, é o intervalo delimitado pelo ponto fixo da redução unidimensional $z^{*}$ e sua pré-imagem $\mathrm{f}^{-1}\left(z^{*}\right)$. A construção essencialmente consiste em determinar as préimagens de ordem superior $\mathrm{f}^{-n}\left(z^{*}\right)$, de modo a ir particionando o domínio fundamental em subintervalos que são mapeados de volta a I em um mesmo número de spikes. No primeiro quadro, as linhas pontilhadas indicam iterados para tempo invertido a partir de $z^{*}$. As primeiras pré-imagens de $z^{*}$ sobre $I, \mathrm{f}^{-3}\left(z^{*}\right)$, delimitam um subintervalo $a \equiv a^{\prime} \cup a^{\prime \prime}$ (em azul). Os estados neste subintervalo retornam a $I$ em 2 iterados (sem inversão temporal), cobrindo todo o domínio fundamental, conforme pode-se ver no quadro central da figura. Desta forma, o mapa de primeiro retorno a I (quadrado sob o intervalo) possui dois ramos diagonais (em azul, sobre $a$ ).

Neste caso específico, o subintervalo central restante $I \backslash a$ retorna inteiramente a $I$ em 3 iterados, sem entretanto cobrir todo o domínio fundamental, já que não há pontos mapeados para além da imagem do máximo. O terceiro painel da figura ilustra este fato, sendo as linhas pontilhadas iterados (sem inversão temporal) do máximo de $\mathbf{f}()$. O subintervalo é mapeado com uma dobra, cobrindo um intervalo de $I$ delimitado pela 
(terceira) imagem do máximo e $z^{*}$, resultando no ramo central unimodal no mapa de primeiro retorno.

\subsection{Bifurcações de acreção de spikes}

A acreção/supressão de spikes em um burst, mediante variação de parâmetros no modelo completo, reflete-se em aproximação/afastamento do gráfico da redução unidimensional $\mathbf{f}()$ da diagonal. Desta forma, as trajetórias passam mais/menos iterados na "subida" via ramo P. Nos mapas de retorno esque-

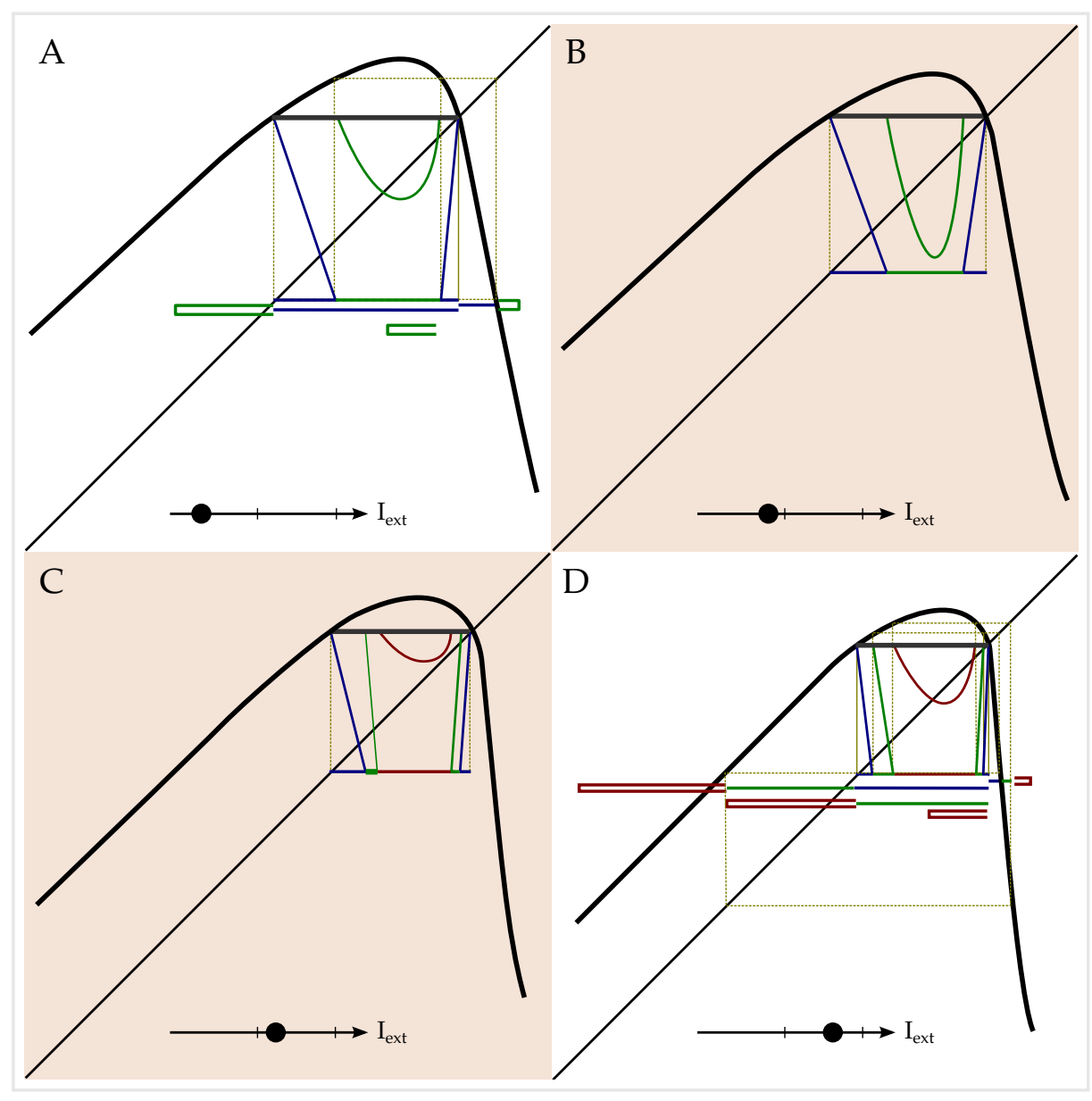

Figura 7.4: Mecanismo de adição de spikes a um burst na redução unidimensional.

Mediante a injeção de corrente externa, o mapa unimodal aproxima-se da diagonal. Desta forma, observa-se uma cascata de adição de período. O valor do parâmetro está indicado esquematicamente em cada painel (círculo), bem como um intervalo que corresponde ao mesmo número de spikes por burst (quebras na linha).

Quando $I_{\text {ext }}$ cruza estes valores (painéis B-C), surge um intervalo do domínio fundamental que retorna em $n+1$ spikes.

matizados na figura 7.4, conforme o gráfico de $\mathbf{f}()$ aproxima-se da diagonal o ramo central "parabólico" (retorno em $n$ spikes) extende-se mais e mais em direção ao eixo das abcissas (a imagem do ponto crítico aproxima-se da fronteira esquerda 
de $I$, quadros A-B, C-D). A adição de um spike ao burst se reflete no encontro deste ramo com o eixo, gerando dois novos ramos diagonais disjuntos (retorno em $n$ spikes), bem como um ramo central parabólico consistindo em estados que levam um iterado adicional $(n+1)$ para retornar a $I$ (quadro c). Note que a construção descrita na seção anterior, através da determinação das pré-imagens do ponto fixo, determina a dinâmica completamente (quadro D). Este é o cenário clássico de cascatas de adição de período, estudado em muito detalhe (Melo e Strien, 1993, e referências internas) no contexto de dinâmica unidimensional.

Figura 7.5: Dinâmica de retorno ao domínio fundamental para casos de ramo hiperpolarizado fortemente atrativo. Nesta classe de modelos, há um platô praticamente horizontal, fortemente dissipativo, que virtualmente elimina a possibilide de órbitas caóticas para um conjunto denso de parâmetros. Nota-se que, perto de uma adição de spike, $o$ ponto fixo perde estabilidade. Isso não exclui entretanto a possibilidade de pontos fixos estáveis para iterados mais altos da transformação de retorno.

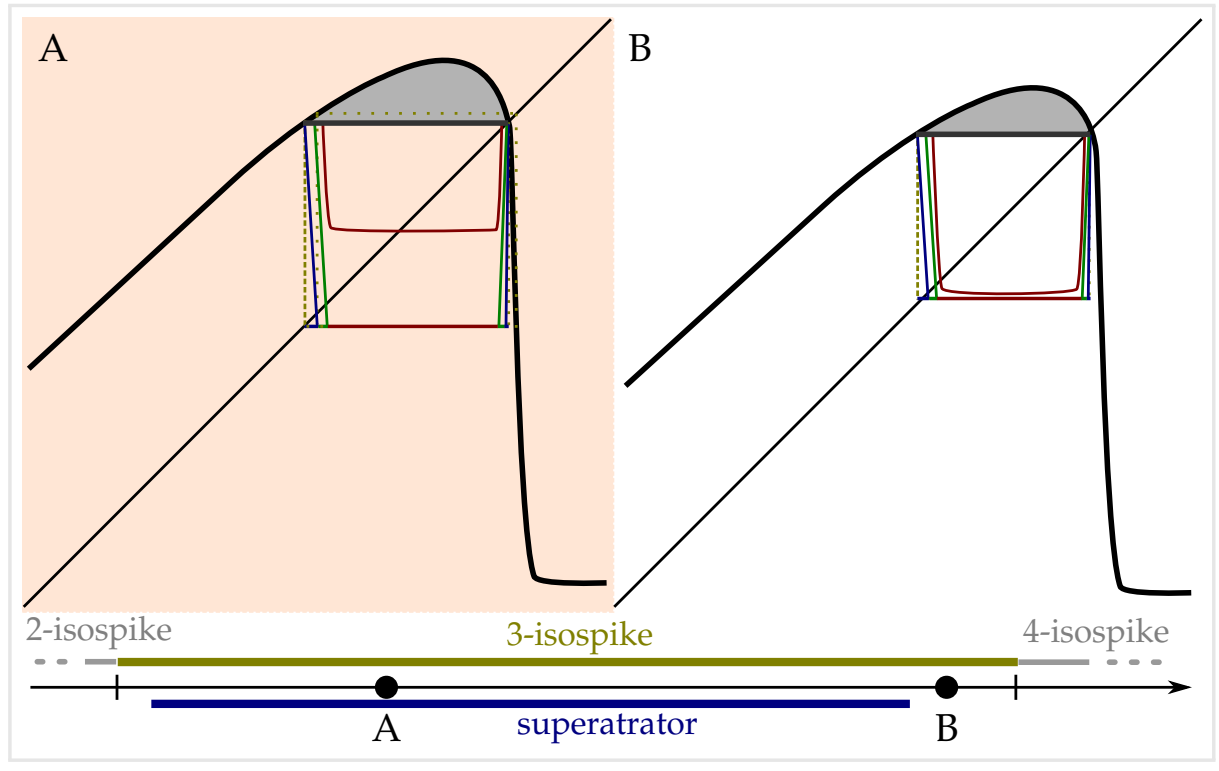

Para o caso do modelo com parâmetros canônicos, conforme discutido no capítulo anterior, o envolvimento do platô dissipativo $\mathrm{D}$ na dinâmica faz com que, para a maior parte de uma janela isospike - ou seja, um conjunto de valores do parâmetro que dá origem a órbitas com um mesmo número de disparos - haja um superatrator (derivada nula) no mapa de primeiro retorno. Assim sendo, os intervalos que comportam dinâmica caótica (ver fig. 7.2) são reduzidos: o ponto fixo pode perder estabilidade apenas próximo a transições no número de spikes. Assim mesmo, iterados superiores da transformação de retorno podem apresentar pontos fixos estáveis, suprimindo ainda mais os regimes caóticos. 


\subsection{Transição bursting-tônico}

A rota de transição bursting-tônico pode ser claramente associada ao ganho de estabilidade do ponto fixo, conforme $\mathbf{f}()$ aproxima-se da diagonal (fig. 7.1). Este mecanismo está de acordo com a observação de que, em square bursters como o modelo de Hindmarsh-Rose (Hindmarsh e Rose, 1984) e ChayKeizer (Chay e Keizer, 1983), a transição para disparos tônicos se dá mediante a aparição de disparos tônicos de período dois. A órbita periódica de período dobrado corresponde justamente a uma bifurcação flip $\mathbf{f}^{\prime}\left(z^{*}\right)=-1$, na passagem de instável para estável do ponto fixo. Nota-se adicionalmente (fig. 7.2) a presença de uma cascata de duplicações de período, de acordo com diversas observações de caos nestas circunstâncias, em diversos cenários de bursting. Em Terman (1992), é apresentada uma análise geométrica da transição bursting/tônico para square bursters, determinando os mecanismos generativos de disparos complexos.

\subsection{Repulsores e atratores caóticos, caos induzido por ruído}

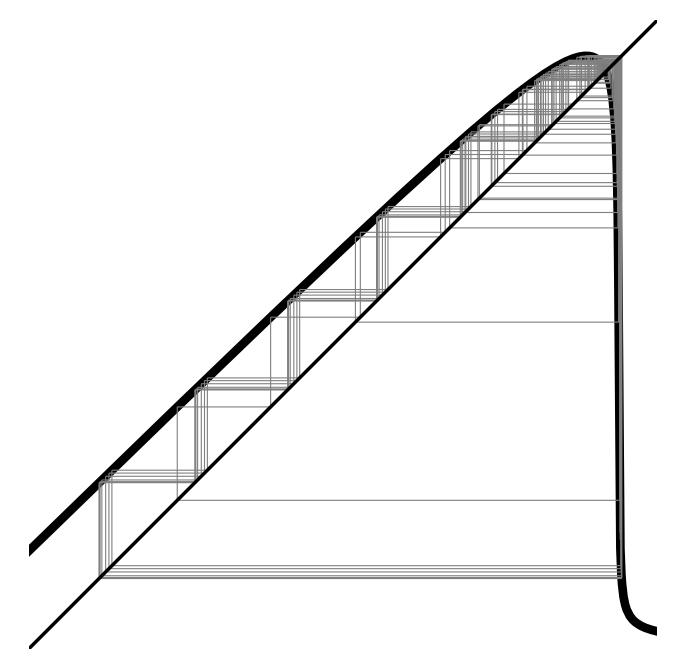

No diagrama de bifurcações (fig. 7.2), podem ser observados diversos intervalos de parâmetros que dão origem a expoentes de Lyapunov positivos. Conforme discutido anteriormente,
Figura 7.6: Caos determinístico no modelo sem ruído, próximo à transição $6 / 7$ spikes por burst (ver fig. 7.2). Próximo a cada uma das transições no número de spikes em um burst, a dinâmica tridimensional visita as proximidades da bifurcação homoclínica, sendo suscetível a evoluir sobre órbitas canard refletidas no ramo $\mathrm{E}$ da redução unidimensional. 
estes intervalos estão associados à transições no regime de disparo, consistindo em alterações no número de spikes em um burst ou à transição de bursting para disparo tônicos. $\mathrm{Na}$ fig. 7.6, apresenta-se uma trajetória caótica no sistema sem ruído, para um valor de parâmetro na janela de transição de 6/7 spikes por burst. Durante a escalada pelo ramo $\mathrm{P}$, há disparos relativamente regulares, até serem atingidas proximidades do ponto fixo. A partir de então ocorrem burstlets, associados a trajetórias canard, com subsequentes reinjeções ao ramo P. Estes burstlets são muito variáveis devido à expansividade do ramo E, compensando qualquer dissipatividade associada às derivadas de módulo pequeno ao redor do ponto de máximo.

Figura 7.7: Mapa de retorno ao domínio fundamental para um caso do modelo com transientes irregulares longos. Cores indicam o número de iterados necessário para retorno.

Aparentemente, há apenas pontos fixos instáveis entretanto, o ponto fixo estável correspondente à órbita periódica surge ao serem considerados iterados superiores da transformação de retorno. Transientes caóticos longos se devem às excursões da dinâmica por regiões de derivada negativa, antes de cair na estreita bacia de atração do ponto fixo estável. Para ruído pequeno, ocorre então 0 fenômeno de caos induzido por ruído.

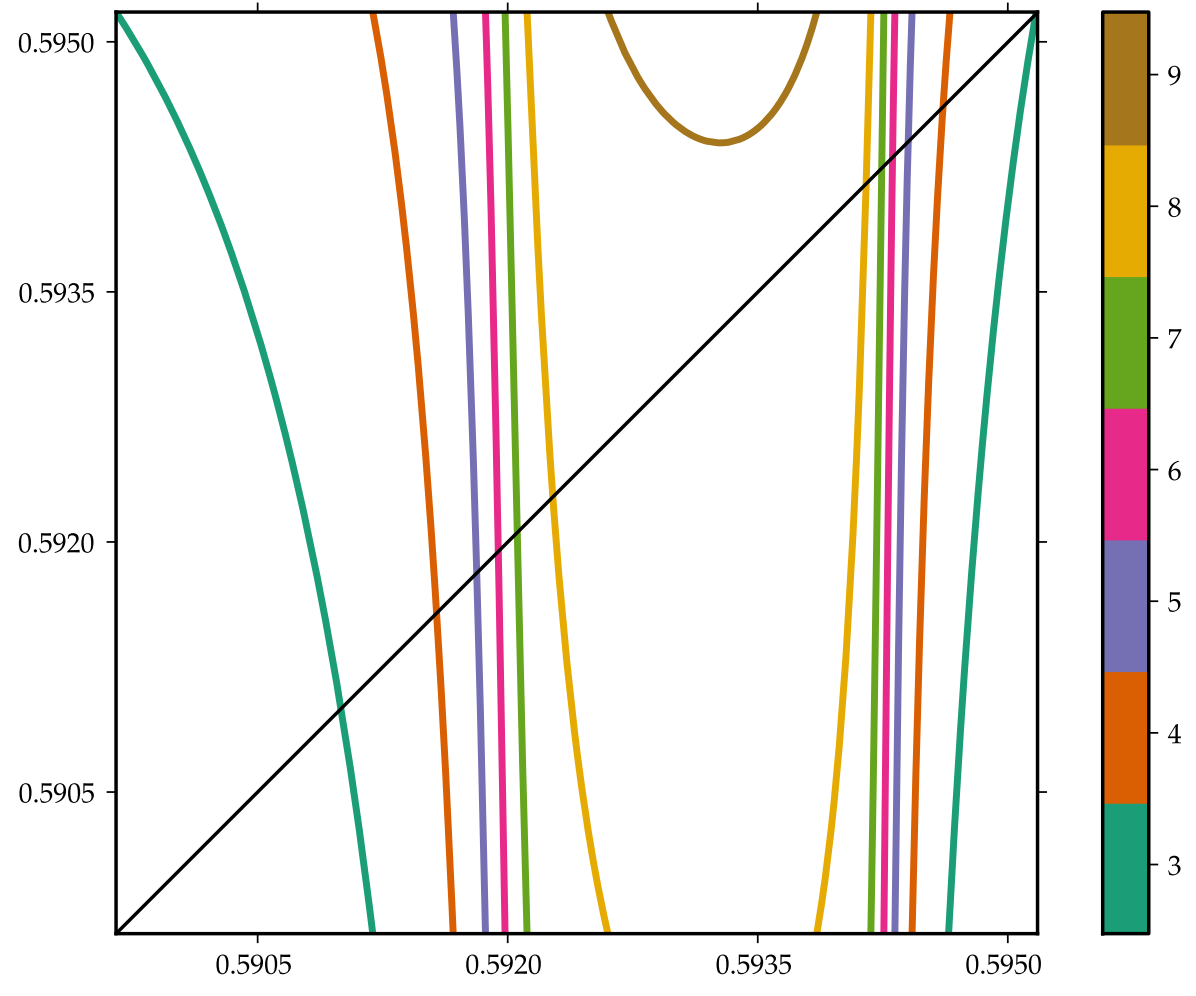

O aparecimento de caos na adição/supressão de spikes, descrito e analisado para um fluxo tridimensional em Terman (1991), é também capturado através da transformação de retorno. Na fig. 7.7, apresenta-se o mapa de retorno ao domínio fundamental para a situação descrita na fig. 7.1DIR. O modelo dispara trens transientes de bursts irregulares, estabilizando-se eventualmente em bursts regulares com 26 spikes. Nota-se que 
a construção esquemática apresentada anteriormente se faz de fato presente, com ramos diagonais delimitando subintervalos isospike e um ramo central unimodal de retorno em 9 spikes. Já que todos os pontos fixos são instáveis, a primeira vista não há a possibilidade de disparo regular de bursts. Entretanto, deve-se considerar adicionalmente a possibilidade de iterados superiores da transformação de retorno, conforme as figuras 7.8. O quadro à esquerda representa o segundo iterado da

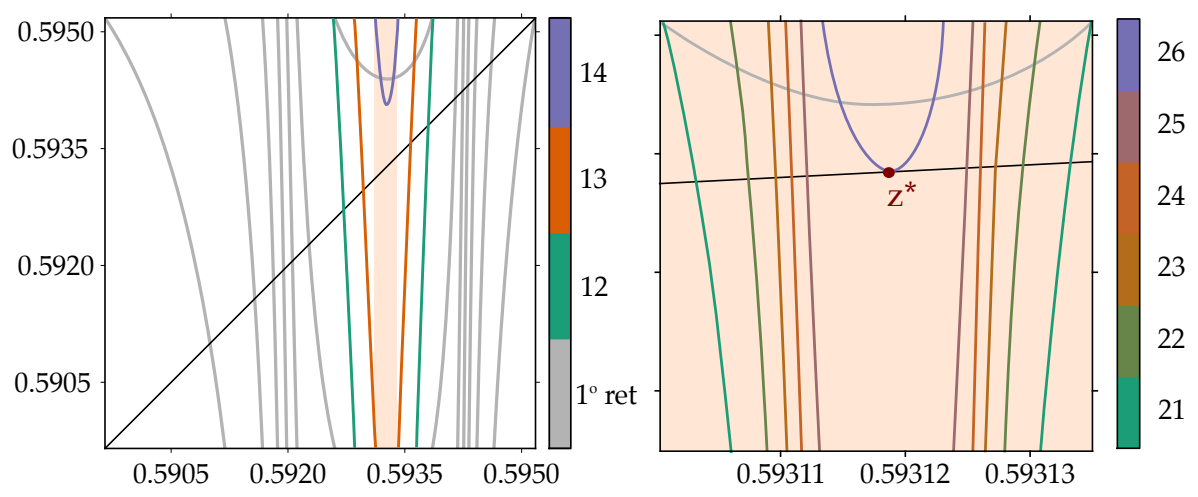

transformação de retorno (ramos coloridos), sobreposto ao primeiro (cinza), para o intervalo que comporta o ramo central. Novamente, este é particionado em subintervalos com segundo retorno para números distintos de spikes, replicando a estrutura em ramos diagonais e unimodal central. Considerando agora o terceiro retorno (quadro da direita, ampliação na região bege da esquerda, com o ramo central do segundo retorno em cinza), encontra-se enfim a órbita periódica, com bursts de 26 spikes, bem como novos ramos diagonais correspondentes a coberturas completas de $I$.

A presença de transientes caóticos longos (fig. 7.1в) é determinada considerando o quão estreita é a vizinhança do ponto fixo estável $z^{*}$ na fig. 7.8. Trajetórias típicas evoluem por tempos longos nas regiões expansivas associadas aos ramos diagonais, até eventualmente atingirem uma vizinhança do ponto fixo, sofrendo influência da dissipatividade. Para o caso de perturbações estocásticas no modelo $z_{n+1}=\mathbf{f}\left(z_{n}\right)+w_{n}$, onde $w_{n}$ são variáveis aleatórias sorteadas de uma distribuição
Figura 7.8: Iterados superiores da transformação de retorno. (ESQ):segundo retorno, superposto ao primeiro (fig. $7 \cdot 7$ em cinza). As cores indicam o número de spikes para retorno. Somente estão representados iterados do ramo central, aproximadamente parabólico. (DIR):terceiro retorno, para o ramo central do gráfico à direita. Note ampliação na escala do eixo das abcissas, correspondente à região em bege do mapa da esquerda. 
Figura 7.9: Perturbação de órbita periódica próxima a adição de um spike. (ESQ):Transiente caótico para órbita periódica estável (vermelho), sistema sem ruído.

O expoente de Lyapunov é negativo, conforme esperado para órbitas regulares. (DIR):com a adição de ruído a dinâmica torna-se caótica, sendo sempre perturbada para fora da bacia de atração (estreita) da órbita periódica. normal, com média nula e desvio padrão $\xi^{2}$, tem-se então um cenário de caos induzido por ruído (conforme a fig. 7.9), sendo as trajetórias capturadas pelo atrator provavelmente reconduzidas às regiões expansivas.
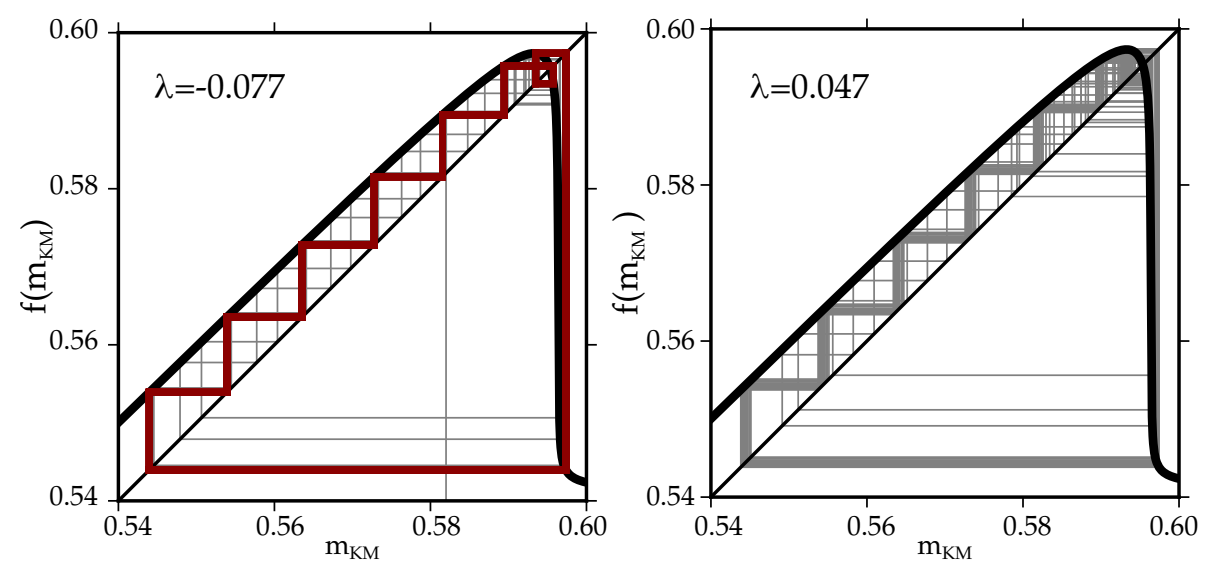

No painel da esquerda da fig. 7.9, têm-se uma órbita periódica (vermelho), e iterações de uma condição inicial arbitrária mostrando comportamento transiente irregular no modelo sem ruído. Evidentemente, obtém-se um expoente de Lyapunov negativo, já que eventualmente é atingida a órbita periódica. Quando é considerado ruído no sistema (painel da direita), entretanto, as excursões transientes tornam-se perenes, e por serem essencialmente expansivas (note a inclinação dos ramos nos mapas da fig. 7.8), contribuem positivamente para $\mathrm{o}$ expoente de Lyapunov.

\subsection{Expoentes de Lyapunov e ruído}

A fim de determinar o cenário de caos induzido por ruído em casos como aquele apresentado na fig. 7.9, bem como a robustez na aproximação dos expoentes de Lyapunov para séries com perturbações estocásticas, considerou-se a variação de $\lambda$ com a intensidade de ruído $\xi$ (perturbações aleatórias sorteadas de uma distribuição Normal de média nula e variância $\left.\xi^{2}\right)$, representada na fig. 7.10. Os expoentes foram estimados utilizando a eq. A.4, apêndice A.

De acordo com o cenário de noise induced chaos, descrito em Gao et al. (1999a); Liu et al. (2002); Tél et al. (2008), espera- 

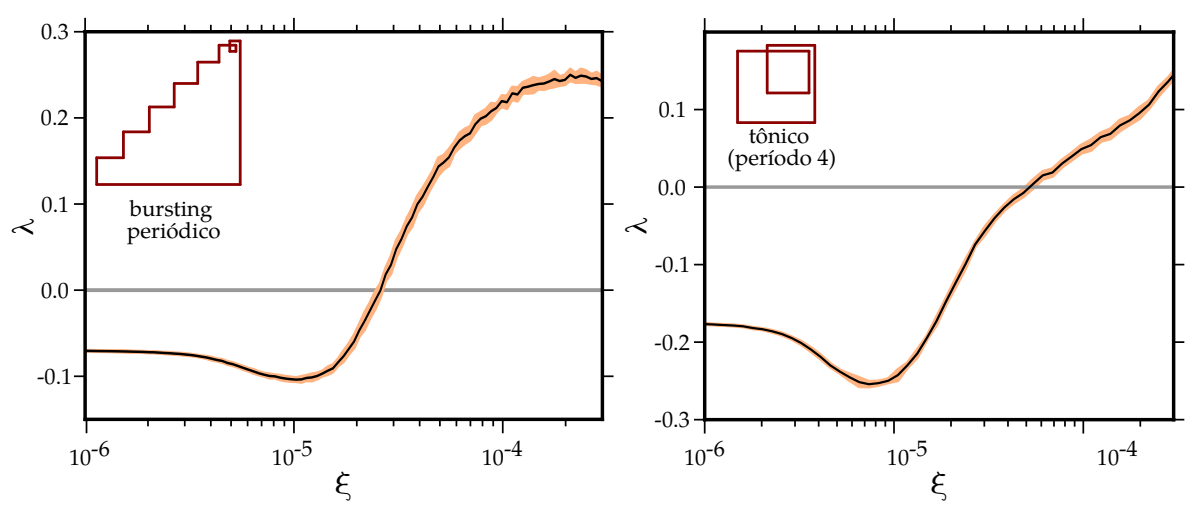

se uma variação contínua dos expoentes de Lyapunov com o ruído, satisfazendo inclusive a uma lei de escala na transição regular/caótica $(\lambda \approx 0)$. Na figura 7.10, correspondente ao caso mostrado na fig. 7.9ESQ., apresenta-se uma evidência deste cenário. A região sombreada ao redor da curva representa o desvio padrão nas aproximações de $\lambda$ para 20 realizações distintas de ruído, indicando robustez nos expoentes obtidos. A diminuição no expoente para ruídos baixos $\left(\xi \approx 1 \times 10^{-5}\right)$ parece ser recorrente para situações de caos induzido por ruído, o que é intrigante considerando trabalhos que mostram que ruído baixo pode aumentar o tempo de vida de transientes caóticos (Reimann, 1996; Altmann e Endler, 2010). Note que,

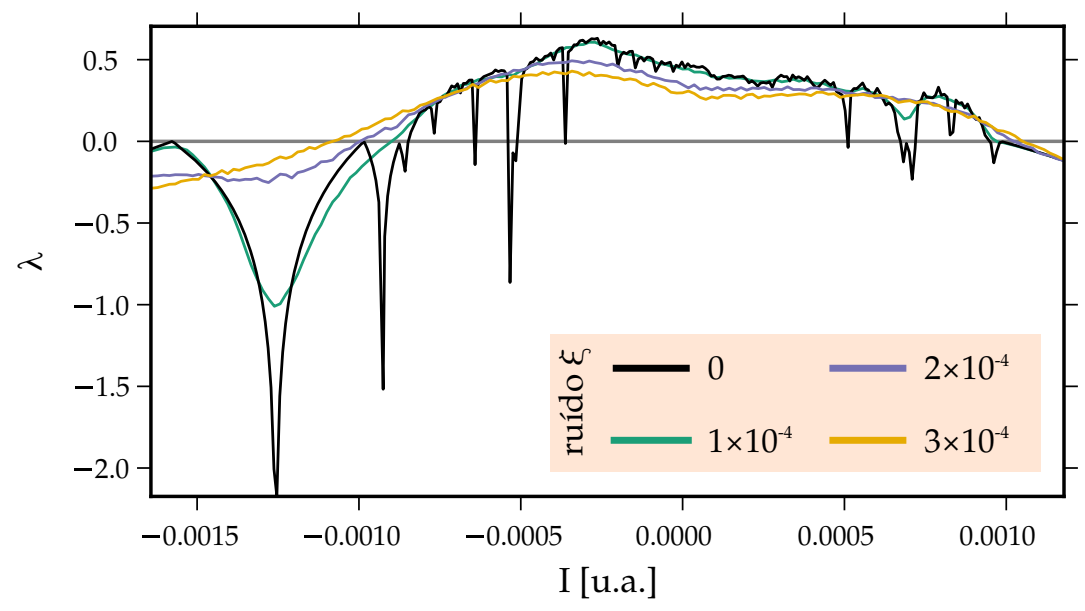

para o painel da direita - no qual a dinâmica sem perturbações apresenta apenas uma órbita periódica de período quatro - também ocorre uma transição para expoentes positivos, entretanto para um valor mais alto de ruído.
Figura 7.10: Variação contínua do expoente de Lyapunov com a intensidade de ruído para o cenário de caos induzido por ruído. A região bege corresponde a mais ou menos o desvio padrão de 20 realizações distintas do ruído para cada valor de intensidade. O mapa sem ruído apresenta (ESQ):bursting regular e (DIR):disparo tônico.

Figura 7.11: Expoentes de Lyapunov para as proximidades da transição bursting/tônico (ver o diagrama de bifurcações 7.2), considerando diversos níveis de ruído (cores). Note a destruição das janelas periódicas, bem como o alargamento do intervalo de expoentes positivos, com o aumento do ruído. 


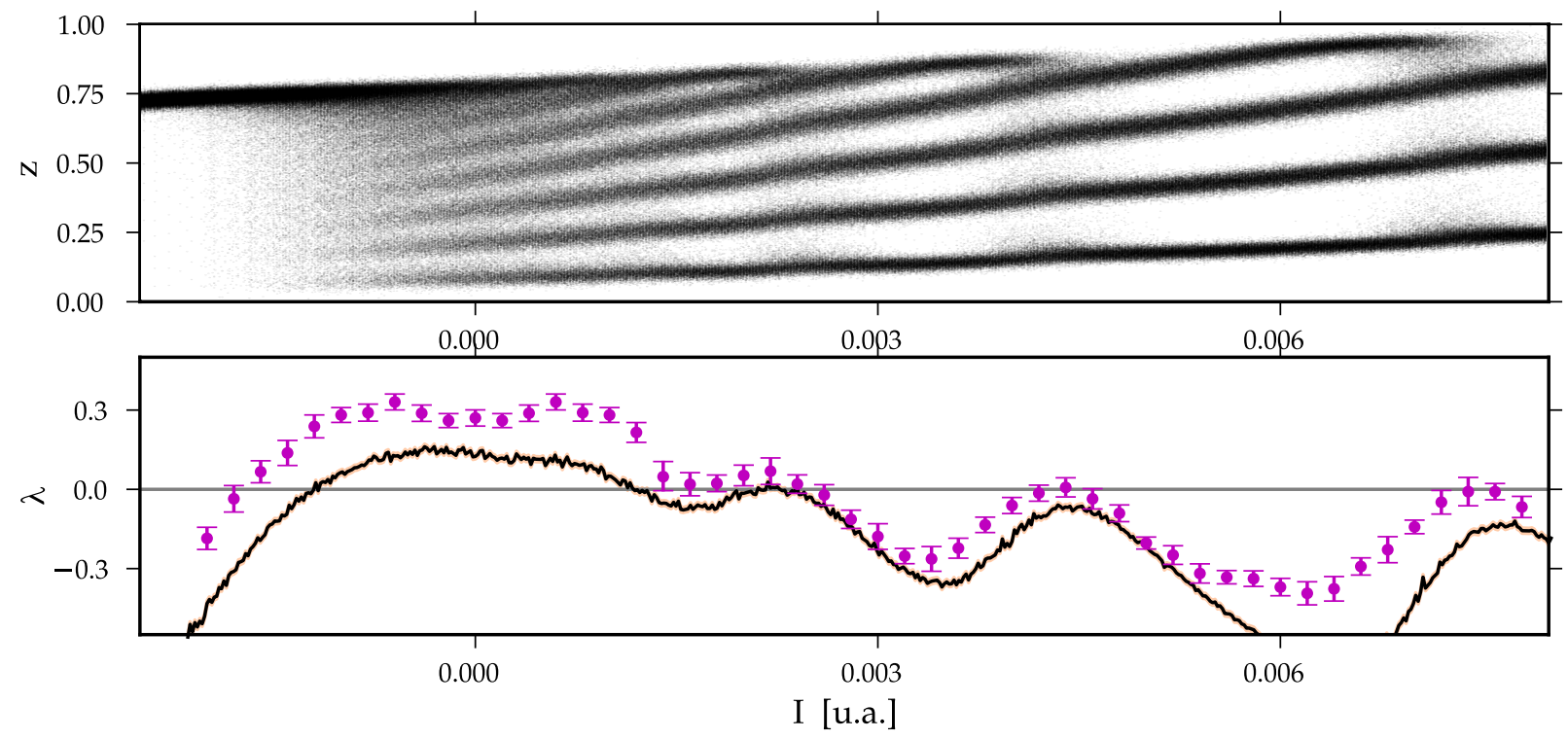

Figura 7.12: Diagrama de bifurcações e expoentes de Lyapunov (linha preta, com erro para dez realizações distintas de ruído em bege) para a vizinhança da transição

bursting/tônico, para ruído

$\xi=1 \times 10^{-3}$. Enfatiza-

se a perda na resolução de duplicações/adições de período. Os pontos com barra de erro em magenta correspondem a aproximações para os expoentes via série temporal, para dez realizações distintas do ruído.
$\mathrm{Na}$ fig. 7.11, considera-se o efeito do ruído sobre os expoentes de Lyapunov ao longo da transição bursting/tônico, mediante variações na corrente (conforme o diagrama 7.2). Nota-se que o ruito oblitera os saltos abruptos associados a janelas periódicas da dinâmica não perturbada (preto), bem como detalhes finos na curva. Ao longo da cascata principal (transição bursting-tônico), as bifurcações de duplicação de período (expoentes nulos) e dinâmica superestável $(\lambda \rightarrow-\infty)$ são obscurecidas, e a transição para expoentes positivos tende a se dar para valores gradativamente menores de $I$, aparentemente acompanhando cada uma das duplicações de período para dados níveis de ruído.

$\mathrm{Na}$ figura 7.12, apresenta-se um detalhe do diagrama de bifurcação e expoentes de Lyapunov para um nível de ruído $\xi=1 \times 10^{-3}$. O sombreado bege ao redor da curva $\lambda(\xi)$ indica o desvio padrão para 10 realizações distintas do processo aleatório. Observa-se que a presença de ruido diminui a resolução dos ramos da cascata, sendo observados claramente apenas os períodos mais baixos. Segundo Crutchfield et al. (1982), o efeito das perturbações é mesclar o atrator associado a dado valor de parâmetro com aqueles associados a valores vizinhos, impondo um truncamento efetivo da cascata dependente da intensidade do ruído. Períodos altos confundemse antes dos mais baixos, já que os intervalos de parâmetros comportando órbitas de períodos superiores decrescem segundo 
uma constante de escala (universalidade de Feigenbaum).

Os pontos em magenta correspondem a aproximações dos expoentes de Lyapunov por séries temporais (não fazendo uso direto da dinâmica linearizada, somente disponível conhecendose o mapa subjacente), via o método de Sano-Sawada (Hegger et al., 1999, pacote TISEAN). As barras de erro são dadas pelo desvio padrão para 10 realizações distintas do ruído. Via de regra, estas aproximações tendem a superestimar os expoentes.

Uma visão global do efeito do ruído nos expoentes de Lyapunov pode ser obtida construindo um mapa de pseudocores para os expoentes, conforme a fig. 7.13. As curvas de nível para $\lambda=\{0,-0.01\}$ são indicadas com linhas pretas contínuas/pontilhadas. Estas últimas devem ser comparadas com os intervalos delimitados por estrelas vermelhas, indicando expoentes positivos calculados via análise de séries temporais.

Os resultados esquematizados nas fig. 7.13, 7.11 indicam que a transição para comportamento caracterizado por expoentes de Lyapunov positivos pode se dar mediante cenários diversos, não sendo necessariamente exacerbada por valores altos de ruído. $\mathrm{O}$ alisamento da dinâmica puramente determinista pelas perturbações se faz uma vez mais evidente, com a perda de janelas periódicas, bem como na tendência a uma curva contínua para os expoentes na cascata principal (correspondente à transição tônico-bursting via duplicações de período).

\subsection{Robustez do mecanismo}

Um comportamento interessante exibido pelo modelo, sugerido no diagrama de bifurcações 7.12, consiste em situações para as quais a dinâmica determinista não exibe atividade em bursts, mas mediante a adição de ruído passa a apresentá-la. Tomase como exemplo a situação descrita pela figura 7.14, onde o sistema possui como atrator uma órbita periódica estável (note que a cor da trajetória indica o tempo, de modo que após ser disparado um burst transiente, o modelo apresenta comportamento tônico). Na redução unidimensional, este cenário corresponde à presença de uma órbita periódica de período baixo ao final do ramo $\mathrm{P}$, tipicamento ao redor do ponto fixo instável (evidentemente, após o ganho de estabilidade deste, há uma órbita periódica de período um). 


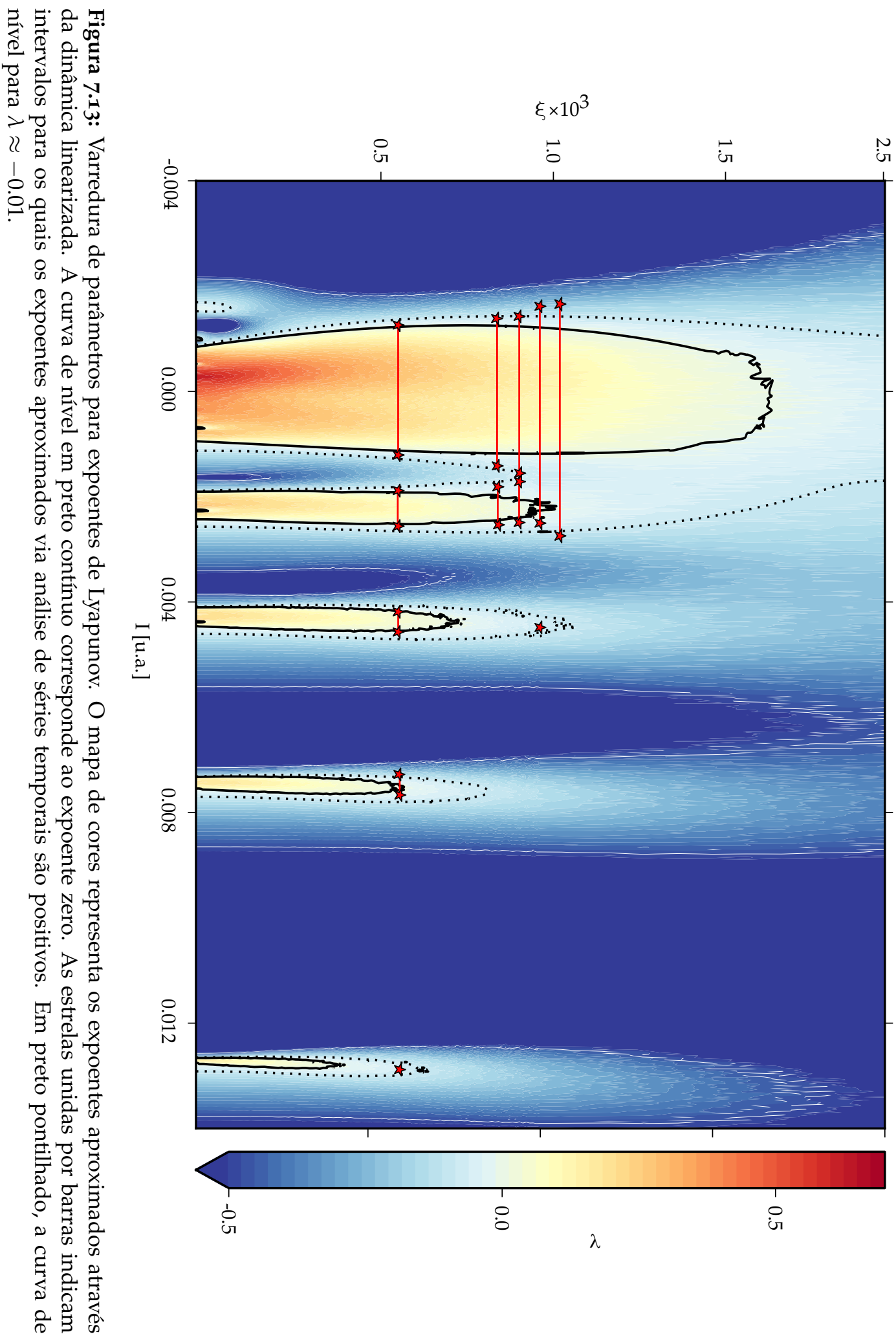




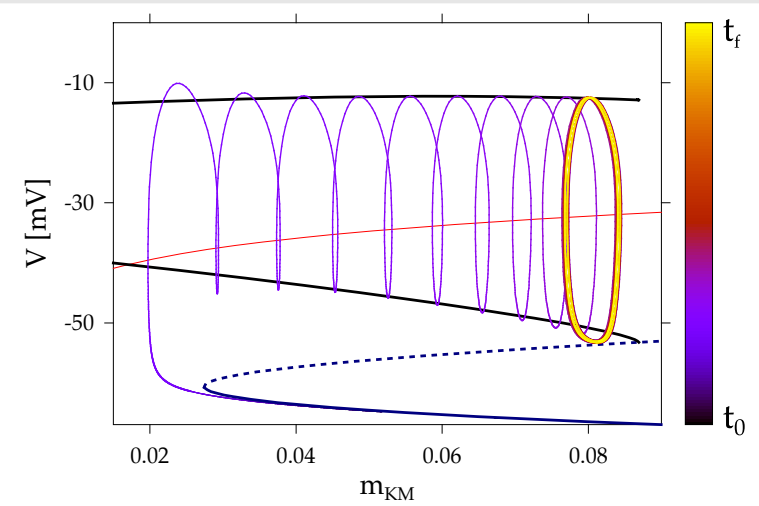

Nesta região de parâmetros, ocorre a cascata de duplicações de período que leva de comportamento tônico a disparo em bursts. No caso, tem-se uma órbita de período 4 (duas duplicações de período a partir do ponto fixo estável), conforme a curva vermelha nos primeiros painéis da fig. 7.15. Na fig. 7.15, mostram-se simulações do mapa unidimensional para esta situação, sem (ESQ):e com (DIR):adição de ruído. Além de bursting induzido pelas perturbações, obtêm-se expoentes de Lyapunov positivos.
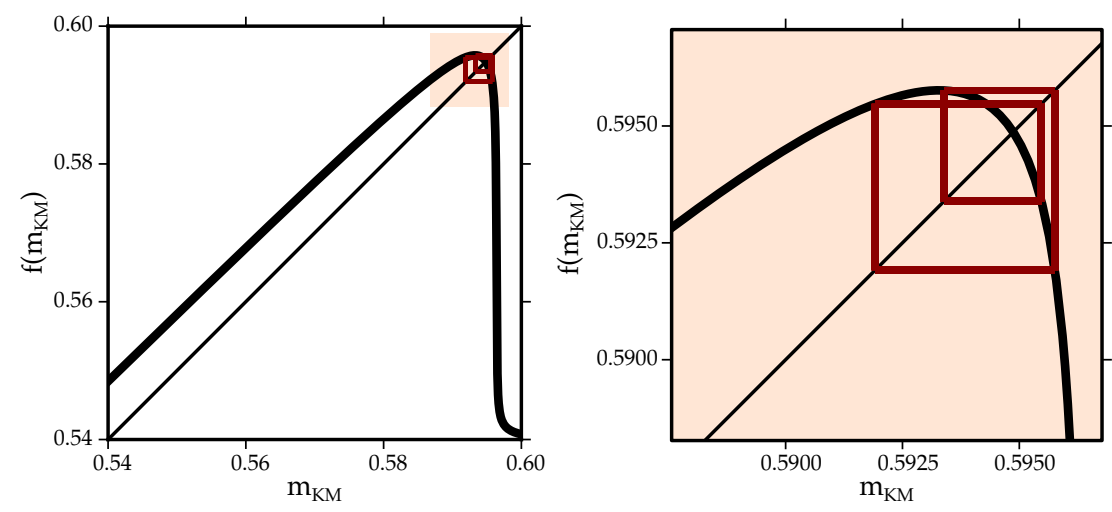

Uma maneira alternativa de descrever a dinâmica consiste em determinar a distribuição estacionária de probabilidades, aproximada por histogramas de um número grande $\left(\approx 1 \times 10^{7}\right)$ de iterados do mapa mediante a aplicação de ruído. Para o sistema determinista, evidentemente, a distribuição consiste em picos $\delta(x)$ sobre os pontos periódicos.
Figura 7.14: Projeção do fluxo para um caso onde o modelo apresenta disparo tônico (fig 7.1ESQ). Condições iniciais próximas ao ramo de equilíbrios $\mathcal{E}$ evoluem com trajetórias análogas às de um burst, sendo entretanto atraídas para o ciclo limite no final da variedade de disparos $\mathcal{L}$.

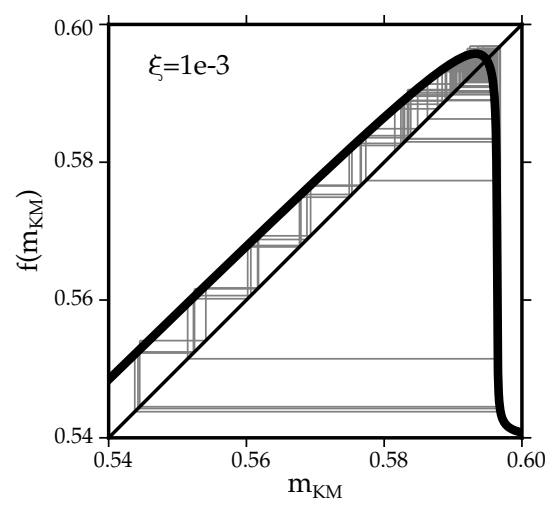

Figura 7.15: Bursts induzidos por ruído, em um caso para o qual o modelo determinista apresenta uma órbita periódica correspondente a disparo tônico de período 4 (vermelho). Mediante adição de ruído suficiente, obtém-se disparo em bursts (DIR), bem como expoentes de Lyapunov positivos. 

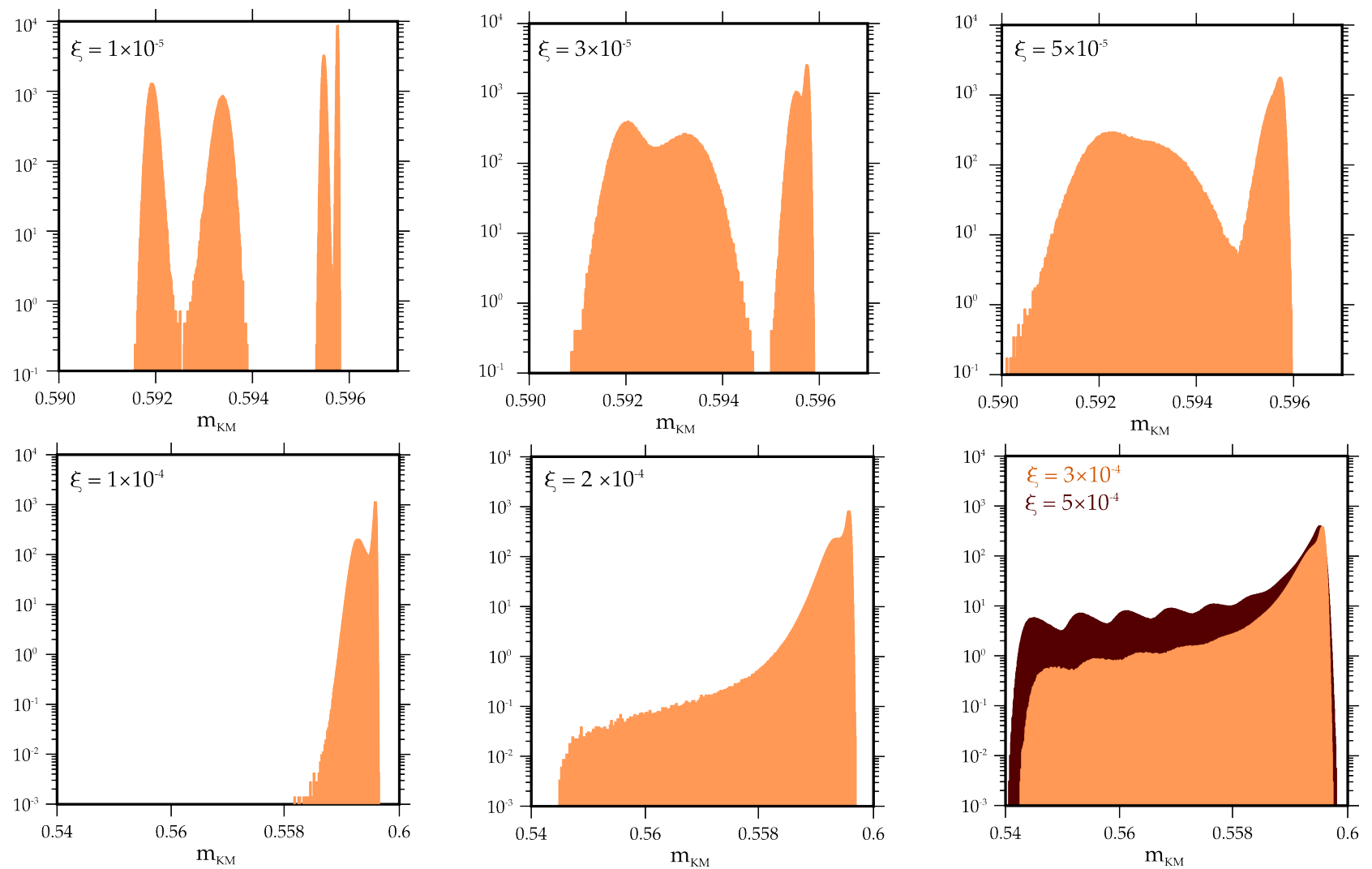

Figura 7.16: Distribuições estacionárias para um caso do modelo que possui uma órbita periódica de período 4 na situação sem ruído , bem como bursting induzido por ruído para perturbaçõe mais altas (fig. 7.15).

Histogramas para vários valores de ruído no caso de uma órbita estável de perído 4 (fig. 7.15) podem ser vistos na figura 7.16. Para perturbações pequenas, têm-se ainda picos concentrados ao redor da órbita periódica, caracterizando comportamento semiperiódico: o sistema visita as "ilhas" correspondentes a cada um dos picos de maneira regular. Entretanto, aumentando o ruído picos vizinhos eventualmente coalescem, dando origem a distribuições características de órbitas de período 2 (distribuição bimodal). Para perturbações mais altas, a dinâmica passa a ocupar um volume substancialmente maior do espaço de estados, chegando eventualmente a exibir os picos associados à órbita bursting correspondente as imagens do ramo D (praticamente horizontal) do mapa. Mudanças qualitativas na distribuição, associadas à impossibilidade de resolver duplicações de período nos diagramas de bifurcação ruidosos (fig. 7.12), são indicativas de bifurcações estocásticas tipo P (Arnold, 1995; Crauel e Gundlach, 1999).

Considerando finalmente as figs. $7 \cdot 11,7.12$, bem como as 
distribuições de probabilidade na fig. 7.16, evidencia-se o fato de que o ruído tende a truncar a estrutura fina determinista, desvanecendo detalhes das distribuições estacionárias associadas a cada atrator. Em geral, as flutuações aumentam o intervalo de parâmetros compatível com atividade irregular, destruindo janelas periódicas, sem porém induzir comportamento regular em intervalos originalmente correspondentes a dinâmica caótica.

Desta maneira, as instabilidades locais associadas tanto à presença de caos determinístico quanto a repulsores regulares aumentam a observabilidade de regimes com expoentes de Lyapunov positivos na presença de ruído. Esta observação é determinante na discussão de critérios (a serem apresentados oportunamente) para separar caos induzido por ruído de comportamento regular mascarado por ruído, introduzindo a noção de escala e localidade como fundamentais. 



\section{Capítulo 8}

\section{Discussão}

O ponto de partida deste trabalho consistiu em investigar, através de modelos eletrofisiologicamente realistas, se a origem da irregularidade na dinâmica de neurônios biológicos se deve a processos caóticos ou aleatórios. Inicialmente, tinha-se por hipótese que o comportamento caótico emergia devido à perturbação de uma órbita periódica estável, ao redor da qual existiam regiões com sensibilidade às condições iniciais - de acordo com os trabalhos em caos induzido por ruído (Liu et al., 2002; Tél et al., 2008). No modelo para neurônios do sTG estudado, as oscilações ocorrem em um espaço de fase com 12 dimensões. Entretanto, devido à presença de uma órbita periódica fortemente atrativa, o comportamento estacionário é reduzido a um atrator de baixa dimensão. O mesmo ocorre com os atratores reconstruídos a partir de séries temporais experimentais (Selverston et al., 2000).

Para investigar este fenômeno, foram desenvolvidos experimentos numéricos sobre o modelo determinístico original. Estes experimentos consistiram em introduzir perturbações instantâneas nas variáveis dinâmicas, a fim de determinar sua influência no comportamento global do modelo. Esta metodologia mostrou-se adequada para reproduzir as propriedades de codificação de informação encontradas em neurônios que disparam em bursts, corroborando resultados experimentais coletados no Laboratório de Fenômenos não-Lineares do IFUSP (Carelli, 2008; Brochini et al., 2011).

Uma adaptação deste método permitiu escolher quais condutâncias seriam sensíveis ou não às perturbações, "dissecando" o modelo e revelando o papel fundamental de correntes de dinâmica lenta na codificação de informação. Estes resultados 
foram posteriormente confirmados experimentalmente por outro pesquisador do grupo (Viegas, 2011).

Esta abordagem exploratória inicial desdobrou-se em duas frentes: a primeira consistiu em estudar a fundo os bancos de dados de modelos neuronais, a fim de determinar se órbitas caóticas estavam presentes no espaço de estados discretizado, coexistindo entretanto com órbitas periódicas fortemente atrativas. Foi desenvolvido um método (Marin et al., 2013) para determinar a presença de multiestabilidade nestes bancos de dados, usando uma técnica híbrida embasada na teoria de bifurcações e varreduras por força bruta. A aplicação destas técnicas mostrou-se frutífera, permitindo estender um banco de dados preexistente (Doloc-Mihu e Calabrese, 2011), incluindo informação acerca de coexistências entre regimes quiescentes e de disparo em bursts. Por outro lado, constatou-se a proeminência de comportamento multiestável sobre monoestável no banco de dados, levantando dúvidas sobre o esquema de classificação apresentado em trabalhos como os de Prinz et al. (2003a); Doloc-Mihu e Calabrese (2011). Paralelamente a estes resultados, foi feita uma análise preliminar de CPG construídos a partir de unidades multiestáveis, determinando que a topologia de acoplamento em mútua inibição pode servir como um mecanismo de proteção da rede, previnindo disfuncionalidades associadas a coexistência entre bursting e equilíbrios estáveis.

A segunda frente consistiu em construir um modelo simplificado, preservando apenas os mecanismos eletrofisiológicos fundamentais de geração de bursts no modelo completo. Utilizaram-se então argumentos geométricos para dissecar o efeito de perturbações aleatórias na dinâmica determinista. Verificou-se que o modelo tridimensional proposto encaixava-se em um cenário de excitabilidade envolvendo bifurcações sela-nó e homoclínica - costumeiramente chamado de square bursting. Desta forma, adotou-se um modelo conhecido (Izhikevich, 2006; Medvedev, 2006; Hitczenko e Medvedev, 2009) para este cenário, juntamente a uma aproximação macroscópica via equações de Langevin para a cinética dos canais iônicos.

A análise geométrica da parte determinista deste modelo mínimo, juntamente com simulações considerando o forçamento estocástico, propiciou determinar um mecanismo generativo para as assinaturas neuronais - padrões estereotipados nos mapas de retorno para os intervalos interspike - em bom acordo com 
resultados experimentais, sem a necessidade de ajuste fino de parâmetros. A essência do mecanismo consiste na presença de trajetórias canard no modelo determinista, correspondentes a órbitas que evoluem sobre estruturas instáveis no espaço de estados, dando origem a burstlets no potencial de membrana. A consideração de ruído mostrou-se fundamental, fazendo com que estas regiões de comportamento transiente sejam visitadas, revelando detalhes ricos da dinâmica.

A fim de determinar em que condições as irregularidades observadas no modelo estão associadas ao caráter determinista da dinâmica, ou se efeitos estocásticos são predominantes, procedeu-se reduzindo o fluxo a uma dinâmica discreta unidimensional. Devido ao caráter expansivo de estruturas regulares como selas ou repulsores, foi possível obter expoentes de Lyapunov positivos mediante a adição de ruído, mesmo em modelos que não apresentam conjuntos usualmente classificados como caóticos - sejam estes atratores ou repulsores.

\subsection{Estocasticidade}

Em neurônios isolados, a principal fonte de aleatoriedade está associada ao chaveamento dos canais iônicos, devido à ausência de bombardeamento sináptico e controle de parâmetros nas condições experimentais. A modelagem desta classe de ruído está associada ao tipo de descrição e escala adotados para o processo de chaveamento, podendo ir de injeções aleatórias de corrente em modelos $\mathrm{HH}$, passando por esquemas cinéticos para a dinâmica de subunidades em canais individuais, até a dinâmica molecular das proteínas e íons envolvidos. Para o tipo de discussão apresentado nesta tese, a origem e forma particulares do ruído não são determinantes, de modo que buscou-se um modelo minimamente plausível que se encaixasse nas EDO associadas aos modelos $\mathrm{HH}$ empregados. Esta abordagem, detalhada no apêndice A.4 levou a equações de Langevin, integradas com os métodos discutidos no apêndice B.1. O fato de aproximações macroscópicas desse tipo serem acuradas é discutível: em Kampen (1992), mostra-se que para processos de ruído intrínseco - que é o caso, já que o chaveamento de canais individuais não é um processo determinístico forçado por ruído externo, não sendo possível "desligar" a fonte de aleatoriedade 
- a descrição de Langevin pode não ser adequada, sendo necessárias expansões da equação mestra para obter equações diferenciais estocásticas mais acuradas. Esta imprecisão resulta na impossibilidade de derivação dos coeficientes aleatórios na equação de Langevin em termos de dados experimentais. Em Fox (1997) é apresentada uma expansão similar no contexto de canais iônicos, enquanto que em Goldwyn e Shea-Brown (2011) mostra-se que, de fato, este tipo de aproximação gera EDE mais fiéis à cinética microscópica Markoviana. De todas as formas, ainda não é consensual qual tipo de descrição deva ser utilizado em modelos neuronais, ou mesmo que a descrição Markoviana seja a mais acurada ou um padrão de comparação.

Ainda assim, para os presentes propósitos, levando em conta uma população grande de canais não interagentes, e supondo um processo tipo salto onde a probabilidade de transição é proporcional ao número de canais abertos/fechados, a aproximação apresentada no apêndice A.4 é suficiente. Nestas condições, admite-se que a função de autocorrelação do ruído seja realmente singular, ou seja uma distribuição $\delta(t)$, de modo que o efeito para amplitudes pequenas de ruído é apenas um deslocamento instantâneo de estado. Evidentemente, para amplitudes suficientemente grandes aparecem efeitos associados a alterações no campo.

\subsection{Caos e ruído}

O formalismo mais adequado para a análise do efeito de ruído em modelos deterministas é o dos sistemas dinâmicos aleatórios (Arnold, 1995; Crauel e Gundlach, 1999). A grosso modo, há duas abordagens para unificar a teoria dos sistemas dinâmicos e a análise estocástica clássica (preocupada com soluções individuais de equações diferenciais estocásticas). A mais "antiga", denominada análise fenomenológica (P-analysis) está diretamente associada aos métodos da teoria dos processos aleatórios, envolvendo estudar trajetórias para todas as (infinitas) possíveis realizações de ruído no sistema. Desta forma, procura-se determinar a evolução temporal de distribuições de probabilidade, em particular se alguma distribuição estacionária, independente do estado inicial, é atingida para $t \rightarrow \infty$. Caso exista, esta distribuição deve ser sensível a variações nos 
parâmetros (tanto da dinâmica determinista quanto do ruído), sendo alterações qualitativas na forma da distribuição definidas como bifurcações estocásticas fenomenológicas (P-bifurcations).

A segunda abordagem, denominada análise Dinâmica, leva a noções mais próximas àquelas da teoria clássica dos sistemas dinâmicos, e envolve a análise da mesma realização do ruído sobre todos os estados do sistema, ou seja, tratando um ensemble de sistemas dinâmicos não autônomos (um para cada possível realização do ruído). Passa-se então à generalização do conceito de fluxo para sistemas aleatórios, considerando que este é uma função não apenas do tempo e estado, mas também da amostra de ruído. Assim como estruturas invariantes - pontos de equilíbrio, ciclos-limite - são a base para a análise geométrica de sistemas deterministas, medidas invariantes desempenham o mesmo papel no caso estocástico. É possível determinar a estabilidade local de medidas via expoentes de Lyapunov, analogamente ao caso sem ruído. Bifurcações estocásticas dinâmicas (D-bifurcations) envolvem então mudanças na estabilidade destas medidas, associadas a trocas de sinal nos expoentes de Lyapunov.

Conjectura-se que o aparecimento de caos no modelo reduzido esteja associado a ocorrência de bifurcações estocásticas tipo D. Geometricamente, argumentou-se que trajetórias canard eram responsáveis pela presença de sensibilidade a condições iniciais e, com um nível suficiente de ruído, a probabilidade de excursões longas envolvendo estas trajetórias (instáveis) tornase grande o suficiente para competir com a dissipatividade do atrator (bursting periódico), dando origem a expoentes de Lyapunov positivos - justamente o ponto de bifurcação estocástica tipo D. Segundo a teoria dos sistemas dinâmicos estocásticos, pode-se inclusive definir um atrator estocástico (evidentemente dependente do tempo e da realização do ruído). Este atrator estranho é qualitativamente muito similar àquele obtido no caso de caos no sistema sem ruído.

Um ponto a ser explorado é o papel de bifurcações estocásticas na redução unidimensional. Na figura 7.11(ESQ), determina-se a variação no expoente de Lyapunov em função da intensidade do ruído, para um caso que na situação determinista apresenta uma órbita periódica de periodo 4. Eventualmente, o expoente muda de sinal, e tem-se caos induzido por ruído $\left(\xi \approx 5.5 \times 10^{-5}\right)$. Considerando os histogramas 7.16 , nota- 
se que justamente próximo a esse valor ocorre uma mudança qualitativa na distribuição, com a perda de resolução da órbita de período quatro difusa, para uma órbita de período dois. Há descrições de sistemas nos quais bifurcações estocásticas tipo P e D não ocorrem simultaneamente (Crauel e Gundlach, 1999), entretanto ainda não foram encontrados trabalhos demonstrando a (im)possibilidade de ocorrência simultânea.

As situações que envolvem caos devido à visitação de trajetórias canard (ramo expansivo nas reduções unidimensionais) tipicamente nas adições de spikes - são naturalmente "estreitas" no espaço de parâmetros, requerendo um balanço fino entre as dinâmicas rápida e lenta: o fluxo, ao final da variedade de disparos $\mathcal{L}$ deve efetuar a última rotação (spike) e pousar sobre uma vizinhança do ponto de bifurcação homoclínica (do limite singular). Aparentemente, este equilíbrio delicado deve ser destruído mediante a adição de ruído.

Há duas considerações em jogo: primeiramente, no caso de modelos nos quais a fase ativa dos bursts é interrompida via a ativação de uma corrente hiperpolarizante (Potássio lento $\mathrm{K}_{\mathrm{M}} \mathrm{ou}$ Potássio dependente de Cálcio $\mathrm{K}_{[\mathrm{Ca}]}$ ), quanto mais próximo do final de um burst maior a fração de canais deste tipo abertos. Assim sendo, as flutuações são proporcionalmente menores $(\sqrt{n} / n \stackrel{n \rightarrow \infty}{\longrightarrow} 0)$, considerando modelos mais realistas com ruído dependente do estado.

Nesta situação, o ruído dispersa os estados ao longo do ramo principal (início dos bursts), efetivamente aumentando a irregularidade, já que esta dispersão é amplificada pela dinâmica do ramo expansivo (conforme os mapas de retorno 7.8), sem contudo destruir o cenário ao final do burst.

A segunda possibilidade refere-se simplesmete ao fato do ruído efetivamente mesclar regimes deterministas para valores adjacentes de parâmetros, fazendo com que visitas ao ramo expansivo se deem mesmo sem a conjunção de valores de parâmetros das dinâmicas rápida e lenta. Considerando ambos contextos, a adição de ruído multiplicativo deve efetivamente ampliar a região do espaço de parâmetros comportando atividade caótica (expoentes de Lyapunov positivos).

Nas figuras 7.11, 7.13 é possível observar que níveis de ruído acima de $2 \times 10^{-3}$ tendem a ter um efeito regularizador da dinâmica (perda de expoentes de Lyapunov positivos). Con- 
siderando a distribuição de probabilidades para flutuações altas (último painel da fig. 7.16), infere-se que esta diminuição se deve ao maior envolvimento do ramo dissipativo na dinâmica - as imagens do trecho com derivada próxima de zero correspondem aos picos cada vez mais pronunciados na distribuição, e a contração alta contribui negativamente para $\lambda$.

Espera-se que, conforme o termo estocástico se torne dominante sobre o determinista, a dinâmica passe a ter caráter predominantemente aleatório. Processos estocásticos possuem Entropia de Kolmogorov-Sinai infinita e, consequentemente o expoente de Lyapunov associado deve também ser infinito (teorema de Pesin). Esta aparente contradição (não se observa crescimento dos expoentes para ruídos muito altos, fig. 7.13) vem do fato do estimador utilizado para $\lambda$ ir a zero para um processo puramento difusivo, já que uma separação entre trajetórias proporcional a $\sqrt{t}$ não corresponde a uma divergência expoencial, desaparecendo no limite de trajetória longas. Este é um mais indicador de que para apreciar corretamente os efeitos de ruído, devem-se levar em conta considerações de escalas espaço-temporais: para tempos curtos, a derivada de um crescimento difusivo proporcional a $\sqrt{t}$ diverge, recuperando o expoente infinito esperado.

Em suma, a diferença fundamental entre expoentes de Lyapunov deterministas e estocásticos consiste nos primeiros estarem associados a médias sobre atratores determinísticos, enquanto os segundos a médias sobre medidas invariantes (convergência garantida para sistemas ergódicos, via teorema de Oseledets). Atratores deterministas são usualmente conjuntos de dimensão reduzida (em comparação com a do espaço de estados). Por outro lado, modelos estocásticos com medidas invariantes geram trajetórias itinerantes ao longo de grandes porções do espaço de estados, incluindo potencialmente regiões expansivas, mesmo quando o "esqueleto" determinista apresenta apenas dinâmica regular de baixa dimensionalidade.

Enfatiza-se que as aproximações dos expoentes de Lyapunov via análise de séries temporais (estrelas vermelhas, fig. 7.13) tendem a superestimar os valores de $\lambda$ (ver também fig. 7.12), fornecendo expoentes positivos para todos os valores acima de uma curva de nível de $\lambda<0$. Evidentemente, não é possível recorrer às aproximações precisas via iteração no espaço tangente dadas séries experimentais, para as quais não se conhece 
a dinâmica linearizada. O emprego de métodos envolvendo noções de escala, como e-entropy (Gaspard e Wang, 1993), Finite Size Lyapunov Exponents (Boffetta et al., 2002) ou Scale-Dependent Lyapunov Exponents (Gao et al., 2006), faz-se impreterível na determinação do carater aleatório ou determinista de séries temporais experimentais.

A questão de comportamento caótico poder ou não ser induzido por perturbações estocásticas não é inédita, e dado o número de trabalhos e argumentações distintas mostra-se de cunho praticamente filosófico ${ }^{1}$. Resultados numéricos de MayerKress e Haken (1981); Crutchfield et al. (1982) sugeriram a possibilidade de, na presença de ruído, expoentes de Lyapunov positivos ocorrerem para conjuntos de parâmetros maiores do que no caso determinista. Um primeiro tratamento sistemático de caos em sistemas dinâmicos aleatórios deve-se a Eckmann e Ruelle (1985), associando comportamento caótico à presença de sensibilidade a condições iniciais (expressa por expoentes de Lyapunov positivos) e flutuações limitadas - sem portanto impor condições aos atratores do sistema determinista subjacente. Neste contexto, os resultados numéricos anteriores podem ser considerados como "caos induzido por ruído".

Na fig. 7.9, mostra-se um caso da redução unidimensional no qual a dinâmica determinista apresenta apenas uma órbita periódica estável e, mediante perturbações, o envolvimento do ramo expansivo na dinâmica por tempo suficiente vem a gerar um expoente positivo. Esta situação é similar àquela descrita por Crutchfield et al. (1982), na qual ocorre truncamento da cascata de adição de período (principal, $2^{n}$ ) do mapa logístico devido ao ruído, com eventuais $\lambda>0$. Neste caso, não há presença de órbitas periódicas instáveis de todos os períodos (caos no sentido de Period Three implies Chaos, Li e Yorke, 1975, reminiscente de ferraduras de Smale/emaranhados homoclínicos - ou seja, conjuntos caóticos no sentido usual). A presença de expoentes de Lyapunov positivos é uma decorrência do simples fato de conjuntos regulares não-atratores - como selas ou repulsores - possuírem algum caráter expansivo. Tendo isso em conta, propôs-se mais recentemente (Gao et al., 1999a,b, 2006; Tél et al.,

\footnotetext{
${ }^{1}$ o mesmo pode-se dizer da própria definição de caos... Para um exemplo de discussão recente, ver Ruelle (2009a); Dyson (2009); Ruelle (2009b); Yorke (2009).
} 
2008) considerar como caos induzido por ruído apenas situações envolvendo conjuntos caóticos não-atratores, ou seja expoentes de Lyapunov positivos devidos a excursões, mediadas por ruído, a transientes caóticos. Segundo esta interpretação, a adição de ruído pode tanto fazer com que novos regimes caóticos surjam no espaço de parâmetros, inibindo cascatas completas de adição de perído via "antecipação" do comportamento caótico, ou simplesmente mascarar a dinâmica regular (apesar dos expoentes positivos) subjacente à cascata .

Para determinar a presença ou não de caos, Tél et al. (2008); Lai e Tél (2011) sugerem levar em conta a fractalidade, uma propriedade indissociável da dinâmica caótica. Desta forma, o fenômeno de caos induzido por ruído estaria necessariamente associado a situações de ruído baixo, já que perturbações intensas destroem a estrutura fractal. A noção de escala também está fundamentalmente presente nesta argumentação: o efeito de ruído (baixo) é impor uma escala limite de resolução no espaço de estados, abaixo da qual as trajetórias preenchem todo o espaço, características de um processo puramente aleatório. Entretanto, Ben-Mizrachi et al. (1984) observaram que flutuações pequenas não modificam as características fractais da dinâmica caótica. Em suma, o cenário de Tél-Lai para caos induzido por ruído implica numa união, devida às perturbações, da variedade instável de uma sela caótica com atratores regulares, gerando um atrator estendido com sensibilidade a condições iniciais. Billings e Schwartz (2002) mostram que este cenário pode também ocorrer em sistemas apresentando apenas selas e atratores regulares, nas proximidades de valores de parâmetros para os quais as respectivas variedades estáveis e instáveis interceptam-se. Na redução unidimensional do modelo neuronal, os expoentes positivos obtidos na vizinhança do ponto de acumulação da cascata se encaixam neste cenário.

\subsection{Assinaturas}

O mecanismo discutido no capítulo 6 permite a geração de disparo em bursts irregulares com assinaturas complexas, em termos de um modelo de condutâncias tridimensional, considerando uma aproximação macroscópica para o chaveamento aleatório dos canais iônicos. O ruído desempenha papel fun- 
damental: apesar do arcabouço determinista (esqueletos) comportar atividade complexa, esta riqueza dinâmica é usualmente suprimida pelo caráter dissipativo dos atratores correspondentes a atividade bursting ou de disparo tônico. O ruído desvela então a dinâmica transiente, "dando carne" ao esqueleto e gerando padrões irregulares nas assinaturas dos IsI. Este mecanismo aplica-se a quaisquer modelos exibindo bursting via cenário sela-nó/homoclínica, conforme pode ser visto na figura 8.1, na qual são apresentadas as assinaturas geradas pelos modelos de Butera et al. (1999) para neurônios do complexo préBötzinger do tronco cerebral, bem como do conhecido modelo adimensional de Hindmarsh e Rose (1984) - ambos square bursters.

Figura 8.1: Assinaturas dos modelos de (ESQ) Butera et al.

(1999), para neurônios do complexo pre-Bötzinger do tronco cerebral; e (DIR)

Hindmarsh e Rose (1984).

Ambos se enquadram no cenário sela-nó/homoclínica, para o qual se aplica o cenário descrito no capítulo 6.

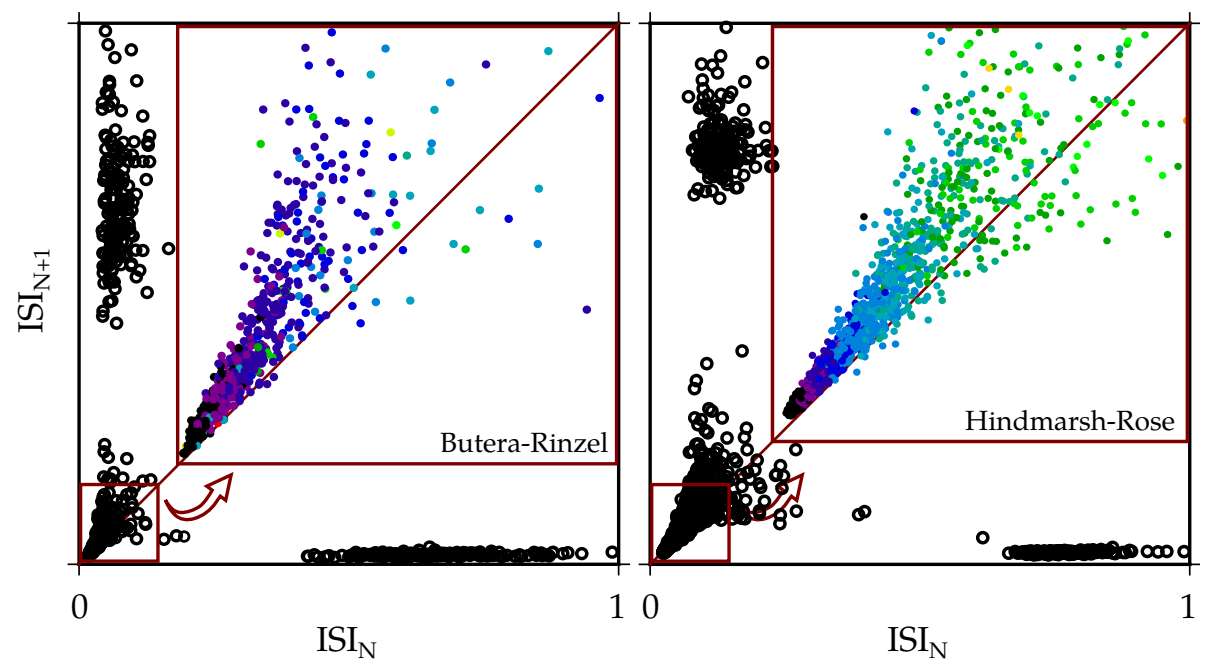

No modelo discutido, os esqueletos (fig. 6.8) são a imagem da transformação de retorno n-ISI, aplicada ao conjunto de intersecções da hipersuperfície $\dot{V}_{\mathrm{M}}=0 \mathrm{com}$ as variedades instáveis de selas (pertencentes ao ramo central da curva de equilíbrios) e seus iterados (fig. 6.7). Enfatiza-se a robustez do esqueleto a flutuações nos parâmetros: por estar intrinsicamente ligado à estrutura de bifurcações do modelo, sua estrutura geral persiste mesmo após transições bursting-tônico (associadas ao ganho de estabilidade do ponto fixo na redução unidimensional). Desta forma, as assinaturas serão essencialmente as mesmas para cenários de bursts induzidos por ruído (Hitczenko e Medvedev, 2009), no qual o sistema dispara tonicamente na ausência de perturbações. Este parece ser o caso para o neurônio LP da fig. 
6.1, dada a presença de bursts muito longos (por vezes mais de 100 spikes) acompanhados por períodos de hiperpolarização comparativamente curtos.

A atividade bursting pode ser gerada através de mecanismos geométricos distintos daquele apresentado (sela-nó / homoclínica), requerendo tratamentos específicos. Assim mesmo, é possível prever características gerais das assinaturas utilizando a metodologia proposta. Como um exemplo, considere-se o cenário de parabolic bursting, onde o ramo de equilíbrios $\mathcal{E}$ e a variedade de disparos $\mathcal{L}$ perdem estabilidade via bifurcações sela-nó em ciclo invariante (SNIC). Neste caso, a proximidade à bifurcação ao começo/final da variedade de disparos dá origem a uma série temporal de ISI em forma de $U$, sendo refletida na assinatura como clusters abaixo da bissetriz (conforme a figura 8.2) com ISI crescentes similares a "subida" observada na assinatura de square bursters. Por outro lado, como não há a parte central (selas) do ramo de equilíbrios para bursters SNICSNIC, o mecanismo de geração de burstlets não se faz presente.
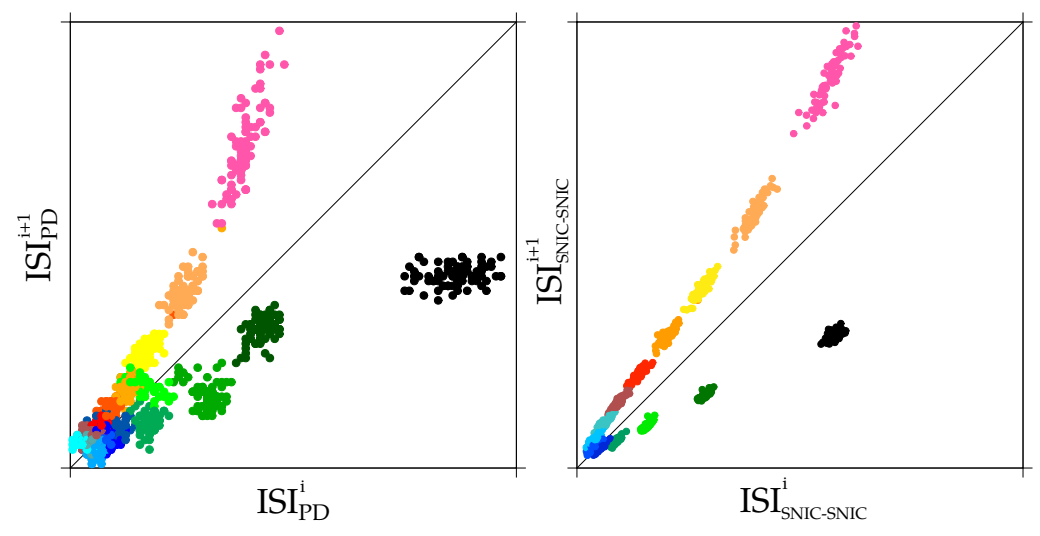

Mostrou-se desta forma que cenários de bifurcações distintos para bursting (sela/homoclínica, SNIC/sNIC) dão origem a assinaturas distintas. Isto sugere que assinaturas obtidas experimentalmente podem ser usadas para determinar a qual classe dinâmica o sistema pertence. O fato da assinatura de neurônios PD no circuito intacto (fig. 8.2) se alterar quando estes são isolados (fig. 2.4), corrobora esta hipótese, assim como como a sensibilidade destas assinaturas a alterações sutis na conectividade do circuito (Szücs et al., 2003). Outra evidência do cenário SNIC-SNIC em neurônios PD no circuito intacto é a ausência de burstlets (Szücs et al., 2003, fig. 4A).
Figura 8.2: Assinaturas para (ESQ) neurônios PD na rede intacta, e (DIR) modelo mínimo para cenário SNIC-SNIC (bursting parabólico). 
Possíveis extensões desta metodologia envolvem seu uso na estimativa de níveis de ruído intrínseco em células individuais, através do comportamento de escala do tamanho dos clusters nas assinaturas para diferentes níveis de ruído. Além disso, a definição e descrição precisa de burstlets pode ser usada para aperfeiçoar algoritmos de alinhamento de bursts como o apresentado em Lago-Fernández et al. (2009).

\section{Bifurcações de codimensão dois e cenários de bursting}

Para os parâmetros canônicos do modelo $\mathrm{Na}_{\mathrm{p}} \mathrm{KK}_{\mathrm{M}}$, as bifurcações de perda de estabilidade do estado quiescente (selanó) e do estado ativo (homoclínica) não estão distantes, em termos da variável lenta $\mathrm{m}_{\mathrm{K}_{\mathrm{M}}}$ (fig. 5.4). Nestas condições, $\mathrm{o}$ sistema deve estar próximo de uma bifurcação de codimensão dois: seguindo as curvas de bifurcação sela-nó e homoclínica em um espaço de parâmetros bidimensional, conforme visto no capítulo 5, determina-se no cruzamento mútuo uma bifurcação sela-nó-homoclínica (fig. 8.3). Um detalhe importante

Figura 8.3: Desdobramento da bifurcação de codimensão 2 sela-nó-homoclínica. O plano corresponde aos dois parâmetros de bifurcação, e linhas coloridas indicam curvas de bifurcações de codimensão 1. Próximo ao ponto de codimensão 2, é possível ter os cenários de bursting indicados no painel da direita, conforme a dinâmica lenta conduz o subsistema rápido através das curvas de bifurcação de codimensão 1. Adaptado de Izhikevich (2006).

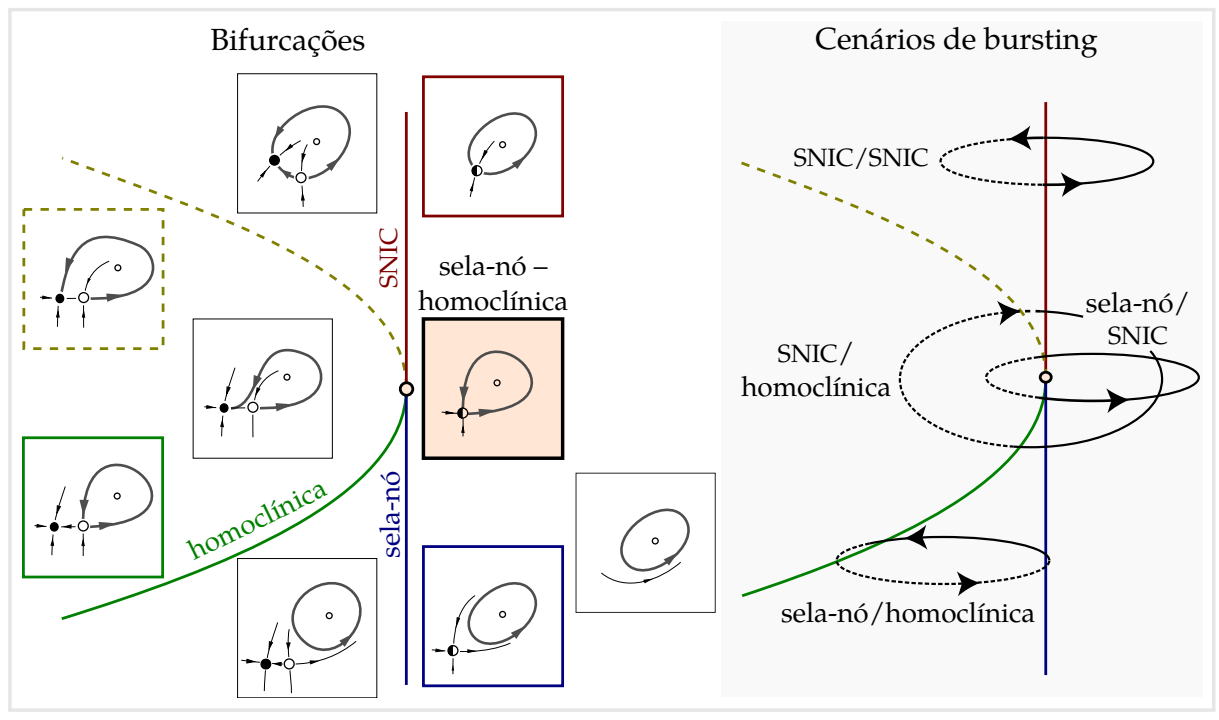

consiste na impossibilidade de existência de bursting tipo SNICSNIC em sistemas tridimensionais, devido à inexistência de biestabilidade entre equilíbrio e ciclo-limite, fazendo com que o subsistema lento tenha de ser ao menos bidimensional. $\mathrm{O}$ modelo $\mathrm{Na}_{\mathrm{p}} \mathrm{KK}_{[\mathrm{Ca}]} \mathrm{Ca}(5.7)$, proposto como primeira simplificação do modelo detalhado, é portanto um candidato a apresentar 
este cenário: seu subsistema lento consiste nas dinâmicas de remoção de Cálcio e uma corrente de Potássio dependente de Cálcio. Desfazendo a aproximação de instantaneidade nesta corrente lenta, considerando uma dinâmica de ativação dependente tanto de $\left[\mathrm{Ca}^{++}\right]$quanto de $V_{\mathrm{M}}$ (Liu et al., 1998), recupera-se uma dimensão no subsistema lento.

A bifurcação sela-nó-homoclínica determina desta forma um mecanismo para transição entre regimes distintos de bursting, conforme o painel da direita na fig 8.3. Por exemplo, se a dinâmica lenta do modelo faz com que este evolua entre as curvas de bifurcações sela-nó e homoclínica (verde e azul) temse o cenário de square bursting. "Acima" da bifurcação de codimensão 2, o sistema pode ser levado ciclicamente através da bifurcação SNIC (vermelho), dando origem ao cenário de parabolic bursting.

Apesar das séries temporais experimentais para o subsistema LP/PD indicarem acoplamento forte - de modo que o espaço de estados para o sistema acoplado está distante do produto dos espaços de cada uma das células - a possibilidade de que a mudança nas assinaturas se dê através de um mecanismo simples, associado a uma bifurcação de codimensão dois em uma célula devido à perturbação sináptica, deve ser explorada mais a fundo. $\mathrm{O}$ fato do modelo mínimo para o cenário SNICSNIC envolver um grau de liberdade a mais do que o selanó/homoclínica também é digno de nota.

A descrição de classes de excitabilidade em termos de centros organizadores da dinâmica - associados a bifurcações de codimensão maior do que um - é uma maneira elegante e promissora de determinar como as variáveis dinâmicas interagem para gerar comportamento excitável distinto, trazendo insights sobre mecanismos de cooperação/competição entre condutâncias individuais, e mesmo desvelando novas classes de excitabilidade (Franci et al., 2012).

\subsection{Abordagens via força bruta e bancos de dados}

A observação de que neurônios identificados em preparações distintas apresentam variações significativas em propriedades 
intrísecas e sinápticas - mantendo entretanto padrões de atividade surpreendentemente similares, de acordo com a funcionalidade esperada do circuito (Marder e Goaillard, 2006; Norris et al., 2011) - vem mudando paradigmas em modelagem neuronal. Ao invés da abordagem clássica, na qual se busca um modelo canônico através do ajuste fino de parâmetros via otimização (a fim de descrever traços experimentais da maneira mais acurada possível), foram propostas varreduras sistemáticas de espaços de parâmetros, classificando regimes de atividade de populações de modelos. Estas abordagens via força bruta mostraram que, de fato, conjuntos muito diversos de parâmetros podem dar origem a atividade similar e funcional, ou seja, que satisfazem vínculos determinados experimentalmente (Prinz et al., 2003a; Doloc-Mihu e Calabrese, 2011; Marder e Taylor, 2011).

\section{Bancos de dados e multiestabilidade}

A metodologia apresentada no capítulo 4, baseada na continuação numérica de pontos de equilíbrio, contorna um problema conhecido mas nunca antes atacado inerente à abordagens via varredura de parâmetros e simulação direta - como escolher condições iniciais convenientes para integração de um modelo possivelmente multiestável? A utilização de força bruta no espaço de estados sobre a própria força bruta no espaço de parâmetros (ambos com dezenas ou mesmo centenas de dimensões, em modelos eletrofisiológicos), em bancos de dados com dezenas de milhões de casos, é claramente inviável. Com a técnica desenvolvida, é possível determinar todos os equilíbrios em cada caso do modelo - tanto estáveis quanto instáveis - sem utilizar integração direta, eliminando arbitrariedades na escolha de condições iniciais e detalhando a classificação dos regimes de atividade de cada caso.

Os resultados descritos demonstram a prevalência de multiestabilidade entre estados quiescentes e oscilatórios, considerando variações (casos) sobre um modelo de neurônio de sanguessugas, parte de um CPG que controlas batimentos cardíacos do animal. A metodologia apresentada pode ser estendida a outros regimes de atividade, como disparo tônico (aplicação imediata dos mesmos protocolos, utilizando entretando continuação numérica de órbitas periódicas) e regimes irregulares. Cabe 
então conjecturar que o comportamento multiestável seja ainda mais prevalente nesta classe de modelos, levando em conta a coexistência de classes adicionais de atratores.

A questão da observabilidade dos novos atratores descritos está relacionada com os mecanismos responsáveis pela existência de multiestabilidade no sistema. A maneira mais direta de quantificar a observabilidade de determinado estado seria determinar as bacias de atração numericamente, e tentar comparar volumes no espaço de parâmetros. Para um mecanismo de biestabildiade em particular - proposto por Rinzel em Segev (1998) - é possível determinar a bacia de atração do equilíbrio via continuação numérica, já que esta é delimitada por um ciclo limite instável, que surge e desaparece em bifurcações de Hopf do próprio equilíbrio. Este é o caso para equilíbrios do tipo hyp2 (fig. 4.7) encontrados no banco de dados. Há diversos outros mecanismos para multiestabilidade descritos, cujo ingrediente fundamental consiste em determinar as estruturas instáveis que segregam os diferentes regimes de atividade. Aparentemente, pontos de sela e ciclos-sela são as mais comuns (Rinzel e Ermentrout em Segev, 1998). Outros casos descritos envolvem bifurcações sela-nó para equilíbrios e ciclos, bifurcações homoclínicas e bifurcações de toro (Meng et al., 2011; Rush e Rinzel, 1995).

Desta forma, determinar bacias de atração via um único procedimento geral mostra-se delicado, dada a variedade de cenários possíveis. Na falta de métodos diretos, pode-se voltar a aproximações via Monte Carlo, simulando o modelo com ruído e analisando estatisticamente saltos entre regimes. $O$ teste final evidentemente vêm da realização experimental: Guttman et al. (1980) mostraram que é possível chavear o axônio gigante da lula entre disparos e quiescência via pulsos curtos de corrente, motivados pela análise geométrica do modelo de $\mathrm{HH}$ que mostrou excitabilidade associada à proximidade de uma bifurcação de Hopf subcrítica (biestabilidade de equilíbrio e ciclo limite, separados por ciclo instável).

Em suma, mostrou-se que abordagens via integração de grades no espaço de parâmetros têm limitações importantes, devido à prevalência de multiestabilidade em modelos neuronais. O método apresentado para contornar estas particularidades (Marin et al., 2013), que permite encontrar todos os pontos de equilíbrio do modelo - estáveis ou instáveis, 
sem depender da escolha de condições iniciais - mostra-se de fundamental importância para futuros trabalhos com bancos de dados, extendendo esta abordagem já muito poderosa. Adicionalmente, a possibilidade de varredura de estruturas instáveis no espaço de estados é atraente para a análise de fenômenos transientes, de fundamental importância no decorrer deste trabalho, e em geral para a determinação da dinâmica na presença de ruído. Um exemplo são as órbitas canard associadas a comportamento complexo no modelo reduzido, não facilmente desveladas através de integração direta, ainda mais considerando que transientes são costumeiramente descartados em varreduras força bruta. Utilizando as técnicas de continuação numérica descritas, não somente foi possível determinar estas órbitas com precisão, mas também o arcabouço dinâmico por trás de sua existência, criação e destruição - no caso, a variedade de pontos de sela do subsistema rápido, na aproximação singular.

\section{Multiestabilidade e fisiologia}

Uma parcela grande dos casos do modelo no banco de dados de interneurônios do coração de sanguessugas apresentou multiestabilidade entre regimes de atividade. Quase 20\% dos casos envolvem coexistência entre estados de repouso e bursting e, levando em conta variações em $g_{\text {leak }}$, a parcela que envolve algum tipo de multiestabilidade chegou a mais de $90 \%$. Estes resultados complementam estudos onde se evidenciou o papel proeminente dos canais de leakage como alvos de modulação (Lu e Feng, 2011; Talley et al., 2000; Wright e Zhong, 1998), mostrando que mediante alterações nestas condutâncias não só é possível promover transições entre regimes de atividade (quiescente, bursting, tônico), mas também chavear comportamento multiestável.

A prevalência de casos multiestáveis no banco de dados é intrigante, já que estas células são responsáveis por ritmar os batimentos cardíacos do animal. Desta forma, a coexistência entre regimes oscilatórios e quiescentes pode vir a ameaçar o funcionamento adequado do CPG, que deve produzir padrões rítmicos regulares. De forma mais geral, são questionáveis os mecanismos através dos quais redes neurais, exibindo coexistência entre regimes funcionais e não funcionais, mantêm operação 
normal mediante flutuações nos parâmetros e perturbações externas, inerentes a quaisquer sistemas biológicos. Sugerese, através de simulações de redes compostas por unidades multiestáveis em mútua inibição, que a topologia half-center oscillator sirva como um mecanismo coletivo de proteção contra disfunções associadas à multiestabilidade. Mais de $95 \%$ dos HCO analisados mostraram-se robustos a este cenário, sugerindo que multiestabilidade envolvendo equilíbrios estáveis não é necessariamente incompatível com a geração confiável de padrões rítmicos.

No complexo pre-Bötzinger do tronco cerebral, há um CPG que controla ritmos respiratórios (Ramirez et al., 2007), constituído por neurônios bursters endógenos. Dada a prevalência de multiestabilidade envolvendo bursting e equilíbrios encontrada no banco de dados, e supondo que os mecanismos discutidos sejam comumente encontrados nesta classe de célula, conjecturase que patologias associadas à perda de atividade rítmica em CPG - como a síndrome da morte súbita infantil (sIDs) - (Peña et al., 2004) possam estar associadas à presença de multiestabilidade.

Por outro lado, uma série de funções implementadas por redes neuronais pode ser desempenhada de maneira mais eficiente, ou mesmo depender inteiramente, de comportamento multiestável em neurônios individuais. Módulos biestáveis são substratos para unidades de memória, chaves seletoras e componentes em centros geradores de padrão multifunção (redes neurais que podem gerar mais de um padrão rítmico funcional) (Mackie e Meech, 1985; Briggman e Kristan, 2008; Berkowitz, 2008; Venugopal et al., 2007). Exemplos destes sistemas incluem circuitos de interneurônios de sanguessugas que contribuem para geração de dois padrões de locomoção: um lento, associado ao rastejamento, e outro rápido associado a natação; em águas-vivas Aglanta digitale, multiestabilidade na dinâmica de neurônios individuais reflete-se na geração de comportamentos distintos: natação lenta enquanto se alimentam e rápida para escapar de ameaças em potencial.

\subsection{Ajustes de parâmetros e homeostase}

A extensão das técnicas de varredura de espaços de parâmetros acima descritas, bem como os resultados evidenciando o papel 
de flutuações na dinâmica neuronal, trazem contribuições para um problema fundamental em modelagem: o do ajuste de parâmetros. Evidências experimentais de que a variabilidade nos parâmetros é regra em redes e células individuais, bem como subsequentes análises em modelos (Marder e Goaillard, 2006; Norris et al., 2011; Marder e Taylor, 2011), apontam na direção de que a sinergia entre parâmetros desempenhe papel fundamental na homeostase, de modo que variações em determinada grandeza tendem a ser compensadas via mecanismos de corregulação. Neste sentido, a busca por regiões de comportamento fisiologicamente similar no espaço de parâmetros - expressa nas abordagens via gridding e bancos de dados parece o caminho a ser seguido em oposição a ajustes ótimos via minimização. Há uma possibilidade interessante, ainda não explorada, envolvendo o uso de continuação numérica no levantamento destes subespaços homeostáticos: um exemplo simples seria explorar como a atividade periódica em um CPG pode ser mantida e modulada, mediante a continuação de órbitas periódicas com o período fixo - em outras palavras, as isoperiódicas no espaço de parâmetros - sem utilizar integração direta, determinando cenários de bifurcações associados à corregulação. 


\section{Capítulo 9}

\section{Conclusão}

Processos biofísicos operando em escalas temporais diversas modulam a atividade motora e o processamento de informação em neurônios de CPG de crustáceos, dando origem a um repertório dinâmico rico. Assinaturas complexas nos ISI permitem identificar neurônios do mesmo tipo em animais de diferentes espécies sem recorrer a aspectos anatômicos - ainda que disparem bursts com propriedades estatísticas distintas. Além disso, mostrou-se que estas assinaturas são capazes de refletir alterações na conectividade da rede.

Apesar da função do CPG pilórico consistir na geração de padrões periódicos, os neurônios PD e LP sempre exibem atividade irregular quando desconectados do circuito. A análise não linear das séries do potencial de membrana de tais células isoladas indicaram a presença de sensibilidade às condições iniciais. Em um popular banco de dados de um modelo determinista destes neurônios, entretanto, prevalece comportamento periódico. Em contrapartida, uma versão estocástica do modelo pareceu recuperar tanto o comportamento irregular quanto a sensibilidade às condições iniciais.

O presente trabalho procurou esclarecer esta suposta discrepância, investigando as origens de irregularidade na dinâmica de neurônios biológicos através de modelos eletrofisiologicamente realistas.

Inicialmente, foram desenvolvidos experimentos numéricos que consistiram em introduzir perturbações no modelo determinístico original (12-dimensional). Com esta metodologia, reproduziram-se as propriedades de codificação de informação, bem como a aparente sensibilidade às condições iniciais. Estes 
resultados sugeriram que estruturas dinâmicas ricas já estavam presentes no modelo determinista. Uma adaptação do método permitiu prever quais condutâncias eram fundamentais para 0 processamento de informação, suscitando um trabalho experimental que corroborou os resultados.

Como um modelo canônico não é representativo da variabilidade encontrada nos sistemas biológicos - nos quais parâmetros podem variar em ordens de grandeza para um mesmo tipo celular -, recorreu-se à análise de bancos de dados. Foi desenvolvida uma metodologia híbrida (baseada em continuação numérica e em varreduras força bruta) para estender tais bancos de dados, que possibilitou contornar o problema da escolha de condições iniciais e revelar instâncias de multiestabilidade.

Descobriu-se que uma grande parcela do banco de dados apresentava coexistência entre regimes oscilatórios e quiescentes, representando um risco à funcionalidade do CPG. Mostrouse, contudo, que a topologia HCo aumenta a robustez do sistema contra disfuncionalidades induzidas pela presença de unidades multiestáveis.

Dada a inviabilidade de reconstruir todo o banco de dados, generalizando as técnicas de continuação numérica para incluir regimes caóticos, optou-se pelo desenvolvimento de modelos simplificados. Neste modelos, pode-se fazer valer de argumentos geométricos para determinar a presença de caos. Preservando apenas os mecanismos eletrofisiológicos fundamentais para a geração de bursts, obteve-se um modelo tridimensional exibindo o cenário de bifurcações sela nó / homoclínica (square bursting).

Modelou-se a presença de ruído através de uma aproximação da dinâmica microscópica de chaveamento dos canais iônicos, via equação de Langevin. Neste contexto, os modelos simplificados dão origem a assinaturas e burstlets similares aos observados in vivo, sem recorrer a ajustes finos de parâmetros ou a construções ad hoc para induzir comportamento caótico. A essência deste mecanismo é a dinâmica transiente rica inerente aos square bursters. Mostrou-se que o ruído induz as trajetórias a povoarem o arcabouço determinista complexo, mesmo em casos do modelo que apresentavam apenas atividade periódica na ausência de perturbações.

Como diferentes cenários de bursting (sela-nó / homoclí- 
nica, SNIC/ SNIC) dão origem a assinaturas neuronais distintas, enfatizou-se que estas podem ser usadas para determinar a qual classe dinâmica pertence dado sistema experimental. Esta hipótese foi corroborada pelo fato do neurônio PD se comportar como square burster quando isolado, e como parabolic burster no circuito intacto. Desta forma, sugere-se que estes sistemas estejam próximos a uma bifurcação de codimensão 2, que organiza os cenários de bursting sela-nó / homoclínica e SNIC/ SNIC.

Determinar se as irregularidades nos neurônios do STG se devem a processos aleatórios ou deterministas envolve, primeiramente, adotar uma definição de caos em sistemas dinâmicos estocásticos. Propõe-se a abordagem de Tél-Lai: caos induzido por ruído se deve a comportamento transiente na presença de conjuntos hiperbólicos não atratores. Assim, fazse necessário aplicar métodos de análise que levem em conta noções de escala - já que a resolução de estados é limitada pelo nível de ruído. Se este for suficiente para obliterar a fractalidade do sistema, o caráter estocástico é dominante. Caso contrário, tem-se caos induzido por ruído. Para situações em que o sistema sem ruído não apresenta conjuntos caóticos, há duas possibilidades: dinâmica regular mascarada por ruído (ausência de fractalidade) ou a criação de conjuntos caóticos pelo ruído. Dada a presença inevitável de flutuações em um contexto experimental, o simples caráter fractal da dinâmica não permite resolver entre o cenário de Tél-Lai (conjunto caótico não atrator + ruído) ou caos ruidoso (conjunto caótico atrator + ruído). 

Apêndices 



\section{Apêndice A}

\section{Sistemas dinâmicos}

Segue-se um resumo das principais definições e resultados em sistemas dinâmicos utilizados no decorrer da tese, a fim de torná-la mais acessível. Para um estudo aprofundado, recomendam-se Strogatz (2001); Abraham e Shaw (1992) (nível introdutório), bem como Guckenheimer e Holmes (1983); Kuznetsov (1995) (mais formais e abrangentes). Parte das técnicas e conceitos abordados nesta tese podem também ser encontrados, de forma mais ou menos detalhada, em Izhikevich (2006).

\section{A.1 Modelos deterministas}

\section{Preliminares e notação}

Ao construir um modelo para determinado fenômeno, inicialmente identificam-se as grandezas físicas (supostamente) importantes para a caracterização do sistema. Segundo a teoria dos sistemas dinâmicos, agrupam-se então essas ditas variáveis dinâmicas como coordenadas de um vetor $\mathbf{x}$, que determina univocamente um estado; ao espaço de todos os estados acessíveis dá-se o nome de espaço de estados ou de fases do sistema. O próximo passo na modelagem consiste em determinar a regra de evolução, denominada dinâmica, que determina a sucessão temporal de estados. Há duas abordagens possíveis, decorrentes do tratamento do tempo como uma variável contínua ou discreta.

Para o caso contínuo, a dinâmica consiste em um campo $\mathbf{f}(\mathbf{x})$ que associa a cada estado um vetor, de modo que em um

variáveis dinâmicas estado espaço de estados

dinâmica 
instante infinitesimal de tempo $\mathrm{d} t$ o estado varia com $\mathrm{d} \mathbf{x}=$ $\mathbf{f}(\mathbf{x}) \mathrm{d} t$. Note que esta definição corresponde à de derivada temporal $\mathbf{f}(\mathbf{x}) \equiv \dot{\mathbf{x}}(t)$. Deste modo, a evolução temporal

trajetória traça uma curva no espaço de estados - denominada trajetória, parametrizada como $\mathbf{x}(t)$; o conjunto de todas as trajetórias fluxo denomina-se fluxo. Desta forma, dinâmicas contínuas são descritas através de sistemas de equações diferenciais ordinárias (EDO).

Fazendo com que $\mathrm{d} t$ deixe de ser infinitesimal, considerando acréscimos discretos de uma unidade de tempo $\Delta t$, denotados por $n$, obtém-se a dinâmica discreta $\mathbf{x}_{n+1}=\mathbf{F}\left(\mathbf{x}_{n}\right)$. É costumário mapa denominar a dinâmica discreta um mapa.

parâmetros

condição inicial

séries temporais

\section{Equilíbrios, Oscilações, Bifurcações}

Em geral a dinâmica é uma função não somente das variáveis de estado, mas também de parâmetros, grandezas supostas constantes e cujo valor está geralmente associado a considerações físicas. Em modelos neuronais, por exemplo, diversas propriedades biofísicas são funções da temperatura. Entretanto, variações desta se dão em escalas temporais muito mais lentas do que a maioria dos processos eletrofisiológicos típicos, de modo que se costuma tratar a temperatura como um parâmetro do sistema.

Uma vez definidos o espaço de estados, a dinâmica e fixado um conjunto de parâmetros, é possível determinar a evolução temporal do sistema através de uma simulação: dado um estado ou condição inicial $\mathbf{x}_{0}$, obtêm-se as trajetórias $\mathbf{x}(t)$, seja através de integração (em geral numérica) no caso de sistemas definidos por EDO, seja iterando diretamente o mapa em uma dinâmica discreta. Dados então um modelo suficientemente detalhado e uma estimativa dos valores de parâmetros, o programa determinista está satisfeito: obtêm-se univocamente os valores de todas as variáveis dinâmicas, passados e futuros (séries temporais), extrapolando um dado estado inicial.

Entretanto, a descrição de um sistema através deste arcabouço teórico permite extrair muito mais informação, não apenas de particulares realizações (parâmetros fixos e dadas condições iniciais), mas do comportamento geral de toda uma classe de modelos. Este tipo de análise é focado em conjuntos especiais no espaço de estados, que são levados sobre si mesmos 
pela dinâmica: conjuntos invariantes.

conjuntos invariantes

\section{Equilíbrios e selas}

Estados isolados que são levados pela dinâmica sobre si mesmos - costumeiramente chamados de equilíbrios ou estados estacionários em fluxos e pontos fixos em mapas - são um exemplo de conjunto invariante (contendo um único elemento). Equilíbrios podem ser estáveis, instáveis ou neutros, sendo a estabilidade determinada pela tendência de estados próximos ao equilíbrio tenderem a aproximar-se, afastar-se ou permanecerem à mesma distância deste, para tempos longos.

Formalmente, a condição para pontos de equilíbrio em fluxos é dada por $\left.\dot{\mathbf{x}}\right|_{\mathbf{x}^{*}}=\mathbf{f}\left(\mathbf{x}^{*}\right)=0$. Para determinar a estabilidade, expande-se a dinâmica ao redor do equilíbrio:

$$
\mathbf{f}(\mathbf{x}+\Delta \mathbf{x})=\frac{\mathrm{d}}{\mathrm{d} t} \Delta \mathbf{x} \approx \overbrace{\mathbf{f}\left(\mathbf{x}^{*}\right)}^{0}+\frac{\partial \mathbf{f}}{\partial \mathbf{x}}\left(\mathbf{x}^{*}\right) \Delta \mathbf{x}+\mathcal{O}\left(\Delta \mathbf{x}^{2}\right)
$$

No caso linear, a expansão é exata em primeira ordem. A matriz $\frac{\partial \mathbf{f}}{\partial \mathbf{x}} \equiv \mathbf{J}$ é chamada matriz jacobiana, reduzindo-se à derivada de f no caso unidimensional. As soluções desta EDO podem ser escritas como combinações dos autovetores $\mathbf{v}_{i}$ de $\mathbf{J}$ :

$$
\frac{\mathrm{d}}{\mathrm{d} t} \boldsymbol{\Delta} \mathbf{x}=\mathbf{J} \Delta \mathbf{x} \rightarrow \boldsymbol{\Delta} \mathbf{x}(t)=\sum_{i} c_{i} e^{\lambda_{i}} \mathbf{v}_{i}
$$

onde $\lambda_{i}$ são os autovalores correspondentes a cada $\mathbf{v}_{i}$, e $c_{i}$ são constantes determinadas pelas condições iniciais.

Desta forma, a evolução da perturbação nas direções dadas por $\mathbf{v}_{i}$ está determinada pela parte real dos $\lambda_{i}$. Sejam $\left(n_{+}, n_{-}\right)$ os números de autovalores com a parte real positiva e negativa respectivamente (deixando momentaneamente de lado os casos com autovalores nulos ou repetidos). Um equilíbrio é estável somente se $\forall i, \Re\left(\lambda_{i}\right)<0$, ou seja $n_{+}=0$. Caso algum dos autovalores tenha parte real positiva, o ponto é instável. Pontos de sela são equilíbrios instáveis, mas com ao menos uma direção contrativa $\left(n_{ \pm}>0\right)$. De um ponto de sela no plano, emergem duas trajetórias importantes, localmente paralelas aos autovetores estável/instável: as variedades estável e instável. A variedade estável/instável é o conjunto (invariante) matriz jacobiana

equilíbrios

pontos fixos

Pontos de sela

variedades estável e instável de todos os estados que tendem à sela quando $t \rightarrow \pm \infty$. 
Em geral, as variedades estável/instável têm dimensão $n_{-} / n_{+}$. Equilíbrios estáveis/instáveis possuem apenas variedades estáveis/instáveis, naturalmente.

A parte imaginária dos autovalores está associada a comportamento oscilatório. Em particular, trajetórias espiralam em direção a equilíbrios estáveis com $\Im\left(\lambda_{i}\right) \neq 0$.

Na figura A.1, apresenta-se uma classificação de todos os pontos de equilíbrio para sistemas no plano, os mais utilizados ao longo da tese.

Figura A.1: Pontos de equilíbrio para fluxos bidimensionais. $\left(n_{+}, n_{-}\right)$ indicam os números de autovalores com parte real positiva e negativa, respectivamente. Pontos estáveis têm $n_{+}=0$. Selas possuem variedades estáveis e instáveis, e autovalores complexos estão associados a comportamento oscilatório. Adaptado de Kuznetsov (1995).

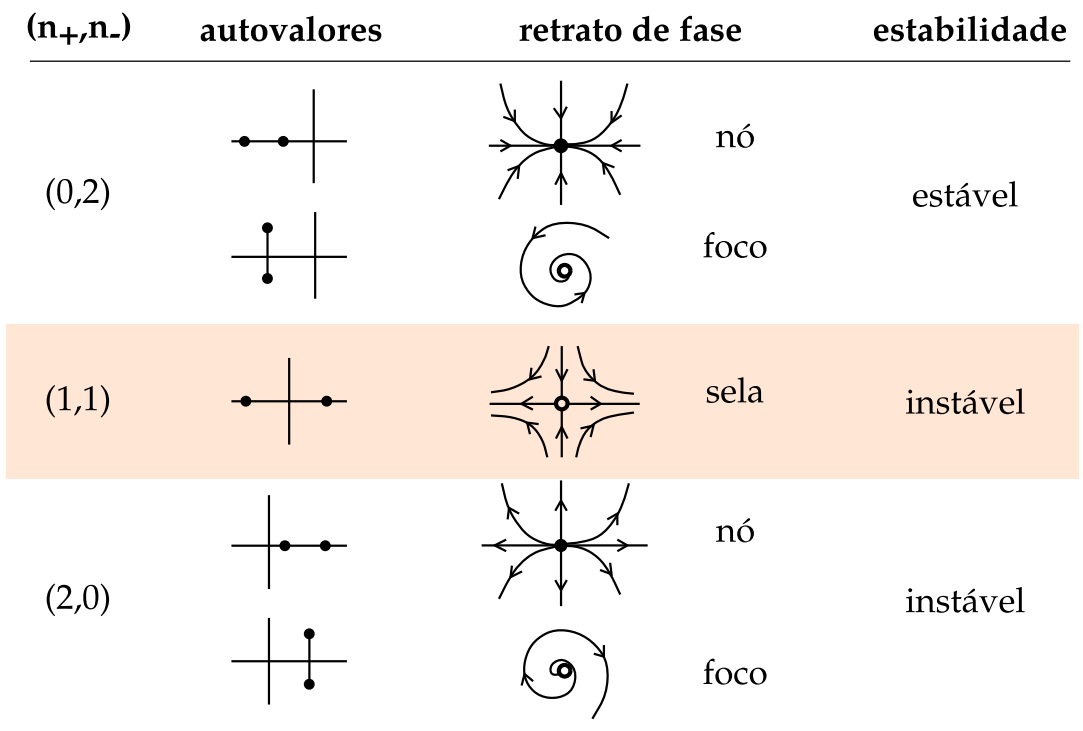

No caso de sistemas dinâmicos a tempo discreto, a análise procede da mesma maneira: em um mapa $x_{n+1}=\mathrm{f}(x)$, pontos fixos são aqueles onde $\mathrm{f}\left(x^{*}\right)=x^{*}$. A estabilidade é calculada com uma expansão em primeira ordem

$$
x_{n+1}=\overbrace{\mathrm{f}\left(x^{*}\right)}^{x^{*}}+\mathrm{f}^{\prime}\left(x^{*}\right)\left(x_{n}-x^{*}\right)
$$

de modo que um desvio de $x^{*}$ diminui/aumenta se $\left|\mathrm{f}^{\prime}\left(x^{*}\right)\right|$ for menor/maior do que um. O sinal de $\mathrm{f}^{\prime}\left(x^{*}\right)$ determina como as trajetórias se aproximam/afastam do ponto fixo: se $\mathrm{f}^{\prime}\left(x^{*}\right)<$ 0 , há uma alternância de pontos da trajetória ao redor de $x^{*}$ na direção dada pelo autovetor correspondente. Na figura A.2, estão representados os equilíbrio elementares no plano. 


\section{Oscilações periódicas}

Outro tipo de conjunto invariante corresponde a órbitas periódicas, trajetórias $\mathbf{x}(t)$ onde $\exists \tau \mid \mathbf{x}(t+\tau)=\mathbf{x}(t), \forall t$. Órbitas periódicas isoladas são chamadas de ciclos limite, podendo ser estáveis ou instáveis.

Apesar de não haver uma maneira analítica direta de determinar a localização de órbitas periódicas em sistema descritos por EDO, há uma técnica de redução dimensional, chamada de seção de Poincaré, que permite discretizar o fluxo, associandoo a um mapa com uma dimensão a menos. Desta maneira, reduz-se o problema de determinar órbitas periódicas no fluxo ao de encontrar pontos fixos em um mapa, discutido anteriormente. A seção de Poincaré é uma hipersuperfície $\Sigma$ $(n-1)$-dimensional em um espaço de estados $(n)$-dimensional, escolhida de modo que as trajetórias sempre a interceptem transversalmente. Obtém-se então um mapa através dos "furos" do fluxo sobre $\Sigma$ numa mesma direção.

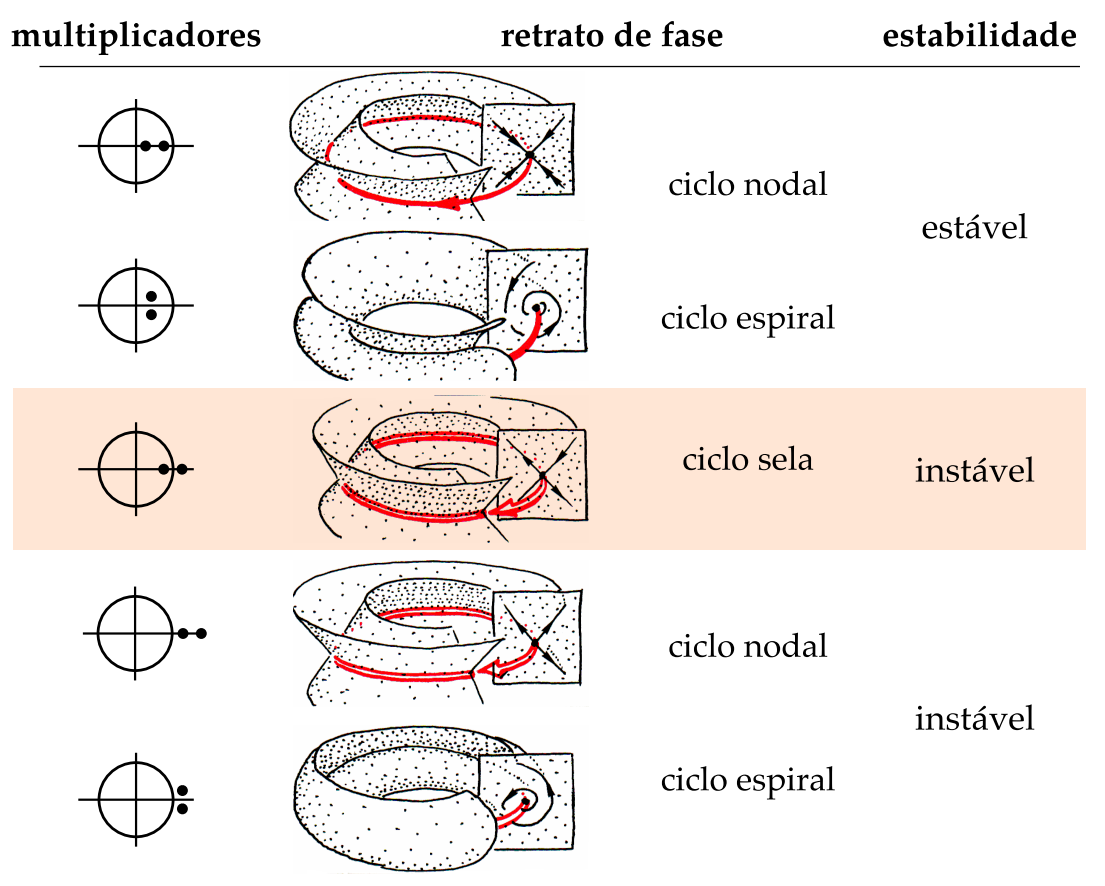

Ao calcular a estabilidade de órbitas periódicas, recorre-se à dinâmica linearizada do mapa de Poincaré. Neste caso, chamase $\mathrm{f}^{\prime}(x)$ de matriz de Floquet, e os seus autovalores de expoentes de Floquet ou multiplicadores. ciclos limite

seção de Poincaré

Figura A.2: Classificação de órbitas periódicas elementares (sem multiplicadores degenerados ou nulos), e respectivas variedades instável/estável. A estabilidade das órbitas é determinada pelos pontos fixos do mapa sobre a seção de Poincaré $\Sigma$. Adaptado de Abraham e Shaw (1992). 

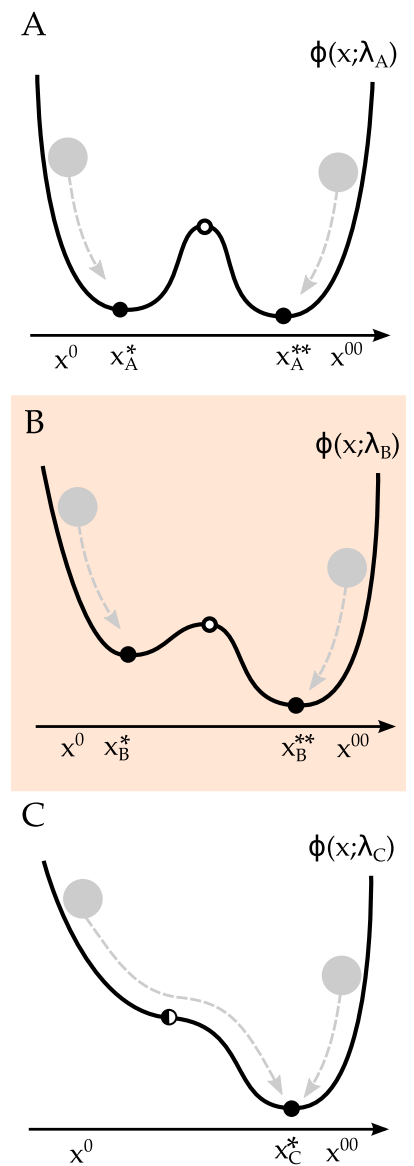

Figura A.3: Dinâmica em um potencial hipotético $\phi(x ; \lambda)$, onde $\lambda$ é um parâmetro. Variando-o de $\lambda_{A}$ a $\lambda_{B}$, não há mudanças qualitativas no comportamento do sistema, apesar da dinâmica (potencial) mudar de forma: as massas deslocam-se das condições iniciais $x_{0}$ a um dos equilíbrios estáveis $x^{*}$. Para $\lambda=\lambda_{C}$, ocorre uma bifurcação, com a coalescência de um dos equilíbrios estáveis com o instável, e o sistema passa de bi a monoestável. Variando $\lambda$ nesta mesma direção, obtém-se um classe de sistemas com dinâmicas qualitivamente iguais (monoestáveis).
Em um mapa $f(x)$, uma órbita $x_{0}^{*}, x_{1}^{*}, \ldots, x_{p-1}^{*}, x_{p}^{*}, \ldots$, com $x_{p}^{*}=x_{0}^{*}$ é chamada órbita periódica de período $p$. Note que ela corresponde a um ponto fixo do mapa $\mathrm{f}^{p}(x)$. A estabilidade de uma órbita é calculada pelo produto dos multiplicadores ao longo da órbita.

\section{Comportamento qualitativo e bifurcações}

A análise geométrica da dinâmica, através da determinação de estruturas no espaço de estados (incluindo conjuntos invariantes como equilíbrios, ciclos limite, separatrizes) permite uma caracterização mais completa do sistema do que aquela obtidas via simulação, onde é possível apenas determinar comportamento associado a conjuntos atratores (para os quais as trajetórias tendem assintoticamente). Conhecida a estrutura geométrica, é possível prever o comportamento qualitativo global do sistema, para condições iniciais quaisquer.

$\mathrm{O}$ passo seguinte na análise consiste em determinar mudanças neste comportamento qualitativo, mediante variações de parâmetros do sistema.

Um conceito fundamental neste contexto é o de equivalência topológica. Sistemas topologicamente equivalente têm o mesmo comportamento qualitativo: é possível fazer com que tenham o mesmo retrato de fase, "esticando" ou "dobrando" o espaço de estados, preservando a estabilidade ou número de equilíbrios ou ciclos.

Na figura A.3, tem-se uma representação de um poço de potencial, onde se move uma bolinha. Do painel A ao в, é variado um parâmetro $\lambda$ - o que se reflete numa mudança do perfil do potencial. Por conveniência, supõe-se $\lambda_{A}<\lambda_{B}<\lambda_{C}$. Entretanto, a dinâmica qualitativa do sistema é equivalente nos dois casos: há dois equilíbrios estáveis separados por uma sela, ou seja, dois atratores - o sistema é dito biestável (considerase dissipação neste sistema, não representada nos diagramas). Note que a sela serve como uma separatriz, já que condições inicias à esquerda/direita desta são atraídas pelo atrator $x^{*} / x^{* *}$. O conjunto de todos os estados atraídos por determinado atrator é chamado bacia de atração. Quando o parâmetro atinge o valor $\lambda_{C}$ (painel c), o sistema está na fronteira de uma mudança qualitativa de comportamento: um dos atratores e o ponto atratores

equivalência topológica

biestável

separatriz

bacia de atração 
de sela coalescem e se aniquilam, e a partir deste valor de parâmetro a dinâmica passa a ser monoestável, comportamento este que persiste para $\lambda>\lambda_{C}$. Desta maneira, há um conjunto de sistemas topologicamente equivalentes (biestabilidade) para $\lambda_{A} \leq \lambda<\lambda_{C}$, e outro para $\lambda>\lambda_{C}$ (monoestabilidade). Definese então o caso $\lambda=\lambda_{C}$ como uma bifurcação.

bifurcação

\section{Classificação de bifurações}

Bifurcações são classificadas conforme o tipo de conjunto invariante envolvido e alterações na respectiva estabilidade, bem como o número de parâmetros envolvido (associado à codimensão da bifurcação).

codimensão

No caso de fluxos autônomos não simétricos, só há duas possibilidades de bifurcações envolvendo equilíbrios, mediante a variação de um único parâmetro $\lambda$. Estes casos refletem cruzamentos dos autovalores do equilíbrio com o eixo real (mudança de estabilidade). Nos diagramas esquemáticos abaixo, as figuras representam estes cruzamentos.

É importante frisar que as condições apresentadas podem não ser suficientes para caracterizar determinada bifurcação, devido a condições adicionais de transversalidade e não degenerescência não discutidas (detalhes em Kuznetsov, 1995).

selá-nó Ocorre com a colescência e aniquilação/criação de dois equilíbrios, formando em $\lambda_{\text {bif }}$ um único equilíbrio com autovalor nulo.

Andronov-Hopf Ocorre quando um equilíbrio ins/estável muda de estabilidade com autovalores puramente imaginários, dando origem a uma órbita periódica ins/estável.
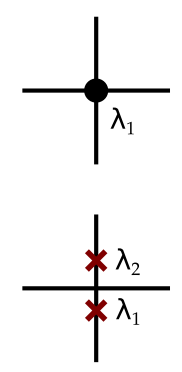

Para mapas e, consequentemente, ciclos limite (via seções de Poincaré), há três possibilidades de cruzamento do círculo unitário (mudança de estabilidade):

sela-nó (para ciclos) Análogo discreto da bifurcação sela-nó. Pontos fixos coalescem e aniquilam-se. No caso de fluxos, corresponde à colisão e desaparecimento de duas órbitas periódicas de estabilidade oposta.

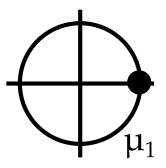




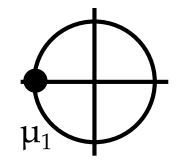

duplicação de período Corresponde ao des/aparecimento de uma órbita periódica com o dobro do período da original. No caso de fluxos, pode ocorrer para dimensões maiores que 2 , onde um ciclo limite perde/ganha estabilidade gerando um ciclo com o dobro do período.

Neimark-Sacker É o análogo discreto da bifurcação de Hopf, com a mudança de estabilidade de um ponto fixo e

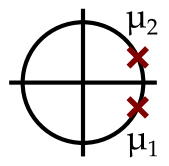
des/aparecimento de uma curva invariante fechada. Também chamada de bifurcação de toro ou de Hopf secundária, em fluxos. Neste caso, a curva invariante na seção corresponde a um toro invariante no fluxo.

Há bifurcações - ditas globais - para as quais não é possível caracterizar a dinâmica através da análise do comportamento local do fluxo. Na figura A.4, está representada uma bifurcação

Figura A.4: Bifurcação órbita homoclínica de sela. Nesta bifurcação global, um ciclo limite é criado/destruído a partir de uma órbita homoclínica.

órbita homoclínica

bifurcação homoclínica

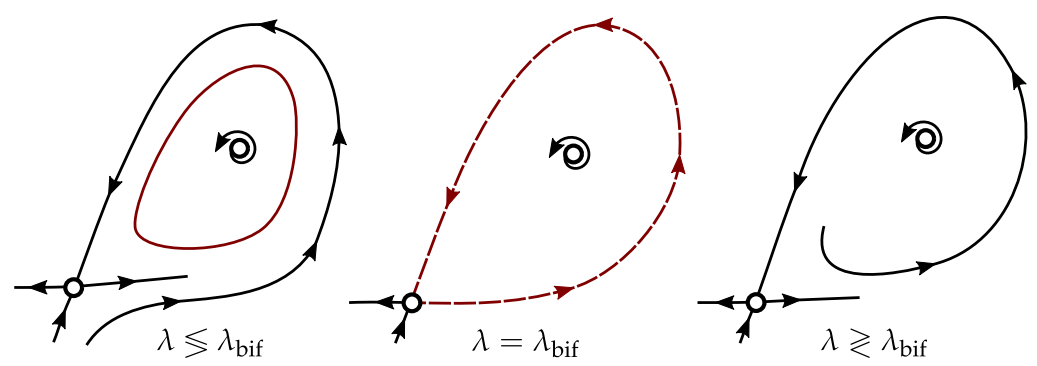

desta classe: Ela envolve a criação/destruição de um ciclo limite, quando este conecta as variedades estável/instável de um ponto de sela, tornando-se uma órbita homoclínica. Próximo ao ponto de bifurcação, o período do ciclo cresce, indo a infinito para

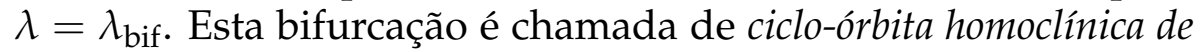
sela, ou simplesmente bifurcação homoclínica.

\section{Exemplo: modelo integra-e-dispara quadrático}

A fim de ilustrar os conceitos apresentados, considera-se um modelo de neurônio muito simplificado, na reta, definido pela equação A.3.

$$
\dot{x}=x^{2}+\lambda
$$

Há duas regiões de dinâmica topologicamente equivalente para variações do parâmetro $\lambda$ : se $\lambda>0$, não há pontos de equilíbrio (pontos onde o campo $\dot{\mathbf{x}}=\mathbf{0}$ ), e as soluções divergem. Já para 
$\lambda<0$, têm-se dois pontos de equilíbrio, cuja estabilidade é determinada pelos autovalores da matriz jacobiana (neste caso, a derivada); no caso, o ponto à esquerda é estável (nó estável) e o da direita instável (sela, que se confunde com um nó instável para o caso unidimensional). Para $\lambda=0$, ocorre então uma bifurcação sela-nó, com a aniquilação mútua destes equilíbrios.

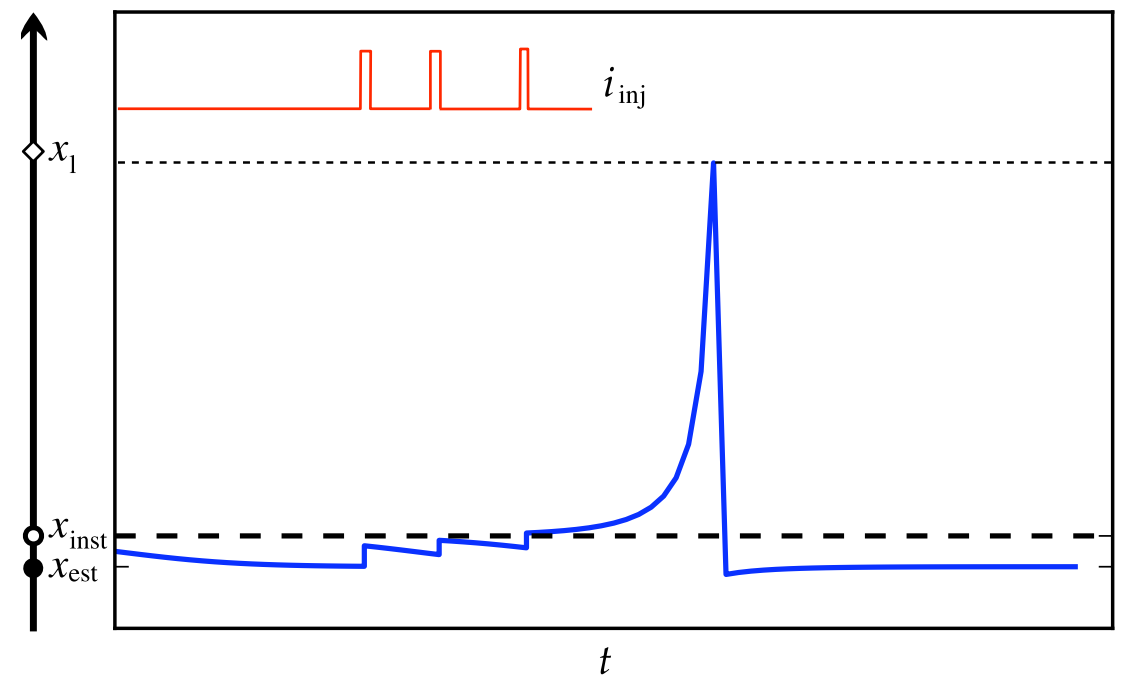

Figura A.5: Comportamento integra e dispara para modelo baseado na forma normal da bifurcação sela-nó (eq. A.3), acrescida de um limiar $x_{l}$ a partir do qual $x$ é reiniciada a um valor $x_{r}$

Para $\lambda<0$, este modelo apresenta um equilíbrio estável $x_{\text {est }}$ separado de uma região de divergência por uma separatriz - neste caso unidimensional, um equilíbrio instável $x_{\text {ins }}$. Adicionando-se à dinâmica um limiar $x_{l}$ e fazendo-se com que $x$ seja reiniciada a $x_{r}$ caso cruze este valor, o sistema resultante possui várias propriedades análogas às do potencial de membrana de neurônios biológicos. Dentre estas propriedades: um valor de repouso $\left(x_{\text {est }}\right.$ ); um limiar de disparo (se $x$ cruza o ponto de equilíbrio instável, cresce exponencialmente até atingir $x_{l}, \mathrm{o}$ que pode ser definido como um spike); comportamento tônico induzido pela "corrente" $\lambda$ (se $x_{r}>x_{\text {inst }}$ ), já que para $\lambda>0$ o sistema passa de quiescente (porém excitável) a oscilatório entre $x_{r}<x<x_{l}$. Este modelo simplificado apresenta também o conhecido comportamento "integra e dispara", já que vai somando as entradas até que $x$ cruze o limiar definido por

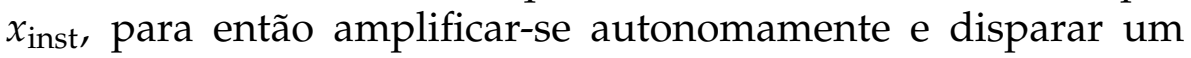
potencial de ação (figura A.5). Um corte é feito em $x_{l}$, com posterior reinício da dinâmica em $x_{r}$, de modo que o fluxo esteja confinado. 


\section{Expansividade e caos}

O modo como trajetórias partindo de condições iniciais próximas se comportam é fundamental para caracterizar a previsibilidade de um dado modelo. Em sistemas lineares, pequenas perturbações na condição inicial permanecem pequenas com a evolução temporal, de modo que um erro na determinação do estado não se traduz em um erro grande de previsão para um estado futuro. Para o caso não linear, isso não é necessariamente verdade: há sistemas, ditos caóticos, para os quais trajetórias próximas divergem exponencialmente, de maneira que pequenos erros são eventualmente amplificados a ponto de acabar com a previsibilidade para tempos longos.

É possível quantificar o comportamento expansivo/contrativo do sistema através da evolução de uma hiperesfera infinitesimal de condições iniciais $\delta \mathbf{x}_{0}$. A evolução temporal destes estados produzirá em geral um elipsóide, e considerando a aproximação linear (eq. A.1) a taxa de divergência/convergência em cada uma das direções está associada a um expoente: os expoentes de Lyapunov. Direções contrativas/expansivas estão associadas a expoentes positivos/negativos. Evidentemente, a fim de manter o fluxo confinado, a soma dos expoentes de Lyapunov deve ser negativa (sistema dissipativo). Sistemas caóticos são sistemas dissipativos que apresentam expoentes de Lyapunov positivos.

Para mapas unidimensionais, considerando a aproximação linear A.2, os expoentes podem ser aproximados através de

$$
\lambda=\lim _{n \rightarrow \infty} \frac{1}{N} \sum_{n} \log \left|\mathbf{f}^{\prime}\left(x_{n}\right)\right|
$$




\section{A.2 Modelos de condutância}

Diversos tipos de célula possuem mecanismos de troca local de informação. Entretanto, as altamente especializadas células neurais permitem a transmissão de impulsos por longas distâncias, carregando informação com confiabilidade e robustez. Os sinais consistem esencialmente na propagação de ondas de depolarização da membrana celular. Para um neurônio típico, em repouso, há uma diferença de potencial fixa ao longo da membrana. A visão clássica da excitabilidade neuronal supõe que, se a célula for perturbada - pertubação esta proveniente por exemplo de entradas sinápticas - a partir de um certo limiar (limiar de disparo) obtêm-se potenciais de ação ou spikes, nada mais do que picos no valor do potencial de membrana, que propagam-se regenerativamente ao longo do neurônio.

\section{Eletrofisiologia de membranas}

O comportamento elétrico de neurônios é determinado por variações nas concentrações intra e extracelular de determinados íons. A membrana plasmática é constituída por um camada dupla de fosfolipídeos, polar nas faces e apolar no interstício de maneira que é praticamente impermeável ao fluxo de íons. Todavia, diversas proteínas existentes ao longo desta membrana funcionam como canais iônicos, permitindo seletivamente sua passagem. Há também mecanismos moleculares (como a conhecida bomba de Sódio e Potássio), que mantêm fixas as concentrações íonicas no meio intracelular, de modo que entre as faces de uma membrana em repouso há naturalmente uma diferença de potencial, denominado potencial de repouso.

Da termodinâmica, tem-se que a situação de equilíbrio para um fluxo de partículas carregadas através de uma membrana se dá através do balanço entre o potencial químico, devido ao gradiente de concentração iônico, e o potencial elétrico, devido ao desbalanço de carga causado por íons que atravessam a membrana. Esta situação é descrita pela equação de Nernst (eq. A.5),

$$
E_{i}=\frac{R T}{Z F} \ln \frac{[i]_{\mathrm{ext}}}{[i]_{\mathrm{int}}}
$$

que dá o potêncial devido à espécie $i$, sendo $R$ a constante universal dos gases, $T$ a temperatura, $Z$ a valência do íon, $F$ a 
Figura A.6: Potencial de repouso em membrana semipermeável, devido ao equilíbrio entre o potencial elétrico (separação de cargas em íons) e químico (gradiente de concentração iônica) através da membrana. Adaptado de Johnston e Wu (1995). constante de Faraday (carga de um mol de elétrons), e os termos entre colchetes as concentrações do íon nos meios externo e interno à membrana. Um esquema deste arranjo microscópico pode ser visto na figura A.6.

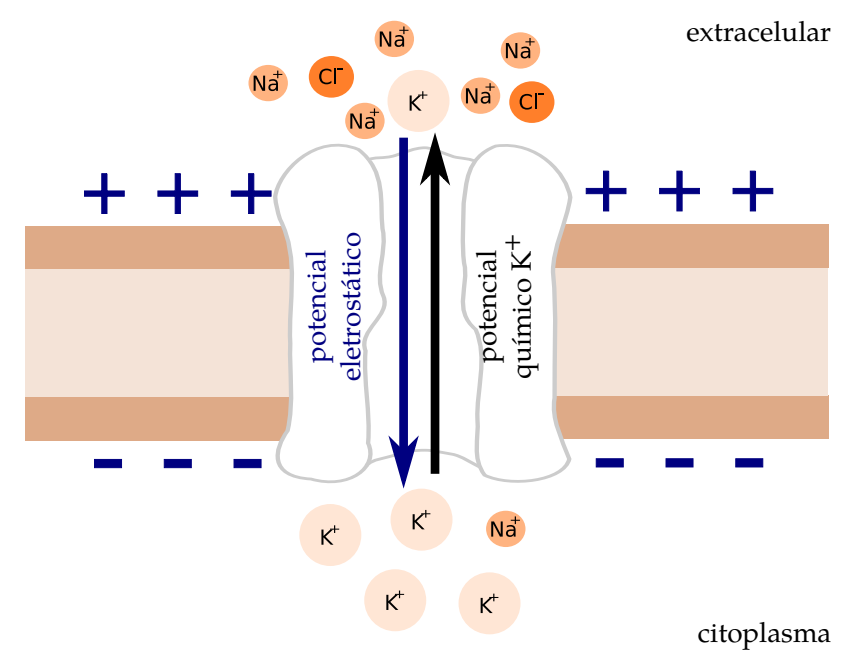

Se os canais iônicos fossem simplesmente "poros" passivos na membrana, a célula permaneceria no estado de equilíbrio (potencial de repouso), tendendo a este sempre que alguma perturbação fosse aplicada. Todavia, a permeabilidade da membrana às diferentes espécies iônicas não é constante, sendo sensível a fatores químicos, mecânicos, ou ao próprio potencial de membrana, o que enriquece muito a dinâmica e permite o comportamento de propagação de sinais observado. Estes fatores fundamentalmente influenciam a abertura ou fechamento de diferentes tipos de canal iônico.

Como exemplo, considera-se a modelagem do comportamento excitável do axônio do neurônio gigante da lula, investigado exaustivamente por Hodgkin e Huxley (Hodgkin e Huxley, 1952).

Utilizando a equação de Goldman (eq. A.6, vide Johnston e $\mathrm{Wu}, 1995)$, calcula-se o potencial de repouso devido aos três íons envolvidos no modelo, que é da ordem de $-60 \mathrm{mV}$ (próximo ao potencial de Nernst para o $\mathrm{K}^{+}$, aproximadamente $-75 \mathrm{mV}$ ). Isto indica que, em repouso, há muito mais canais de Potássio no estado permissivo do que canais das outras espécies iônicas consideradas, no caso Sódio e Cloreto. Efetivamente, têm-se $P_{\mathrm{K}}: P_{\mathrm{Na}}: P_{\mathrm{Cl}}=1: 0.04: 0.45$. 


$$
V_{\text {rep }}=\frac{R T}{F} \ln \frac{P_{\mathrm{K}}\left[\mathrm{K}^{+}\right]_{\text {ext }}+P_{\mathrm{Na}}\left[\mathrm{Na}^{+}\right]_{\text {ext }}+P_{\mathrm{Cl}}\left[\mathrm{Cl}^{-}\right]_{\mathrm{ext}}}{P_{\mathrm{K}}\left[\mathrm{K}^{+}\right]_{\mathrm{int}}+P_{\mathrm{Na}}\left[\mathrm{Na}^{+}\right]_{\mathrm{int}}+P_{\mathrm{Cl}}\left[\mathrm{Cl}^{-}\right]_{\mathrm{ext}}}
$$

Contudo, durante um potencial de ação, o melhor ajuste via equação de Goldman para o potencial de membrana ocorre se as permeabilidades forem escolhidas na proporção $P_{\mathrm{K}}: P_{\mathrm{Na}}: P_{\mathrm{Cl}}=$ 1 : 20 : 0.45, ou seja, $V_{\mathrm{M}}$ aproxima-se do potencial de Nernst para os íons Sódio. Esta corrente iônica é então dominante no disparo de potenciais de ação.

Pode-se, considerando as propriedades dos canais iônicos e da membrana, modelar um neurônio com um circuito equivalente (fig. A.7).

A equação que define a dinâmica de $V_{M}$ é então obtida diretamente da conservação de carga no circuito.

\section{A.3 O modelo de Hodgkin e Huxley}

Na década de 1950, Hodgkin, Huxley e Katz realizaram uma série de experimentos em eletrofisiologia, nos quais destaca-se o desenvolvimento e aplicação da técnica de voltage clamping: mediante eletrodos intracelulares, o potencial de membrana é mantido constante, permitindo determinar a corrente transmembrânica total. Estes resultados culminaram no desenvolvimento de um modelo para o comportamento elétrico de neurônios que se tornou um paradigma em neurociência, estabelecendo uma base sólida para toda a classe de modelos eletrofisiologicamente detalhados, amplamente utilizados até os dias atuais.

O modelo possui 4 variáveis dinâmicas. A primeira é o potencial de membrana, e as outras três governam a dinâmica de condução de Sódio e Potássio através da membrana. Estas são supostas independentes entre si, e as respectivas dinâmicas dependem de $V_{\mathrm{M}}$; há uma terceira condutância chamada de leak, devida a canais iônicos não específicos, cujo valor é constante. Desta maneira, a corrente iônica total através da membrana é

$$
I_{\text {ion }}=I_{\mathrm{Na}}+I_{\mathrm{K}}+I_{\text {leak }}
$$

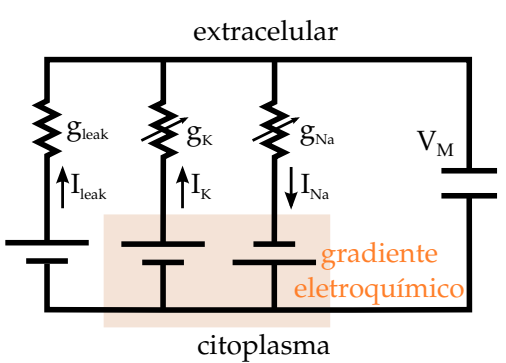

Figura A.7: Circuito correspondente a uma membrana semipermeável, com canais iônicos de Sódio e Potássio dependentes de voltagem, e canais passivos leak. 
Os canais iônicos comportam-se como condutores ohmicos, ou seja, a dependência entre a corrente e o potencial de membrana é linear:

$$
I_{i}(t)=g_{i}(V(t)) \cdot\left[V(t)-E_{i}\right]
$$

onde $g_{i}$ a condutância associada à i-ésima espécie iônica, e $E_{i}$ é o potencial reverso para essa espécie, dado pela equação de Nernst (eq. A.5).

Cada uma das duas condutâncias específicas é expressada em termos de uma condutância máxima $\left(\overline{g_{i}}\right)$, multiplicada por um coeficiente representando a fração desta condutância máxima realmente ativa. A essência do modelo de Hodgkin e Huxley consiste em propor dinâmicas para estas variáveis de ativação. Em seu modelo original, eles referem-se a partículas de ativação e inativação, podendo cada uma delas estar em um de dois estados (aberto ou fechado), dependendo do tempo e do potencial de membrana. Para que a condutância esteja ativa, todas partículas devem estar no estado aberto simultaneamente.

O melhor ajuste obtido para a corrente de Potássio foi

$$
I_{\mathrm{K}}=\overline{g_{\mathrm{K}}} n^{4}\left(V-E_{\mathrm{K}}\right)
$$

Onde $n$, adimensional, descreve o estado da hipotética partícula de ativação, podendo assumir valores entre o e 1. Supondo que a fração de partículas de ativação no estado permissivo seja $n$ (consequentemente, $1-n$ está no estado não permissivo), $\mathrm{e}$ considerando uma cinética de primeira ordem, determina-se o seguinte esquema de transições:

$$
n \underset{\beta_{n}(V)}{\stackrel{\alpha_{n}(V)}{\rightleftharpoons}} 1-n
$$

sendo $\alpha_{n}$ e $\beta_{n}$ taxas (dependentes do potencial de membrana) especificando quantas transições ocorrem entre os estados em uma unidade de tempo. Esse esquema corresponde a uma equação diferencial de primeira ordem:

$$
\frac{\mathrm{d} n}{\mathrm{~d} t}=\alpha_{n}(V)[1-n]-\beta_{n}(V) n
$$

Ao longo da tese, utiliza-se um parametrização em termos de uma constante temporal $\tau_{n}(V)$ e um valor de estado estacionário 
$n_{\infty}(V)$

$$
n_{\infty}=\frac{\alpha_{n}}{\alpha_{n}+\beta_{n}} \quad \tau_{n}=\frac{1}{\alpha_{n}+\beta_{n}}
$$

de modo que a dinâmica é escrita como

$$
\frac{\mathrm{d} n}{\mathrm{~d} t}=\frac{n_{\infty}-n}{\tau_{n}}
$$

Desta maneira, tem-se uma interpretação direta de que, para um valor fixo do potencial de membrana, $n$ tende assintoticament a $n_{\infty}$, com um tempo de relaxação caracterizado por $\tau_{n}$.

A dependência das taxas $\alpha$ e $\beta$ com o potencial de membrana foi obtida através de ajustes aos dados experimentais, e as expressões propostas por HH são

$$
\alpha_{n}(V)=\frac{10-V}{100 e^{\frac{10-V}{10}}} \quad \beta_{n}(V)=0.125 e^{-\frac{V}{80}}
$$

onde $V$ é o potencial da membrana medido em relação ao potencial de repouso do axônio em $\mathrm{mV}$.

Para os canais de Sódio, a dinâmica é mais complexa. A fim de ajustar o comportamento desta corrente, Hodkgin e Huxley tiveram de postular a existência de uma partícula de ativação $m$, bem como uma de inativação $h$ :

$$
I_{\mathrm{Na}}=\overline{g_{\mathrm{Na}}} m^{3} h\left(V-E_{\mathrm{Na}}\right)
$$

Analogamente à corrente de Potássio, as equações diferenciais que regem a dinâmica de $m$ e $h$ são

$$
\begin{aligned}
& \frac{\mathrm{d} m}{\mathrm{~d} t}=\alpha_{m}(V)[1-m]-\beta_{m}(V) m \\
& \frac{\mathrm{d} h}{\mathrm{~d} t}=\alpha_{h}(V)[1-h]-\beta_{h}(V) h
\end{aligned}
$$

Com os valores empíricos

$$
\begin{aligned}
\alpha_{m}(V)=\frac{25-V}{10 e^{\frac{25-V}{10}}-1} & \beta_{m}(V)=4 e^{-\frac{V}{18}} \\
\alpha_{h}(V)=0.07 e^{-\frac{V}{20}} & \beta_{h}(V)=\frac{1}{e^{\frac{30-V}{10}}+1}
\end{aligned}
$$


Combinando as correntes ativas de Sódio e Potássio, bem como a passiva de leak, obtém-se a dinâmica do potencial de membrana, através do circuito equivalente na fig. A.7:

$$
\begin{array}{r}
C_{m} \frac{\mathrm{d} V}{\mathrm{~d} t}=-\overline{g_{\mathrm{Na}}} m^{3} h\left(V-E_{\mathrm{Na}}\right)-\overline{g_{\mathrm{K}}} n^{4}\left(V-E_{\mathrm{K}}\right)+ \\
-g_{\text {leak }}\left(V-E_{\text {leak }}\right)+I_{\text {inj }}
\end{array}
$$

Esta equação leva em conta a injeção de corrente externa, proveniente por exemplo de excitações sinápticas.

\section{A.4 Ruído na dinâmica neuronal}

Com o advento de técnicas de patch-clamping, determinou-se que os canais responsáveis pelo transporte transmembrânico de íons comportam-se de maneira estocástica, chaveando entre estados permissíveis e não permissíveis aleatoriamente (com uma possível dependência com o potencial de membrana).

É factível - embora computacionalmente custoso - rastrear o comportamento individual de cada um dos canais, ou mesmo de populações (Johnston e $\mathrm{Wu}, 1995)$, utilizando um esquema de Monte Carlo e as probabilidades de transição. Entretanto, para modelos de membranas com dimensões celulares, os números típicos de canais envolvidos fazem com que as flutuações $(\sqrt{N} / N)$ sejam pequenas, de modo que convém buscar modelos concentrados (Kampen, 1992, lumped models), onde uma variável macroscópica codifica o comportamento médio das unidades microscópicas, mas está sujeita a pequenas perturbações aleatórias (enfatiza-se que, no próprio modelo de $\mathrm{HH}$, as variáveis de ativação e inativação $m_{i}, h_{i}$ descrevem este comportamento médio).

Uma maneira intuitiva (para a comunidade de física, ao menos) de modelar o efeito de ruído sobre uma dinâmica fundamentalmente determinística é a através de Equações de Langevin:

$$
\begin{aligned}
& \dot{x}=\mathrm{F}(x)+\mathrm{G}(x) \Xi(t) \\
& \langle\Xi(t)\rangle=0 \quad\left\langle\Xi(t) \Xi\left(t^{\prime}\right)\right\rangle=\delta\left(t-t^{\prime}\right)
\end{aligned}
$$


Ou seja, uma dinâmica determinista acrescida de um forçamento aleatório descorrelacionado, cuja intensidade em geral é uma função de estado (o dito ruído multiplicativo, em oposição a aditivo no caso de G independente de $x$ ). Provavelmente, a popularidade deste método se dê porque ele parece infiniment plus simple (Langevin, 1908) do que as abordagens de Einstein e Smoluchowski para a análise do Movimento Browniano - um dos exemplos mais famosos de processo aleatório.

Segue-se uma derivação da equação de Langevin para uma condutância iônica hipotética, gerada por um conjunto de canais que podem assumir dois estados (podendo ser estendida para canais com esquemas de chaveamento mais elaborado, incluindo estados intermediários e inativação).

Tomam-se $N$ canais microscópicos não interagentes, descritos por variáveis aleatórias independentes $\sigma_{i}$, podendo assumir os valores $\{0,1\}$ (estados não permissivo e permissivo, respectivamente). Transições entre microestados seguem as regras

$$
\sigma_{i}: 0 \underset{\beta(V)}{\stackrel{\alpha(V)}{\rightleftharpoons}} 1
$$

onde as taxas de transição $\alpha, \beta$ são derivadas diretamente do modelo de $\mathbf{H H}$.

Denotando por $n$ o número de canais no estado permissivo $\left(n=\sum \sigma_{i}\right)$, tem-se o seguinte esquema de transição

$$
\begin{aligned}
& n \stackrel{(N-n) \alpha}{\longrightarrow} n+1 \\
& n \stackrel{n \beta}{\longrightarrow} n-1
\end{aligned}
$$

ao qual está associada a equação mestra

$$
\begin{array}{r}
\frac{\mathrm{dP}_{n}}{\mathrm{~d} t}(t)=[N-(n-1)] \alpha \mathrm{P}_{n-1}(t)+(n+1) \beta \mathrm{P}_{n+1}(t)+ \\
-[(N-n) \alpha+n \beta] \mathrm{P}_{n}(t)
\end{array}
$$

onde $\mathrm{P}_{n}(t)$ é a probabilidade de encontrar $n$ canais no estado permissivo.

Como as variáveis de ativação $m$ em modelos tipo HH correspondem à fração de canais no estado permissivo, definimos 
$m \equiv n / N$; adicionalmente, convém fazer as seguintes definições:

$$
\begin{array}{r}
\frac{n}{N} \mathrm{P}_{n}=m \mathcal{P}(m) \equiv \mathrm{f}(m) \\
\left(1-\frac{n}{N}\right) \mathrm{P}_{n}=(1-m) \mathcal{P}(m) \equiv \mathrm{g}(m)
\end{array}
$$

(deixando implícitas as dependências temporais). Obtém-se desta maneira

$$
\begin{array}{r}
\frac{\partial \mathcal{P}}{\partial t}(m, t)=N\{\alpha[\mathrm{g}(m-1 / N)-\mathrm{g}(m)]+ \\
+\beta[\mathrm{f}(m+1 / N)-\mathrm{f}(m)]\}
\end{array}
$$

Expandindo as distribuições até segunda ordem em 1/N,

$$
\begin{array}{r}
\frac{\partial \mathcal{P}}{\partial t}=N\left(-\frac{\alpha}{N} \frac{\partial \mathrm{g}}{\partial m}+\frac{\alpha}{2 N^{2}} \frac{\partial^{2} \mathrm{~g}}{\partial m^{2}}+\frac{\beta}{N} \frac{\partial \mathrm{f}}{\partial m}+\frac{\beta}{2 N^{2}} \frac{\partial^{2} \mathrm{f}}{\partial m^{2}}\right)= \\
=-\alpha \frac{\partial \mathrm{g}}{\partial m}+\beta \frac{\partial \mathrm{f}}{\partial m}+\frac{\alpha}{2 N} \frac{\partial^{2} \mathrm{~g}}{\partial m^{2}}+\frac{\beta}{2 N} \frac{\partial^{2} \mathrm{f}}{\partial m^{2}}
\end{array}
$$

Desfazendo as mudanças de variáveis (eq. A.24):

$$
\begin{aligned}
\frac{\partial \mathcal{P}}{\partial t}(m, t)= & -\frac{\partial}{\partial m}\{[(\alpha(1-m)-\beta m)] \mathcal{P}(m, t)\}+ \\
& \frac{1}{2 N} \frac{\partial^{2}}{\partial m^{2}}\{[\alpha(1-m)+\beta m] \mathcal{P}(m, t)\}
\end{aligned}
$$

que é uma equação de Fokker-Planck para a distribuição $\mathcal{P}(m, t)$. Segundo Itō (Kampen, 1992, capítulo IX.4), a esta equação de Fokker-Planck corresponde a seguinte equação de Langevin:

$$
\frac{\mathrm{d} m}{\mathrm{~d} t}=\alpha(1-m)-\beta m+\sqrt{\frac{\alpha(1-m)+\beta m}{N}} \xi
$$

onde $\xi$ é uma variável aleatória, com uma distribuição gaussiana de média zero e variância unitária. Note que, no limite para um número grande de canais, recupera-se o modelo original de $\mathrm{HH}$ (eq. A.11).

No apêndice B.1, discutem-se métodos numéricos para a simulação de equações diferenciais estocásticas (EDE) como a A.25. 


\section{Apêndice B}

\section{Métodos numéricos}

Os métodos numéricos utilizados nas simulações serão apresentados de uma maneira pragmática, sem deduções rigorosas, fazendo referência direta a implementações robustas em pacotes de computação científica (todos de utilização e código-fonte livres). Desta maneira, pretende-se agilizar a vida do leitor, levantando sutilezas e pontos comumente problemáticos na aplicação de cada técnica. Todas as simulações apresentadas na tese foram desenvolvidas com base nesses pacotes, utilizando quando possível a linguagem de programação Python (em casos onde se fez necessária performance extrema, foi utilizada c).

\section{B.1 Integração numérica}

Ao lidar-se com modelos expressos em termos de equações diferenciais, é indispensável fazer uso de integradores numéricos para estudos exploratórios, ou mesmo mais aprofundados - na forma de métodos de força-bruta (ver capítulo 4). Seguem-se comentários sobre os métodos utilizados para a integração de modelos de condutância, tanto deterministas quanto estocásticos. Há duas referências muito completas sobre ambos os temas: Hairer et al. (2002); Kloeden e Platen (1992).

De um ponto de vista pragmático, o uso de integradores de EDO com controle de erro é extremamente importante na análise de modelos neuronais. Pode-se fazer uma analogia com uma corrida sobre um terreno desigual: procura-se avançar a passos largos em partes planas e niveladas do terreno, sem risco de quedas. Entretanto, em terreno pedregoso vale a 
pena prosseguir cautelosamente, analisando o melhor trajeto e prosseguindo pela rota mais segura, a passos curtos. Além do evidente ganho de informação acerca da confiabilidade da solução numérica, em muitos casos a performance cresce em ordens de grandeza. O aparente aumento do custo computacional, ao estimar o erro e ajustar o passo ou método de integração, é muito pequeno comparado com o ganho de eficiência na solução do problema: com o passo fixo, há um jogo entre o tempo total de integração e as menores escalas temporais resolvíveis. A isso agrega-se a possibilidade de instabilidade numérica para passos demasiadamente grandes.

\section{Equações diferenciais "stiff"}

Sistemas cuja solução possui regiões de variação lenta, onde a EDO é muito estável (convergência rápida para a solução), assim como sistemas com multiplas escalas temporais, são ditos stiff. Programas para integração de EDO não stiff costumam ser muito ineficientes quando usados em sistemas stiff. Integradores de passo adaptável recebem como entrada do usuário uma tolerância a erro, a ser checada a cada passo contra a diferença entre duas estimativas, uma delas de ordem maior. $\mathrm{O}$ algoritmo ajusta o passo de modo que o erro sempre é menor do que a tolerância. A fim de resolver o problema de maneira eficiente, $o$ maior passo possível é escolhido. Há dois fatores principais afetando a escolha deste passo - acurácia e estabilidade. Métodos populares produzem resultados qualitativamente satisfatórios apenas quando passo/tolerância são suficientemente pequenos. Para problemas stiff, requerimentos de estabilidade são muito mais restritivos do que os de acurácia. Todos métodos especiais para equações stiff são implícitos, isto é, envolvem a cada passo a solução de uma equação algébrica: $x_{n+1}=\mathbf{f}\left(x_{n}, x_{n+1}\right)$ (em oposição aos métodos explícitos onde $\left.x_{n+1}=\mathbf{f}\left(x_{n}\right)\right)$. O custo computacional adicional acaba sendo compensado globalmente, devido à grande estabilidade de métodos implícitos.

Todos os pacotes usados neste projeto possuem mais de um integrador para EDO, com métodos específicos para problemas stiff inclusive. Empiricamente, para modelos de condutância de alta dimensionalidade, o método RADAUII descrito em Hairer et al. (2002) mostrou-se o mais eficiente, para uma dada tolerância. O pacote LSODE detecta stiffness automaticamente, 
requerendo entretanto ajuste fino de diversos parâmetros para atingir maior eficiência.

De maneira geral, modelos de neurônios que disparam bursts têm dinâmicas operando em escalas temporais distintas - estando sujeitos a considerações de stiffness.

\section{Equações diferenciais estocásticas}

A interpretação de equações diferenciais estocásticas (EDE) do tipo A.21 apresenta uma série de sutilezas. Uma constatação fundamental é de que o efeito do ruído, se considerado como uma soma de pulsos $\delta\left(t-t^{\prime}\right)$, é provocar saltos no estado $x(t)$. Desta forma, o valor de $x$ nos instantes de chegada de pulsos $t^{\prime}$ é indefinido, bem como os pesos $\mathrm{G}(x)$. Considerando um incremento temporal $\Delta t$, obtém-se

$$
x(t+\Delta t)-x(t)=\mathrm{F}(x) \Delta t+\mathrm{G}(x(?)) \int_{t}^{t+\Delta t} \Xi\left(t^{\prime}\right) \mathrm{d} t^{\prime}
$$

A ambiguidade na escolha do estado a ser usado no peso $\mathrm{G}(x(?))$ foi resolvida de duas maneiras distintas. A chamada regra de Itō leva em conta o valor de $x(t)$ anterior a chegada do pulso, enquanto a de Stratonovich utiliza a média $\frac{x(t+\Delta t)+x(t)}{2}$. A grosso modo, quando o processo em questão pode ser interpretado como essencialmente determinista, mas acoplado uma fonte "externa" de ruído (ruído extrínseco) utiliza-se o método de Stratonovich. Por outro lado, em processos associados a cinética química a intepretação de Itō é mais apropriada: em um processo $A \leftrightharpoons B$, a probabilidade de que o número de $A$ decresça uma unidade é efetivamente proporcional ao número atual de $A$. Ao longo desta tese, adotou-se a convenção de Itō. ${ }^{1}$

A integral estocástica restante pode ser interpretada como uma variável aleatória, cujas propriedades podem ser calculadas

\footnotetext{
${ }^{1}$ A questão da aplicabilidade do formalismo de Langevin, bem como uma discussão detalhada do dilema Itō/Stratonovich, podem ser encontradas em Kampen (1992).
} 
usando a definição de $\Xi$ :

$$
\begin{aligned}
\left\langle\int_{t}^{t+\Delta t} \Xi(t) \mathrm{d} t^{\prime}\right\rangle & =\int_{t}^{t+\Delta t}\langle\Xi(t)\rangle \mathrm{d} t^{\prime}=0 \\
\left\langle\left(\int_{t}^{t+\Delta t} \Xi(t) \mathrm{d} t^{\prime}\right)^{2}\right\rangle & =\int_{t}^{t+\Delta t} \int_{t}^{t+\Delta t}\left\langle\Xi\left(t^{\prime}\right) \Xi\left(t^{\prime \prime}\right)\right\rangle \mathrm{d} t^{\prime} \mathrm{d} t^{\prime \prime} \\
& =\int_{t}^{t+\Delta t} \int_{t}^{t+\Delta t} \delta\left(t^{\prime}-t^{\prime \prime}\right) \mathrm{d} t^{\prime} \mathrm{d} t^{\prime \prime}=\int_{t}^{t+\Delta t} \mathrm{~d} t^{\prime}=\Delta t
\end{aligned}
$$

Ou seja, a variável aleatória tem variância $\Delta t$, de modo que aproximações numéricas para a equação A.21 podem ser obtidas a partir de

$$
x_{n+1}=x_{n}+\mathrm{F}\left(x_{n}\right) \Delta t+\sqrt{\Delta t \mathrm{G}^{2}\left(x_{n}\right)} \mathcal{N}(0,1)
$$

com $\mathcal{N}(0,1)$ um número aleatório de média zero e variância unitária (usualmente sorteado de uma distribuição normal, evocando o teorema central do limite). Esta relação de recorrência é chamada de método de Euler-Maruyama.

Na literatura de matemática e finanças, é usual encontrar equações diferenciais estocásticas na forma

$$
\mathrm{d} x=a(x) \mathrm{d} t+b(x) \mathrm{d} W .
$$

Neste contexto, são genericamente chamadas de equação de Itō. O termo d $W$ deve ser interpretado como um processo de Wiener, que nada mais é do que um processo aleatório a tempo discreto onde para instantes subsequentes $t, s: W_{t}-W_{s} \approx \mathcal{N}(0, t-s)$, ou seja as mesmas propriedades da integral estocástica analisada anteriormente.

\section{B.2 Continuação numérica}

A análise geométrica de sistemas simples é uma ferramenta fundamental no estudo da excitabilidade neuronal. Entretanto, ao lidar-se com sistemas eletrofisiologicamente realistas (formalismo de Hodgkin e Huxley), para a mais simples das células obtêm-se modelos com muitas dimensões. Nesta seção, delinease um procedimento de análise numérica que possibilita caracterizar a dinâmica de um sistema genérico, enfatizando estruturas 
topológicas como pontos de equilíbrio, órbitas periódicas, bem como pontos de bifurcação destas estruturas em função da variação de parâmetros nos modelo. Pretende-se apresentar uma idéia intuitiva do procedimento de continuação numérica, sem nenhuma pretensão a rigor ou construção de algoritmos eficientes. Para tanto, apontamos as referências definitivas Kuznetsov (1995); Govaerts (1987).

Como exemplo de aplicação da técnica, considere-se o modelo neuronal simplificado, baseado na forma normal da bifurcação sela-nó, analisado no apêndice A.

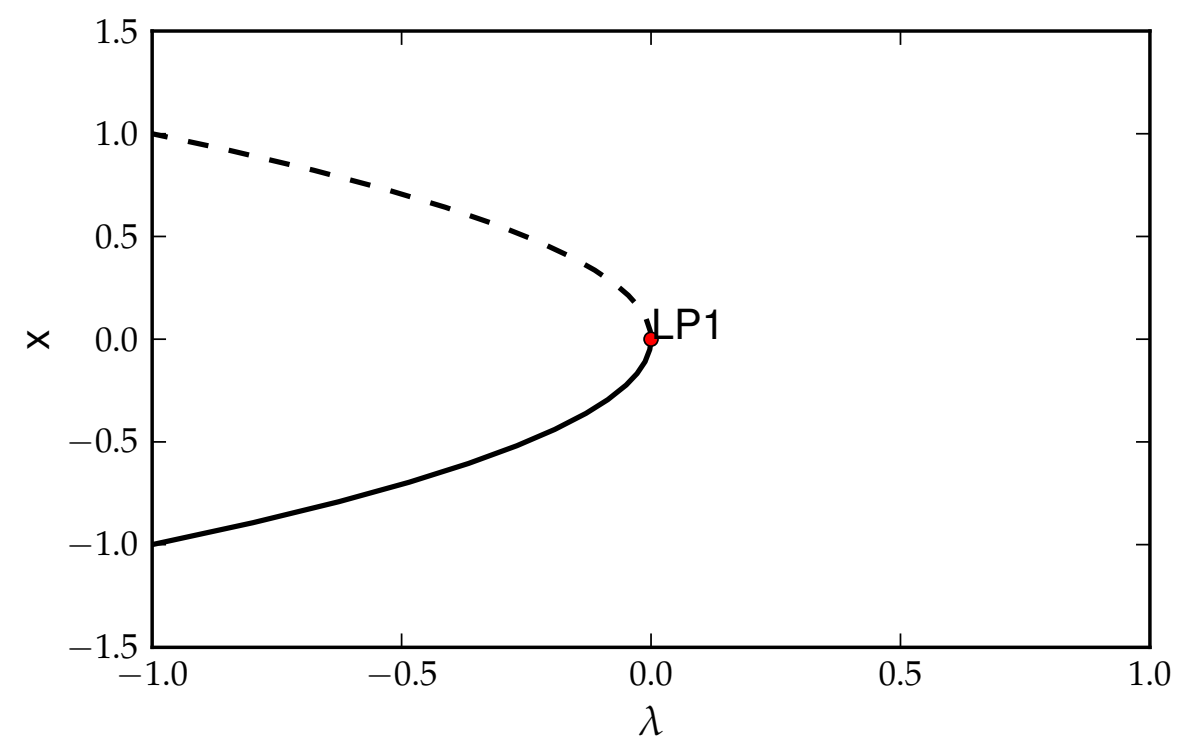

Toda a informação obtida analiticamente na análise de bifurcações descrita está resumida no diagrama B.1, onde a curva de nível $\dot{x}=0$ foi obtida numericamente pelo método de Newton-Raphson (método clássico para aproximação iterativa de raízes de equações, ver por exemplo Burden e Faires 2010). Cada nova estimativa para o valor de $\dot{x}=0$ em função de $\lambda$ utiliza como condição inicial de iteração o valor obtido para o parâmetro anterior. A fim de determinar a estabilidade dos equilíbrios, calculam-se adicionalmente aproximações da dinâmica linearizada (a matriz Jacobiana $J$, utilizada no próprio método de Newton), aproximando derivadas por diferenças finitas. A partir dos autovalores de $J$, é possível detectar pontos de bifurcação associados à mudança de estabilidade de pontos de equilíbrio, bem como o surgimento de ciclos-limite via
Figura B.1: Diagrama de bifurcações para a forma normal da bifurcação sela-nó (equação A.3), obtido através do método de continuação numérica. A bifurcação ocorre no ponto marcado como LPI $(\lambda=0)$. Ao contrário de resultados obtidos por integração direta, é possível determinar equilíbrios instáveis (linha tracejada), bem como estáveis. 
bifurcações de Andronov-Hopf (autovalores puramente imaginários, ver apêndice A). Órbitas periódicas podem também ser continuadas, e as respectivas bifurcações detectadas através dos respectivos multiplicadores de Floquet.

Há pacotes especializados para este tipo de análise, dentre os quais

- auto (http://indy.cs.concordia.ca/auto). O mais clássico e eficiente pacote de continuação numérica. Sua curva de aprendizado é bem inclinada, dadas a falta de um manual introdutório e as muitas idiossincrasias na definição da dinâmica (programas em c ou fortran) e scripts de controle (linguagem própria ou Python). A maior parte dos resultados em continuação numérica nesta tese foi gerada com este programa.

- PyDSTool (http: //pydstool s sourceforge .net). Provê um empacotamento em Python do auto e de ferramentas para a análise de sistemas dinâmicos (integradores eficientes, análise no plano, estimativa de parâmetros). De mais simples utilização do que o auto, porém não tão usado e validado pela comunidade - por ser um projeto relativamente novo.

- Matcont (http://matcont.sourceforge.net/). Toolbox para matlab. Possui uma interface gráfica, o que supostamente facilita a vida de usuários de primeira viagem. Dentre os três pacotes mencionados, é o que está em desenvolvimento mais ativo, e os programadores envolvidos afirmam ser o mais completo em termos de deteção de bifurcações. Muito menos eficiente do que o auto para continuação de órbitas periódicas, e menos automatizável.

Através destes pacotes, é possível então continuar equilíbrios e órbitas periódicas, estáveis ou instáveis, bem como determinar as eventuais bifurcações. Curvas de bifurcações no espaço de parâmetros podem também ser obtidas. Enfatiza-se que este procedimento é aplicável a sistemas de EDo quaisquer, sendo em geral mais eficiente - bem como evitando as ambiguidades inerentes - do que métodos de integração numérica. 


\section{Referências Bibliográficas}

Abarbanel, H. D. I. (1996). Analysis of observed chaotic data. Springer.

Abraham, R. e Shaw, C. D. (1992). Dynamics: The Geometry of Behavior. Addison-Wesley.

Altmann, E. e Endler, A. (2010). Noise-Enhanced Trapping in Chaotic Scattering. Physical Review Letters, 105(24):244102.

Arnold, L. (1995). Random dynamical systems. In Johnson, R., editor, Dynamical Systems, volume 1609 of Lecture Notes in Mathematics. Springer Berlin Heidelberg.

Arnold, V. I. e Avez, A. (1968). Ergodic Problems of Classical Mechanics (The Mathematical physics monograph series). Benjamin.

Bal, T., Nagy, F., e Moulins, M. (1988). The pyloric central pattern generator in Crustacea: a set of conditional neuronal oscillators. Journal of Comparative Physiology A, 163(6):715-727.

Ben-Mizrachi, A., Procaccia, I., e Grassberger, P. (1984). Characterization of experimental (noisy) strange attractors. Physical Review A, 29(2):975-977.

Berger, A. (2001). Chaos and Chance: An Introduction to Stochastic Apects of Dynamics. Walter De Gruyter Inc.

Berkowitz, A. (2008). Physiology and morphology of shared and specialized spinal interneurons for locomotion and scratching. Journal of Neurophysiology, 99(6):2887-901.

Bhalla, U. S. e Bower, J. M. (1993). Exploring parameter space in detailed single neuron models: simulations of the mitral and 
granule cells of the olfactory bulb. Journal of Neurophysiology, 69(6):1948-65.

Billings, L. e Schwartz, I. (2002). Exciting chaos with noise: unexpected dynamics in epidemic outbreaks. Journal of Mathematical Biology, 44(1):31-48.

Boffetta, G., Cencini, M., Falcioni, M., e Vulpiani, A. (2002). Predictability: a way to characterize complexity. Physics Reports, 356:367-474.

Borst, a. e Theunissen, F. E. (1999). Information theory and neural coding. Nature Neuroscience, 2(11):947-57.

Briggman, K. L. e Kristan, W. B. (2008). Multifunctional patterngenerating circuits. Annual Review of Neuroscience, 31:271-94.

Brochini, L., Carelli, P. V., e Pinto, R. D. (2011). Single synapse information coding in intraburst spike patterns of central pattern generator motor neurons. Journal of Neuroscience, 31(34):12297-306.

Buchholtz, F., Golowasch, J., Epstein, I. R., e Marder, E. (1992). Mathematical model of an identified stomatogastric ganglion neuron. Journal of Neurophysiology, 67(2):332-40.

Burden, R. L. e Faires, J. D. (2010). Numerical Analysis. Cengage Learning.

Butera, R. J., Rinzel, J., e Smith, J. C. (1999). Models of respiratory rhythm generation in the pre-Bötzinger complex. I. Bursting pacemaker neurons. Journal of Neurophysiology, 82(1):382-97.

Carelli, P. V. (2008). Modelagem estocástica de neurônios e sua interação em tempo real com neurônios biológicos. Tese de Doutoramento, USP.

Carelli, P. V., Reyes, M. B., Sartorelli, J. C., e Pinto, R. D. (2005). Whole cell stochastic model reproduces the irregularities found in the membrane potential of bursting neurons. Journal of Neurophysiology, 94(2):1169-79. 
Chay, T. R. e Keizer, J. (1983). Minimal model for membrane oscillations in the pancreatic beta-cell. Biophysical Journal, 42(2):181-90.

Clewley, R. H., Sherwood, W. E., Lamar, M. D., e Guckenheimer, J. M. (2010). PyDSTool: a software environment for dynamical systems modeling.

Crauel, H. e Gundlach, M. (1999). Stochastic Dynamics. Springer New York, New York, NY.

Crutchfield, J., Farmer, J., e Huberman, B. (1982). Fluctuations and simple chaotic dynamics. Physics Reports, 92(2):45-82.

Cymbalyuk, G. S., Gaudry, Q., Masino, M. A., e Calabrese, R. L. (2002). Bursting in leech heart interneurons: cell-autonomous and network-based mechanisms. Journal of Neuroscience, 22(24):10580-92.

Dayan, P. e Abbott, L. F. (2001). Theoretical Neuroscience: Computational and Mathematical Modeling of Neural Systems. MIT Press, Cambdridge, MA, 1st edition.

de Borja Rodríguez, F., Latorre, R., e Varona, P. (2002). Artificial Neural Networks - ICANN 2002, volume 2415 of Lecture Notes in Computer Science. Springer Berlin Heidelberg, Berlin, Heidelberg.

De Schutter, E., editor (2009). Computational modeling methods for neuroscientists. The MIT Press, Cambdridge, MA, Ist edition.

Doloc-Mihu, A. e Calabrese, R. L. (2011). A database of computational models of a half-center oscillator for analyzing how neuronal parameters influence network activity. Journal of Biological Physics, pages 1-21-21.

Dyson, F. (2009). Replies and Correction - Letters to the Editor. Notices of the American Mathematical Society, 56(6).

Eckmann, J. e Ruelle, D. (1985). Ergodic theory of chaos and strange attractors. Reviews of Modern Physics, 57(3):617-656.

Elson, R. C., Huerta, R., Abarbanel, H. D. I., Rabinovich, M. I., e Selverston, A. I. (1999). Dynamic Control of Irregular Bursting 
in an Identified Neuron of an Oscillatory Circuit. Journal of Neurophysiology, 82(1):115-122.

Elson, R. C., Selverston, A. I., Huerta, R., Rulkov, N., Rabinovich, M., e Abarbanel, H. (1998). Synchronous Behavior of Two Coupled Biological Neurons. Physical Review Letters, 81(25):5692-5695.

Falcke, M., Huerta, R., Rabinovich, M. I., Abarbanel, H. D. I., Elson, R. C., e Selverston, A. I. (2000). Modeling observed chaotic oscillations in bursting neurons: the role of calcium dynamics and $\mathrm{IP}_{3}$. Biological Cybernetics, 82(6):517-27.

Fenichel, N. (1979). Geometric singular perturbation theory for ordinary differential equations. Journal of Differential Equations, 31(1):53-98.

Fitzhugh, R. (1961). Impulses and Physiological States in Theoretical Models of Nerve Membrane. Biophysical Journal, I(6):445-66.

Fox, R. F. (1997). Stochastic versions of the Hodgkin-Huxley equations. Biophysical Journal, 72(5):2068-2074.

Franci, A., Drion, G., e Sepulchre, R. (2012). An Organizing Center in a Planar Model of Neuronal Excitability. SIAM Journal on Applied Dynamical Systems, 11(4):1698-1722.

Gao, J., Chen, C. C., Hwang, S. K., e Liu, J. M. (1999a). Noise-induced chaos. International Journal of Modern Physics, 13(28):3283-3305.

Gao, J., Hu, J., Tung, W., e Cao, Y. (2006). Distinguishing chaos from noise by scale-dependent Lyapunov exponent. Physical Review E, 74(6).

Gao, J., Hwang, S., e Liu, J. (1999b). When Can Noise Induce Chaos? Physical Review Letters, 82(6):1132-1135.

Garcia, L., D'Alessandro, G., Fernagut, P.-O., Bioulac, B., e Hammond, C. (2005). Impact of high-frequency stimulation parameters on the pattern of discharge of subthalamic neurons. Journal of Neurophysiology, 94(6):3662-9. 
Gaspard, P. e Wang, X.-J. (1993). Noise, chaos, and $(\epsilon, \tau)$-entropy per unit time. Physics Reports, 235(6):291-343.

Goldwyn, J. H. e Shea-Brown, E. (2011). The what and where of adding channel noise to the Hodgkin-Huxley equations. PLoS Computational Biology, 7(11):e1002247.

Govaerts, W. J. F. (1987). Numerical Methods for Bifurcations of Dynamical Equilibria.

Guckenheimer, J., Gueron, S., e Harris-Warrick, R. M. (1993). Mapping the dynamics of a bursting neuron. Philosophical transactions of the Royal Society of London, 341(1298):345-59.

Guckenheimer, J. e Holmes, P. (1983). Nonlinear Oscillations, Dynamical Systems, and Bifurcations of Vector Fields (Applied Mathematical Sciences Vol. 42). Springer.

Günay, C., Edgerton, J. R., Li, S., Sangrey, T., Prinz, A. A., e Jaeger, D. (2009). Database analysis of simulated and recorded electrophysiological datasets with PANDORA's toolbox. Neuroinformatics, 7(2):93-111.

Guttman, R., Lewis, S., e Rinzel, J. (1980). Control of repetitive firing in squid axon membrane as a model for a neuroneoscillator. The Journal of Physiology, 305:377-95.

Hairer, E., Norset, S., e Wanner, G. (2002). Solving Ordinary Differential Equations II. Stiff and Differential-Algebraic Problems. Springer-Verlag, 2nd edition.

Hänggi, P. (2002). Stochastic resonance in biology. How noise can enhance detection of weak signals and help improve biological information processing. Chemphyschem : a European journal of chemical physics and physical chemistry, 3(3):285-90.

Harris-Warrick, R. M. (1992). Dynamic Biological Networks: The Stomatogastric Nervous System. MIT Press.

Hegger, R., Kantz, H., e Schreiber, T. (1999). Practical implementation of nonlinear time series methods: The TISEAN package. Chaos (Woodbury, N.Y.), 9(2):413-435. 
Hill, A. A. V., Lu, J., Masino, M. A., Olsen, O. H., e Calabrese, R. L. (2001). A Model of a Segmental Oscillator in the Leech Heartbeat Neuronal Network. Journal of Computational Neuroscience, 10(3):281-302-302.

Hindmarsh, J. L. e Rose, R. M. (1984). A model of neuronal bursting using three coupled first order differential equations. Proceedings of the Royal Society of London, 221(1222):87-102.

Hitczenko, P. e Medvedev, G. S. (2009). Bursting oscillations induced by small noise. SIAM Journal on Applied Mathematics, 69(5):1359.

Hodgkin, A. L. e Huxley, A. F. (1952). A quantitative description of membrane current and its application to conduction and excitation in nerve. The Journal of Physiology, 117(4):500-44.

Ibarz, B., Casado, J., e Sanjuán, M. (2011). Map-based models in neuronal dynamics. Physics Reports, 501(1-2):1-74.

Izhikevich, E. M. (2000). Neural Excitablity, Spiking and Bursting. International Journal of Bifurcations and Chaos, 10(6):1171-1266.

Izhikevich, E. M. (2006). Dynamical Systems in Neuroscience: The Geometry of Excitability and Bursting.

Izhikevich, E. M., Desai, N. S., Walcott, E. C., e Hoppensteadt, F. C. (2003). Bursts as a unit of neural information: selective communication via resonance. Trends in Neurosciences, 26(3):161-167.

Johnston, D. e Wu, S. M.-S. (1995). Foundations of Cellular Neurophysiology. Bradford Books, 1st edition.

Kampen, N. V. (1992). Stochastic Processes in Physics and Chemistry, Volume 1, Second Edition (North-Holland Personal Library). North Holland.

Kloeden, P. e Platen, E. (1992). Numerical Solution of Stochastic Differential Equations. Springer-Verlag, Berlin.

Kuznetsov, Y. A. (1995). Elements Of Applied Bifurcation Theory. Springer-Verlag, New York. 
Lago-Fernández, L. F., Szücs, A., e Varona, P. (2009). Determining Burst Firing Time Distributions from Multiple Spike Trains. Neural Computation, 21(4):973-90.

Lai, Y.-C. e Tél, T. (2011). Transient Chaos: Complex Dynamics on Finite Time Scales (Applied Mathematical Sciences). Springer.

Langevin, P. (1908). Sur la théorie du mouvement brownien. Comptes Rendues Acad. Sci. (Paris), 146:530.

Latorre, R., de Borja Rodríguez, F., e Varona, P. (2006). Neural signatures: multiple coding in spiking-bursting cells. Biological Cybernetics, 95(2):169-83.

Li, T. Y. e Yorke, J. A. (1975). Period three implies chaos. American Mathematical Monthly, 82(10):985-992.

Lisman, J. (1997). Bursts as a unit of neural information: making unreliable synapses reliable. Trends in Neurosciences, 20(1):3843 .

Liu, Z., Golowasch, J., Marder, E., e Abbott, L. F. (1998). A Model Neuron with Activity-Dependent Conductances Regulated by Multiple Calcium Sensors. Journal of Neuroscience, 18(7):23092320.

Liu, Z., Lai, Y.-C., Billings, L., e Schwartz, I. (2002). Transition to Chaos in Continuous-Time Random Dynamical Systems. Physical Review Letters, 88(12):124101.

Lu, T. Z. e Feng, Z.-P. (2011). A sodium leak current regulates pacemaker activity of adult central pattern generator neurons in Lymnaea stagnalis. PloS one, 6(4):e18745.

Mackie, G. O. e Meech, R. W. (1985). Separate sodium and calcium spikes in the same axon. Nature, 313(6005):791-793.

Mainen, Z. e Sejnowski, T. (1995). Reliability of spike timing in neocortical neurons. Science, 268(5216):1503-1506.

Marder, E. e Bucher, D. (2001). Central pattern generators and the control of rhythmic movements. Current Biology, 11(23):R986-R996. 
Marder, E. e Goaillard, J.-M. (2006). Variability, compensation and homeostasis in neuron and network function. Nature reviews. Neuroscience, 7(7):563-74.

Marder, E. e Taylor, A. L. (2011). Multiple models to capture the variability in biological neurons and networks. Nature Neuroscience, 14(2):133-8.

Marder, E., Tobin, A.-E., e Grashow, R. (2007). How tightly tuned are network parameters? Insight from computational and experimental studies in small rhythmic motor networks. Progress in brain research, 165:193-200.

Marin, B., Barnett, W. H., Doloc-Mihu, A., Calabrese, R. L., e Cymbalyuk, G. S. (2013). High Prevalence of Multistability of Rest States and Bursting in a Database of a Model Neuron. PLoS Computational Biology, 9(3):e1002930.

Mayer-Kress, G. e Haken, H. (1981). The influence of noise on the logistic model. Journal of Statistical Physics, 26(1):149-171.

Medvedev, G. (2006). Transition to Bursting via Deterministic Chaos. Physical Review Letters, 97(4):1-4.

Melo, W. D. e Strien, S. V. (1993). One-Dimensional Dynamics (Ergebnisse Der Mathematik Und Ihrer Grenzgebiete 3 Folge). Springer-Verlag.

Meng, X., Lu, Q., e Rinzel, J. (2011). Control of firing patterns by two transient potassium currents: leading spike, latency, bistability. Journal of Computational Neuroscience, 31(1):117-36.

Miller, J. P. e Selverston, A. I. (1982). Mechanisms underlying pattern generation in lobster stomatogastric ganglion as determined by selective inactivation of identified neurons. IV. Network properties of pyloric system. Journal of Neurophysiology, 48(6):1416-32.

Morris, C. e Lecar, H. (1981). Voltage oscillations in the barnacle giant muscle fiber. Biophysical Journal, 35(1):193-213.

Moss, F., Ward, L. M., e Sannita, W. G. (2004). Stochastic resonance and sensory information processing: a tutorial and review of application. Clinical neurophysiology : official 
journal of the International Federation of Clinical Neurophysiology, 115(2):267-81.

Mulloney, B. e Selverston, A. I. (1974). Organization of the stomatogastric ganglion of the spiny lobster. Journal of Comparative Physiology, 91(1):1-32.

Norris, B. J., Wenning, A., Wright, T. M., e Calabrese, R. L. (2011). Constancy and variability in the output of a central pattern generator. Journal of Neuroscience, 31(12):4663-74.

Nowotny, T., Levi, R., e Selverston, A. I. (2008). Probing the dynamics of identified neurons with a data-driven modeling approach. PloS one, 3(7):e2627.

Nowotny, T., Szücs, A., Pinto, R. D., e Selverston, A. I. (2006). StdpC: a modern dynamic clamp. Journal of Neuroscience Methods, 158(2):287-99.

Nusbaum, M. P. e Beenhakker, M. P. (2002). A small-systems approach to motor pattern generation. Nature, 417(6886):34350.

Peña, F., Parkis, M. A., Tryba, A. K., e Ramirez, J.-M. (2004). Differential contribution of pacemaker properties to the generation of respiratory rhythms during normoxia and hypoxia. Neuron, 43(1):105-17.

Pinto, R. D., Elson, R. C., Szücs, A., Rabinovich, M. I., Selverston, A. I., e Abarbanel, H. D. I. (2001). Extended dynamic clamp: controlling up to four neurons using a single desktop computer and interface. Journal of Neurophysiology, 108:39-48.

Prinz, A. A., Billimoria, C. P., e Marder, E. (2003a). Alternative to hand-tuning conductance-based models: construction and analysis of databases of model neurons. Journal of Neurophysiology, 90(6):3998-4015.

Prinz, A. A., Bucher, D., e Marder, E. (2004). Similar network activity from disparate circuit parameters. Nature Neuroscience, 7(12):1345-52.

Prinz, A. A., Thirumalai, V., e Marder, E. (2003b). The functional consequences of changes in the strength and duration of 
synaptic inputs to oscillatory neurons. Journal of Neuroscience, 23(3):943-54.

Rabinovich, M. I. e Abarbanel, H. D. I. (1998). The role of chaos in neural systems. Neuroscience, $87(1): 5-14$.

Rabinovich, M. I., Abarbanel, H. D. I., Huerta, R., Elson, R. C., e Selverston, A. I. (1997). Self-regularization of chaos in neural systems: experimental and theoretical results. IEEE Transactions on Circuits and Systems I, 44(10):997-1005.

Ramirez, J.-M., Folkow, L. P., e Blix, A. S. (2007). Hypoxia tolerance in mammals and birds: from the wilderness to the clinic. Annual review of physiology, 69:113-43.

Reimann, P. (1996). Noisy one-dimensional maps near a crisis. I. Weak Gaussian white and colored noise. Journal of Statistical Physics, 82(5-6):1467-1501.

Rinzel, J. (1998). Propagating Activity Patterns in Large-Scale Inhibitory Neuronal Networks. Science, 279(5355):1351-1355.

Ruelle, D. (2009a). Reply to Yorke - Letters to the Editor. Notices of the American Mathematical Society, 56(10).

Ruelle, D. (2009b). Some Comments on "Period Three Implies Chaos" - Letters to the Editor. Notices of the American Mathematical Society, 56(6).

Rush, M. E. e Rinzel, J. (1995). The potassium A-current, low firing rates and rebound excitation in Hodgkin-Huxley models. Bulletin of Mathematical Biology, 57(6):899-929.

Schulz, D. J., Goaillard, J.-M., e Marder, E. (2006). Variable channel expression in identified single and electrically coupled neurons in different animals. Nature Neuroscience, $9(3): 356-62$.

Segev, C. K. I. (1998). Methods in Neuronal Modeling, 2nd Edition: From Ions to Networks, volume 1.

Selverston, A. I., Rabinovich, M. I. M. I., Abarbanel, H. D. I., Elson, R. C., Szücs, A., Pinto, R. D., Huerta, R., e Varona, P. (2000). Reliable circuits from irregular neurons: a dynamical 
approach to understanding central pattern generators. Journal of Physiology, Paris, 94(5-6):357-74.

Selverston, A. I., Russell, D. F., e Miller, J. P. (1976). The stomatogastric nervous system: structure and function of a small neural network. Progress in Neurobiology, 7(3):215-90.

Shannon, C. (1948). A mathematical theory of communication. The Bell System Technical Journal, 27:379-423.

Sporns, O., Tononi, G., e Kötter, R. (2005). The human connectome: A structural description of the human brain. PLoS Computational Biology, 1(4):e42.

Strogatz, S. H. (2001). Nonlinear Dynamics And Chaos: With Applications To Physics, Biology, Chemistry, And Engineering (Studies in Nonlinearity). Westview Press.

Szücs, A., Abarbanel, H. D. I., Rabinovich, M. I., e Selverston, A. I. (2005). Dopamine modulation of spike dynamics in bursting neurons. The European Journal of Neuroscience, 21(3):763-72.

Szücs, A., Pinto, R. D., Rabinovich, M. I. M. I., Abarbanel, H. D. I., Selverston, A. I., e Szucs, A. (2003). Synaptic modulation of the interspike interval signatures of bursting pyloric neurons. Journal of Neurophysiology, 89(3):1363-77.

Talley, E. M., Lei, Q., Sirois, J. E., e Bayliss, D. A. (2000). TASK1 , a two-pore domain $\mathrm{K}+$ channel, is modulated by multiple neurotransmitters in motoneurons. Neuron, 25(2):399-410.

Taylor, A. L., Goaillard, J.-M., e Marder, E. (2009). How multiple conductances determine electrophysiological properties in a multicompartment model. Journal of Neuroscience, 29(17):557386.

Taylor, A. L., Prinz, A. a., Hickey, T. J., e Marder, E. (2006). Structure and visualization of high-dimensional conductance spaces. Journal of Neurophysiology, 96(2):891-905.

Tél, T., Lai, Y.-C., e Gruiz, M. A. R. M. (2008). Noise-induced Chaos: A consequence of long deterministic transients. International Journal of Bifurcation and Chaos, 18(2):509-520. 
Terman, D. (1991). Chaotic spikes arising from a model of bursting in excitable membranes. SIAM Journal on Applied Mathematics, 51(5):1418-1450.

Terman, D. (1992). The transition from bursting to continuous spiking in excitable membrane models. Journal of Nonlinear Science, 2(2):135-182.

Tristan, A., De Borja Rodriguez, F., Serrano, E., e Varona, P. (2004). Networks of neurons that emit and recognize signatures. Neurocomputing, 58-60:41-46.

Turrigiano, G., LeMasson, G., e Marder, E. (1995). Selective regulation of current densities underlies spontaneous changes in the activity of cultured neurons. Journal of Neuroscience, 15(5 Pt 1):3640-52.

Venugopal, S., Travers, J. B., e Terman, D. H. (2007). A computational model for motor pattern switching between taste-induced ingestion and rejection oromotor behaviors. Journal of Computational Neuroscience, 22(2):223-38.

Viegas, R. G. (2011). Dissecação dinâmica de condutâncias iônicas em tempo real. Dissertação de Mestrado, USP.

Wiesenfeld, K. e Moss, F. (1995). Stochastic resonance and the benefits of noise: from ice ages to crayfish and SQUIDs. Nature, 373(6509):33-6.

Wright, N. J. e Zhong, Y. (1998). Serotonin-sensitive leakage channel in Drosophila central neurons. Journal of Neurobiology, 34(1):83-95.

Yorke, J. (2009). Response to David Ruelle - Letters to the Editor. Notices of the American Mathematical Society, 56(10).

Zeck, G. M. e Masland, R. H. (2007). Spike train signatures of retinal ganglion cell types. The European Journal of Neuroscience, 26(2):367-80.

Zhurov, Y. e Brezina, V. (2006). Variability of motor neuron spike timing maintains and shapes contractions of the accessory radula closer muscle of Aplysia. Journal of Neuroscience, 26(26):7056-70. 